\title{
Studies on Quality Teachers and Quality In-service \\ Teacher Education
}

Edited by

Joanna Madalińska-Michalak
TEPE Network

Teacher Education Policy in Europe

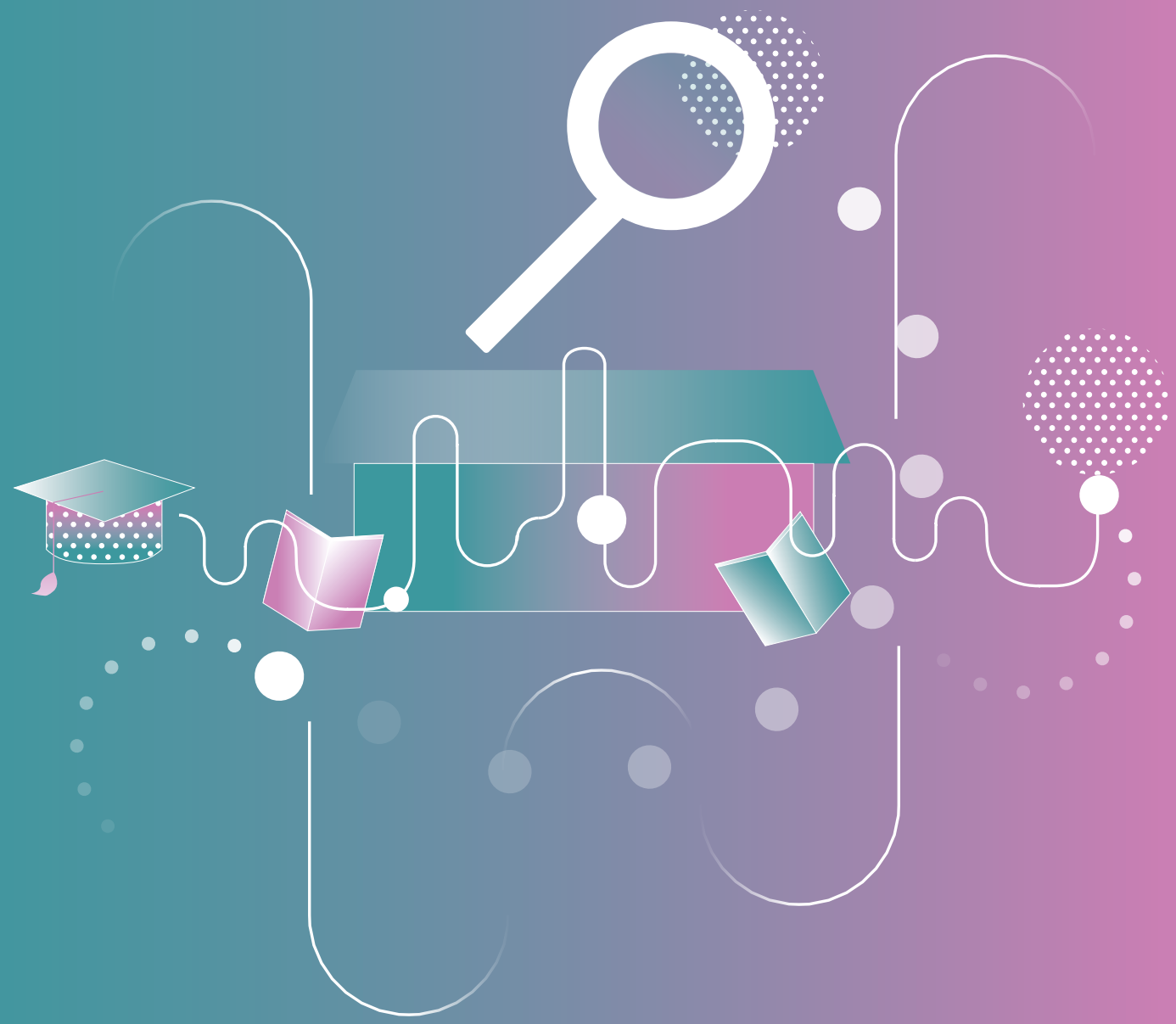


Studies on Quality Teachers

and Quality In-service Teacher Education 


\section{Studies on Quality Teachers and Quality In-service Teacher Education}

Edited by

Joanna Madalińska-Michalak

TEPE NETWORK

Teacher Education

Policy in Europe

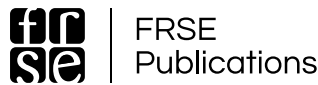

Warsaw 2020 
KEY CONCEPTS SERIES. VOL. 11

Studies on Quality Teachers and Quality In-service Teacher Education

Edited by:

Reviewed by:

Co-operation:

Proofreading:

Production editor:

Co-operation:

Cover design:

Design:

DTP:

Printed by:

Publisher:
Joanna Madalińska-Michalak

Erika Löfström

Agnieszka Rybińska

Anthony Wright

Barbara Jędraszko

Karolina Kwiatosz

Dorota Zajączkowska

Diana Makulska/Podpunkt

R rzeczYobrazkowe

Drukarnia KOLUMB Chorzów

Foundation for the Development of the Education System

National Agency for the Erasmus+ Programme

Al. Jerozolimskie 142a, 02-305 Warsaw

www.frse.org.pl | kontakt@frse.org.pl

(c) Foundation for the Development of the Education System, Warsaw 2020

ISBN 978-83-66515-32-1

doi $10.47050 / 66515321$

This publication has been developed with the financial support from the European Commission in the framework of the Erasmus+ programme. The information and views set out in this publication are those of the authors and the European Commission may not be held responsible for the use, which may be made of the information contained herein.

Free copy

\section{Citation:}

Studies on Quality Teachers and Quality In-service Teacher Education, J. Madalińska-Michalak (ed.), Foundation for the Development of the Education System, Key Concepts Series, vol. 11, Warsaw 2020, doi: 10.47050/66515321

FRSE Publishing House periodicals and portals:

\section{[jezzyкı: овсе] EUropa eurodesk}

FRSE publications are available on: $\square$ www.czytelnia.frse.org.pl 


\section{Table of Contents}

9

Acknowledgements

10

Introduction

Quality Teachers and Quality In-service Teacher Education Joanna Madalińska-Michalak

18

The Best, Average, or Weak?

The Level of Competencies of Candidates for the Teaching Profession in European Countries

Magdalena Jelonek, Barbara Worek, Marcin Kocór

42

Quality Teachers and Quality Teacher Education

Exploring Wellbeing, Gender and Job Satisfaction

Suzanne O'Keeffe

58

Generational Differences and Professional Values of Teachers

Wanda Dróżka 
Mining Quality

Evaluation of Teachers' Professional Identity

in the Greek Educational System

Eugenia Tsiouplis, Dimitrios Stamovlasis

104

Research on Quality of In-Service Teacher Education and Professional Development in Ukraine by TALIS

Methodology and its Policy Impact

Oksana Zabolotna, Svitlana Shchudlo

130

Teaching Quality Assurance

Ukrainian and Australian Perspectives

Nataliya Avshenyuk, Nataliya Seminikhyna

150

Teacher Experiences and Perceptions of Collaboration and Peer Support in an Innovative Learning Environment Louise Campbell

170

The Role of Graphic Organisers in Learning and Teaching Marine H. Arakelyan

186

School Social Work and Inclusion of Refugee Students in Greek Schools

Teachers' Perspectives and Experiences

Irene Katsama, Stefania Bakirtzi

212

Expressing a Sense of Readiness About Research-Inquiry In-service Teachers After a Master's Course

Maria Antonietta Impedovo 
Teacher Training Project

An Attempt to Devise an In-service Training Programme for English Language Teachers

Meretguly Gurbanov

250

English Language Teachers' Cognition in Foreign Language Reading Instruction in Slovak Upper-Secondary Education Interpretative Research

Martina Šipošová

280

Teaching a Second Language to Young Learners

A Theoretical Approach

Jenny Johana Izquierdo Casadiego, Olesya Parakhina

302

Promoting Quality in Teaching through Moving into English-medium Instruction

Melanie Ellis

326

World Educates Us... Naturally!

Anna Krzyżanowska 


\section{Acknowledgements}

This book was completed with the contribution and assistance of many people. I wish to acknowledge and thank the many individuals who shared their expertise and donated their time and energy to support me in the editorial work on this book. Firstly, I would like to express my sincere gratitude to my colleagues from the Teacher Education Policy in Europe (TEPE) Scientific Network, who deserve recognition for acting as the main inspiration for this book. The 2019 annual TEPE Conference acted as a platform for the book contributors to present their research, and the TEPE Board Members provided all the necessary academic support to review the abstracts, advise on the themes selected and suggest valuable feedback throughout.

Secondly, I would like to thank Professor Erika Löfström from the University of Helsinki, the book reviewer, for her invaluable comments on the book and suggestions for its improvement.

I would like to express my sincere appreciation to each author of the book's chapters for sharing with the readers their knowledge and expertise in the field of teacher education, for their contributions to the discussion on how to best ensure that teachers and teacher educators are able to meet the challenges of the contemporary society head-on, and for their concern about understanding today in order to build our future better. I also want to thank them for their invaluable cooperation throughout the whole publication process of the book.

Finally, I would like to extend my special thanks to the publisher of this monograph - the Foundation for the Development of the Education System. 


\section{Introduction}

\section{Quality Teachers and Quality In-service Teacher Education}

Joanna Madalińska-Michalak

In many countries, teachers' daily life and work has been marked by demanding and sometimes contradictory school contexts characterised by performative cultures that concentrate on effectiveness and learning outcomes as well as the need to meet the increasingly diverse expectations and backgrounds of student populations. This has direct implications on teacher education, which is embedded in the wider social, cultural, historical, political and economic contexts. When discussing national and international public policies on education and the promotion of quality in the educational system, teachers and teacher education are often considered as the key issues for debate, reflection and scientific analysis. The present book examines different aspects of teaching and teacher education and responses to the challenges posed by the current conditions to teacher education and the teaching profession. It provides a significant contribution to the wider body of scholarly literature on teacher education policy, research and practice in different countries through the lenses of quality teachers and quality teacher education.

The concept of quality in teaching and teacher education is complex and elusive (Imig \& Imig, 2007, p. 99). This complexity is because teacher quality and quality teacher education may hinge on myriad different perspectives ranging from emphasis on teachers' qualifications, competences, motivations, engagement, and credentials to teachers' cognitive and affective resources (i.e. teachers' knowledge, awareness, sills, attitudes, emotions), as well as teachers' work and performance in actual school conditions and context of education, and teachers' impact on student educational outcomes (Wang et. al., 2011, pp. 331-333). 
Despite the observed conceptual ambiguity, no one seems to be against "quality teacher" and "quality teacher education", or even "high quality teacher education". Raising teacher quality and reforming teacher education has earned in the research, policy, and practice considerable attention. There is an increased focus on policy reforms to improve teacher quality and greater emphasis on quality assurance processes in teacher education. At the same time, teaching in today's complex globalised world is acknowledged as challenging and ever-changing. Teaching is perceived as more than prescribed knowledge delivered using a toolbox of teacher strategies. The dynamic nature of teaching and the many roles required of a teacher direct our attention to individual teacher and student differences, the relationships between them and the context in which teaching and education take place, as well as to the current status and prestige of teachers and teaching (Hargreaves, 2009, pp. 217-229).

As Linda Darling-Hammond et al. (2017) identified in high-performing systems, the policies that shape the teaching force and the quality of work of teachers are those relating to teacher recruitment; initial teacher education, teacher induction and mentoring; teacher continuous professional learning; teacher appraisal; and career and leadership development. These policies are mutually supportive and affect each other in a direct manner. Policy systems that support high quality teaching practices are extremely important and they are characterised by knowledge expansion and change. What are teachers expected to teach students entering school today? We see that teachers may well work in jobs that do not yet exist, so they need to be able to find and evaluate knowledge to new ideas, answers and solutions. Moreover, societies are becoming increasingly more diverse and people with different perspectives and cultures bring new ideas and possibilities. The kind of teaching which is required in this context is challenging and dynamic.

Teachers need to "enable very diverse students to learn higher-order skills, so they themselves need a range of new skills; be able to understand the content more deeply and flexibly; understand how children learn and develop in cultural contexts; develop effective teaching strategies that foster reasoning and incorporate the appropriate technologies in their practice. Policy must thus be directed towards the development of a teacher workforce that is able to make the best 
decisions about teaching based on the expertise they have nurtured from their training and the wisdom they have accumulated from their experiences. Apart from having a strong teaching workforce, policies must also focus on how to develop teaching contexts that enable good practice. In the policy design process, the learning environment and the teaching context must be acknowledged as vital components of effective teaching as the qualities of individual teachers" (Attard Tonna \& Madalińska-Michalak, 2018, p. 15).

This book Studies on Quality Teachers and Quality In-service Teacher Education is directly connected with the book Studies on Quality Teachers and Quality Initial Teacher Education (Madalińska-Michalak, 2020). Both books focus on original and research informed writings related to prospective teachers, teacher educators, and teachers, and they address teacher education in the $21^{\text {st }}$ century. In these books a comprehensive definition of the term "teacher education" is adopted. According to it, teacher education is understood as an education that includes pre-service, induction and continuing professional development of the teacher. Teacher education is perceived as a highly complex process raising many challenges as well as many opportunities in the process itself. Therefore, the book offers to go beyond static understanding of teacher quality and focus not only on initial teacher education, but at the same time on the the contribution of faculties and schools of education on the development of teachers during their careers. The books proposes to answer the following main questions, namely: What is high quality in teacher education? What does it take to educate high quality teachers? What can be done to create such systems where every learner can have well-trained, qualified, and motivated teachers who promote inclusive and equitable quality education for all? How do working conditions for teachers influence teacher quality?

The distinctiveness of the books lies in the comprehensive and interconnected ways in which teaching and professional learning in teacher education in Europe and beyond are seen. In the face of global challenges and opportunities, and local contexts it is important to address teaching and learning in teacher education as it relates to different levels of education as well as opportunities for future teachers, for teachers and teacher educators to learn and develop. A high quality teacher workforce requires deliberate policy choices 
and the building of the human resource systems and by concentrating on attracting, preparing, and supporting high-quality teachers and nurturing educational leadership at different levels of education system.

The present volume, Studies on Quality Teachers and Quality In-service Teacher Education, is dedicated to teacher induction and in-service teacher education. Approaches to in-service teacher education are diverse, and examinations of the various practices in different countries indicate that many education systems have to contend with challenges linked to a smooth transition from the stage of teachers' initial education to the stage of teachers' continuing professional development. A review of in-service teacher education in many countries across the world indicates the diversity of ideas and solutions to problems (OECD, 2014, 2019). In presenting some examples of these solutions in policy and practice and the trends in research on teachers and teacher education, both the vast variation in these areas and the recognition that some may stand in direct contrast to others are acknowledged in this book. The contributions put an emphasis on teachers' continuous professional development and life-long learning as vital elements of the career path of teachers and school principals that can affect both classroom and school practices. The chapters examine barriers to participation in training and the support received by teachers and principals to overcome them, as well as the quality of in-service teacher education.

The content of the book leads us to the question: "How do we see education, teaching profession and teacher education not just for the here and now, but for the unknown, but inevitable future"? This question has its significance especially in time when our current professional and personal situation is extremely challenging due to the COVID-19 crisis in the world. Around 63 million primary and secondary teachers around the world have been affected by school closures in 165 countries due to the COVID-19 pandemic. There is a number of specific challenges we have to cope with regarding distance learning for students in confinement, with or without the use of digital technologies, providing adequate professional tools, support and training for teachers and teacher educator, putting equity at the heart of education responses.

While the contributions were written before the global COVID-19 outbreak, a number of them address issues that have 
a highlighted relevance for post-pandemic societies, which can be seen in Wanda Dróżka's chapter on teacher values and Anna Krzyżanowska's on outdoor learning experiences. Some contributions highlight research findings that direct our attention to issues that will need to be reconsidered in the era of post-pandemic teacher education and societies, such as teacher wellbeing, gender and job satisfaction (Suzanne O'Keeffe), new kinds of physical spaces as learning environments (Louise Campbell), teacher candidates' profiles and competences (Magdalena Jelonek, Barbara Worek and Marcin Kocór), teachers' sense of readiness about research inquiry (Maria Antonietta Impedovo), teacher identity (Eugenia Tsiouplis and Dimitrios Stamovlasis), teaching quality assurance (Nataliya Avshenyuk and Nataliya Seminikhyna), and promoting quality through teaching and learning (Melanie Ellis, Martina Šipošová, Jenny Johana Izquierdo Casadiego, Olesya Parakhina, Marine H. Arakelyan and Meretguly Gurbanov). While these contributions naturally did not anticipate the pandemic, they are likely to trigger topical reflections in the reader.

The chapters addressing teachers and teacher education quality through the perspectives of equality and social justice are true contributions to the field. Good examples of this are the contribution by Irene Katsama and Stefania Bakirtzi on teachers' perspectives on integration and inclusion, Oksana Zabolotna and Svitlana Shchudlo's chapter on the nature of the presence of multiculturalism and inclusiveness in Ukrainian education policy, and Suzanne O'Keeffe's considerations on teacher wellbeing and gender.

The situation we have now calls for (re)imagining and remaking teacher education. Nowadays, it is not enough just to discuss preparing teachers to teach at school; we should have a real debate on how to educate teachers across their careers in such a way that they can serve society as best as they can, long beyond the $21^{\text {st }}$ century. Teachers and teacher educators have to face changes taking place at school, in its surroundings, and in the expectations directed towards them from different subjects of education, namely: students, parents, policy makers, government, and civil society. Teacher educators should be able to recognise these expectations and understand these changes, prepare teachers for new challenges, and help them to develop the appropriate competences and reflect on their values. 
Teachers are universally expected to develop and demonstrate appropriate personal and professional values, and yet these values are only weakly defined. While some national governments rely on cultural traditions to guide values in education, others directly intervene through policy changes, trying to shape the values promoted by schools and teachers. At the institutional level, school leaders vary in their efforts and strategies to encourage reflection, debate and inquiry by teachers to help develop shared professional values as a school within its local community. We see that there is a huge need to focus on explorations of personal and professional values and on their implications for teacher education, teachers' professional learning, school leadership and educational policy.

The present chapters were selected through submissions elicited from a call for abstracts to scholars concentrated around the Teacher Education Policy in Europe Scientific Network (TEPE Network), and its annual conference was organised by the Faculty of Education, University of Warsaw, Poland and the Foundation for the Development of the Education System (FRSE), Poland, in co-operation with the Pedagogical University of Cracow, Poland. The conference was held from 16-18 May 2019 in Cracow, which is the second largest city in Poland and the country's former capital.

The TEPE Network is an academic network that brings together teacher educators, educational researchers, policy makers, teachers and practitioners from Europe and beyond to discuss and identify key elements that contribute to strengthening teacher education and the quality and professionalism of teachers in schools. The TEPE Network is dedicated to advancing research in and on teacher education that can influence policy making. The network builds on previous European collaborative projects in the field of teacher education policy - principally the Thematic Network on Teacher Education in Europe (TNTEE) funded by the European Commission (1996-1999) and the European Doctorate in Teaching and Teacher Education (EUDORA) project funded by the European Commission (2000-2005).

The TEPE Network's annual conferences show that, in the past 13 years, the network's initiative has established firm roots, and we can notice that the number of TEPE supporters and contributors has continuously grown year after year. The TEPE conferences show that the manifold dimensions of teacher education are increasingly 
attracting the attention of researchers, teacher educators, policy makers and prospective and in-service teachers. A significant feature of contemporary theory, research and practice in the field of teacher education is consensus on the value of exploring the diversity of international experiences for understanding the dynamic process of the development of education systems in different parts of the world with a particular focus on the role of the teacher and teacher education.

The theme of the $13^{\text {th }}$ TEPE Network conference, "Quality Teachers and Quality Teacher Education: Research, Policy and Practice", encouraged academics, teachers, teacher educators and education officials to present their research and engage in discerning discussions about their work, their concerns and their visions for school education, teachers and teacher education. The theme further opened the debate related to the elusive concept of quality teachers and quality (in) teacher education, and also to lifelong opportunities for all teachers to learn and to grow.

The following five sub-themes were established to explore the general theme of the conference:

1. Exploring international and European perspectives on quality in education and teacher education and their impact on policy;

2. Reforming teaching and teacher education towards high-quality education for all;

3. Raising teacher quality: attracting, supporting and preparing a diverse student teacher population;

4. Strengthening teacher education and the teaching profession: conditions for quality teaching and learning;

5. Developing cultures of sharing and collaboration as a means of supporting teachers' professional learning and development.

The submitted abstracts were selected by blind review by respected scholars whose expertise I would like to duly acknowledge. The chapters are based on high scholarly quality and relevance to the book's two volumes and the objectives of the book. The selection process resulted in invitations for chapters from a range of countries, namely Armenia, Belgium, Ecuador, France, Germany, Greece, Hungary, Ireland, Italy, Oman, Poland, Portugal, Russia, Slovakia, Spain, Turkmenistan, Ukraine, and the United Kingdom. It is worth pointing out that contributions are also included from countries that have generally been less visible 
in the international literature devoted to the issues of teachers and teacher education (e.g. Oman, Turkmenistan, Armenia, and Ukraine). The authors of the book, experts in the field, provide us with insights, perspectives, and policy initiatives as to how the issues of quality teachers and quality teacher education are being addressed in their respective countries. The book is targeted at a global readership and the global community of scholars who share our concerns over the current conditions of teachers' work, teacher education, and teacher education policies, research and practice.

\section{References}

$\rightarrow$ Attard Tonna, M. and Madalińska-Michalak, J. (2018). Teacher education - perspectives and inspirations. In: M. Attard Tonna, J. Madalińska-Michalak (eds.), Teacher Education Policy and Practice. International Perspectives and Inspiration (pp. 11-21). Warszawa: Fundacja Rozwoju Systemu Edukacji.

$\rightarrow$ Darling-Hammond, L., Burns, D., Campbell, C., Goodwin, A.L., Hammerness, K., Low, E.-L., Mclntyre, A., Sato, M. and Zeichner, K. (2017). Empowered educators: How high-performing systems shape teaching quality around the world. San Francisco: Jossey-Bass.

$\rightarrow$ Hargreaves, L. (2009). The status and prestige of teachers and teaching. In: L.J. Saha, A.G. Dworkin (eds.), International Handbook of Research on Teachers and Teaching (pp. 217-229). Dordrecht: Springer Science + Business Media LLC.

$\rightarrow$ Imig, D.G. and Imig, S.R. (2007). Quality in teacher education: Seeking a common definition. In: T. Townsend, R. Bates (eds.), Handbook of teacher education: Globalization, standards and professionalism in times of change (pp. 95-112). Dordrecht: Springer.

$\rightarrow$ Madalińska-Michalak, J. (ed.) (2020). Studies on Quality Teachers and Quality Initial Teacher Education. Warszawa: Fundacja Rozwoju Systemu Edukacji.

$\rightarrow$ OECD (2014). TALIS 2013 Results: An International Perspective on Teaching and Learning. Paris: Organisation for Economic Cooperation and Development.

$\rightarrow$ OECD (2019). TALIS 2018 Results. Vol. 1: Teachers and School Leaders as Lifelong Learners. Paris: Organisation for Economic Cooperation and Development.

$\rightarrow$ Wang, J., Lin, E., Spalding, E., Klecka, C.L. and Odell, S.J. (2011). Quality teaching and teacher education: A kaleidoscope of notions. Journal of Teacher Education, 62(4), 331-338. 


\section{The Best, Average, or Weak? \\ The Level of Competencies \\ of Candidates for the Teaching \\ Profession in European Countries}

DOI: $10.47050 / 66515321.18-41$

Magdalena Jelonek, Barbara Worek, Marcin Kocór

This chapter presents the results of a segmentation of teaching faculties' students from selected European countries. The segmentation was based on study data from the Programme for the International Assessment of Adult Competencies (PIAAC), particularly the level of the information processing skills (literacy and numeracy) of teaching faculties' students and the difference in the level of these skills between those students and their colleagues from other majors. The main goal of the segmentation was to distinguish clusters of European countries similar to each other in terms of the characteristics of candidates in the profession of teaching and then describe each group and identify factors that explain the observed differences. We propose a thesis that the skills of candidates in the teaching profession are of key importance for the quality of future staff working in European schools. The quality of these personnel has a major impact on students' educational achievements and, thus, on the quality of the human capital of society in general.

\section{Keywords: \\ teachers' skills \\ education policy \\ quality of education \\ teachers' selection and preparation}




\section{Introduction}

Given the current state of the literature, it can be emphasised that among the key factors influencing sustainable economic development is broad access to high-quality education permitting the formation of appropriate competencies (Aghion et al., 2009; Hanushek, 2012). Teachers are an important link in the process of education, and the quality and effectiveness of their work has a significant impact on the achievements of their pupils and consequently the professional and general successes of the schools' graduates (Carrell \& West, 2010; Hattie, 2009; Hanushek \& Rivkin, 2012; Hanushek et al., 2014; Meroni et al., 2015). This is why it is so important to seek out the best candidates for the teaching profession; in practice, therefore, this means recruiting for teacher training studies individuals who stand out among their peers in terms of competencies and are highly motivated to work in a school (Darling-Hammond et al., 2017) and thereafter encouraging the best graduates to undertake such work (Barber \& Mourshed, 2007). Naturally, encouraging high-potential candidates to become teachers is not a sufficient condition to ensure high-quality education, but this is - as many researchers point out - an important factor that contributes to this quality (Schleicher, 2018). It can therefore be assumed that the optimum scenario is one in which candidates for the teaching profession are people with suitable motivation to work in this field, characterised by competencies that are at least as high as, or ideally higher than, their colleagues studying other subjects, as well as by a willingness to learn and develop (OECD, 2005, 2018).

In practice, however, attracting such candidates can prove to be very difficult for a number of reasons (Henke et al., 1996; Wexler \& Maagan, 2002). In this respect, the situation varies in different European countries - diverse selection strategies are employed, and the systems used for motivating candidates to choose this kind of study programme also vary (OECD, 2005; Eurydice, 2006; European Commission/ EACEA/Eurydice, 2015). Certain countries, for example, have entrance examinations in place for teaching degrees, whereas others recruit candidates on the basis of the results obtained at the previous stage of education (European Commission/EACEA/Eurydice, 2015; Ingvarson \& Rowley, 2017; OECD, 2012). However, the mere fact of whether exams are used as a recruitment criterion for teaching degrees would seem to be a weak indicator of high demands towards candidates. More 
significant is the nature of this exam, as well as the scope of knowledge and skills tested (Wang et al., 2003). The complexity of the educational solutions in force in the various European countries makes comparing the systems they use for training future teachers a more difficult task than it might seem at first, providing material for a separate study.

It is for this reason that we adopt a different perspective in this article. Rather than comparing the instruments with a potential impact on the quality of candidates for teaching studies, as Ingvarson and Rowley did (2017), we propose a comparison of the cognitive competencies of students taking teaching degrees in various European countries. Following Mateos-Romero and Salinas-Jiménez's approach (2017), we treat information processing skills as components of more general cognitive competencies. It can be assumed that the presence of candidates with high cognitive competences in teaching faculties is an important basis for shaping other competencies that are important from the point of view of future professional work.

We will treat these competencies as a proxy indicator of the quality of future teachers. Of course, this indicator only gives an approximate indication of this quality, since it does not take into account the important factor of the motivation to take up this kind of work after graduation. We therefore do not know whether it will be the best or the weakest students who later become teachers. Nevertheless, the high cognitive competencies of teaching faculties' students are certainly a factor conducive to a high quality of staff in schools. We will thus be interested in the first level of selection for the teaching profession, i.e. the choice of degrees preparing students for this profession. The objective of this comparison is first to identify clusters of European countries similar to each other in terms of the characteristics of teaching candidates, and then to describe the identified groups and attempt to identify the potential factors that might explain the differences observed. We understand the candidates' characteristics as their level of information processing skills (literacy and numeracy) as well as the difference in the level of these competencies between students of teaching subjects and other students. We assume that, from the point of view of optimising the selection of candidates for the teaching profession, those countries where the competencies of candidates for this profession are high, or on average higher than those of students in other degree programmes, are in the best position. If this is the case, it might 
suggest the existence of positive selection for the teaching profession in these countries. We chose the two information processing skills (literacy and numeracy) because of their general nature, which points not so much to the teacher's professional preparation as to his or her potential that might be exploited during their further career.

The purpose of this paper is to address the following questions:

1. Which countries are similar to each other, considering the quality of candidates at the first level of selection for the teaching profession? By the first level of selection, we mean the selection of candidates for teaching faculties.

2. Can this similarity be explained using selected external factors?

To answer these questions, we propose a three-step approach around which this article is structured. Firstly, based on the literature, we identify factors influencing the number and quality of students preparing to work in the teaching profession. Secondly, we distinguish segments of similar countries (considering the level of competence of candidates for the teaching profession) in order to (thirdly) interpret the differences between these countries on the basis of additional existing data.

\section{Conceptual background}

This article is based on the fundamental premise that the quality of candidates for the teaching profession (teaching faculties' students) has a direct influence on the quality of teachers working in schools, which is in turn linked to the educational achievements of pupils (Hanushek \& Rivkin, 2012; Hattie, 2009; Meroni et al., 2015). Accepting this premise leads us to the question of the factors that may affect whether the best candidates are indeed attracted to this profession. This area has been the subject of attention for some time (Applegate, 1987; Blake et al., 2010; European Commission/EACEA/Eurydice, 2015; Eurydice, 2006; Henke et al., 1996; Ingvarson \& Rowley, 2017; OECD, 2005; Santiago, 2004). However, a relatively high number of analyses have dealt with teachers' professional preparation, the significance of their qualifications (e.g. possessing higher education), the certification of their competencies and the need for professional development rather than concentrating directly on the factors that can influence the quality of candidates for the teaching profession (Beauchamp et al., 2013; Darling-Hammond \& Bransford, 2005; European Commission, 2013; 
Mourshed et al., 2010; OECD, 2005, 2011, 2013a, 2013b; Tucker, 2012). Research on teacher training, meanwhile, often focuses on subjective motivations for choosing this career path (OECD, 2015; Walczak, 2012). Although such analyses are important and make it possible to reconstruct the process by which teachers choose their profession, they do not offer a full insight into all the factors and conditions that may have an impact on the process of selection of candidates for the profession. And yet, Wang et al. (2003) point out that attracting suitable candidates to the teaching profession is one of the more important filter mechanisms occurring in the process that these authors refer to as the "policy model of the teacher-supply pipeline". The significance of this mechanism is confirmed by the results of the analyses conducted by Barber and Mourshed (2007), who evaluated the teacher quality policies in countries obtaining high results in Programme for International Student Assessment (PISA) research. Summarising the patterns they found, they note that "the top-performing school systems we studied recruit their teachers from the top third of each cohort that graduate from their school systems; the top 5\% in South Korea, the top $10 \%$ in Finland, the top 30\% in Singapore" (Barber \& Mourshed, 2007, p. 16). These authors were working from a somewhat different perspective to our own, focusing not on the first stage of the selection of candidates for the teaching profession - acceptance for degree programmes preparing students to be teachers - but rather on the second stage - the selection of candidates to be teachers out of teaching degree graduates. We can assume, however, that selection at the first stage will be a significant factor in the quality of graduates completing teaching degrees, from whom future teachers will subsequently be recruited. None the less, as Ingersoll et al. (2007) point out, the countries with the best educational results do not confine themselves to setting high requirements for candidates for teacher training degrees but rather endeavour to make this profession attractive for candidates in terms of both salary level and working conditions. The results of the analyses conducted by this team suggest that policies geared solely towards tightening the recruitment criteria for teaching degrees are only effective to a limited extent in terms of attracting the best candidates. They need to be complemented by actions aimed at providing teachers with comparable working conditions to those offered in other specialist professions. 
However, the factors potentially influencing the question of whether the best candidates train to be teachers are not limited to selection mechanisms or economic issues. Santiago (2004) demonstrated this in his model of the teaching job market, which is characterised by supply and demand and affected by its environment - the existing social, cultural, and administrative conditions. Figure 1 illustrates Santiago's model in a modified version (prepared specifically for this study), paying greater attention to the decisive factors in the choice to train as a teacher rather than to work in a different profession. This model will be used in this article as a theoretical framework to explain differences between countries in the quality of their teaching candidates.

Figure 1. Factors influencing the number and quality of students preparing to work in the teaching profession

\section{TEACHER TRAINING SYSTEM}

$\rightarrow$ number of places on courses

$\rightarrow$ (comparative) requirements of candidates for teaching programmes

$\rightarrow$ duration of degree, programme flexibility

$\rightarrow$ difficulty level

$\rightarrow$ support and motivation instruments aimed at students of teaching degrees

\section{WORK IN SCHOOL AND POSITION OF TEACHERS IN EDUCATION SYSTEM \\ $\rightarrow$ career path in profession, promotion opportunities \\ $\rightarrow$ remuneration practices \\ $\rightarrow$ working conditions (teaching burden, number of hours, additional duties) \\ $\rightarrow$ management system (degree of independence, decision-making powers, etc.)}

\section{EARLIER STAGES} OF EDUCATION

$\rightarrow$ quality and effects of education at lower levels

NUMBER

AND QUALITY

OF CANDIDATES

FOR THE TEACHING PROFESSION

SOCIO-CULTURAL

$\rightarrow$ prestige of profession

$\rightarrow$ attitudes towards teachers of significant reference groups (parents, pupils, decision makers, media)

\section{INDIVIDUAL}

$\rightarrow$ evaluation of own predispositions for taking a teaching degree $\rightarrow$ assessment of chances for employment in the profession

$\rightarrow$ subjective assessment of attractiveness of profession

$\rightarrow$ candidate's family and social environment

\section{ECONOMIC}

$\rightarrow$ employment opportunities, unemployment rate $\rightarrow$ economic and non-economic working conditions of teachers (salary, additional benefits)

$\rightarrow$ alternative career paths and their relative attractiveness

Source: own elaboration based on: Santiago, 2004. 
As well as affecting the quality of candidates for the teaching profession, various factors may also have an impact on each other. For example, the quality of education and its differentiation at lower levels of education will influence graduates' competencies, which will in turn have an effect on their choice of degree programmes suited to their potential. There will also be a link between socio-cultural and economic factors. Furthermore, the decision to train to be a teacher may be affected by the prestige of the profession and social recognition of teachers. The readiness of the best candidates to choose this career, however, may be reduced by economic factors - such as job opportunities in the profession, teachers' salaries, and attractiveness of alternative career paths.

The various factors may influence potential teaching candidates both at the stage of choosing what to study and after their completion of the programme when they decide to begin working in a school. From the perspective of people choosing a degree course, the factors directly influencing their choice are, in particular, the organisation of the teacher training system, including the number of places available on such study programmes, the requirements candidates need to satisfy compared to those for applicants for different courses, and the availability of scholarships and other forms of support acting as motivation for the choice of training in this profession (European Commission/EACEA/ Eurydice, 2015; OECD, 2005).

Individual and social factors also play a major role in the choice of an educational path preparing students for the teaching profession. These include candidates' evaluation of their own capabilities and predispositions for studying and working in this field, their family and social background (e.g. parents' socio-economic status, teaching traditions in the family, previous experience of working with children and teenagers), the prestige of the profession or their subjective assessment of the teaching profession (Barber \& Mourshed, 2007; Ingvarson \& Rowley, 2017; Tenore et al., 2010).

Among the factors mentioned as being responsible for difficulties in recruiting the best candidates to be teachers are the reduced prestige of the profession and the worsening of its relative economic potential (European Commission, 2013; European Commission/EACEA/Eurydice, 2015). As a result of this, it has been pointed out that one of the ways of making teaching more attractive might be to concentrate on factors 
such as teachers' job satisfaction and perceptions of how much society values their work, as well as the school environment and working conditions (European Commission/EACEA/Eurydice, 2015).

Whether candidates are ready to embark on preparatory programmes for a teaching career, and if so which candidates, may also depend on their evaluation of the employment prospects in this profession, itself related to the anticipated demand for labour following their completion of the programme. Demand for teachers is affected by various factors. The following are mentioned most frequently (European Commission/ EACEA/Eurydice, 2015; OECD, 2005; Santiago, 2004):

1. size of school-age population,

2. average class size,

3. expected teaching burden,

4. teaching hours requirements,

5. use of assistants or other people in the education process,

6. use of information technologies or distance learning,

7. duration of mandatory education.

Some of these factors are susceptible to the influence of political decisions (e.g. age at which children begin and end compulsory schooling, class size, teaching burden), while others are not subject to direct influence (e.g. size of school-age population). Budget constraints and the resultant decisions are factors that must also be taken into account. These decisions include setting class sizes, for example. The reduction of class sizes results in a greater demand for teachers, which, coupled with a capped salary budget, may lead to a drop in earnings. Lower average salaries might in turn put good teachers off working in a school or dissuade candidates from entering teacher training programmes.

As Hanushek and Pace (1995) point out, however, the amount of teachers' earnings is less significant in deciding whether to embark on teaching studies or not. The importance of this factor increases when graduates of such programmes decide to look for work in a school or to choose a different career path. As studies conducted in the United Kingdom show (Dolton, 1990), the relative level of pay in teaching and nonteaching professions as well as the likely increase in earnings in the two categories has a major impact on the decisions taken by graduates. If teaching salaries are lower than the earnings of other categories of specialists and grow more slowly than earnings in other groups, 
fewer people take jobs as teachers after completing their degrees. Similar results are given by the analyses of Wolter and Denzler (2003) conducted in Switzerland on data concerning graduates from 1981-1999. These confirm that the supply of teachers is closely linked to the relative earnings of teachers - the higher the salaries of teachers in comparison to those of other specialists, the larger the supply of teachers (Chevalier et al., 2007; Department of Education, Science and Training, 2006; Dolton, 2014, 2016; Dolton \& Marcenaro-Gutierrez, 2011; Dolton et al., 2003). At the same time, high earnings do not guarantee that the best candidates are selected for the teaching profession, since non-financial factors play a more important role in many cases (OECD, 2008).

The factors discussed above may explain the differentiation between candidates beginning training for the teaching profession. Without doubt, however, the competencies of students of teaching degrees are also affected by the quality of education in the programmes themselves. These two elements are closely related - the selection of high-quality and motivated candidates for teacher training brings positive results during their studies. If we wish to obtain similar effects when recruiting weaker candidates, expenditure on and the organisation of the education process must be adapted accordingly. We can therefore assume that preparing high-quality teachers will be hampered significantly in the case of the recruitment of candidates with lower levels of competency. The optimum solution is therefore to admit very good candidates for teaching degrees, develop their competencies during the programme, employ them in the profession and stimulate them for further development.

The next section of the article presents the results of an analysis designed to help to show which factors explain the differentiation in the level of candidates' competencies for the teaching profession. First of all, on the basis of empirical data, we classified the countries into six segments that ultimately fit into three large groups, in which the situation in terms of the competencies of candidates for the teaching profession is (1) optimal, (2) average, or (3) suboptimal. Based on the available secondary data, we attempted to identify the factors differentiating the various segments, particularly taking into account the extreme segments in which the situation is optimal or suboptimal. 


\section{Data and method}

For our analysis, we used data from the Programme for the International Assessment of Adult Competencies (PIAAC) collected by the OECD in over 40 countries (approximately 5,000 individuals in each participating country). The PIAAC is an international survey that assesses the skills of working-age adults (aged 16-65). It provides estimates of adults' competencies in key information processing skills: numeracy and literacy skills, and the capacity to solve problems in technology-rich environments. Often, these skills are assumed to be components of more general cognitive competence (Mateos-Romero \& Salinas-Jiménez, 2017) alternatively, a level of cognitive skills which is commensurate with their job. Different returns are found for each group of overeducated individuals both when compared with adequately educated peers within a similar level of education (with greater wage penalties for apparently overeducated workers.

For our analysis, we selected only European countries from the first and second rounds of studies (2008-2016), with the exceptions of Italy and Lithuania, where the number of teacher candidates was too small to guarantee good estimates. We defined teacher candidates as those studying in programmes classified in the group "Teacher training and education science". The selected sample of teacher candidates was composed of 1,327 cases. The analysis included all the countries in which the subject of study was asked about (i.e. where the identification of students of teaching degrees was possible).

We employed a hierarchical cluster analysis to examine the similarities and dissimilarities of the teacher candidates' information processing skills (numeracy and literacy) in selected European countries. For this study, a set of indicators was used to identify similar countries using a hierarchical clustering analysis. These variables were: (1) average literacy scores for teacher candidates, (2) average numeracy scores for teacher candidates, (3) differences between average literacy scores for teacher candidates and other students, and (4) differences between average numeracy scores for teacher candidates and other students.

As was mentioned in the first part of the article, we assumed that the optimal situation is in countries where (1) the information processing skills of all students are high and (2) teacher candidates' competencies are higher than other students' skills, which indicates a positive 
selection for the teaching profession. The reverse relation is suboptimal and demonstrates a negative selection for the teaching profession.

\section{Results}

In the cluster analysis, we found evidence of six distinct groups (see Table 1). First, there were groups with a "super-optimal" (cluster 4 -Finland) or optimal situation (clusters 3 and 1), where we observed very high literacy and numeracy skills for all students and positive selection of teacher candidates (higher competencies of teacher candidates than other students). This group is composed of six countries (two in cluster 3 and four in cluster 1): Estonia, Netherlands (positive selection only on literacy scores), Finland (positive selection on both scores with higher positive selection on numeracy and the highest numeracy and literacy scores for the whole population), Austria, Belgium, Norway, and Sweden, where we identified a positive selection of teacher candidates (for both numeracy and literacy) and quite high literacy and numeracy skills for all students. Some mediocre countries (cluster 2: Czech Republic, Denmark, France, Ireland, Slovenia, Spain, and the United Kingdom ${ }^{1}$ ) showed no significant difference between students on courses in the "Teacher training and education science" group and others. Students from this group instead demonstrated a less good performance (average literacy and numeracy scores). The last groups (clusters 5 and 6 ) can be regarded as poorly performing countries. The worst situation is in cluster 5, composed of Greece and the Russian Federation, where all students had extremely low literacy and numeracy scores and teacher candidates were negatively selected. An equally suboptimal situation was observed in cluster 6, including Poland and Slovakia, characterised by medium literacy and numeracy scores for all students and also a negative selection for teacher candidates. 
Table 1. Cluster characteristics

\begin{tabular}{|c|c|c|c|c|c|c|c|}
\hline COUNTRY & CLUSTER & $\begin{array}{c}\text { LIT } \\
\text { (DIFFER.) }\end{array}$ & $\begin{array}{c}\text { NUM } \\
\text { (DIFFER.) }\end{array}$ & $\begin{array}{c}\text { LIT } \\
\text { MEAN } \\
\text { (TEACHER } \\
\text { CANDI- } \\
\text { DATES) }\end{array}$ & $\begin{array}{c}\text { NUM MEAN } \\
\text { (TEACHER } \\
\text { CANDI- } \\
\text { DATES) }\end{array}$ & $\begin{array}{c}\text { LIT } \\
\text { MEAN } \\
\text { (ALL } \\
\text { STUDENTS) }\end{array}$ & $\begin{array}{l}\text { NUM MEAN } \\
\text { (ALL } \\
\text { STUDENTS) }\end{array}$ \\
\hline Poland & \multirow{2}{*}{6} & -5.19 & -12.1 & 287.43 & 269.96 & 292.62 & 282.07 \\
\hline Slovakia & & -3.36 & -10.78 & 281.92 & 279.55 & 285.29 & 290.33 \\
\hline Greece & \multirow[b]{2}{*}{5} & -14.81 & -6.85 & 257.16 & 260.05 & 271.96 & 266.9 \\
\hline $\begin{array}{l}\text { Russian } \\
\text { Federation }\end{array}$ & & -17.63 & -16.05 & 264.38 & 263.82 & 282.01 & 279.87 \\
\hline Finland & 4 & 7 & 12.48 & 313.37 & 310.69 & 306.37 & 298.21 \\
\hline Estonia & \multirow{2}{*}{3} & 11.79 & 1.06 & 308.4 & 290.94 & 296.62 & 289.88 \\
\hline Netherlands & & 13.54 & 1.85 & 314.4 & 294.23 & 300.85 & 292.39 \\
\hline Czech Republic & \multirow{7}{*}{2} & 0.28 & -1.82 & 289.52 & 284.44 & 289.24 & 286.26 \\
\hline Denmark & & 3.51 & -7.61 & 284.51 & 275.49 & 281 & 283.11 \\
\hline France & & 2.52 & 5.18 & 289.6 & 281.79 & 287.08 & 276.6 \\
\hline Ireland & & 6.49 & 2.47 & 291 & 275.94 & 284.51 & 273.47 \\
\hline Slovenia & & 1.03 & -3.28 & 283.97 & 281.14 & 282.95 & 284.42 \\
\hline Spain & & 3.22 & -1.15 & 283.09 & 271.29 & 279.87 & 272.44 \\
\hline UK & & 9.38 & -3.19 & 294.03 & 270.48 & 284.64 & 273.66 \\
\hline Austria & \multirow{4}{*}{1} & 15.79 & 9.47 & 305.16 & 303.22 & 289.37 & 293.74 \\
\hline Belgium & & 12.37 & 9.41 & 302.03 & 299.15 & 289.66 & 289.74 \\
\hline Norway & & 16.62 & 15.43 & 299.36 & 295.96 & 282.73 & 280.53 \\
\hline Sweden & & 12.81 & 6.68 & 301.57 & 291.8 & 288.76 & 285.12 \\
\hline
\end{tabular}

Source: PIAAC Study 2008-2016.

\section{Data interpretation and discussion}

In order to explain the results of the segmentation, we need to refer to the factors influencing the quality of teacher candidates, i.e. students of teaching degree programmes. This is a major challenge as a result of the diversity of systems of the selection and training of candidates for the teaching profession in different countries, as well as their 
varying economic, social and cultural situations. A further difficulty is access to fully comparable data that can be used to evaluate the selection system of candidates for the teaching profession and the factors influencing this system. Despite these obstacles, we attempted to assemble indicators for the analysed countries which, according to Santiago's model (2004) presented in the first section, have an impact on the quality of teachers and which are also used in comparative international studies. These indicators, presented in Table 1 in the Annex, take into account five types of factors with a potential influence on the quality of candidates for the teaching profession: (1) achievements at earlier stages of education, (2) teacher education system, (3) socio-cultural conditions, (4) working conditions in school, and (5) earnings.

Before the conclusions are presented, certain caveats are necessary. Firstly, the analysed factors best distinguish countries at the extremes -i.e. the best situation (cluster 4: Finland) and the worst (clusters 5 and 6: Greece, Russian Federation, Poland and Slovakia). With the remaining countries, it is hard to make unambiguous judgements: in their case, certain indicators have optimal values, and others less favourable ones. Secondly, among the aforementioned classes of factors influencing the quality of future teachers, we can distinguish those which (1) clearly distinguish extreme groups, (2) distinguish countries, but with the caveat that one outlier can be observed, and (3) cannot be interpreted in one clear-cut way when describing the groups in question.

Dimensions that are hard to interpret include the teacher training system and working conditions in schools. International studies usually describe the teacher training system by taking into account the implementation of an examination of qualifying candidates to be employed as teachers, as well as the duration of the training process. Working conditions, meanwhile, often refer to working time or subjective job satisfaction. However, the indicators customarily employed for analysing the teacher training system do not appear to fully reflect the qualitative differences between countries. For example, the duration of the training process might act as both a motivation and a demotivation for candidates for a teaching programme. It is therefore better to look for explanations in qualitative factors, the hard-to-measure, specific ways in which the candidates' selection and training system are organised. 
Finland, for example, an independent, outstanding super-optimal segment, is a country regarded as having one of the most effective teacher recruitment and training systems in the world (Barber \& Mourshed, 2007). The teaching profession enjoys high prestige, attractive salaries and good working conditions (Akiba et al., 2012; Sahlberg, 2011; Wong et al., 2013). It is very difficult to gain a place on a Finnish teaching programme - primary school teacher courses usually accept one in ten candidates (Sahlberg, 2010).

In Poland, meanwhile, which belongs to the suboptimal segment in terms of the competencies of students of teaching degrees, numerous places are available on programmes training future teachers. Candidates for the teaching profession can attend various types of higher education institutions (public and private), offering training of varying quality and on either a full-time or part-time basis (Jelonek et al., 2017). Universities and colleges recruiting candidates for teaching programmes apply diverse criteria and often accept a large number of applicants, with selection based solely on the completion of the school-leaving exam. Moreover, teaching degrees are perceived as relatively easy in Poland, which might encourage candidates with lower competencies to apply for such programmes. As a result, the number of teachers trained in Poland exceeds demand, and negative selection takes place in the process of recruitment for the profession.

There is slightly better variation in the extreme clusters of average teacher earnings: in suboptimal clusters, minimum earnings - usually those of young teachers - tend to be low. An exception here is Greece. Salary seems to be a factor that attracts candidates to the teaching profession, yet there is no evidence that increases in pay levels encourage the most talented candidates to apply (Dolton, 2014; 2016). Studies show that material factors, including earnings, are important in this case, but are not the most important factor - especially when there are genuine alternatives of working in another, better-paid specialist profession.

The dimension that differentiates a super-optimal cluster most strongly from a suboptimal one is achievements at earlier stages of education, which can be characterised from the perspective of the aspirations of better or worse school pupils to work in the teaching profession. These aspirations are usually formed between the ages of 10 and 14 (Ashby \& Schoon, 2010; The Royal Society, 2006; 
Schoon \& Parsons, 2002). Pupils' perception of the teaching profession as well as early career aspirations can therefore be important for later career selection, including the decision to continue in education as a teacher.

In the suboptimal cluster, it is usually weaker school pupils (on average with lower literacy and numeracy skills than pupils interested in pursuing other specialist professions) who aspire to the teaching profession. In these countries, a lower total percentage of pupils aspire to be teachers, and children from higher social classes (parents with higher education) relatively seldom have the ambition to enter this profession. Again, Greece is something of an exception here. In this context, the results of OECD (2018) research on 15-year-old school pupils are a concern, revealing that in Europe, pupils aspiring to the teaching profession generally tend to have a lower level of competencies than their peers seeking to enter other specialist professions. Among the countries considered in this analysis, Estonia stands out; the pupils contemplating a teaching career in this country obtain better results in competency tests than those planning to work in a different specialist profession. This shows that the teaching profession is attractive for able 15-year-olds, and the selection mechanisms for the profession sustain this trend.

Apart from selection mechanisms, many countries also employ incentive systems aiming to reduce the overall shortage of teachers or shortages in specific subjects, as well as to attract good candidates to the profession (OECD, 2005). An example of a country with such instruments in place is the United Kingdom, a country in the optimal segment. Schemes include scholarships, fee waivers, reimbursements for the repayment of loans after graduates have commenced teaching work, or financial incentives for people training in a given subject or who are willing to work in a specific field. A report on the implementation of these schemes stated that they resulted in increased numbers of teacher trainees (OECD, 2005). The available data also reveals that the candidates commencing teacher training programmes after the implementation of these instruments are characterised by higher competencies (Ross \& Hutchings, 2003).

As mentioned above, however, optimal results in the selection of suitable candidates for the teaching profession are not guaranteed either by a restrictive recruitment policy alone or by systems designed 
to increase the attractiveness of teacher training programmes (Ingersoll et al., 2007). It is also essential for students on such courses to have high motivation, which is in turn closely associated with the prestige of the teaching profession and teachers' working conditions (European Commission/EACEA/Eurydice, 2015; Han et al., 2017; Park \& Byun, 2015). It is difficult to assess the prestige of the teaching profession in the countries in the various segments as a result of the lack of comparable international studies. We can look to the results of TALIS research, however, which shows whether teachers view their profession as enjoying social recognition or not. Although the results are not unequivocal here either, teachers regarded their profession as socially respected in countries from the optimal segment (e.g. Finland, Belgium) considerably more often than in countries from the suboptimal segment (e.g. Poland, Slovakia). Here, too, there are certain exceptions (e.g. Sweden), where the percentage of teachers declaring that their profession is valued in society is similar to, or even lower than, countries from the suboptimal segment (e.g. Poland). Poland also offers an interesting comparison between the actual perception of the prestige of the teaching profession and teachers' views of this prestige. In a long-term nationwide study on the hierarchy of professions, teachers have occupied a relatively high position for years. According to the results of this study from 2013, teachers were ranked seventh in the hierarchy of professions' prestige, ahead of doctors and lawyers (CBOS, 2013). Teachers themselves, however, judge their work not to be prestigious (Federowicz et al., 2013). Their rating of the financial attractiveness of their profession is similarly low - just $16 \%$ agreed with the statement that teaching salaries were satisfactory (ibidem).

Significant elements encouraging people to choose the path of education leading to the teaching profession are internal motivators, including a perception of this career as favouring independence and individual development and being an interesting occupation that provides a sense of being useful to society. This perception might be connected to working conditions in the teaching profession, the nature of the work, or the extent of freedom that it gives. This factor can be approximated by assessing teachers' job satisfaction. As the data presented in Table 1 shows, once again, Finland stands out in this regard, and of the countries for which data is available, the least satisfied with their work are teachers from Slovakia. Although again this trend 
is not entirely clear, we might tentatively conclude that in countries in the optimal segment, teachers are slightly more satisfied with their work than their counterparts in countries in the suboptimal segment.

\section{Conclusions}

In summary, it is again worth noting the rather worrying trend in the case of countries in the suboptimal segment. In these countries, the average level of literacy and numeracy is low, and additionally, teaching degree programmes select individuals with lower competencies than is the case for other subjects. As a result, positive selection for the teaching profession in these countries is hampered considerably - even if the best students in the cohort ultimately opt for the teaching profession, they will not be the best overall. A low standard of teachers is likely to translate into low achievements by pupils, which again leads to a lower standard of individuals aspiring to work in schools in future.

PISA data confirms the existence of a feedback mechanism, which can also be observed at the micro level. In the case of schools located in peripheral regions of the country, with more children with greater educational needs on average, teachers' level of competency is relatively low (OECD, 2018). For countries in the suboptimal segment, the matter is complicated as a result of the overlap of the primary and secondary mechanisms of professional selection. The former is responsible for negative selection for the teaching profession. This phenomenon is visible, for instance, in the on average lower competencies of individuals participating in teaching degree programmes. This has been described in this article and has been confirmed by, among others, the OECD's research on aspirations to pursue specific careers among 15 -year-olds (OECD, 2018). Consequently, there is a reasonable risk that the teachers responsible for assessing, selecting and increasing the potential of children in the countries in this segment will possess lower competencies and potential than the parents of these children. Considering the fact that one of the objectives of education is to increase young people's potential, the situation appears extremely unfavourable. As the OECD's research reports, the above mechanism is further exacerbated by additional micro differentiation visible at the stage of leaving the higher education system. Talented graduates of teaching degrees choose to work in better schools, which are usually attended by more able pupils. While the former of these mechanisms 
is responsible for the generally lower effectiveness of the education system (low level of teaching) and children's potential is consequently not completely fulfilled, the latter reinforces social inequalities at the local level.

We are aware that the mere fact of studying on a teaching programme does not necessarily mean the same as working in this field, and indeed some students opt for a career not connected to their degree subject. The question of which students are more inclined to make the final decision to be a teacher is the next important factor deciding on the quality of school teaching staff. Further research questions that are well worth investigating concern the chances that the most capable students of teaching programmes will decide to work in a school, as well as what could be done to increase this likelihood. 


\section{Annex}

Table 1. Key characteristics of the countries selected

\begin{tabular}{|c|c|c|c|c|c|c|c|}
\hline COUNTRY & 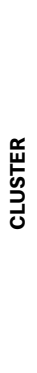 & 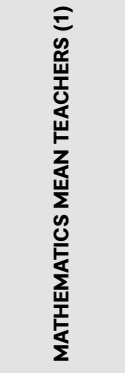 & 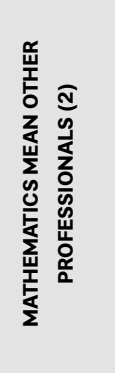 & 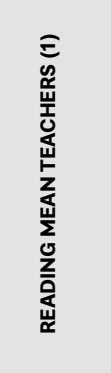 & 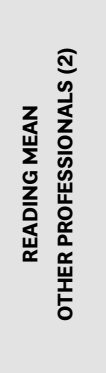 & $\begin{array}{l}\mathbf{\Sigma} \\
\mathbf{x} \\
\mathbf{x} \\
\mathbf{u} \\
\mathbf{0} \\
\mathbf{z} \\
\mathbf{c} \\
\mathbf{c} \\
\mathbf{z} \\
\mathbf{z}\end{array}$ & 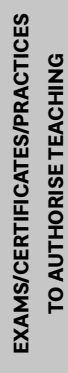 \\
\hline AUSTRIA & \multirow{4}{*}{1} & 519.84 & 523.46 & $533.73^{\star}$ & $516.13^{*}$ & 1 & 1 \\
\hline BELGIUM & & $495.84^{\star}$ & $527.64^{\star}$ & $491.96^{\star}$ & $526.56^{*}$ & 0 & 0 \\
\hline NORWAY & & 518.23 & 525.07 & 542.74 & 544.56 & 0 & 0 \\
\hline SWEDEN & & 502.92 & 516.32 & 518.55 & 532.77 & 0 & 0 \\
\hline CZECH REPUBLIC & \multirow{7}{*}{2} & 536.58 & 534.46 & 539.30 & 538.83 & 0 & 0 \\
\hline DENMARK & & 528.42 & 528.83 & 526.38 & 525.39 & 0 & 1 \\
\hline FRANCE & & $510.11^{\star}$ & $533.16^{\star}$ & $529.07^{\star}$ & $546.95^{*}$ & 0 & 1 \\
\hline IRELAND & & $503.23^{\star}$ & $521.83^{*}$ & $526.81^{*}$ & $543.90^{*}$ & 1 & 1 \\
\hline SLOVENIA & & 544.52 & 538.22 & 553.45 & 541.42 & 0 & 0 \\
\hline SPAIN & & $476.09^{\star}$ & $503.58^{\star}$ & $493.86^{\star}$ & $517.22^{*}$ & 0 & 1 \\
\hline UNITED KINGDOM & & $491.42^{*}$ & $510.34^{\star}$ & $505.83^{*}$ & $518.32^{*}$ & 0 & 1 \\
\hline ESTONIA & \multirow{2}{*}{3} & $546.34^{\star}$ & $538.69^{*}$ & 552.97 & 542.78 & 0 & 0 \\
\hline NETHERLANDS & & $510.62^{\star}$ & $549.12^{\star}$ & $508.38^{\star}$ & $544.17^{\star}$ & 0 & 0 \\
\hline FINLAND & 4 & $528.57^{\star}$ & $544.75^{\star}$ & $555.04^{*}$ & $567.09^{*}$ & 1 & 1 \\
\hline GREECE & \multirow{2}{*}{5} & 451.24 & $475.43^{\star}$ & $474.51^{*}$ & $495.92^{*}$ & 1 & 1 \\
\hline RUSSIAN FEDERATION & & 494.50 & 507.71 & 506.52 & 514.56 & 0 & 0 \\
\hline POLAND & \multirow{2}{*}{6} & 520.58 & 533.84 & 533.65 & 543.98 & 0 & 0 \\
\hline \multirow[t]{2}{*}{ SLOVAKIA } & & $481.79^{\star}$ & $516.60^{\star}$ & $480.13^{\star}$ & $506.44^{*}$ & 0 & 0 \\
\hline & & \multicolumn{4}{|l|}{ PISA 2015} & \multicolumn{2}{|l|}{ OECD } \\
\hline
\end{tabular}

*) Significant differences on the level $p<0.05$.

1) Mean score in mathematics and reading among students who expect to become a teacher.

2) Mean score in mathematics and reading among students who expect to become other professionals, include scientists, engineers, medical professionals, teachers, and business, legal, social science and related. 


\begin{tabular}{|c|c|c|c|c|c|c|c|c|c|c|}
\hline 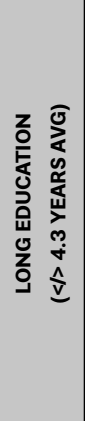 & 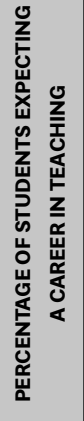 & 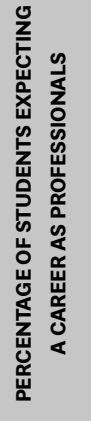 & 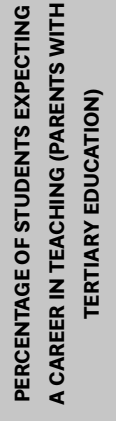 & 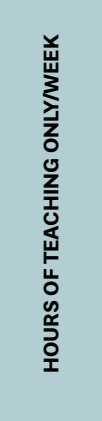 & 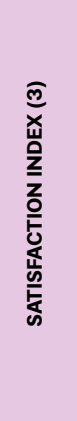 & 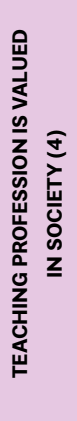 & 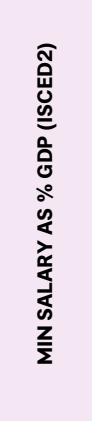 & 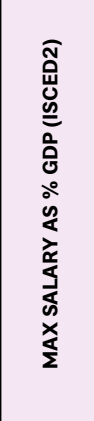 & 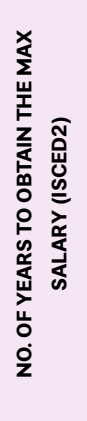 & 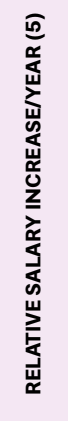 \\
\hline 1 & 5.2 & 49.1 & 5.1 & - & - & - & 84.6 & 170.0 & 34 & 1.99 \\
\hline 0 & 4.5 & 51.2 & 4.6 & 20.95 & 7.93 & 45.9 & 88.6 & 151.2 & 27 & 2.07 \\
\hline 1 & 3.2 & 46.7 & 3.4 & 15.53 & 7.71 & 30.6 & 65.2 & - & - & - \\
\hline 0 & 1.5 & 42.2 & 1.7 & 17.58 & 5.95 & 5.0 & 67.0 & 93.4 & - & - \\
\hline 1 & 3.3 & 35.6 & 3.3 & 17.84 & 6.21 & 12.2 & 62.6 & 77.4 & 27 & 0.82 \\
\hline 0 & 1.2 & 33.1 & 1.1 & 18.60 & 7.57 & 18.4 & 94.0 & 116.1 & 12 & 1.94 \\
\hline 1 & 3.8 & 44.3 & 3.8 & 18.59 & 6.17 & 4.9 & 87.6 & 152.3 & 29 & 1.99 \\
\hline 1 & 11.8 & 61.4 & 11.1 & - & - & - & 78.1 & 166.7 & 22 & 3.68 \\
\hline 0 & 4.4 & 45.7 & 4.8 & - & - & - & 98.3 & 158.1 & 25 & 2.00 \\
\hline 1 & 5.6 & 60.7 & 5.7 & 18.60 & 7.22 & 8.5 & 144.1 & 201.5 & 38 & 0.94 \\
\hline 0 & 5.0 & 61.4 & 4.7 & 19.63 & 7.40 & 35.4 & 84.3 & 143.5 & 10 & 6.09 \\
\hline 1 & 1.4 & 55.3 & 1.4 & 20.86 & 6.38 & 13.7 & 67.1 & 77.3 & 8 & 2.04 \\
\hline 1 & 4.9 & 36.3 & 4.8 & 16.87 & 7.62 & 40.4 & 95.3 & 196.3 & 12 & 6.78 \\
\hline 1 & 4.6 & 37.1 & 4.9 & 20.29 & 8.41 & 58.6 & 96.2 & 125.1 & 20 & 1.39 \\
\hline 0 & 5.9 & 59.4 & 6.0 & - & - & - & 75.3 & 142.3 & 33 & 2.01 \\
\hline 0 & 2.6 & 50.9 & 2.6 & - & - & - & - & - & - & - \\
\hline 0 & 2.4 & 39.7 & 2.9 & 18.93 & 7.13 & 17.9 & 60.8 & 102.6 & 20 & 2.80 \\
\hline 1 & 2.9 & 34.5 & 2.9 & 19.85 & 5.84 & 4.0 & 50.6 & 68.5 & 32 & 0.98 \\
\hline & & & & \multicolumn{3}{|l|}{ TALIS } & \multicolumn{4}{|c|}{ Eurydice } \\
\hline
\end{tabular}

3) The satisfaction index was calculated based on four questions (TT2G46A, TT2G46B, TT2G46H, TT2G46J) and its values may vary from 0 (the lowest satisfaction) to 12 (the highest satisfaction).

4) Percentages of respondents answering "agree" and "strongly agree" to the question "I think that the teaching profession is valued in society".

5) Coefficient calculated on the basis of "Multiple-Year Growth Rate Percentage" $\left(P=\left[(f / s)^{\wedge}(1 / y)\right]-1\right)$. 


\section{References}

$\rightarrow$ Aghion, P., David, P. A. and Foray, D. (2009). Science, technology and innovation for economic growth: Linking policy research and practice in "STIG Systems", Research Policy, 38(4), 681-693.

$\rightarrow$ Akiba, M., Chiu, Y., Shimizu, K. and Liang, G. (2012). Teacher salary and student achievement: A cross-national analysis of 30 countries, International Journal of Educational Research, 53, 171-181.

$\rightarrow$ Applegate, J. H. (1987). Teacher candidate selection: An overview, Journal of Teacher Education, 38(2), 2-6.

$\rightarrow$ Ashby, J. and Schoon, I. (2010). Career success: The role of teenage career aspirations, ambition value and gender in predicting adult social status and earnings, Journal of Vocational Behavior, 77(3), 350-360.

$\rightarrow$ Barber, M. and Mourshed, M. (2007). How the best performing school systems come out on top. London: McKinsey \& Co.

$\rightarrow$ Beauchamp, G., Clarke, L., Hulme, M. and Murray, J. (2013). Research and teacher education: The BERA-RSA inquiry. Policy and practice within the United Kingdom. Project report. London: British Educational Research Association.

$\rightarrow$ CBOS (2013). Prestiż zawodów. Komunikat z badań, Warszawa: Centrum Badania Opinii Społecznej, www.cbos.pl/SPISKOM.POL/2013/K_164_13.PDF

$\rightarrow$ Carrell, S. and West, J. (2010). Does Professor Quality Matter? Evidence from Random Assignment of Students to Professors, Journal of Political Economy, 118(3), 409-432.

$\rightarrow$ Chevalier, A., Dolton, P. and Mclntosh, S. (2007). Recruiting and retaining teachers in the UK: An analysis of graduate occupational choice from the 1960s to the 1990s, Economica, 74(293), 69-96.

$\rightarrow$ Darling-Hammond, L. Burns, D., Campbell, C., Goodwin, A.L., Hammerness, K., Low, E., Mclntyre, A., Sato, M. and Zeichner, K. (2017). Empowered Educators: How High-Performing Systems Shape Teaching Quality Around the World. San Francisco: Jossey-Bass.

$\rightarrow$ Department of Education, Science and Training (2006). Attitudes to teaching as a career: A synthesis of attitudinal research. Canberra: Commonwealth of Australia.

$\rightarrow$ Dolton, P. (1990). The Economics of UK Teacher Supply: The Graduate's Decision, The Economic Journal, 100, 91-104.

$\rightarrow$ Dolton, P. (2014). The Economics of UK Teacher Supply: The Graduate's Decision, The Economic Journal, 100(400), 91-104. 
$\rightarrow$ Dolton, P. (2016). Teacher Supply. In: E. Hanushek, S. Machin, L. Woessmann (eds.), Handbook of the economics of education (Vol. 2, pp. 1079-1161). Amsterdam: Elsevier.

$\rightarrow$ Dolton, P., Tremayne, A. and Chung, T. (2003). The Economic Cycle and Teacher Supply, paper commissioned for the Attracting, Developing and Retaining Effective Teachers Activity, Directorate for Education. Paris: Organisation for Economic Cooperation and Development, www.oecd.org/edu/teacherpolicy

$\rightarrow$ Dolton, P. and Marcenaro-Gutierrez, D. (2011). If you pay peanuts you get monkeys? A cross-country analysis of teacher pay and pupil performance, Economic Policy, 26(65), 5-55.

$\rightarrow$ European Commission (2013). Study on Policy Measures to Improve the Attractiveness of the Teaching Profession in Europe. Vol. 2: Final report. Luxembourg: Publications Office of the European Union, http://bookshop. europa.eu/en/study-on-policy-measures-to-improve-the-attractiveness-ofthe-teaching-profession-in-europe-pbNC0113029/

$\rightarrow$ European Commission (2013). EU performance and first inferences regarding education and training policies in Europe. Brussels: European Commission, http://ec.europa.eu/dgs/education_culture/repository/education/policy/ strategic-framework/doc/pisa2012_en.pdf

$\rightarrow$ European Commission/EACEA/Eurydice (2006). Quality assurance in teacher education in Europe. Brussels: European Commission.

$\rightarrow$ European Commission/EACEA/Eurydice (2015). The teaching profession in Europe: Practices, perceptions, and policies. Eurydice report. Luxembourg: Publications Office of the European Union.

$\rightarrow$ Federowicz, M., Choińska-Mika, J. and Walczak, D. (2014). Liczq̨ się nauczyciele. Raport o stanie edukacji 2013, Warszawa: Instytut Badań Edukacyjnych.

$\rightarrow$ Gromkowska-Melosik, A. (2013). Feminizacja zawodu nauczycielskiego - „różowe kołnierzyki" i paradoksy rynku pracy, Studia Edukacyjne, 25, 85-100.

$\rightarrow$ Han, S., Borgonovi, F. and Guerriero, S. (2017). What Motivates High School Students to Want to Be Teachers? The Role of Salary, Working Conditions, and Societal Evaluations About Occupations in a Comparative Perspective, American Educational Research Journal, 55(1), 3-39.

$\rightarrow$ Hanushek, E. (2012). Education quality and economic growth. In: B. Miniter (ed.), The 4 percent solution: Unleashing the economic growth America needs. New York: Crown Business.

$\rightarrow$ Hanushek E. and Rivkin S. (2012). The Distribution of Teacher Quality and Implications for Policy, Annual Review of Economics, 4, 131-157. 
$\rightarrow$ Hanushek, E., Piopiunik, M. and Wiederhold, S. (2014). The Value of Smarter Teachers: International Evidence on Teacher Cognitive Skills and Student Performance. Working Paper No. 20727. Cambridge: National Bureau of Economic Research.

$\rightarrow$ Hattie, J. (2009). Visible learning. A synthesis of over 800 meta-analyses relating to achievement. London: Routledge.

$\rightarrow$ Henke, R., Geis, S. and Giambattista, J. (1996). Out of the Lecture Hall and into the Classroom: 1992-93 College Graduates and Elementary/Secondary School Teaching, Statistical Analysis Report, NCES 96-899. Washington: National Center for Education Statistics, U.S. Department of Education.

$\rightarrow$ Ingersoll, R., Boonyananta, S., Fujita, H., Gang, D., Kim, E.G., Lai, K.C., Wong, A.F.L. (2007). A comparative study of teacher preparation and qualifications in six nations. Philadelphia: Consortium for Policy Research in Education.

$\rightarrow$ Ingvarson, L. and Rowley, G. (2017). Quality Assurance in Teacher Education and Outcomes: A Study of 17 Countries, Educational Researcher, 46(4), 177-193.

$\rightarrow$ Mateos-Romero, L. and Salinas-Jiménez, M. (2017). Competencias cognitivas y desajustes en el mercado laboral: una revisión de la literature, Boletín Económico de ICE, August, 29-43.

$\rightarrow$ Meroni, E.C. and Vera-Toscano, P.C. (2015). Can low skill teachers make good students? Empirical evidence from PIAAC and PISA, Journal of Policy Modelling, 37, 308-323.

$\rightarrow$ Mourshed, M., Chijioke, C. and Barber, M. (2010). How the world's most improved school systems come out on top. London: McKinsey \& Co.

$\rightarrow$ OECD (2005). Teachers Matter Education and Training Policy. Attracting, Developing and Retaining Effective Teachers. Paris: Organisation for Economic Cooperation and Development Publishing.

$\rightarrow$ OECD (2011). Strong performers and successful reformers: Lessons from PISA for the United States. Paris: Organisation for Economic Cooperation and Development Publishing.

$\rightarrow$ OECD (2013a). Lessons from PISA 2012 for the United States: Strong performers and successful reformers in education. Paris: Organisation for Economic Cooperation and Development Publishing.

$\rightarrow$ OECD (2013b). PISA 2012 Results: What Makes Schools Successful? Resources, Policies and Practices. Vol. 4: PISA. Paris: Organisation for Economic Cooperation and Development Publishing.

$\rightarrow$ OECD (2018). Effective Teacher Policies: Insights from PISA. Paris: Organisation for Economic Cooperation and Development Publishing. 
$\rightarrow$ Park, H. and Byun, S. (2015). Why Some Countries Attract More High-Ability Young Students to Teaching: Cross-National Comparisons of Students' Expectation of Becoming a Teacher, Comparative Education Review, 59(3), 523-549.

$\rightarrow$ Ross, A. and Hutchings, M. (2003). Attracting, developing and retaining effective teachers in the United Kingdom of Great Britain and Northern Ireland. OECD country background report. London: Institute for Policy Studies in Education London Metropolitan University, https://search.oecd.org/ education/school/2635748.pdf

$\rightarrow$ Sahlberg, P. (2010). The Secret to Finland's Success: Educating Teachers. Stanford: Stanford Center for Opportunity Policy in Education, www.nnstoy. org/download/preparation/Secret $\% 20$ to $\% 20$ Finland's $\% 20$ Success $\% 20$ - $\% 20$ Education\%20Teachers.pdf

$\rightarrow$ Sahlberg, P. (2011). Developing effective teachers and school leaders: The case of Finland. In: L. Darling-Hammond, R. Rothman (eds.), Teacher and leader effectiveness in high-performing education systems (pp. 13-21). WashingtonStanford: Alliance for Excellent Education and Stanford Center for Opportunity Policy in Education.

$\rightarrow$ Santiago, P. (2004). The labour market for teachers. In: G. Johnes, J. Johnes (eds.), International Handbook on the Economics of Education (pp. 522-578). Cheltenham: Edward Elgar.

$\rightarrow$ Schleicher, A. (2018). World Class: How to build a $21^{\text {st }}$-century school system, Strong Performers and Successful Reformers in Education. Paris: Organisation for Economic Cooperation and Development Publishing.

$\rightarrow$ Schoon, I. and Parsons, S. (2002). Teenage Aspirations for Future Careers and Occupational Outcomes, Journal of Vocational Behavior, 60(2), 262-288.

$\rightarrow$ Tenore, F. B., Dunn, A.C., Judson C., Laughter J.C. and Milner, H.R. (2010). Teacher Candidate Selection, Recruitment and Induction. A Critical Analysis with Implications for Transformation. In: V. Hill-Jackson, C.W. Lewis (eds.), Transforming Teacher Education. What Went Wrong with Teacher Training, And How We Can Fix It. Sterling, VA: Stylus.

$\rightarrow$ The Royal Society with OPM (2006). Taking a leading role - Scientists survey. London: The Royal Society.

$\rightarrow$ Wang, A., Coleman, A., Coley, R. and Phelps, R. (2003). Preparing Teachers around the World. Policy Information Report. Princeton: Policy Information Center.

$\rightarrow$ Wexler, A. and Maagan, D. (2002). Teaching Force Forecasting Demand, Intermediate Report. Jerusalem: CBS.

$\rightarrow$ Wolter, S., Denzler, S. (2003). Wage Elasticity of the Teacher Supply in Switzerland, Discussion Paper No. 733. Bonn: Institute for the Study of Labor. 


\section{Quality Teachers and Quality \\ Teacher Education \\ Exploring Wellbeing, Gender \\ and Job Satisfaction}

DOI: $10.47050 / 66515321.42-57$

Suzanne O'Keeffe

This chapter explores four Irish male primary teachers' daily experiences of care and gender in contemporary Irish schools. Taking a feminist poststructural approach, the study employs three data-collection phases using the interview as the primary method of enquiry. It employs a voice-centred relational method of data analysis, which involves four readings of data with each reading troubling the data in different ways. The current climate of professionalisation within the profession creates a dispassionate distance dictating how teachers should conduct their professional lives. This is further problematised through the concept of gender. Men who perform "caring" roles face special difficulties as "feminised" discourses of service and care often carry a devalued status and do not align with dominant definitions of masculinities. If men perform femininity through nurturance and care, their sexuality is called into question; if they display masculinity through emotional distance and control, their caring skills are questioned. Is there a link between gender, care and teacher wellbeing? How does the concept of "care" impact on teacher job satisfaction?

\section{Keywords:}




\section{Introduction}

Wellbeing and happiness are a major subject of public policy concern internationally. The need to include mental health among the first priorities of the public health agenda has been increasingly recognised in Europe over the past decades (EU Joint Action on Mental Health and Wellbeing, 2016). International performance indicators routinely include data on wellbeing. In 2013, a dedicated module containing 18 indicators on subjective wellbeing was included in the Improvement of Living and Working Conditions (Eurofound) survey, which has been collecting data through its European Quality of Life Survey (EQLS) since 2003. According to the Years Lived with Disability (YLD) statistics, mental disorders represent $22 \%$ of the EU's burden of disability. More recently, Health at a Glance: Europe 2019 (OECD, 2020) reports that mental health problems, such as depression, anxiety disorders and alcohol and drug use disorders, affect more than one in six people across the European Union in any given year. Mindful of the current educational landscape, the emotional atmosphere in a school setting is a worthy area of further exploration in terms of wellbeing, gender and job satisfaction. This may be even more relevant when considering that many educational policies are at odds with teacher identities of public good, further impacting on job satisfaction. Performance targets, curriculum changes and heavy workloads are the realities of educational policies that impact daily on teacher wellbeing and job satisfaction.

Increasing literature exists that details the positive relationship between job satisfaction and wellbeing (Sironi, 2019; Judge et al., 2001). The promotion of wellbeing is central to European educational policy, which intends to enable children and young people to achieve their full potential and contribute to Europe's social, cultural and economic development. Wellbeing in the workplace has increasing prominence in the policy and research agenda in Europe, and education is a key context in which the challenge of occupational stress has been reported (Skinner et al., 2019). This may be, in part, owed to socio-cultural understandings of teaching prior to its professionalisation. In Ireland, schools have traditionally been embedded in communities. High cultural prestige has been placed on teaching as a "vocation" and on teachers hearing "a call" to teach (Coolahan, 2013). Indeed, Irish novelist John McGahern referred to teaching as the second priesthood. This vocational interpretation of teaching has focused teachers' 
commitment on the "social good" of their work rather than on personal occupational stress. In recent times, the increasing move towards neoliberal conceptions of quality in education has created new forms of occupational stress, particularly for male teachers. The evolving requirements of global capitalism have meant that the nature of work requires the cultivation of an elite masculinity that is more sensitive and reflexive (Haywood \& Mac an Ghaill, 2013). There is now a greater emphasis on feminised features such as empathy, patience and understanding as assets in business, which also inform our understandings of "good teaching", since emotions are considered more powerful than thought when used as "tools" for career advancement (Ahmed, 2014). According to the World Health Organisation (WHO), gender is one of the critical determinants of mental health as it determines the power and control men and women have over the socio-economic causes of their mental health and lives; their social position; social status and treatment in society. Despite the presence and acceptance of a variety of versions of "maleness" in the classroom, gender issues such as gender stereotyping and the inability to reconcile their professional and personal identities (Mills, Haase \& Charlton, 2008) result in male teachers' subsequent decision to withdraw from teacher education or to cut their career short (Cushman, 2005).

The principal focus of this chapter is to underpin the complicated interplay between emotions, gender and teaching with the everyday experiences of four Irish male primary school teachers. This chapter begins by exploring the concept of emotions and its relevance to teaching. Next, gender is examined in relation to education. Then, the body and what the body says about a person in an educational setting are discussed. This chapter concludes with a discussion centred on the problems of and possibilities for men who teach at primary level.

\section{Understanding the relationship between gender and emotions}

The everyday language of emotion is based on the presumption of "interiority" (Ahmed, 2004, p. 8). Emotions are considered as individual, internal and private responses to situations. Such a model of emotion looks inside to "idiosyncratic" conditions (Walby et al., 2012, p. 4) or to feelings that "are mine" (Ahmed, 2004, p. 8). Yet, like everything else that is human, emotions are in part socially constructed, 
"bearing the marks" of the society that created them (Jaggar, 2008, p. 386). We know that emotional experiences connect persons to others, both moving us and holding us in place. We absorb the norms and values of our society in the form of social and cultural practices that preserve society. Within a hierarchical society, the norms and values that predominate tend to serve the interests of the dominant groups, which in turn inform our emotional constitution in particular ways (Jaggar, 2008). In other words, emotions are brought into line with the rules proposed by society or by the self. Dominant values are implicit in responses taken to be pre-cultural or acultural, hampering alternative ways of living (Jaggar, 2008). As Butler (1999, p. 17) suggests, gender is a culturally authorised performance, "a repetition and a ritual". These understandings are significant for men in non-traditional occupations such as teaching.

It is significant that teaching is considered a "soft option" career for men (Connell, 1985) and an essentially feminised occupation rather than a masculine one. Softness is very often defined in terms of weakness or proneness to injury (Ahmed, 2004) and is associated with all that is considered feminine, including the body. Typically, reason is associated with the mental, the public and the male, and emotion is associated with the irrational, the private and the female (Jaggar, 2008). To be emotional is to be "reactive rather than active, dependent rather than autonomous" (Ahmed, 2004, p. 3). Therefore, emotions are always subordinate to reason and potentially or actually subversive of knowledge (Jaggar, 2008). The association of emotions to the body, or the "inner" self, works to remind us that the very concept of the body has been formed in opposition to the mind or as "the chief enemy of objectivity" (Jaggar \& Bordo, 1992, p. 4). Doing work that involves emotions is fundamentally an "act of doing gender in the context of 'women's allegedly greater facility with emotions - the feminine capacity to console, and comfort, flatter'" (Frith \& Kitzinger, 1998, p. 300, cited in: Mirchandani, 2008, p. 265). Indeed, King (1998, p. 126) notes that it is "[...] striking that the options for care are identical for men and women, but the choices are weighed differently based on gender". Certain behaviour is seen as appropriate for female teachers but not for male teachers. This is illustrated in David's story, a participant, about holding children's hands on the yard. 
David: There was a special unit in the school I was working in... I remember I had to bring them [the pupils] out to the yard and you have to hold hands with them and stuff but I would not feel comfortable holding hands with kids. I know it is for their safety but still, you would not feel comfortable holding hands and people walking past the school... Whereas for a female teacher, probably, it is completely natural.

One way of reflecting on David's story is to consider a rethinking of the relationship between emotion, bodily sensations and reason. Whilst it is somewhat true that physiological disturbances characterise emotions - sweating, trembling and tears are "instinctive biological responses" (Jaggar, 2008, p. 381) -, emotions are not pre-social, involuntary responses. A cognitivist view (as cited in: Ahmed, 2004, p. 5) suggests that emotions involve appraisals, judgements and attitudes shaped by memory and by histories that come before the subject. Emotions in this way are social and cultural rather than a presumption of interiority.

\section{Research Design}

This chapter draws on research that was inspired by feminism and poststructuralism (O'Keeffe, 2016). Feminism places the personal being at the centre of one's enquiry. A feminist theoretical orientation disrupts traditional ways of knowing through its commitment to studying the lived experiences of gender, as outlined by Pillow and Mayo (2007). This creates rich new meanings by highlighting concerns of boundaries, identities and speaking. Running parallel to this is poststructuralism, which facilitates a constant engagement with the tensions and omissions in a text (Jackson \& Mazzei, 2012). A poststructural reading of data troubles the innocent idea of any term. As a result, poststructuralism holds the idea that no reading or writing of a life is ever complete. From this belief emerges accounts that are playful, open-ended, and incomplete (Van Maanen, 2011). This study draws on the work of the feminist theorists and methodologists Karen Barad, Judith Butler, Patti Lather and Susan Hekman to methodologically engage with the concepts, ideas and theories put forward by the male teachers. Together, a feminist perspective and a poststructuralist methodology critically deconstruct gendered social practice and 
support alternative understandings of power and subject formation. Deconstruction, in this sense, does not mean dismantling. Instead, it is a tool that facilitates the possibilities for the stories of each teacher to go far beyond the pages of this chapter.

\section{The Site}

The Republic of Ireland, the site of this paper, is an interesting place to engage with issues of identity, politics and power as the societal landscape of Ireland has recently experienced a gender political awakening. The historic 2015 Irish Marriage Equality Referendum (Griffith, 2013) is such an exemplar. Similarly, in 2015, the Gender Recognition Act was enacted and came into effect. This Act allows all individuals over the age of 18 to self-declare their own gender identity in Ireland. These historic changes initiated a series of passionate public discussions and high-profile debates in Ireland. Gender emerged, to borrow Woodward and Woodward's (2015) words, as a field that was "hotly contested". Such intense debate has resulted in an increased public awareness of gender and gender politics. The topic of men in primary education is a controversial political issue, particularly when one considers increasing global calls to increase the number of male entrants to the teaching profession without empirical evidence that proves that their presence is of actual benefit to students' learning and attainment. As men have traditionally been seen to hold a privileged role in national and international society in terms of power and prestige, very little opportunity is afforded to men in marginal positions, such as primary teaching, to have their voices heard. As Michael, a participant in this study, stated, "If you accept that there is some sort of element of maleness about men, then you either value it or you do not value it. At the moment, we do not value it".

\section{Ethical considerations}

Ethical approval for this study was sought from, and granted by, the Research Ethics Committee (MIREC) at Mary Immaculate College, Ireland. Participants were advised of the following: the voluntary nature of their participation, their confidentiality and anonymity, and the purpose of the research. The participants were offered the choice of using a pseudonym. Many participants were in favour of this option, while others were happy to retain the use of their name. 
Feminist ethical considerations

The attention given to relationships with the participants illustrates the goals of feminist research to be "for" rather than "on" people. This suggests that research "on" a particular group is not necessarily beneficial for them. However, research "for" people fosters empowerment, gives back reports to participants to check descriptive and interpretive validity and is highly interactive. Relationship-building was an important consideration in this research and was fostered by:

1. Regular and open communication before, during, and after each phase of the interviews,

2. Inviting participants to select the most convenient time and place to meet,

3. Informing participants of emerging themes,

4. Offering transcripts to participants for review, and

5. Offering draft chapters to participants for feedback.

\section{Findings}

Finding 1: The Relational Realities of Nurturing

Care is a priority topic for all teachers due to the key roles they play in the transmission of values, knowledge, and the development of human potential and skills. Care is also a practical consideration for every teacher regardless of gender. Teaching involves care and emotions as much as "pure reasoning" (Connell, 1993, p. 63). However, when men exhibit caring attributes at work, they are not considered compatible with dominant definitions of masculinities. Caring qualities are not deemed appropriate for the masculinised domain of management or authority. This results in the relational realities of nurturing constituting a concealed site of social practice through which inequalities are created (Lynch, 2013).

The gendered aspect of teaching considers that emotions and care are the "natural" domains of women. However, this belief is problematic because it assumes that emotions are something we have. Emotions are not "in" an individual. Emotions are both movement and attachment, which connect us and hold us in place. It is their regulatory force (Butler, 1993) that shapes the very surface of bodies and worlds. The power of emotions is a productive power that produces the bodies it controls (ibidem). This is clearly illustrated when adult behaviours such as patting and hugging are deemed 
feminine until they are performed by men. Then they are marked as conspicuous.

\section{Michael: One of the girls [teachers] here would not have thought twice about giving them a hug, would not have thought twice, but as a man you do think twice.}

Michael's words can be read in relation to Ahmed's belief that we are shaped by, and take the shape of, contact with others. Ahmed (2014, p. 10) suggests that emotions create a social presence rather than a self-presence. It is through emotions, or how we respond to objects and others, that boundaries are made. Ahmed's theory builds on Butler's concept of materialisation $(1993,1999)$, which suggests that emotions shape the surface of the body through the repetition of actions over time. The performativity of gender illustrates that what is taken to be an internal essence of gender is manufactured through a sustained set of acts. It is through the repetition of norms that worlds materialise and boundaries are produced (Butler, 1993, p. 9). The boundaries of our understanding of bodies are relevant here. Boundaries are not merely epistemological, what we know to be true, but ontological, how we understand the world. Questions concerning abstract bodies such as neoliberalism, neoconservatism, meeting economic needs and their interaction with education are pertinent considerations in the study of job satisfaction.

Men working in female-dominated professions often fear feminisation and stigmatisation that influence the way men carry out their job. Tim believes people question his sexuality because he is an infant teacher but also believes that he still has his "authority" because "there is Mr. in front of my name". In Western culture and in our society, women usually fulfil the role of caregiver (Hekman, 2005, p. 125). However, care in relation to male teachers is a concept that is often misinterpreted and surrounded with suspicion. David alludes to this suspicion by giving an example of a junior infant female teacher who "might have them up on their lap" and who "might give the child a hug, you know like, affectionate stuff..." However, a male teacher does not have the same options of care: "if that was a male, they could not really do that, it is not an option [...] and it is not professional either [...] it only takes one person to be suspicious". 
This is in part due to the fact that emotions are treated and interpreted differently when expressed by a woman or a man (Gottfried, 2013, pp. 83-84). Furthermore, it is a result of the complicated ways in which gender is constructed and embedded in work norms and practices. When men work within an environment of care and exhibit caring and emotional attributes, "these qualities are not consonant with dominant definitions of masculinities" (Haywood \& Mac an Ghaill, 2003, p. 27). Consequently, men appear out of place when performing work that contradicts gender-stereotypical expectations. When men do not correspond to the perceptions of occupational masculinities, assumptions regarding heterosexuality are informed by "ordinary and academic discourses on sexuality" (Butler, 1999, p. xxi). However, men in female-type jobs often experience different expectations and rewards from women doing the same work (Gottfried, 2013, p. 84). A male teacher can shift from exhibiting nurturance to exercising rational authority without appearing abrupt. This notion of feminisation suggests a more complex analytical understanding that goes beyond the simpler framework of male and female employment participation rates (Haywood \& Mac an Ghaill, 2003, p. 27). As education is a process "operating through relationships" (Connell, 1993, p. 19), care is an issue that confronts all teachers in primary schools. However, for men who wish to teach within a caring environment, the understanding of these issues can take interesting "twists and turns" (King, 1998, p. 24), which have real consequences in terms of job satisfaction and wellbeing.

Finding 2: The school and the cultural landscape Locating the school on the cultural landscape meant bringing culture and society into an uneasy relationship (Butler, 1993). This can be read in relation to the stories presented in this section, which illustrate a sense of powerlessness and a sense of attack. Apple (1996) believes that a relationship exists between education and larger issues of economy and politics. He advises that more attention should be paid to the creative ideological work that the Right has been doing, for "we are not alone in acting in the space of changing the connections between education and other major institutions in society" (Apple, 2013, p. 128). Apple also considers that the unrest associated with issues such as international assessment measures 
and league tables are used by dominant groups to shift the debate on education "and all things social" onto the "terrain of traditionalism, standardization, productivity, marketization, and industrial needs" $(2013$, p. 6). Citing the Italian theorist Antonio Gramsci (1971), who believed that cultural experiences and religion coupled with people's "good sense" and "bad sense" embodies popular understanding, Apple (2013) argues that part of the success of this shift of focus has been the tension between a neoliberal emphasis on market values and a neoconservative attachment to traditional norms and values. This tension and the driving force behind it have established "ideological tendencies" that have been introduced to schools by "neoconservative intellectuals who want a 'return' to higher standards and a 'common culture' [...] accountability, measurement and management" (Apple, 2013, p. 128). Within education, we must question the neoliberal agenda and how it has influenced common sense understandings of schools and society's expectation of what a school should provide. It supports the binary between us and them; hard-working and law-abiding with lazy and permissive. Behind this ideological agenda is "a thoroughgoing attack on teachers and especially teacher unions [...] a massive weakening of teachers' power plays a large part here" (Apple, 2013, p. 7). This observation correlates with Neil's and Eoin's observations. Firstly, Neil feels that teachers have no professional support:

Neil: There is no support for teachers now [...] Nobody feels like it is their job [...] The job is overwhelming. It is all-encompassing. It is the first time that on a Sunday I am thinking about Monday.

Eoin develops this point by referring to trade unions, their lack of influence and how gender may be impacting on decisions made within the unions: 
Similarly, Eoin goes on to state:

Eoin: Society's view of the primary school now has more like that of a caregiver and a lot of parents, working parents, are actually quite happy with the idea. You know, there is no problem if it is an all-female institution [...] There is a public view out there that would say that it is actually probably kind of better.

A "management by stress" (Robertson, 1992, p. 36, cited in: Apple, 2006, p. 7) pattern can be read in the accounts of these four teachers, as illustrated by Neil and Eoin. Neil specifically alluded to the concept of "management by stress" when he referred to a lack of teacher support from managerial levels.

Neil: That creates a climate of fear because when you know there is no back up at the top that creates [...] if you know there is nothing behind you, you are done. A lot of schools, I think a lot of teachers feel that now. They kind of say to themselves that is creating this culture [...] there is bad management, they will abandon you immediately to make sure to protect themselves [...] That creates a very bad atmosphere in schools...

The words and worlds of the teachers in this section outline how gender, whether real or perceived, has practical implications for teachers' wellbeing and job satisfaction within the profession.

\section{Discussion}

Gender in teaching: problems and possibilities

According to Skelton et al. (2013), gender-related matters are a particularly important facet of the experience of being a primary school teacher. Primary teaching is commonly and problematically constructed as a "female" occupation, with its ethic of care understood as compatible with the nature of women (Thornton \& Bricheno, 2006). For men who choose to become teachers, the decision is frequently influenced by factors related to their gender, such as a call for more male teachers as role models (Cushman, 2008), the ease of winning jobs (Mulholland \& Hansen, 2003) and promotional opportunities. 
This expectancy was also evident in male teachers in the early stages of their career in England who reported fears of being perceived as "deviant" if they behaved in non-stereotypically masculine ways (Francis \& Skelton, 2001; Martino \& Berrill, 2003). These anxieties are commonly grounded in the public perception that associates non-normative masculinities with attributions of homosexuality, which in turn are conflated with paedophilia (Martino \& Berrill, 2003). Francis and Skelton's (2001) finding that men risk marginalisation from peers if they do not "achieve" an acceptable construction of masculinity further justifies Roulston and Mills' claim that homophobia often works in "insidious ways to reinforce dominant constructs of masculinity" (2000, p. 227). Similarly, Connell $(2000$, p. 153) notes that the "most important" feeling rules in schools are those relating to "sexuality, and the prohibition on homosexuality". These feeling rules may be particularly important in definitions of masculinities and wellbeing at work.

The body and teaching

The body is one of the first identifiers of a male teacher's presence in a primary school. An association between the feminised environment and the male body indicates something unusual or strange in our mind's eye. This is primarily due to a taken-for-granted relationship between male bodies and masculinities. Society categorises men as active and women as passive in order to address and attempt to deal with "the chaos" that surrounds both concepts (Grosz, 2011, p. 78). If we consider that men's bodies and destructive work are "proof of the toughness of the work and the worker" (Connell, 1995, p. 36), then men who teach young children are not believed to be traditionally masculine. Additionally, feminine conduct combined with a male body "is felt to be anomalous or transgressive" (Connell, 2000, p. 12). When teaching is considered a caring profession carried out in an emotional environment, recognition is given to the central role of the body. This is because we associate all that is biological and natural with the body and the feminine. As a result of lateral associations, which "link the mind / body opposition to a whole series of other oppositional (or binarized) terms, enabling them to function interchangeably" (Grosz, 2011, p. 3), the body is associated with women's social subordination. Further associations of lateral thinking include outside and inside, natural and 
cultural, self and other, depth and surface, and so on. The body and all associated feminine characteristics are presumed to be the latter, and the mind and all associated masculine characteristics are considered the former. The relationship between care labour, gender and work does not align with traditional Western reasoning, and this has practical consequences for male teachers' job satisfaction.

\section{Conclusion}

Understanding how gender emerges from a set of linkages with abstract "bodies" such as economic practices, increasing workload demands and decreasing pay scales assists in gaining a full picture of the interplay between gender, wellbeing and job satisfaction. Feminism shares with poststructuralism the need for renewed conceptual creativity in research. This chapter supports a reinsertion of the material into an analysis of gender and job satisfaction, which is considered to be highly valuable in future evaluations of wellbeing at work. People's practices are constrained by educational institutions and their structures, which go deep into an individual's emotional life. This chapter aimed to provide readers with an insight into the lives of four Irish male teachers focusing specifically on gender and care. The overall theme running through the interviews is that gender is a performance that is dependent on how others receive it. Daily interactions with the materiality of their teaching worlds create sets of linkages with other bodies: human and nonhuman. Job satisfaction and wellbeing is an inextricable part of this matrix. Focusing on these complex constructions afford future research with the possibilities of advancing knowledge in our contemporary world.

\section{References}

$\rightarrow$ Ahmed, S. (2004). The cultural politics of emotion. Edinburgh: Edinburgh University Press.

$\rightarrow$ Ahmed, S. (2014). The cultural politics of emotion ( $2^{\text {nd }}$ ed.). Edinburgh: Edinburgh University Press.

$\rightarrow$ Apple, M. W. (1996). Cultural politics and education. New York: Teachers College Press.

$\rightarrow$ Apple, M. W. (2013). Knowledge, Power, and Education: The Selected Works of Michael W. Apple. New York: Routledge.

$\rightarrow$ Butler, J. (1993). Bodies that matter: on the discursive limits of "sex". New York: Routledge. 
$\rightarrow$ Butler, J. (1999). Gender trouble: feminism and the subversion of identity. New York: Routledge

$\rightarrow$ Connell, R. W. (1985). Teachers' Work. London: Allen \& Unwin.

$\rightarrow$ Connell, R. W. (1993). The big picture: masculinities in recent world history, Theory and Society, 22(5), 597-623.

$\rightarrow$ Connell, R. W. (1995). Masculinities. Cambridge: Polity.

$\rightarrow$ Connell, R. W (2000). The Men and the Boys. Cambridge: Polity.

$\rightarrow$ Coolahan, J. (2013). Towards an era for teacher education and the engagement of the teaching profession, Irish Teachers' Journal, 1(1), 9-26.

$\rightarrow$ Cushman, P. (2005). It's just not a real bloke's job: male teachers in the primary school, Asia-Pacific Journal of Teacher Education, 33(3), 321-338.

$\rightarrow$ Cushman, P. (2008). So what exactly do you want? What principals mean when they say "male role model", Gender and Education, 20(2), 123-136.

$\rightarrow$ Eurofound (2020). Gender equality at work, European Working Conditions Survey 2015 series. Luxembourg: Publications Office of the European Union.

$\rightarrow$ European Commission (2013). Study on Policy Measures to Improve the Attractiveness of the Teaching Profession in Europe. Vol. 1. Luxembourg: Publications Office of the European Union.

$\rightarrow$ European Commission (2016). Joint Action on Mental Health and Well-being. Mental Health and Schools. Joint Action on Mental Health and Well-being. Situation analysis and Recommendations for action, https://ec.europa.eu/ health/sites/health/files/mental_health/docs/2017_mh_schools_en.pdf

$\rightarrow$ European Commission/EACEA/Eurydice (2018). Teaching Careers in Europe: Access, Progression, and support. Eurydice Report. Luxembourg: Publications Office of the European Union.

$\rightarrow$ Francis, B. and Skelton, C. (2001). Men Teachers and the Construction of Heterosexual Masculinity in the Classroom, Sex Education, 1(1), 9-21.

$\rightarrow$ Gottfried, H. (2013). Gender, Work, and Economy: Unpacking the Global Economy. Cambridge: Polity.

$\rightarrow$ Gramsci, A. (1971). Selections from the prison notebooks of Antonio Gramsci, edited and translated by Quintin Hoare and Geoffrey Nowell Smith. London: Lawrence and Wishart.

$\rightarrow$ Grosz, E. (2011). Becoming undone. Darwinian reflections on life, politics, and art. Durham: Duke University Press.

$\rightarrow$ Haywood, C. and Mac an Ghaill, M. (2003). Men and Masculinities: Theory, Research and Social Practice. Buckingham-Philadelphia: Open University Press.

$\rightarrow$ Haywood, C. and Mac an Ghaill, M. (2013). Education and Masculinities. Social, Cultural and Global Transformations. London-New York: Routledge. 
$\rightarrow$ Hekman, S. (2005). Private selves, public identities: reconsidering identity politics, The Philosophical Review, 25(1), 29-31.

$\rightarrow$ Jackson, A. Y. and Mazzei, L. A. (2012). Thinking with Theory in Qualitative Research: Viewing Data across Multiple Perspectives. London-New York: Routledge.

$\rightarrow$ Jaggar, A. M. (2008). Love and knowledge: emotion in feminist epistemology. In: A. M. Jaggar (ed.), Just methods. An Interdisciplinary Feminist Reader. Boulder, CO-London: Paradigm Publishers.

$\rightarrow$ Jaggar, A. M. and Bordo, S. (1992). Gender/Body/Knowledge: Feminist Reconstructions of Being and Knowing. Portland: Rutgers University Press.

$\rightarrow$ Judge, T. A., Thoresen, C. J., Bono, J. E. and Patton, G. K. (2001). The job satisfaction - job performance relationship: a qualitative and quantitative review, Psychological. Bulletin, 127(3), 376-407.

$\rightarrow$ King, J. R. (1998). Uncommon caring: learning from men who teach young children. New York: Teachers College Press.

$\rightarrow$ Lynch, K. (2013). Why love, care and solidarity are political matters: Affective equality and Fraser's model of social justice. In: A. Jónadóttir, A. Ferguson (eds.), Love: A Question of Feminism in the Twenty-First Century (pp. 173-189). New York: Routledge.

$\rightarrow$ Martino, W. and Berrill, D. (2003). Boys, Schooling and Masculinities: Interrogating the "Right" way to educate boys, Educational Review, 55(2), 99-117.

$\rightarrow$ Mills, M., Haase, H. and Charlton, E. (2008). Being the "right" kind of male teacher: the disciplining of John, Pedagogy, Culture \& Society, 16(1), 71-84.

$\rightarrow$ Mirchandani, K. (2008). Challenging racial silences in studies of emotion work. In: M. Greco, P. Stenner (eds.), Emotions. A social reader (pp. 264-275). London-New York: Routledge.

$\rightarrow$ Mulholland, J. and Hansen, P. (2003). Men who become teachers: An early portrait, Asia-Pacific Journal of Teacher Education, 31(3), 213-224.

$\rightarrow$ OECD (2019). Health at a Glance 2019: OECD Indicators. Paris: Organisation for Economic Cooperation and Development Publishing.

$\rightarrow$ O'Keeffe, S. (2016). What are male teachers' understandings of masculinities? - an exploration of sex, gender and bodies in Irish primary schools, Palgrave Communications, 2, 16007.

$\rightarrow$ Pillow, W. S. and Mayo, C. (2007). Toward understandings of feminist ethnography. In: S. N. Hesse-Biber (ed.), Handbook of feminist research: theory and practice (pp. 155-171). London-New Delhi-Thousand Oaks: Sage Publications. 
$\rightarrow$ Roulston, K. and Mills, M. (2000). Male teachers in feminised teaching areas: marching to the men's movement drums, Oxford Review of Education, 26, 221-237.

$\rightarrow$ Skelton, C., Carrington, B., Francis, B., Hutchings, M., Read, B. and Hall, I. (2013). Gender "matters" in the primary classroom: Pupils' and teachers' perspectives, British Educational Research Journal, 35(2), 187-204.

$\rightarrow$ Sironi, E. (2019). Job satisfaction as a determinant of employees' optimal well-being in an instrumental variable approach, Quality and Quantity, 53, 1721-1742.

$\rightarrow$ Skinner, B., Leavey, G. and Rothi, D. (2019). Managerialism and teacher professional identity: impact on well-being among teachers in the UK, Educational Review, DOI: 10.1080/00131911.2018.1556205

$\rightarrow$ TALIS (2018). The OECD Teaching and Learning International Survey. Paris: Organisation for Economic Cooperation and Development Publishing.

$\rightarrow$ Thornton, M. E. and Bricheno, P. (2006., Missing Men in Education. Stoke-onTrent: Trentham Books.

$\rightarrow$ Van Maanen, J. (2011). Tales of the Field: On Writing Ethnography (Chicago Guides to Writing, Editing, and Publishing) (2 ${ }^{\text {nd }}$ ed.). Chicago-London: Chicago University Press.

$\rightarrow$ Walby, S., Armstrong, J. and Strid, S. (2012). Intersectionality: multiple inequalities in social theory, Sociology, 46(2), 224-240.

$\rightarrow$ Woodward, K. and Woodward, S. (2015). Gender studies and interdisciplinarity, Palgrave Communications, 15018, www.palgrave-journals.com/articles/ palcomms201518 


\section{Generational Differences \\ and Professional Values of lleachers}

DOI: $10.47050 / 66515321.58-80$

Wanda Dróżka

The aim of this chapter is to attempt to show the direction of changes in the teaching profession and the teaching community in Poland in recent years. Questions were asked as to whether - and if so, to what extent and in relation to which areas of values - one can talk about the continuity of the teaching role, mission and ethos, and whether their values and aspirations are clear evidence of a generational change. The origins of this change could be sought in the young generation of current teachers, the network generation, who with their individualisation and competition are so different in their habits from teachers of the older generation. The results of quantitative and qualitative research will be presented, using a survey on life aspirations, the values and needs of teachers, and an autobiographical statement on "The meaning and dignity of my life and work". In total, 405 questionnaires and 112 statements from teachers were collected from three age (generational) groups.

\section{Keywords: \\ teaching profession \\ values \\ generation \\ change}




\section{Introduction. Outline of research issues and reasoning of questions}

The analyses undertaken used the results of a broader study on values, goals, and life as well as the professional ambitions of currently active teachers (Dróżka, 2017).

The special aim of the text is to attempt to show the direction of changes in the profession and the teaching community in Poland in recent years using a generational approach. The considerations focus on the following questions: How teachers perceive their social role, life and work, and what values teachers from different generations value.

Questions were asked as to whether - and if so, to what extent and in relation to which areas of values - one can talk about the continuity of the teaching role, mission and ethos, and whether their values and aspirations are clear evidence of a generational change.

The concept of "generation" is here understood in the cultural-historical sense - as a collective of people with common years of birth, attitudes and values shaped under the influence of the momentous experience related to the significant historical events witnessed in their youth (15-25 years).

In this approach, each generation has its own "generational experience", which is a kind of spiritual shock, and is about their way of thinking in life. This experience is the common cultural heritage of those who survived it, differentiating them from other generations.

Using this concept of a generation culturally, sociologically and historically, the generations of teachers surveyed could be characterised as follows (Ostrowska, 1963):

1. Older generation (55 to 65 years and older) - born between 1950 and 1965, the "solidarity" generation, whose political breakthrough came in 1989. Core values and aspirations in youth: freedom, subjectivity, dignity, autonomy, unity.

2. Middle-age generation (36-54 years) - born between 1969 and 1975, the generation of educational reform since 1999, experienced a radical change in the school (gymnasium) regime, new rules for promotion in the teaching profession, a new neoliberal order leading to chaos in values in the sphere of education, and an axiological vacuum.

3. Young generation (up to 35 years) - born between 1980 and 1995, the "join the EU" generation, but above all, 
the generation of the financial crisis of 2008 , labour emigration, demographic decline, closing schools, openness, virtual reality, and individualism.

The origins of this change could be sought in the young generation of current teachers, the network generation, who with their individualisation and competition are so different in their habits from teachers of the older generation.

The older generation, which we can call the "generation of Polish transformation 1989", were raised and educated in a previous epoch, with a "social ethos" strengthened by struggles in the pursuit of freedom and democracy, at the turn of the political system of the $80 \mathrm{~s}$ and $90 \mathrm{~s}$ of the last century in Poland.

It should be noted that in Poland there is an ongoing handover between generations of teachers. The generation of older teachers are leaving the professional scene today to retire and take their pensions. They are the last generation of the Polish political and educational transformation - the last of the Mohicans, as they call themselves in their memoirs and writings.

The teaching profession now includes the new generation, born, raised and educated in a liberal democracy, a market economy and digital civilisation during the phase of radical cultural changes in the world.

Other levels of comparison could also be taken into account, such as the different school missions that have been carried out over the last 30-40 years, the career span of the older generation: from school as a public sphere, governed by values, as places for the upbringing of citizens of the socialist system, focused on social values, to school as an increasingly commercial, market-oriented place, focused on educating efficient and enterprising workers, consumers in the neoliberal system, etc.

More broadly, the context of the life and work of the current older generation of teachers also includes the changes of a global, cultural and civilisational nature that have taken place, known as post-modernity. Among the many characteristics of post-modernity described in the literature, it is worth pointing out those that have had a particularly strong impact on the sphere of education, on its philosophy and on the way teachers function. 
These are:

$\rightarrow$ Variability manifested by fluidity (Bauman, 2000), impermanence, dispersion (values, principles, lifestyle), fragmentation, periodicity - requires flexibility, creativity, mobility, understanding, tolerance, etc.;

$\rightarrow$ Interdependence as a result of the relation of social structures together with a phenomenon known as the "dialectics of modernity" (Giddens, 1991) - requires co-operation, team action, dialogue, participation, reconciliation, negotiation, sharing vision, responsibility, etc.;

$\rightarrow$ Reflexivity as a methodological principle of doubt, both in generalised knowledge and in one's own cognitive resources - requires continuous learning, improvement of one's personality, knowledge of theory and research, practice, research in action, continuous reflection, and a broader ethical and political awareness.

In the Polish (European) dimension, but also in the sense of a global one, the following important changes should also be noted:

$\rightarrow$ The fall of communism and the opening of borders - the change of regime in Poland (1989) and the change of the school system (1999);

$\rightarrow$ Poland'saccession to the EuropeanUnion(2004)-the consolidation of the neoliberal order, the pursuit of the market, the privatisation of the public sphere (including education) and its subordination to consumerism, and the ongoing crisis of this system that began in 2008;

$\rightarrow$ The explosion of digital technology (e.g. the internet), giving universal access to information and lifestyle patterns (experience brokered in the virtual world).

During this period, new processes and phenomena have emerged that affect the axiological condition of schools and teachers. The following should be emphasised here:

$\rightarrow$ Changes in philosophy and lifestyle: a move away from traditional forms of community for more individualistic ones - attitudes towards the rights of the child; 
$\rightarrow$ The expansion of consumerism, the focus on work, earning and "having", on careers, material, "successful" aspects of activity, mobility, and migration abroad after work;

$\rightarrow$ Shifting socialisation towards self-socialisation in the cyberspace network (the internet);

$\rightarrow$ Mass communication, and much more.

New generations have been brought up and educated in this new space, including the young teachers who are currently working there.

The following question thus arises: as the new network-, digitaland world-raised generations are more virtual than the real, "purely professional" one, with a more pragmatic and less romantic and idealistic approach to the profession, what do they bring that is new and valuable?

\section{Type, method and scope of research}

The research was conducted in early 2015, using the survey "Life aspirations, values and needs of teachers".

This questionnaire consisted of an introduction (explaining the idea and goals of the research, as well as appealing for participation in it, etc.) and several consecutive parts containing (semi-)open-ended and close-ended questions that were group into the section titled:

1. Life goals and aspirations,

2. Subjectivity,

3. Values which are commonly recognised and cherished in the teaching community,

4. Needs,

5. Data of the person fulfilling the survey.

The studies also used a personal, autobiographical statement on "The meaning and dignity of my life and work".

In total, 405 surveys and 112 autobiographical narrations were collected from teachers belonging to three age groups:

$\rightarrow$ young teachers (up to 35 years of age): 141 surveys and 35 statements,

$\rightarrow$ middle-aged teachers (from 36 to 50 years of age): 154 surveys and 39 statements, 
$\rightarrow$ older teachers (above 51 years of age): 110 surveys and 38 statements.

In order to draw conclusions from the research sample, its most characteristic features should be mentioned. Of the 405 persons who completed the survey, women constituted the majority (89.7\%), and men the minority (10.3\%). $94.4 \%$ were persons with an MA degree, $4.5 \%$ had a BA degree, and three persons $(0.1 \%)$ had a doctor's degree. $75.9 \%$ of them were married, and $20.3 \%$ were single. $31.9 \%$ of these persons did not have children, while $26.7 \%$ had one child, $30.7 \%$ had two children, and $8.7 \%$ had three or more children.

$24.3 \%$ of the examined group lived in traditional villages, while $18.0 \%$ lived in communal villages, $24.1 \%$ in commune towns, $19.0 \%$ in medium-sized towns, and $14.6 \%$ in large cities. The collected data indicated that the place of residence generally corresponds to the place of employment.

\section{Selected survey results}

The analysis will present the results of studies concerning social values, everyday life values, significant differences in terms of professional and occupational values, and significant changes in the autobiographical narrations.

\section{Social values}

The teachers were asked about the importance they attach to the values that determine the success of life in the long term, as well as the successful development of their society and country. These are values such as: (1) a high moral level of citizens, (2) the material goods of the population (rich society, prosperity), (3) a high level of mental culture, (4) efficient work practices (efficiency, initiative, diligence), (5) patriotism, and (6) wise governments. The subjects determined the importance of these values on a three-point scale: from 3 (high importance) to 1 (little importance).

The study shows, as shown in Table 1, that the value most appreciated by the subjects is productive work $(M=2.86)$, followed by wise governments (2.85) and a high level of mental and moral culture (2.85). 
In general, teachers have a high opinion of these values. The lowest scores were received for patriotism and the material goods of the population.

Table 1. Teachers and social values

\begin{tabular}{l|c|c|c|c|c}
\multicolumn{1}{c|}{ VALUE } & M & SD & MINIMUM & MAXIMUM & N \\
\hline High level of moral culture & 2.85 & .36 & 2 & 3 & 400 \\
\hline Material goods & 2.42 & .59 & 1 & 3 & 400 \\
\hline High level of intellectual culture & 2.85 & .37 & 1 & 3 & 400 \\
\hline Productive work & 2.86 & .36 & 1 & 3 & 400 \\
\hline Patriotism & 2.63 & .55 & 1 & 3 & 398 \\
\hline Wise goverments & 2.85 & .42 & 1 & 3 & 399
\end{tabular}

Table 2 represents a breakdown between the generations of teachers according to the importance each group attributed to the values concerned.

Table 2. Hierarchy of social values in different generations of teachers

\begin{tabular}{|c|c|c|c|c|c|c|c|c|c|c|c|c|}
\hline \multirow{2}{*}{$\begin{array}{c}\text { THE SOCIAL } \\
\text { VALUES AND THEIR } \\
\text { SIGNIFICANCE } \\
\text { IN TEACHERS' LIVES } \\
\text { AND GROWTH }\end{array}$} & \multicolumn{2}{|c|}{$\begin{array}{c}\text { UP } \\
\text { TO } 35 \text { YEARS } \\
\text { N }=135\end{array}$} & \multicolumn{2}{|c|}{$\begin{array}{c}\mathbf{3 6 - 5 0} \\
\text { YEARS } \\
\mathbf{N}=134\end{array}$} & \multicolumn{2}{|c|}{$\begin{array}{c}51 \text { YEARS } \\
\text { AND MORE } \\
N=110\end{array}$} & \multicolumn{2}{|c|}{ IN TOTAL } & \multirow[t]{2}{*}{$\mathbf{F}$} & \multirow[t]{2}{*}{ DF } & \multirow{2}{*}{ 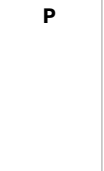 } & \multirow{2}{*}{$\begin{array}{l}\text { DIFFERENCES } \\
\text { BETWEEN } \\
\text { GROUPS IN } \\
\text { THE POST- } \\
\text {-HOC TEST }\end{array}$} \\
\hline & $\mathbf{M}$ & SD & $\mathbf{M}$ & SD & $\mathbf{M}$ & SD & $\mathbf{M}$ & SD & & & & \\
\hline $\begin{array}{l}\text { High level } \\
\text { of moral culture }\end{array}$ & 2.75 & 0.43 & 2.87 & 3.42 & 2.93 & 0.26 & 2.84 & 0.36 & 7.60 & $2 ; 376$ & 0.0006 & $1-2 ; 1-3$ \\
\hline Material goods & 234 & 0.65 & 2.46 & 0.56 & 2.45 & 0.57 & 2.41 & 0.60 & 1.48 & $2 ; 376$ & 0.2293 & none \\
\hline $\begin{array}{l}\text { High level } \\
\text { of intellectual } \\
\text { culture }\end{array}$ & 2.80 & 0.44 & 2.89 & 0.32 & 2.86 & 0.35 & 2.85 & 0.37 & 1.97 & $2 ; 376$ & 0.1415 & none \\
\hline Effective work & 2.85 & 0.38 & 2.87 & 0.34 & 2.87 & 0.33 & 2.86 & 0.35 & 0.14 & $2 ; 376$ & 0.8718 & none \\
\hline Patriotism & 2.56 & 0.57 & 2.62 & 0.56 & 2.69 & 0.54 & 2.62 & 0.56 & 1.85 & $2 ; 374$ & 0.1589 & none \\
\hline Wise goverments & 2.78 & 0.53 & 2.89 & 0.36 & 2.91 & 0.29 & 2.85 & 0.42 & 3.84 & $2 ; 376$ & 0.0222 & $1-2 ; 1-3$ \\
\hline
\end{tabular}


From the above data, generational diversity exists only in terms of the value "high level of moral culture". This is valued most by the older generation; as the age of the teachers decreases, there is an accompanying decrease in this value (the proportion of "high" importance given to it decreases from $92.8 \%$ in the oldest teachers to $75.4 \%$ in the youngest generation). The value of the chi-squared frequency distribution difference was 14.16; df = 2 (meaning the "little" importance category did not occur); $p=0.0006$; Cramer's V $=0.1972$, and the strength of the compound is small.

The values and goals of everyday life

Teachers were asked the question "What do you think a successful life means?" in order to find out the most valued values in everyday life. This was an open question in order to obtain a broader perspective in terms of life values, teachers' approaches to these values, and a kind of programme of life, a vision of a successful, valuable life. What values, aspirations, desires, and aspirations are associated with a successful life? What does it mean to have a successful life? What life is of value? Which values are the most important ones that make you feel happy with life?

Table 3. Hierarchy of teachers' life values

\begin{tabular}{c|l|c|c} 
No & VALUES - THE MOST SIGNIFICANT & $\mathbf{N}$ & $\%$ \\
\hline 1. & Personal and family happiness & 288 & 71.1 \\
\hline 2. & High achievements at work & 140 & 34.6 \\
\hline 3. & Good health & 110 & 27.2 \\
\hline 4. & Material security & 95 & 23.5 \\
\hline 5. & Enjoyment of life & 35 & 8.6 \\
\hline 6. & Self-improvement and self-realisation & 34 & 8.4 \\
\hline 7. & High level of morale & 31 & 7.7 \\
\hline 8. & Recognition and authority & 17 & 4.2 \\
\hline 9. & Peaceful and stable life & 17 & 4.2 \\
\hline 10. & The sense of usefulness and work for the others & 9 & 2.2 \\
\hline 11. & The sense of a job well done & 9 & 2.2 \\
\hline 12. & Higher education & 8 & 2.0 \\
\hline 13. & Good relations at work & 1 & 0.2 \\
\hline 14. & Cultural participation and social life & 0 & 0 \\
\hline
\end{tabular}

NB: The percentages do not add up to $100 \%$ because the respondents could choose more than 1 category. 
From Table 3, we can see that teachers value and strive to achieve personal and family happiness in their lives $(71.1 \%)$, high achievements at work (34.6\%), good health (27.2\%), and material security $(23.5 \%)$.

Further analysis (Table 4) shows that significant generational diversity only occurs in the "self-improvement and self-realisation" category, which was most often chosen by the youngest teachers (up to 35 years), and significantly less often by the second and the oldest generations. The significance of the diversity was $p<0.05$ and Cramer's $V$ was 0.1899 , signifying the strength of the average relationship of the generation-choice value.

Also of relevance is the value of good health, to which the youngest teachers attach the most importance: $p=0.0597$. The preferences of the younger generation may be due to the dominant characteristics of their socialisation time, when there is pressure from popular culture patterns, but it may also be due to market requirements, the needs of the self-presentation of physicality, and the cult of a healthy lifestyle.

Table 4. Hierarchy of life-values - differences between generations $(N=380)$

\begin{tabular}{|c|c|c|c|c|c|c|c|c|c|c|c|}
\hline \multirow{2}{*}{$\begin{array}{l}\text { THE MOST } \\
\text { SIGNIFICANT } \\
\text { VALUES }\end{array}$} & \multicolumn{2}{|c|}{$\begin{array}{c}\text { UP } \\
\text { TO } 35 \text { YEARS } \\
\mathbf{N}=135\end{array}$} & \multicolumn{2}{|c|}{$\begin{array}{c}36-50 \text { YEARS } \\
N=134\end{array}$} & \multicolumn{2}{|c|}{$\begin{array}{c}51 \text { YEARS } \\
\text { AND MORE } \\
N=111\end{array}$} & \multicolumn{2}{|c|}{ TOTAL } & \multirow[t]{2}{*}{$\mathrm{C}^{2}$} & \multirow[t]{2}{*}{$\mathbf{P}$} & \multirow[t]{2}{*}{ CRAMER'S V } \\
\hline & $\mathbf{N}$ & $\%$ & $\mathbf{N}$ & $\%$ & $\mathbf{N}$ & $\%$ & $\mathbf{N}$ & $\%$ & & & \\
\hline $\begin{array}{l}\text { Personal and } \\
\text { family happiness }\end{array}$ & 105 & 77.8 & 91 & 64.9 & 79 & 71.2 & 275 & 72.4 & 3.39 & 0.1839 & 0.0944 \\
\hline $\begin{array}{l}\text { High } \\
\text { achievements } \\
\text { at work }\end{array}$ & 53 & 39.3 & 42 & 31.3 & 41 & 36.9 & 136 & 35.8 & 1.92 & 0.3822 & 0.0711 \\
\hline Good health & 45 & 33.3 & 36 & 26.9 & 22 & 19.8 & 103 & 27.1 & 5.64 & 0.0597 & 0.1218 \\
\hline Material security & 32 & 23.7 & 32 & 23.9 & 26 & 23.4 & 90 & 23.7 & 0.01 & 0.9965 & 0.0043 \\
\hline $\begin{array}{l}\text { Enjoyment } \\
\text { of life }\end{array}$ & 15 & 11.1 & 8 & 6.0 & 12 & 10.8 & 35 & 9.2 & 2.61 & 0.2718 & 0.0828 \\
\hline $\begin{array}{l}\text { Self-realisation } \\
\text { and self- } \\
\text {-improvement }\end{array}$ & 21 & 15.6 & 9 & 6.7 & 3 & 2.7 & 33 & 8.7 & 13.70 & 0.0011 & 0.1899 \\
\hline $\begin{array}{l}\text { High level } \\
\text { of morale }\end{array}$ & 7 & 5.2 & 8 & 6.0 & 13 & 11.7 & 28 & 7.4 & 4.39 & 01111 & 0.1075 \\
\hline
\end{tabular}


Another question the study teachers were asked was "What is the importance of your life goals?" and they were asked to respond to 10 categories of values on a 5-point scale, from 0 (irrelevant) to 4 (very important). The data obtained is represented in Tables 5 and 6.

Table 5. Hierarchy of values - life goals $(N=405)$

\begin{tabular}{|c|c|c|c|c|c|}
\hline VALUES & MEAN & STD DEV & MINIMUM & MAXIMUM & N SIGNIFICANT \\
\hline $\begin{array}{l}\text { 1. Social activity } \\
\text { for the benefit } \\
\text { of others }\end{array}$ & 3.01 & 0.73 & 0.00 & 4.00 & 401 \\
\hline $\begin{array}{l}\text { 2. Social } \\
\text { advancement }\end{array}$ & 2.20 & 0.99 & 0.00 & 4.00 & 400 \\
\hline $\begin{array}{l}\text { 3. To secure } \\
\text { a succesful family } \\
\text { life }\end{array}$ & 3.82 & 0.51 & 0.00 & 4.00 & 401 \\
\hline 4. High salary & 3.04 & 0.72 & 0.00 & 4.00 & 398 \\
\hline $\begin{array}{l}\text { 5. Getting } \\
\text { the highest } \\
\text { education }\end{array}$ & 3.11 & 0.87 & 0.00 & 4.00 & 397 \\
\hline 6. Enjoyment of life & 2.62 & 0.88 & 0.00 & 4.00 & 399 \\
\hline $\begin{array}{l}\text { 7. Achieving high } \\
\text { results at work }\end{array}$ & 3.33 & 0.65 & 0.00 & 4.00 & 401 \\
\hline $\begin{array}{l}\text { 8. Authority and } \\
\text { recognition in } \\
\text { the environment }\end{array}$ & 3.18 & 0.76 & 0.00 & 4.00 & 400 \\
\hline $\begin{array}{l}\text { 9. Participation } \\
\text { in cultural life }\end{array}$ & 2.91 & 0.70 & 0.00 & 4.00 & 400 \\
\hline 10. Hobbies/passions & 3.05 & 0.81 & 0.00 & 4.00 & 400 \\
\hline
\end{tabular}

A comparison of averages across the group of teachers shows that the decisive value is "to secure a successful family life"; this reaches an average of 3.82 , very close to the maximum possible, and must accordingly be interpreted as "very important". Next in the hierarchy, where the values are higher than the "significant" scale value (3), are "achieving high results at work" (3.33), "authority and recognition in the environment" (3.18), and "getting the highest education" (3.11) 
The method of analysis reflected in Table 6 makes it possible to identify a statistically significant diversity between teacher generations with regard to two objectives: "ensuring a successful family life" (young teachers) and "authority and recognition in the environment" (teachers from the older generation).

Table 6. Hierarchy of values - life goals and the generations $(N=379)$

\begin{tabular}{|c|c|c|c|c|c|c|c|c|c|c|c|c|}
\hline \multirow{2}{*}{$\begin{array}{l}\text { LIFE GOALS } \\
\text { AND THEIR } \\
\text { SIGNIFICANCE }\end{array}$} & \multicolumn{2}{|c|}{$\begin{array}{c}\text { UP } \\
\text { TO } 35 \text { YEARS } \\
\text { N }=135\end{array}$} & \multicolumn{2}{|c|}{$\begin{array}{c}\mathbf{3 6 - 5 0} \\
\text { YEARS } \\
\mathrm{N}=134\end{array}$} & \multicolumn{2}{|c|}{$\begin{array}{c}51 \text { YEARS } \\
\text { AND MORE } \\
N=110\end{array}$} & \multicolumn{2}{|c|}{ TOTAL } & \multirow[t]{2}{*}{$\mathbf{F}$} & \multirow[t]{2}{*}{ DF } & \multirow[t]{2}{*}{$\mathbf{P}$} & \multirow{2}{*}{$\begin{array}{l}\text { DIFFERENCES } \\
\text { BETWEEN } \\
\text { GROUPS IN } \\
\text { POST-HOC } \\
\text { TEST }\end{array}$} \\
\hline & M & SD & $\mathbf{M}$ & SD & $\mathbf{M}$ & SD & $\mathbf{M}$ & SD & & & & \\
\hline $\begin{array}{l}\text { Social } \\
\text { activity for } \\
\text { the benefit } \\
\text { of others }\end{array}$ & 2.96 & 0.75 & 3.05 & 0.74 & 3.05 & 0.71 & 302 & 0.73 & 0.60 & $2 ; 378$ & 0,5476 & none \\
\hline $\begin{array}{l}\text { Social } \\
\text { advancement }\end{array}$ & 2.29 & 1.01 & 2.11 & 0.97 & 2.18 & 1.00 & 2.19 & 0.99 & 1.15 & $2 ; 377$ & 0,3168 & none \\
\hline $\begin{array}{l}\text { To secure } \\
\text { a successful } \\
\text { family life }\end{array}$ & 3.73 & 0.69 & 3.89 & 0.34 & 3.86 & 0.37 & 3.82 & 0.51 & 3.64 & $2 ; 378$ & 0,0273 & $1-2 ; 1-3$ \\
\hline High salary & 3.01 & 0.70 & 3.08 & 0.73 & 3.02 & 0.73 & 303 & 0.72 & 0.33 & $2 ; 375$ & 0,7171 & none \\
\hline $\begin{array}{l}\text { Getting } \\
\text { the highest } \\
\text { education }\end{array}$ & 3.18 & 0.83 & 3.09 & 0.84 & 3.06 & 0.97 & 3.11 & 0.87 & 0.65 & $2 ; 375$ & 0.5225 & none \\
\hline $\begin{array}{l}\text { Enjoyment } \\
\text { of life }\end{array}$ & 3.66 & 0.81 & 2.56 & 0.91 & 2.65 & 0.88 & 2.62 & 0.87 & 0.52 & $2 ; 376$ & 0.5986 & none \\
\hline $\begin{array}{l}\text { Getting } \\
\text { high results } \\
\text { at work }\end{array}$ & 3.31 & 0.59 & 3.42 & 0.58 & 3.24 & 0.79 & 3.33 & 0.65 & 2.20 & $2 ; 378$ & 0.1124 & none \\
\hline $\begin{array}{l}\text { Authority and } \\
\text { recognition } \\
\text { in the } \\
\text { environment }\end{array}$ & 3.05 & 0.83 & 3.21 & 0.76 & 3.29 & 0.68 & 3.18 & 0.77 & 3,15 & $2 ; 378$ & 0.0439 & $1-3$ \\
\hline $\begin{array}{l}\text { Participation } \\
\text { in cultural life }\end{array}$ & 2.79 & 0.65 & 2.94 & 0.67 & 2.99 & 0.79 & 2.90 & .70 & 2.74 & $2 ; 377$ & 0.0657 & $1-3$ \\
\hline $\begin{array}{l}\text { Hobbies/ } \\
\text { passions }\end{array}$ & 3.02 & 0.74 & 3.07 & 0.86 & $3 . .01$ & 0.84 & 3.04 & 0.81 & 0.23 & $2 ; 377$ & 0.7942 & none \\
\hline
\end{tabular}




\section{Significant differences in terms of professional and occupational values}

The examined group of teachers was also asked "What do you care about most in your work?". Their responses are summarised in Table 7.

Table 7. Values of the teachers' professional work

\begin{tabular}{|c|c|c|}
\hline PROFESSIONAL VALUES & $\mathbf{T}$ & $\%$ \\
\hline $\begin{array}{l}\text { 1. Content of work and its results: thorough fulfillment of one's obligations, } \\
\text { professionalism, education of open-minded, wise, healthy generations, } \\
\text { which could change the world for the better, transfer of knowledge } \\
\text { to the youth so that pupils can understand the knowledge presented } \\
\text { to them, inculcate sophistication, teach pupils to be active, propagate } \\
\text { patriotic attitudes among them, etc. }\end{array}$ & 194 & 47.9 \\
\hline $\begin{array}{l}\text { 2. Creative atmosphere and good interpersonal relations: honesty, warm } \\
\text { relationships within the group, good atmosphere, mutual respect, etc. }\end{array}$ & 115 & 28.4 \\
\hline $\begin{array}{l}\text { 3. High salary and fair assessment of work: conscientious, appropriate } \\
\text { assessment of efforts invested in work, boosts to self-esteem through } \\
\text { work, appreciation at work, good co-operation with parents/children, etc. }\end{array}$ & 27 & 6.7 \\
\hline $\begin{array}{l}\text { 4. Working conditions: good organisation, child safety, permanent/steady } \\
\text { character of employment, co-operation within teams, work taking place } \\
\text { during favorable hours, availability of didactic aids, opportunities to rest, etc. }\end{array}$ & 31 & 7.7 \\
\hline $\begin{array}{l}\text { 5. Opportunities for self-fulfillment and professional development: favorable } \\
\text { conditions for advancement, opportunities for supplementary training and } \\
\text { professional training, etc. }\end{array}$ & 19 & 4.7 \\
\hline 6. The sense of being needed and deriving satisfaction from work & 28 & 6.9 \\
\hline $\begin{array}{l}\text { 7. Respect, esteem, authority: respect, understanding, satisfaction } \\
\text { from the children, etc. }\end{array}$ & 41 & 10.1 \\
\hline $\begin{array}{l}\text { 8. Independence, autonomy, recognition: freedom in decision making, } \\
\text { independence in teaching, etc. }\end{array}$ & 1 & 0.2 \\
\hline 9. Personal and family aspects: own family, health, peace of mind, etc. & 6 & 1.5 \\
\hline
\end{tabular}

Table 7 shows that the examined group of teachers first and foremost cares about the inherent values of work, such as the content of work and its results ( $47.9 \%)$, followed by a creative atmosphere and good interpersonal relations (28.4\%) and having respect, esteem and authority $(10.1 \%)$. 
Table 8. Values connected to the teachers' professional work by generation $(N=380)$

\begin{tabular}{|c|c|c|c|c|c|c|c|c|c|c|c|}
\hline \multirow[t]{2}{*}{$\begin{array}{l}\text { WHAT IS MOST } \\
\text { IMPORTANT TO YOU } \\
\text { IN YOUR WORK? }\end{array}$} & \multicolumn{2}{|c|}{$\begin{array}{l}\text { YOUNG } \\
\text { GENERA- } \\
\text { TION } \\
\text { (UP TO 35) }\end{array}$} & \multicolumn{2}{|c|}{$\begin{array}{l}\text { MIDDLE- } \\
\text {-AGED GEN- } \\
\text { ERATION } \\
\text { (36 TO 50) }\end{array}$} & \multicolumn{2}{|c|}{$\begin{array}{l}\text { OLDER GEN- } \\
\text { ERATION } \\
\text { (51 AND } \\
\text { OVER) }\end{array}$} & \multicolumn{2}{|c|}{ TOTAL } & \multirow[t]{2}{*}{$\begin{array}{c}\text { CHI- } \\
\text {-SQUARED }\end{array}$} & \multirow[t]{2}{*}{$\mathbf{P}$} & \multirow[t]{2}{*}{ CRAMER'S V } \\
\hline & $\mathbf{T}$ & $\%$ & $\mathbf{T}$ & $\%$ & $\mathbf{T}$ & $\%$ & $\mathbf{T}$ & $\%$ & & & \\
\hline $\begin{array}{l}\text { 1. Content } \\
\text { of work and } \\
\text { its results }\end{array}$ & 59 & 56.3 & 71 & 53.0 & 57 & 51.4 & 187 & 49.2 & 2.61 & 0.2718 & 0.0828 \\
\hline $\begin{array}{l}\text { 2. Creative } \\
\text { atmosphere } \\
\text { and good } \\
\text { interpersonal } \\
\text { relations }\end{array}$ & 45 & 33.3 & 36 & 26.9 & 28 & 25.2 & 109 & 28.7 & 2.29 & 0.3179 & 0.0777 \\
\hline $\begin{array}{l}\text { 3. High salary and } \\
\text { fair assessment } \\
\text { of work }\end{array}$ & 8 & 5.9 & 6 & 4.5 & 10 & 9.0 & 24 & 6.3 & 2.16 & 0.3395 & 0.0754 \\
\hline $\begin{array}{l}\text { 4. Working } \\
\text { conditions }\end{array}$ & 10 & 7.4 & 12 & 9.0 & 8 & 7.2 & 30 & 7.9 & 0.32 & 0.8506 & 0.0292 \\
\hline $\begin{array}{l}\text { 5. Opportunities for } \\
\text { self-fulfillment } \\
\text { and professional } \\
\text { development }\end{array}$ & 8 & 5.9 & 5 & 3.7 & 3 & 2.7 & 16 & 4.2 & 1.69 & 0.4302 & 0.0666 \\
\hline $\begin{array}{l}\text { 6. The sense } \\
\text { of being needed } \\
\text { and deriving } \\
\text { satisfaction } \\
\text { from work }\end{array}$ & 8 & 5.9 & 10 & 7.5 & 7 & 6.3 & 25 & 6.6 & 0.28 & 0.8705 & 0.0270 \\
\hline $\begin{array}{l}\text { 7. Respect, esteem, } \\
\text { authority }\end{array}$ & 12 & 8.9 & 17 & 12.7 & 9 & 8.1 & 38 & 10.0 & 1.70 & 0.4271 & 0.0669 \\
\hline $\begin{array}{l}\text { 8. Independence, } \\
\text { autonomy, } \\
\text { recognition }\end{array}$ & - & - & - & - & 1 & 0.9 & 1 & 0.3 & - & - & - \\
\hline $\begin{array}{l}\text { 9. Personal, } \\
\text { family aspects }\end{array}$ & 1 & 0.7 & 3 & 2.2 & 2 & 1.8 & 6 & 1.6 & - & - & - \\
\hline
\end{tabular}


Results presented in Table 8 are not statistically diversified in any meaningful way with respect to the generation of the examined persons. Nevertheless, the data presented in Table 6 shows that certain differences are present in particular age groups of teachers. And so, for the youngest teachers, for whom the most important aspects are a creative atmosphere and good interpersonal relations (33.3\%), we can see a similar situation where opportunities for self-fulfilment and professional development are concerned (5.9\%). Among the oldest teachers, a high salary and fair assessment of work are most popular $(9.0 \%)$. Middle-aged teachers care the most about recognition and respect $(12.7 \%)$.

\section{Common difficulties and problems in teachers' work}

Another important aspect of this research is an attempt to establish what elements of their professional work evoked the greatest dissatisfaction among the teachers. To examine this, open-ended questions about what the teachers would like to change in their work right away and what the greatest thorn in their side is were asked.

Table 9. What evokes the greatest dissatisfaction

\begin{tabular}{l|c|c}
\hline THE ASPECTS OF THE TEACHING PROFESSION THAT EVOKE THE GREATEST DISSATISFACTION & T & $\%$ \\
\hline $\begin{array}{l}\text { 1. Bad interpersonal relationships: atmosphere, elimination of falsity, duplicity, } \\
\text { not enough kindness among the teachers, in their contacts with superiors, } \\
\text { and with the parents, rat race, etc. }\end{array}$ & 98 & $\mathbf{2 4 . 2}$ \\
\hline $\begin{array}{l}\text { 2. Bad behaviour of the pupils: pupils have only rights, they can do everything, etc. } \\
\text { 3. Working conditions: regulations pertaining to employment, low salary, } \\
\text { favouritism of the older employees, change in management, overseeing entity } \\
\text { or minister, lack of appreciation for the experience and reliability of a teacher, } \\
\text { lack of methods and means to prevent aggressive behaviour and violence } \\
\text { at school originating from pupils, better accessories, connections, corruption, etc. }\end{array}$ & 17 & 4.2 \\
\hline $\begin{array}{l}\text { 4. Professional career paths and evaluation of work. } \\
\text { 5. Bureaucracy: abiding by procedures, lack of autonomy, lack of freedom to act, etc. }\end{array}$ & 40 & $\mathbf{4 5 . 7}$ \\
\hline \begin{tabular}{l} 
6. Nothing, I am satisfied. \\
\hline
\end{tabular} & 41 & 10.1 \\
\hline
\end{tabular}


Table 9 shows that the most unsatisfactory issue, which according to the examined group needs to be changed immediately, are the working conditions $(45.7 \%)$. Another unsatisfactory element relates to bad interpersonal relationships $(24.2 \%)$. It is also worth pointing out that bureaucracy was indicated by $9.9 \%$ of the examined group.

Table 10. What evokes the greatest dissatisfaction by generation $(\mathrm{N}=380)$

\begin{tabular}{|c|c|c|c|c|c|c|c|c|c|c|c|}
\hline \multirow{2}{*}{$\begin{array}{l}\text { THE ASPECTS } \\
\text { OF THE TEACHING } \\
\text { PROFESSION } \\
\text { THAT EVOKE } \\
\text { THE GREATEST } \\
\text { DISSATISFACTION }\end{array}$} & \multicolumn{2}{|c|}{$\begin{array}{c}\text { YOUNG } \\
\text { GENERATION } \\
\text { (UP TO 35) }\end{array}$} & \multicolumn{2}{|c|}{$\begin{array}{l}\text { MIDDLE- } \\
\text {-AGED } \\
\text { GENERATION } \\
\text { (36 TO 50) }\end{array}$} & \multicolumn{2}{|c|}{$\begin{array}{l}\text { OLDER } \\
\text { GENERATION } \\
\text { (51 AND } \\
\text { OVER) }\end{array}$} & \multicolumn{2}{|c|}{ TOTAL } & \multirow[t]{2}{*}{$\begin{array}{c}\text { CHI- } \\
\text { SQUARED }\end{array}$} & \multirow[t]{2}{*}{$\mathbf{P}$} & \multirow[t]{2}{*}{ CRAMER'S V } \\
\hline & $\mathbf{T}$ & $\%$ & $\mathbf{T}$ & $\%$ & $\mathbf{T}$ & $\%$ & $\mathbf{T}$ & $\%$ & & & \\
\hline $\begin{array}{l}\text { 1. Bad } \\
\text { interpersonal } \\
\text { relationships }\end{array}$ & 38 & 28.1 & 30 & 22.4 & 29 & 26.1 & 97 & 25.5 & 1.20 & 0.5479 & 0.0563 \\
\hline $\begin{array}{l}\text { 2. Bad } \\
\text { behavior } \\
\text { of the pupils }\end{array}$ & 7 & 5.2 & 4 & 3.0 & 6 & 5.4 & 17 & 4.5 & 1.08 & 0.5827 & 0.0533 \\
\hline $\begin{array}{l}\text { 3. Working } \\
\text { conditions }\end{array}$ & 60 & 44.4 & 64 & 47.8 & 49 & 44.1 & 173 & 45.5 & 0.42 & 0.8109 & 0.0332 \\
\hline $\begin{array}{l}\text { 4. Professional } \\
\text { career } \\
\text { paths and } \\
\text { evaluation } \\
\text { of work }\end{array}$ & 1 & 0.7 & 2 & 1.5 & - & - & 3 & 0.8 & - & - & - \\
\hline 5. Bureaucracy & 7 & 5.2 & 15 & 11.2 & 14 & 12.6 & 36 & 9.5 & 4.63 & 0.0986 & 0.1104 \\
\hline $\begin{array}{l}\text { 6. Nothing, } \\
\text { I am } \\
\text { satisfied }\end{array}$ & 15 & 11.1 & 15 & 11.2 & 11 & 9.9 & 41 & 10.8 & 0.13 & 0.9387 & 0.0182 \\
\hline
\end{tabular}

There are no significant interrelations connected to age and generation (Table 10); nevertheless, the percentage data show that bureaucracy is most bemoaned by older teachers, whose memories are still fresh of schools before the reform of 1999, schools that did not enforce detailed reporting and complex procedures, and of the time before the so-called "playing of an office worker by the teacher". The youngest representatives of the examined group, on the other hand, treat bureaucracy as something obvious, as something that is inseparable from their work. 
The results were confirmed in the light of responses given to a different open-ended question on which prevailing difficulties and problems are experienced first and foremost by contemporary teachers.

Table 11. Prevailing difficulties and problems experienced by the teachers

\begin{tabular}{l|c|c}
\multicolumn{1}{|c|}{ PREVAILING DIFFICULTIES AND PROBLEMS EXPERIENCED BY THE TEACHERS } & T & $\%$ \\
\hline $\begin{array}{l}\text { 1. Small salary: for hard, underappreciated work, etc. } \\
\text { 2. Overly complex path of professional advancement. }\end{array}$ & 64 & $\mathbf{1 5 . 8}$ \\
\hline $\begin{array}{l}\text { 3. Overwhelming amount of "fancy bureaucracy" } \\
\text { that does not lead to anything, etc. }\end{array}$ & 02 \\
\hline $\begin{array}{l}\text { 4. Difficult entry into the occupation for young persons: difficulties connected } \\
\text { to finding employment, lack of full-time jobs, lack of positions, lack of stability, etc. }\end{array}$ & $\mathbf{2 0 . 2}$ \\
\hline $\begin{array}{l}\text { 5. Lack of sufficient professional competences that would help them handle } \\
\text { the children: pertaining to keeping discipline, educational failures, } \\
\text { being a teacher rather than a buddy, lack of esteem, etc. }\end{array}$ & 0.5 \\
\hline
\end{tabular}

6. Tough, inadequate working conditions: ongoing reforms of the educational system, changes in the minister's position, unclear regulations, overloaded curricula, lack of time for school tasks, bringing work home, lack of time/ opportunity for an individual approach to pupils, insufficient school staff (lack of educators, psychologists) combined with a growing risk of addictions, pupils' aggression, overwhelming amount of work per teacher, too great a number of pupils in classes, the necessity to constantly train further, lack of opportunities for advancement when the ultimate professional advancement has already been obtained, few chances for a professional career, unfair treatment, lack of support, lack of agreement, envy, helplessness, jealousy, competition, "stereotypical" curriculum, management's reluctance to introduce new methods of teaching, criticism of work methods, lack of free training, lack of courses/training on a particular subject, etc.

7. Lack of respect from pupils, parents, community/society: difficult/lack of co-operation with parents, problems in relations between teachers and parents, lack of interest in school on the part of the parents, fear of being negatively assessed by parents, parents with demanding attitudes, lack of respect within the community/society, lack of adequate appreciation, lack of understanding for the teaching profession, decline of esteem for schools and teachers, media's negative campaign, etc.

8. Problems originating with pupils: pupils' laziness, pupils without any hobbies, addiction to computers, low intellectual level of the youth, pupils' inadequate behaviour at school, aggression, etc.

9. Poor equipping of schools: too low a number of didactic aids, underfinancing of the educational system, etc.

10. Existential aspects: lack of employment stability, fear of losing one's job, emotional problems (frustration, helplessness, stress, professional burnout, occupational diseases), etc. 
Data in Table 11 shows that the most frequently perceived prevailing difficulties are such problems as a lack of respect from pupils, parents, community/society (39.0\%), tough, inadequate working conditions $(26.7 \%)$, and existential problems related to a lack of employment stability, a fear of losing one's job, frustration, helplessness, etc. (25.7\%).

Inadequate work conditions constitute the greatest difficulty for middle-aged teachers, who are burdened with duties to the greatest degree $(p=0.0126)$. There were no statistically significant interrelations between age (generation) and the other most acute problems and difficulties.

Significant changes in the autobiographical narrations Some additions to the survey data presented were provided by teachers' personal statements on "The meaning and dignity of my life and work".

Young teachers note that being a teacher once meant admiration, recognition, and respect, whereas today, it too often means a struggle for work and the ability to maintain a reliable level of the work.

One wrote: "The changing conditions of life, beliefs, trends make it not easy to be a teacher. The social pressures, the perception of the profession due to the holidays and vacations, and teachers' social position is not what I knew in my youth, from my time at school".

Young teachers notice a change in the social status of their profession, in which it is becoming more and more difficult to win social respect, prestige and understanding for what they have taken the trouble and effort to do. They also demand clearer clarification of the tasks for which they have responsibility and a strict determination of their functions and professional competence.

Other issues and difficulties regard the very demanding attitudes of parents, the loneliness and alienation of students, uncertainty with regard to the future of the children, and pupils' ongoing generational change, which is very radical and deep: "It scares me, the growing gap between me and successive generations of young people. We do not have common cultural codes".

Teachers write about intense feelings of their incomprehension or even disregard by society, about children from broken families and the effects of the crisis of social life, as well as about the consequences of educational inequalities and fatigue of the teacher: "The father, 
the mother in Germany, children on grandparents. [...] This is the reality of the school".

Another teacher states: "Did I choose well? I do not know. I have been in the profession for eight years and it is really hard for me to take stock. It is certainly a difficult profession, requiring a very high level of commitment and mental and emotional effort. [...] I happen to work with difficult and difficult and family-related, emotional, with whom the work is hard and often fruitless. Especially today, when busy parents for training and responsibility is transferred to teachers not only for the knowledge of their children but also for their upbringing. Nevertheless, I believe that the work I do has sense. After all, the teacher conveys knowledge to young people, awakens curiosity about the world in them and motivates learning, thus shaping the younger generation of Poles" (female, 1983, MA, mathematics, married, two children, city-municipality).

"Today, working at school is quite a challenge", writes another teacher, who notes that teachers work in difficult times today. "People are increasingly demanding - unfortunately, rarely of themselves, instead they look at others. They run away from taking responsibility for themselves - it is easier to blame the other person (i.e. it is the teacher who is responsible for how my child behaves in school, for what his relationship with his peers is). This is very demotivating and discourages work. Of course, I do not generalise, but it is happening more and more often. Today, it is the school that is supposed to educate, to teach subjects, the approach to life, responsibility - when, how? The authority of the teacher is almost none. Hearing the responses of students (unfortunately even young ones) to teachers, a man wonders what he did wrong, and who more confidently 'what were the parents saying to their children about us again?' [...] Every day at work is a challenge for me, sometimes it is too much for my own abilities. [...] It is a pity that others do not see it. It is a pity that they see only our holidays, which for me are very necessary to cut myself off from work, from these crowds of people every day, in order to gain strength, ideas and the desire to work with children, and now probably mostly with parents. It is a pity" (female, 1987, MA, pedagogy, single, traditional village).

It is difficult to look for value when there is no work-it is a strong novum in the teaching profession in Poland, where, because of demographic decline, and now another structural reform for many teachers, work 
is becoming an inaccessible luxury. This is what one teacher writes about this: "Free to look for meaning and dignity when there is no work. It is well known that work ennobles, adds life values. I found myself in a difficult situation; two years ago, I lost my job as a kindergarten teacher. It was not only the loss of my livelihood but also the realisation of my passion, which was working with children" (female, 1982, MA, pedagogy and early school education, single, traditional village).

Pursue your goals with dignity, that is, do not litter your path to the goal with corpses, but act in accordance with the prevailing moral and ethical principles - this is the aspiration of another teacher (female, 51), who continues by saying that "I would like to have a permanent and good job that would allow me to live a decent life. Without work, there is no money, and without money, you do not have enough for the basic things you need for life".

Having money is a common consideration in the collected texts. For example, another states the following on their personal relationships: "It is worth it for me to have financial independence, my own home, and my own car. It is also about holidays [the author takes trips 1-2 times a year] with the family, taking care of your own affairs, having respect for yourself and others" (female, 1982, MA, mathematics and computer science, married, one child, traditional village).

The statements also give a thread of difficulties for some teachers in finding their place in society, in situations of adverse phenomena that are taking place and which limit them.

At the same time, young teachers point out that important values, e.g. family love and family happiness are seriously threatened in the present world "through our spontaneous and uncontrollable behaviours and unhappy states. In today's busy world, we rarely have time for ourselves; hurry, routine, the pursuit of money, precarious financial situations, and instability in the labour market kill love and time for the family. [...] A life without faith, hope and love is shallow, meaningless, meaningless. Of all the gifts, they are the most hidden, inaccessible, but at the same time the most important and strongest".

It should also be noted that young teachers who are currently entering the profession are a generation whose youth was shaped by the years since 2008: the years of the global crisis, unemployment, emigration, the education crisis, the devaluation of diplomas, crisis and 
the neoliberal order, the precariat, etc. These teachers do not remember the lack of democracy, freedom, and material deprivation.

They were born in a time of advanced democratic transformation, learnt in neoliberal-oriented schools with their cult of instrumental and pragmatic prowess, and individualistic and consumerist mentalities. Hence, this generation attaches high importance to work being a source of earning in order to live a decent life, maintaining creditworthiness, and achieving as many competencies and certificates as possible in order to be able to compete in the labour market. And the reality of the squabble? The material side of the profession - but how often do the salaries of young and novice teachers allow them a decent life, to start a family, to meet the cultural needs of modern young people living in a consumer and pragmatic environment?

The statements of the older generation of teachers could be put in the form of a metaphor: "Between pride and bitterness". These statements reveal a number of tensions and dilemmas related to their life and professional role in the years of transformation in Poland after 1989, a period full of radical and traumatic changes (Dróżka, 2008).

Today's older generation of teachers, this generation of social advancement, are the children of the great boom of the 1950s and later, who are generally descended from peasant, working-class families from small towns and villages. Higher education was a dream come true for a better life, and studying in a larger city is entering into a relationship with culture and nobilitation.

Education and knowledge are great offerings to society, state, culture, tradition. They are parts of a social ethos, requiring a lifestyle marked by the pursuit of high levels of ethical and moral awareness and of cultural, literary and wider interests to help everyone at the expense of their time and family. It is also marked by a failure to attach greater importance to material matters, although it is a pity that pensions are now so low; this reduction is reflected in a similar reduction in the sense of worth and dignity in many teachers of this generation. Was it worth trying so hard? There are currently some bitter inquiries ongoing on this topic.

According to the statements of senior teachers, the dignity of the teacher's work was very high during the initial period of their work, but now the fear of one's own fate and existence prevails in the teachers' community, the fear of survival in the midst of constant 
change. Teachers are very hurt that society sees only their holidays; stereotypes persist that the teacher does nothing but take these.

The older generation of teachers invariably sticks to traditional, basic values and the belief that the meaning of life is given to family, children and their prosperity. It is a work in which the moral code applies; the teacher deserves recognition from society, and respect and gratitude from parents and students.

They also express the belief that the teacher must be credible, for the teaching profession is a great responsibility: it is a matter of pride and prestige, and it is the most important social mission.

\section{Conclusion}

The presented study has highlighted the tendency of a shift in the emphasis of the ethos values that are characteristic of the older generation of teachers (lifestyle oriented on the educational mission, responsibility for the younger generation and for the future of the country, etc.) towards values that are more concerned with everyday life, characteristic of young teachers, as well as others (work, school, qualifications, degrees, advancement, teaching practice, working conditions, life).

There is less emphasis on the importance of the values associated with this aforementioned ethos: lifestyle-oriented projects and intelligence missions, responsibility for the younger generation and for the future of the country, the values specific to the tradition of Polish culture and the progressive, democratic role of intelligence in the history of our country.

The study has indicated that, in the professional lives of teachers, there are a significant number of challenging cases and issues, such as worry, the root causes of discontent, and barriers to work and life. These include such things as teachers' material situation, conditions of rest, the availability of entertainment and social relations in school.

The observations made in this chapter may indicate a generational change, one of the manifestations of which is the progressive disappearance among teachers, especially young ones, of their willingness to take a deeper, reflective attitude towards their own profession, life and work. This may be related to the overall change in society, which is expressed in the pursuit of shortness of speech, imagery and laconicism, patterns and examples of which flow from the internet and 
social media. It could also be the result of, in the case of some novice teachers, a weakened process of identification with the profession under the influence of the increasing phenomenon of hiring teachers, especially young ones, on so-called zero-hours contracts, order agreements, and other forms of temporary contracts (precariat).

A certain explanation may be noted in the statements in terms of the predominance of pragmatic and instrumental attitudes of young teachers towards their profession. These teachers attach importance to and demonstrate an understanding (estimation) for deeper, traditional categories of occupation, the so-called ethical "vocation" related to social, cultural and national settlements, but they nevertheless expect, above all, clear criteria for defining the tasks and professional functions to which they are entitled and for which they are responsible. In the statements, conversely, there is a lack of broader perceptions of the profession, with few references made thereto, as a responsible effort to educate young generations and prepare them for further multiplying and enriching the economy, culture, national identity, and quality of life.

Today, the teaching profession is seen by young people more as a source of earning and a dignified life and is seen more often in terms of material aspects than symbolic aspects. A decent life is above all good material conditions, but also kindness, good people-to-people relations, good opinions, not doing harm to others, and having and giving respect to students and people (Dróżka \& Madalińska-Michalak, 2016).

Meanwhile, in the older generation, work means above all a source of social and ethical values - these come to the fore in the statements of senior teachers, together with social service, being useful, and creating a well-fulfilled society, which all gives a sense of meaning and dignity to life and work.

It should be added, however, that the current older generation, as well as a high proportion of middle-aged teachers, present a significant amount of bitterness and dissatisfaction with their professional career and even life in their statements. They believe that, due to the socio-cultural and systemic conditions and aspects of the profession and teacher training they experienced (mostly in the 1970s), the ethos of the mission, service, and social and professional engagement prevail in their generation, as well as even a kind of enlightenment, which, in essence, this profession requires in those realities. 
As a result, today, at the end of their careers living and working in the changing socio-political and cultural realities, some of them regret that they were not more assertive, that they sacrificed their own family for work, that they had no chance of a social and cultural life, that they did not take time for themselves or for trips, travel, or sightseeing. Some, though mostly only above the age of fifty, did manage to build a house and set up a garden, thus obtaining a substitute for a certain luxury, for the much-needed distance and rest required in this profession.

For younger teachers, one's career is instead a source of earning to have a decent life and family, for the sake of creditworthiness, to obtain the largest possible number of competencies and certificates, and to be able to compete on the labour market.

\section{References}

$\rightarrow$ Bauman, Z. (2000). Liquid Modernity. Cambridge: Polity.

$\rightarrow$ Dróżka, W. (2008). Generacja wielkiej zmiany. Studium autobiografii średniego pokolenia nauczycieli polskich 2004. Kielce: Wydawnictwo Naukowe UJK.

$\rightarrow$ Dróżka, W. (2017). Wartości oraz cele życiowe i zawodowe nauczyciel. Pokolenia z lat 1989/1990; 2014/2015. Kielce: Wydawnictwo Naukowe UJK.

$\rightarrow$ Dróżka, W. and Madalińska-Michalak, J. (2016). Prospective teachers' motivation for choosing teaching as a career, Kwartalnik Pedagogiczny, 1, 83-101.

$\rightarrow$ Giddens, A. (1991). Modernity and Self-identity: Self and Society in the Late Modern Age. Stanford: Stanford University Press.

$\rightarrow$ Ossowska, M. (1963). Koncepcja pokolenia, Studia Socjologiczne, 2, 47-51. 


\section{Mining Quality \\ Evaluation of Teachers' Professional \\ Identity in the Greek Educational System}

DOI: 10.47050/66515321.82-103

Eugenia Tsiouplis, Dimitrios Stamovlasis

Teachers' evaluation is a crucial issue directly linked to the career and professional empowerment of teachers. Regarding this issue, since 1982, the Greek educational system has experienced numerous educational changes and reforms, which, interestingly, have all been unproductive. These failures have never been convincingly interpreted by experts, and usually they are perceived as merely being rooted in political and ideological reasons. However, besides the political aspects, in our opinion, the weak points of this field, in realising reforms or interpreting phenomena, are the underpinning theoretical and philosophical views and the methods applied. Contrary to the traditional ways, the present chapter, being part of a wider project, attempts to introduce a different epistemology in the field, fostering the complex dynamic system (CDS) perspective. The present endeavor is a qualitative approach aiming to identify the impact of the long-term absence of an evaluation system affecting teachers' professional identity. Methodologically, teachers' views on evaluation issues are explored through discourse analyses of focus group interactions.

\section{Keywords: \\ complexity theory \\ educational policy \\ quality education \\ teachers' evaluation \\ teachers' identity}




\section{Introduction}

Achieving and maintaining quality in modern educational systems is an ongoing objective, although its exact definition remains vague. The controversy concerning the concepts of development, quality and measurement persists at all levels regarding the main actors, the aims, and the desired outcomes (Adams, Acedo \& Popa, 2012). The term "quality" originating from the market language, has become "anathema" (Doherty, 2008, p. 255) to many academics, however, it remains a central issue, despite its vagueness that allows multiple interpretations.

The main quarrel in the quality-in-education discussion focuses on the role of teachers and their responsibility for attaining high-quality education (for details, see Clement, 2009). According to Lovat's (2009) literature review, a teacher has at least a $60 \%$ probability of influencing students' achievement, regardless of their initial socio-economic background, and the odds of the teacher's impact on students over the impact of the school is $75 \%$. Therefore, teachers' competencies in the classroom and the academic criteria became the determining factors in optimising pupils' performance, achieving school goals and, consequently, improving the overall school function (Darling-Hammond, 2000; Darling-Hammond \& Youngs, 2002; Nye, Konstantopoulos \& Hedges, 2004).

Acknowledging the importance of teachers' roles led to a growing interest that focused on the quality of teaching at all stages (Tonna \& Madalińska-Michalak, 2018). Academic researchers and analysts have pointed out that teaching processes encompassing the modes of practice in conjunction with fundamental ideas are dynamical processes and, as such, can be subjected to continual amendments on the path to achieving quality objectives (Creemers, Kyriakides \& Antoniou, 2013). In order to improve teaching and learning and sustain accountability, highly scholastic measures for successful professional development have been put in place on the agenda of experts and policy-makers, albeit with a variety of methods and approaches (e.g. for the USA, Derrington \& Martinez, 2019; for Portugal, Flores, 2018; for Belgium, Tuytens \& Devos, 2018; for China, Liu, Xu \& Stronge, 2016). The educational systems worldwide have undertaken reforms aiming to enhance the quality of education, but many of these efforts have failed, despite their honorable intentions. These failures have usually been explained by blaming fragmentary implementation and isolated 
efforts that were ineffective in addressing the teachers' demands (Borko, 2004; Lee \& Day, 2016).

It is imperative to comment at this point that interpreting the reforms' failures is a determining step towards understanding educational reforms. In our opinion, the underpinning theoretical framework is the most important prerequisite for this purpose. The usual interpretations are rather simplistic and naïve. They are simplistic because they consider that the application of a reform's regulatory framework is not achieved with absolute fidelity due to the varying degrees of unwillingness shown by teachers. This is a reductionistic view that will be elaborated in the following sections. They are also naïve because they assume that the successful implementation of new proposals in one educational environment, school or region guarantees the same positive development in another (Moran, 2015; Trombly, 2014). Both of the above criticisms are posited to emphasize that there is a lack of a deeper understanding of the system under study within the traditional epistemological framework. Not ignoring that, as with all educational disputes, the controversial notion of quality in education is a deeply social and political issue (Biesta \& Osberg, 2010; Biesta, 2019), we maintain that a paradigm shift is needed to investigate it that will provide a different world view and potentially reduce the gaps between the different approaches. This shift can be summed up as the fostering of a complex systems view of educational processes.

\section{Complexity Theory and Complex Adaptive Systems}

Complexity theory was developed in the field of the natural sciences in the mid-20 $0^{\text {th }}$ century and concerns nonlinear systems evolving in time, dynamical and complex in nature. The notion of complexity encompasses a number of properties that differentiate those systems from simple mechanical and linear systems (Nicolis \& Nicolis, 2007). The theory itself was founded in the field of mathematics, which provides the concepts and tools to describe those systems and to develop models for investigating them. Complexity theory is a new perspective, a new science, which has also influenced social and life sciences, such as psychology, neuroscience, medicine and education (Guastello, Koopmans \& Pincus, 2009; Koopmans \& Stamovlasis, 2016). The operational definition of a complex system is a system comprising a large number of parts or sub-systems which are connected and 
exchange energy and/or information. Their evolution is driven by self-organisation mechanisms, while new properties emerge as a result of the dynamic interactions among the contributing components. Changes occur through feedback loops where small changes can cause large differences over time. This generally distinguishes complex systems from simple and complicated ones. They are characterised by the term "Complex Adaptive Systems" (CAS) because their dynamic and self-organising behaviour allows them to adapt to a continuously changing environment (Nicolis \& Prigogine, 1977; Nicolis \& Nicolis, 2007).

Fostering the CDS ontology in investigating organisations, one may recognize analogous structures and interaction dynamics amongst multiple networked agents and potential emergent events - such as originality, knowledge or adaptableness - arising from those relationships (Mason, 2008; Poutanen, Siira \& Aula, 2016). The organisations and human systems could be seen or function as CAS in the sense that their evolution is the result of a dynamical and interactive process that cannot be traced back to its constituent parts, since the whole is more than the sum of its components. Contrary to CAS, the mechanistic systems can be broken down into parts and restructured without affecting their functionality and entity, and their relationships can be studied and formulated in terms of linear mathematics and be understood by Newtonian laws, even if a high level of expertise is required (Snyder, 2013). It can be argued that social processes and evolutions in human systems, such as education, belong primarily to the realm of complex systems. CAS properties are not always apparent but can manifest themselves under certain circumstances, especially when changes are sought. CAS frameworks in such human systems can help us to better understand the phenomena related to the emergence of meanings, new knowledge, new perceptions, and the ways in which they change, develop and evolve over time (Stamovlasis \& Koopmans, 2014, 2017; Poutanen, Siira \& Aula, 2016).

\section{Education as a Complex Dynamical System}

Education is the space in which a multitude of entities or agents coexist: students, teachers, content, media, time, goals, curricula and context. The above elements and the relationships between them create a dynamical system and an active structure that 
ontologically is an interconnected network (Ni \& Branch, 2008). Onecan perceive those complex structures at different levels of complexity. That is, learning at an individual level within a student's mind, learning at a collective level within a collaborative school setting, and even learning at a higher level when considering the whole educational system.

The current literature has presented many theoretical and empirical studies that are based on the complexity of education-related phenomena that can only be understood if examined at the level at which they emerge. For example, these phenomena include the emergence of learning-teaching trajectories (Steenbeek \& Geert, 2013), research on private university curricula (Adhiambo-Amimo, 2016), the role of complexity theory in pedagogical developments in physical education in Scotland (Jess et al., 2011), students' problem-solving and physical science (Stamovlasis, 2011), teachers' degree of resistance to change (Tsiouplis \& Stamovlasis, 2019), dynamical views of high school attendance (Koopmans, 2016), teachers' career decision-making (Stamovlasis \& Vaiopoulou, 2017), learning interactions within the classroom (Pennings \& Mainhard, 2016), the contribution of complex dynamic systems to child development (Geert, 2011), etc. The impressive amount of empirical studies advocating a departure from Newtonian assumptions about educational practice has already established a new way of thinking. This is not another metaphor or another interpretative scheme but, starting as an inter-discourse emerging from multi-perspective discussions, became a new paradigm with the Kuhnian notion. The comparative advantage of this approach is a new world view along with its capacity to provide "a rich and widely applicable vocabulary to capture processes of change and the interaction between individuals and larger organisational constellations" (Koopmans \& Stamovlasis, 2016, p. 1). Through this framework, which provides both the language for process description and the methodological tools for studying it, the nonlinear and unpredictable nature of educational processes becomes apparent and the related phenomena can be better understood.

\section{Teachers' evaluation in Greece}

The methods of developing human resources in education is an omnipresent issue in countries' political agenda aimed at attracting and retaining effective teachers, where the evaluation process has 
a central position (Stylianidou, Bagakis \& Stamovlasis, 2004). In the past, evaluation in the Greek educational system relied on authoritarian and strict school inspectors. This practice ceased in 1982 and the inspectors were replaced by school consultants, who, taking the role of a merely advisory character, failed to conduct an essential and effective evaluation system. Note that teacher evaluation became optional, appealing to those who wished to claim higher rank positions, e.g. school principal. The Greek educational system, thus far, has displayed a negative disposition towards formal evaluation, and similar behaviour has also been observed in other countries, as mentioned before. Nevertheless, the need for change in this matter at the theoretical level remains imperative when considering the professionalism of teachers and the empowerment of their educational identity. On the other hand, an effective self-evaluation process is undoubtedly a prerequisite, perhaps even to a greater extent, for supporting the desirable autonomous and self-managed school units (Chrysos, 2000; Betsas \& Amarantidou, 2011).

The most recent reform changing the legislative framework on teachers' evaluation and the self-assessment of school units was attempted over the period 2013-2015. Accordingly, evaluation was applied hierarchically through a top-down approach, where each prospective evaluator had to follow a training process in order to evaluate their subordinates. This reforming effort encountered great difficulties and faced strong objections at all levels of education until it was finally stopped in 2015 (Tsiouplis, 2016).

Since then, given the financial crisis, the limited resources available and the substantial reduction of budgets in all areas, initiatives for educational reform have not been attempted. The issue remains open, and since education is the lever to stimulate productivity, despite the economic downturn, it is necessary for the weak points of the educational system regarding evaluation to be addressed following the actions of most European countries (OECD, 2017). Note that in Greece, the only evaluation mechanisms are the comparative studies on student performance, the PISA, and the entrance examinations to institutions of higher education. 


\section{Rationale and Research Questions}

The absence of an evaluation system in the Greek education system from 1982 until today, co-examined along with the series of failed reforms, encompasses a unique feature that attracts the attention of researchers. This work, being part of a wider project aimed at the application of complexity theory in education, re-examines educational reforms through the prism of the new paradigm. The theoretical elaboration for such an epistemological shift was presented in a previous section. Following the CDS approach, in the first stage of this project, an attempt was made to provide empirical evidence for existing nonlinearity when examining teachers' attitudes towards reforms (Tsiouplis \& Stamovlasis, 2019). Their positions and perceptions that emerge over time, as well as their resulting behaviour, have been consolidated into a "force" resisting change, opposing "forces" acting for change/reform. In the above-mentioned empirical study, it was shown that that modeling this force-field dynamic via catastrophe theory (Thom, 1975) revealed nonlinear effects, which reflect the underlying complex dynamical system. The nonlinear model suggests that some variables, such as emotional states, act as bifurcation factors. That is, when a bifurcation factor exceeds a threshold value, the state variable - which is the teachers' position related to educational reforms - becomes bimodal. The two modes or behavioural attractors represent the two qualitatively different states: for and against educational reforms, respectively. Beyond the threshold value, the relationships are nonlinear and transitions between the two behavioural attractors can occur, that is, abrupt changes in teacher position ensue. The findings are of paramount importance because they demonstrate a nonlinear system, where small changes in a control variable can result in sudden large changes in the dependent variable. The message from this CDS application is that, in practice, the dynamical system under study can proceed via discontinuous changes or transitions between behavioural attractors, if the bifurcation factors exceed certain critical points. This directly suggests that a better understanding of the system encompasses knowledge of the potential bifurcation factors. The literature provides information about the characteristics of these kinds of variables, which can deductively be hypothesised as bifurcation factors. These are associated directly or indirectly with affective states and emotions and 
can be very susceptible to changes. In addition, the moderator variables are good candidates for bifurcation factors (Stamovlasis, 2016a). Based on the above, in the second stage of the project, the present work was carried out as a systematic investigation of the latent factors associated with teachers' attitudes contributing to resistance to change regarding the reform of the evaluation system. The working hypothesis and the main research question concerns the number and the nature of those variables, which introduced nonlinearity to teachers' positions (dependent variable). For this, we developed and applied a qualitative method for exploring those latent variables. The method is based on a focus group approach, where, through nonlinear interaction processes, the latent variables in question became apparent.

\section{Method}

Focus groups - data collection

The choice of the method of data collection depends on the specific objectives of a piece of research. Focus groups, which have become increasingly popular in the social sciences, have certain advantages over traditional approaches, e.g. interviews, because they allow the collection of a large amount of data from an important group of individuals related to a range of contexts, including attitudes, opinions, feelings and expectations (Wilson, 2012). The dynamics of the nonlinear interaction process are a key element of focus groups, which in this approach was taken into consideration when organising the focus group settings.

The design of the method allows association and interaction among group members, and the dynamics of the process expedite the appearance of aspects that would otherwise be difficult to reveal. The recursive interactions within brain-storming conditions facilitate latent variables, such as attitudes, certain memories, past experiences, positions, ideologies, feelings, practices or desires, to emerge. It is therefore expected that - under these conditions - teachers will function spontaneously, without restraints and discomfitures, and the interaction patterns will disclose the looked-for factors that determine their readiness for educational change. The factors in question were documented via a suitable coding scheme in the subsequent discourse analysis. 
The size of the groups was 3-4 individuals, a choice which was thought to be the optimal one, given the disadvantages of larger groups, such as the difficulties to control and the limited chances for each member to equally contribute to the discussion (Guest, Namey \& McKenna, 2017; Carlsen \& Glenton, 2011; Onwuegbuzie et al., 2009). The participants in the micro focus groups were selected on a voluntary basis, but an attempt was made to include teachers with varying ages, genders, teaching experiences, specialisations and positions in the educational system. Empirical data were collected from 10 mini focus groups, involving 27 schoolteachers and 7 school principals. Their years of service in education ranged from 8 to 33 (with a mean of 17.9 years). The participants were subsequently anonymised using the capital letter $\mathrm{P}$ and a number from 1 to 27 (P1-P27), and the school principals similarly as $\mathrm{H} 1-\mathrm{H} 7$. The focus group discourses were audio recorded and transcribed. Consequently, they were explored via discourse analyses.

\section{Organisational discourse analysis}

The participants were teachers or school principals in urban school units, and the discourses focused on specific issues of reforming the evaluation system, that are directly associated with their everyday work. Therefore, we chose to analyze the discourses in focus groups using the organisational discourse analysis method. There are a variety of theories and approaches regarding organisational discourse analysis; in this work, for reasons of methodological clarity, we adopt the definition which considers a "discourse" as a way of talking about and understanding the world or some aspects of it (Phillips \& Jorgensen, 2002, p. 1). Discourse analysis provides a theoretical prism for understanding social reality via language use. The field of organisational discourse analysis refers to "the systematic study of texts - including their production, dissemination and consumption - in order to explore the relationships between discourse and social reality"(Phillips, Lawrence \& Hardy, 2004, p. 636). Contemporary discourse studies within organisations following specific thought processes have demonstrated the "linguistic turn"that has enhanced the power, the capabilities and, more importantly, the complexities of language (Alvesson \& Karreman, 2000, 2011). Also, researchers should bear in mind that individuals do not use language to accurately 
represent the perceived reality (Chia, 2000) but often to achieve a kind of self-fulfilling goal (Alvesson \& Karreman, 2000). The above makes the work of researchers even more difficult as they must classify and interpret those discourses. In the present inquiry, we re-emphasize, here, that we avoided any post-modern interpretative stance and that the language used was not interpreted at a metaphorical level of thinking. The discourse analysis focuses on identifying specific speech configurations that describe conditional agreements, disparities or negotiations and reflect complex nonlinear relationships between the looked-for variables.

\section{Coding}

The transcribed material of the mini focus group discourses was checked by a second researcher and imported to Atlas.ti, a computer-assisted qualitative data analysis software (CAQDAS) package. So, the coding process and the analysis become easier and more sophisticated, given the advanced facilities that the software offers. For example, CAQDAS makes it possible to process data using qualitative and quantitative processes or combinations of them, e.g. frequencies of pairs of words, or "bi-grams" (Akarsu, Gencer \& Yıldırım, 2018). In this chapter, we present a sample of the qualitative data and the corresponding analyses. Initially, the coding procedure started inductively, and after a thorough elaboration, the ensuing code scheme was applied to the whole data set.

The codes were applied to utterances that were meaningful segments of the discourse and expressed desired information related to the main hypotheses. The final code scheme included axes related to (1) the meaning of the concept of "evaluation" (for principals and teachers), (2) the consequences of evaluation on the quality of education, and (3) the impact that changing the assessment system had on them.

\section{Results}

The transcribed discourses were analysed via the proposed coding scheme. Some examples of the recordings are presented below that express a variety of views of the principals and teachers involved. In the flow of the discourses, the teachers' positions often seemed clear at the beginning, but then they subsequently appeared not to be firm or stable, and in the following sentence, 
they contradicted their previous stance. They introduced doubt by using "but" or "what if", which denotes that their opinion holds conditionally and could be changed if some other factor meets an agreeable level. This level of satisfaction, for a given variable, will not be the same for everybody, but it is reasonable to hypothesize that it will be for a part of the population, which statistically speaking will lead to bimodality. Theoretically, within the CDS framework, the above description reflects a "bifurcation effect". This is not a metaphorical concept but a qualitative description, which is not empirical evidence per se, but a strong clue that a nonlinear phenomenon might occur in a policy-making system (teachers' attitudes for or against reforms) due to the concomitant operation of antithetic factors, attitudes or opinions (Stamovlasis \& Vaiopoulou, 2018).

The present analysis of the discourse flows includes, among other elements, the identification of such bifurcation points, which imply the crucial role of the corresponding bifurcation variables. Next, some selected segments of the discourses are presented, demonstrating the emergence of those qualitative findings.

At the beginning, most participants (both school principals and teachers) expressed their assent to implement a form of evaluation:

First, it is inconceivable that there is no evaluation system; the school is an institution that evaluates students and it is inconceivable that school staff is not being evaluated. [H1]

Yes, I think it is absolutely necessary to have an evalution system for both the school unit and for each of us, and for the counselors; things cannot continue in any other way. [P2]

Moreover, they express their deep resentment over the absence of generalised and organised evaluation frameworks for teachers:

Historically, since 1983, there has been no substantive evaluation or even a measurement of the educational work produced. I think our field loses good reputation on its lack of evaluation; we do not get even an "elementary feedback" on what is taking place. 
However, there are unclear positions regarding the suitability of the evaluation procedures that should be applied. Primarily, the responses seem to be "filtered" through personal views and, interestingly, their opinions were formulated as (rhetorical) questions rather than statements.

What are the issues that will be solved? Will there be any problems? There will be a lot of people involved in this thing, and parents will be involved, but parents, not in a decisive role, but they can speak their minds and, in particular, if they can come in, they have to ask specifically: Why you are saying this? Why do you say that? [H2]

Since 82 there has been a plateau. Three years ago, this evaluation went on to have some reactions from our unions that were not so unjustified to me. That is, I was against that assessment and I was against it, the way it was implemented that is, with the school counselor coming [to school] and reminding me of the "inspector". That the same assessment would be done, that is, no evaluation, nothing, that is why I was opposed, not opposed to the notion of evaluation, leveling is, I think, a perfect injustice, leveling is a perfect injustice. [H4]

It depends on what I am looking for. Do I want managers and executives? I get something else to evaluate. Do I want educators? Something else to evaluate. Do I want people who "grab" a position and will not move from it? I leave them in this position for the next 20 years. Again, it depends on what kind of education you want and what kind of schools you want. [P9]

An important "bifurcation point" is the great contrast or discrepancy- usually within the same utterance - between the agreement for evaluation and a different perspective, which essentially nullifies the previous agreement and takes on the form of prerequisites. In this case, there is always a latent "but" or "what if".

Personally, I am convinced, we already discussed this [before in the session], that the legislation of 2013 [until 2015] was a good tool which we could interact with and ask for some improvements. At the beginning the evaluation should not be related with dismissal 
or wage developments, [...] maybe [relate] with the [professional] development, in a position of responsibility ok, but without any financial disincentives. [H5]

I agree, I am and I will be in favour of the evaluation, provided that we know exactly how the evaluation will be done and by whom it will be done. I think we are the only industry that is not evaluated, and so instead of getting better, it is going to get worse. [P2]

I am new to education, I have 9 years' experience and I think we need to be evaluated, improved and, because we are in a class that is a living organism, children have needs, because we too will be trained to be able to follow children, to evaluate if we are good, to see what we need to improve. It is not bad to change, and [especially if] someone tells us that we need to improve something simply by doing so in a context that does not undermine our capabilities, nor our personality, but in the context of self-improvement. [P12]

Regarding the quality of education provided, the most important element was the effectiveness of teachers. Here, the key elements can be traced to the effectiveness of themselves as well as the effectiveness of other colleagues. The focus on using the evaluation process as a lever to remove ineffective teachers was also a cause of great distress.

Think, how many thousands of our colleagues have been appointed since the 1990s. I think there is no one who has been judged incapable. With the law of averages, should not there be some, even if they count on their fingers, who can not do this job? [H1]

Evaluation does not scare me, changes do not scare me; when you feel good, they do not scare you. It goes without saying that anyone who wants can come to my class, into my lesson, I have no objection to this. Now, how exactly can the evaluation be done? If we go into practical matters, we all-sometimes - feel that some colleagues are not doing their job right, we feel it. [P7] 
Well, there is a very vague, fuzzy landscape in which everything works, you never know what really works and what does not. How can we help and how can we help both colleagues and students throughout this vague landscape? And because in Greece we have a constant phobia when we hear this word, "evaluation", we associate it with a wage increase, with whether I will have my job tomorrow. In the end, in the end, we reject anything that can get us a little further. [P11]

In addition to professional effectiveness, this ambiguity is illustrated by two other factors: (1) the deep concern about the possibility of their poor evaluation and dismissal, and (2) the political fluidity in relation to a stable and reliable evaluation system.

So, we were all scared, we were, after all, there was this feeling that we were heading towards layoffs, that is, for mass layoffs, and that this self-evaluation would lead there. Bad schools will close, right? Good schools will emerge. [H3]

If I was evaluating colleagues now that I see them every day and knew that their job would be affected financially either for their grade or transfer, it would be more convenient for me to give them all "Excellent". But if I knew that it would be just a report that could play a role in not being a manager, I would say: "OK, colleague, I do not think you need to be a manager" or "You do not have the skills". [H5]

That is, from one minister to another in the same government, they have a completely different philosophy. The same government, you can notice now, they are supposed to have a specific plan as a government, but the replacement of the minister completely changes this plan. [H3]

How will he come to evaluate me? If he has political criteria in his mind? I have heard from others about this; if he has [different] political criteria in mind... [P17] 
Their attitudes about evaluation are closely related to their comfort zone and the steadiness of their daily routine.

We are wary of the new, of the different, we want the usual so that we do not have to get out of a routine. [P12]

We are not unconventional [...]. We have been getting by with it, and we do not like doing our job. So, no one is supposed to bother us because we feel we are doing well, so there is no need to evaluate us. [...] Yes, certainly, because no one bothers us to do so we are not obliged to do so, nor do we participate, and so we settle down [in the current situation]. [H7]

\section{Discussion and Concluding Remarks}

The present research has studied the emerging attitudes and behaviours of teachers in Greece under changing situations and, particularly, the leveling off in the teachers' evaluation system. The innovative feature of this endeavor is that it fills a gap in the literature since no similar studies on teachers' positions have been reported, especially using the proposed methodological approach. The dynamical process of focus group interactions allowed the emergence of verbal patterns revealing related views, opinions, agreements, objections, fears, emotions and attitudes towards the evaluation issues. Although numerous shortcomings were reported (e.g. uneven work distribution, excessive workload and a lack of resources) as regards the implementation of evaluation (OECD, 2013), it was not possible to establish a causal framework for teachers' attitudes and positions on the evaluation system, since most discourses revealed contrasts and inconsistencies when expressing conditional agreements. Moreover, since teachers have no previous experiences of assessment, it is apparent that their positions are founded on misconceptions and myths about what an evaluation system is and what it can offer.

An element that could induce bifurcation effects originates from the lack of a consistent collective attitude towards evaluation processes of any form. This fragmented view of the issue in question is associated with various erroneous and spasmodic conceptions about the reasons for reforming education, which are interpreted 
either as due to ineffective colleagues or as some impersonal, punitive governmental policy. The "distance" between teachers' institutional logics regarding change and evaluation and those that policy-makers adopt is well-known, as is the need that teachers have to believe that reforms have some kind of cognitive legitimacy (Bridwell-Mitchell \& Sherer, 2017).

The latest attempt for reforming the evaluation system, same as all the previous ones, was imposed from top to bottom. The results were disappointing:

1. it did not achieve any of its key objectives,

2. it was downgraded to a form that added even more bureaucratic work, and

3. it created confusion and controversial positions for teachers.

The reform was initiated and applied at a superficial level, thus the consequences were not favorable. The previous negative attitudes were consolidated and reinforced the contrasting positions arguing against a meaningless change, which added nothing constructive to the quality of the educational work. In general, teachers' attitudes and behaviours do not differ from those observed in other countries. Reaching evaluations' objectives is a thorny issue in many European educational systems since teachers do not accept the reforms resignedly but seemingly mediate the changes and, in some cases, actively subvert them (Osborn, 2006).

Another important hint that came out of the discourse analysis was the teachers' worries about the impact of the evaluation on their personal lives and careers. In fact, they were the foremost bifurcation factors detected. The teachers' apprehension is based on the idea that they will be accountable for any failures or shortcomings in the entire education system, which makes them at least skeptical, if not hostile, to any interruption of the existing status quo. An interesting point is that some of the teachers implicitly requested beneficial rewards for their possible participation in an evaluation process, while the majority were concerned about possible discrimination or injustice.

Returning to the theoretical issues and analyses, the reductionistic interpretation that the reforms have failed due to the lack of appropriate information delivered on the expected benefits for both teachers and the quality of education is an over-simplified one. Our position is that 
the failures are due to all of the philosophical and epistemological views driving the top-down interventions, which ignore the complex nature of the educational system, as was described in a previous section. The network-based ontology of education and the dynamic underlying processes mean that the ensuing changes do not follow Newtonian laws. We argue that the meta-theoretical framework of complexity can enrich and support the development of local theory in organisational and educational management and suggest different ways to address changes and reforms. This prospect is in line with the views of numerous scholars who have advocated the complexity perspective (e.g. Goldstein, Hazy \& Lichtenstein, 2010; Sanderson, 2000). It is important that theoretical considerations should incorporate the notions of self-organisation and bottom-up processes in their philosophical assumptions, as well as in research and/or evaluation designs. Theoretical conjectures should not ignore, but rather take into consideration, the bifurcation role of certain variables and anticipate that the outcomes are not linear sums of the acting components. Sudden transitions might occur through the self-organisation mechanism, which must be facilitated by controlling the right variables. In the quantitative empirical research implementing catastrophe theory models, Tsiouplis and Stamovlasis (2019) showed that psychological coordination encompasses all views, opinions, agreements, objections, fears, emotions and attitudes towards educational evaluation and reform, which is a nonlinear system where sudden transitions can occur between behavioural attractors. The implications are evocative of how changes could occur in such a complex nonlinear system. In the present qualitative study, using a novel methodological approach, we revealed some potential bifurcation variables, which are currently under further investigation in in-progress quantitative research. The message here is the novel theoretical framework and its implications on ways of thinking and acting.

As a generalised final remark, a message can be conveyed to politicians and policy-makers saying that instead of considering merely public prejudices, opinion polls and the general social context of a given historical context, it is advisable to consider findings from theory-based social research as well (Stame, 2004). Finally, when the strategic aim is institutional change, CDS informs stakeholders and policy-makers that there is no unique structured training that is tailored 
for those who are supposed to go through an evaluation process for professional development; top-down interventions, with their strict legislation and control, even when they are fair and well-designed, are condemned to failure because they ignore the dynamic complexity of human systems.

\section{References}

$\rightarrow$ Adams, D., Acedo, C. and Popa, S. (2012). In Search of Quality Education. In: D. Adams, C. Acedo, S. Popa (eds.), Quality and Qualities: Tensions in Education Reforms (pp. 1-23). Rotterdam: Sense Publishers.

$\rightarrow$ Adhiambo-Amimo, K. (2016). Private Universities in Kenya Seek Alternative Ways to Manage Change in Teacher Education Curriculum in Compliance with the Commission for University Education Reforms, Australian Journal of Teacher Education, 41(10), 1-14.

$\rightarrow$ Akarsu, O., Gencer, M. and Yıldırım, S. (2018). Listening to the organization: change evaluation with discourse analysis, Journal of Organizational Change Management, 31(5), 1040-1053.

$\rightarrow$ Alvesson, M. and Karreman, D. (2000). Taking the linguistic turn in organizational research. Challenges, Responses, Consequences, The Journal of Applied Behavioral Science, 36(2), 136-158.

$\rightarrow$ Alvesson, M. and Kärreman, D. (2011). Decolonializing discourse: Critical reflections on organizational discourse analysis, Human Relations, 64(9), 1121-1146.

$\rightarrow$ Betsas, I. and Amarantidou, K. (2011). Teacher Evaluation in Greece: Political \& Pedagogical Dimensions in School Inspections During the 50's \& 60's. In: A. Pejatović (ed.), 14 ${ }^{\text {th }}$ International Conference Evaluation in Education in the Balkan Countries: Belgrade, 16-18 ${ }^{\text {th }}$ June 2011, Belgrade.

$\rightarrow$ Biesta, G. (2019). What Kind of Society Does the School Need? Redefining the Democratic Work of Education in Impatient Times, Studies in Philosophy and Education, 38(6), 657-668.

$\rightarrow$ Biesta, G. and Osberg, D. (2010). Complexity, Education and Politics from the Inside-Out and the Outside-In. An introduction. In: D. Osberg, G. Biesta (eds.), Complexity Theory and the Politics of Education (pp. 1-3). Rotterdam: Sense Publishers.

$\rightarrow$ Borko, H. (2004). Professional Development and Teacher Learning: Mapping the Terrain, Educational Researcher, 33(8), 3-15. 
$\rightarrow$ Bridwell-Mitchell, E. N. and Sherer, D. G. (2017). Institutional Complexity and Policy Implementation: How Underlying Logics Drive Teacher Interpretations of Reform, Educational Evaluation and Policy Analysis, 2, 223-247.

$\rightarrow$ Carlsen, B. and Glenton, C. (2011). What about N? A methodological study of sample-size reporting in focus group studies, BMC Medical Research Methodology, 11(26), 1-10.

$\rightarrow$ Chia, R. (2000), Discourse Analysis as Organizational Analysis, Organization, 7(3), 513-518.

$\rightarrow$ Chrysos, M. (2000). Government Policy on Teacher Evaluation in Greece: Revolutionary Change or Repetition of the Past?, Education Policy Analysis Archives, 8(28), 1-11.

$\rightarrow$ Clement, N. (2009). Perspectives from Research and Practice in Values Education. In: T. Lovat, R. Toomey (eds.), Values Education and Quality Teaching. The Double Helix Effect (pp. 13-27). Dordrecht: Springer.

$\rightarrow$ Creemers, B., Kyriakides, L. and Antoniou, P. (2013). Teacher Professional Development for Improving Quality of Teaching. Dordrecht: Springer.

$\rightarrow$ Darling-Hammond, L. (2000). Teacher Quality and Student Achievement: A Review of State Policy Evidence, Education Policy Analysis Archives, 8(1), $1-44$.

$\rightarrow$ Darling-Hammond, L. and Youngs, P. (2002). Defining "highly qualified teachers": What does "scientifically-based research" actually tell us?, Educational Researcher, 31, 13-25.

$\rightarrow$ Derrington, M. and Martinez, J. (2019). Exploring Teachers' Evaluation Perceptions: A Snapshot, NASSP Bulletin, 103(1), 32-50.

$\rightarrow$ Doherty, G. D. (2008). On quality in education, Quality Assurance in Education, 16(3), 255-265.

$\rightarrow$ Flores, M. (2018). Teacher evaluation in Portugal: persisting challenges and perceived effects, Teachers and Teaching, 24(3), 223-245.

$\rightarrow$ Goldstein, J., Hazy, J. and Lichtenstein, B. (2010). Complexity and the Nexus of Leadership: Leveraging Nonlinear Science to Create Ecologies of Innovation. New York: Macmillan.

$\rightarrow$ Guest, G., Namey, E. and McKenna, K. (2017). How Many Focus Groups Are Enough? Building an Evidence Base for Nonprobability Sample Sizes, Field Methods, 29(1), 3-22.

$\rightarrow$ Jess, M., Atencio, M. and Thorburn, M. (2011). Complexity theory: supporting curriculum and pedagogy developments in Scottish physical education, Sport, Education and Society, 16(2), 179-199. 
$\rightarrow$ Jorgensen, M. and Phillips, L. (2002). Discourse analysis as theory and method. London: Sage Publications.

$\rightarrow$ Koopmans, M. (2016). Investigating the Long Memory Process in Daily High School Attendance Data. In: M. Koopmans, D. Stamovlasis (eds.), Complex Dynamical Systems in Education: Concepts, Methods and Applications (pp. 299-321). New York: Springer.

$\rightarrow$ Koopmans, M. and Stamovlasis, D. (eds.) (2016). Complex Dynamical Systems in Education. Concepts, Methods and Applications. Cham: Springer.

$\rightarrow$ Lee, J. and Day, C. (eds.) (2016). Quality and Change in Teacher Education. Western and Chinese Perspectives. New York: Springer.

$\rightarrow$ Liu, S., Xu, S. and Stronge, J. (2016). Chinese middle school teachers' preferences regarding performance evaluation measures, Educational Assessment, Evaluation and Accountability, 28, 161-177.

$\rightarrow$ Lovat, T. (2009). Values Education and Quality Teaching: Two Sides of the Learning Coin. In: T. Lovat, R. Toomey (eds.), Values Education and Quality Teaching. The Double Helix Effect (pp. 1-12). Dordrecht: Springer.

$\rightarrow$ Mason, M. (2008). What is Complexity Theory and what are its implications for educational change, Educational Philosophy and Theory, 40(1), 35-49.

$\rightarrow$ Moran, R. (2015). The Implications of teacher performance assessment and the impact on teacher decision making, Language Arts, 93(2), 96-107.

$\rightarrow \mathrm{Ni}$, X. and Branch, R. M. (2008). Complexity Theory. In: J. Spector, M. D. Merrill, J. van Merrienboel, M. P. Driscoll (eds.), Handbook of research on educational communications and technology (3 ${ }^{\text {rd }}$ ed.) (pp. 29-32). New York: Lawrence Erlbaum Associates.

$\rightarrow$ Nicolis, G. and Nicolis, C. (2007). Foundations of Complex Systems. Singapore: World Scientific.

$\rightarrow$ Nicolis, G. and Prigogine, I. (1977). Self-organization in non-equilibrium systems. New York: Wiley.

$\rightarrow$ Nye, B., Konstantopoulos, S. and Hedges, L.V. (2004). How Large Are Teacher Effects?, Educational Evaluation and Policy Analysis, 26(3), 237-257.

$\rightarrow$ OECD (2013). Teachers for the $21^{\text {st }}$ century: Using Evaluation to Improve Teaching, Paris: Organisation for Economic Cooperation and Development Publishing.

$\rightarrow$ OECD (2017). Education Policy in Greece. A Preliminary Assessment, www.oecd. org/education/Education-Policy-in-Greece-Preliminary-Assessment-2017.pdf

$\rightarrow$ Onwuegbuzie, A. J., Dickinson, W. B., Leech, N. L., Zoran, A.G. (2009). A Qualitative Framework for Collecting and Analyzing Data in Focus Group Research, International Journal of Qualitative Methods, 8(3), 1-21. 
$\rightarrow$ Osborn, M. (2006). Changing the context of teachers' work and professional development: A European perspective, International Journal of Educational Research, 45, 242-253.

$\rightarrow$ Pennings, H. and Mainhard, Y. (2016). Analyzing teacher-student interactions with State Space Grids. In: M. Koopmans, D. Stamovlasis (eds.), Complex Dynamical Systems in Education. Concepts, Methods and Applications (pp. 233-271). New York: Springer.

$\rightarrow$ Phillips, N., Lawrence, T. B. and Hardy, C. (2004). Discourse and Institutions, The Academy of Management Review, 29(4), 635-652.

$\rightarrow$ Poutanen, P., Siira, K. and Aula, P. (2016). Complexity and Organizational Communication: A Quest for Common Ground, Human Resource Development Review, 15(2), 182-207.

$\rightarrow$ Sanderson, I. (2000). Evaluation in Complex Policy Systems, Evaluation, 6(4), 433-454.

$\rightarrow$ Snyder, S. (2013). The Simple, the Complicated, and the Complex: Educational Reform Through the Lens of Complexity Theory (OECD Education Working Papers, No. 96). Paris: Organisation for Economic Cooperation and Development Publishing.

$\rightarrow$ Stame, N. (2004). Theory-based Evaluation and Types of Complexity, Evaluation, 10(1), 58-76.

$\rightarrow$ Stamovlasis, D. (2016). Nonlinear dynamical interaction patterns in collaborative groups: Discourse analysis with orbital decomposition. In: M. Koopmans, D. Stamovlasis (eds.), Complex dynamical systems in education. Concepts, Methods and Applications (pp. 273-297). New York: Springer.

$\rightarrow$ Stamovlasis, D. and Koopmans, M. (2014). Editorial Introduction: Education is a Dynamical System, Nonlinear Dynamics, 18(1), 1-5.

$\rightarrow$ Stamovlasis, D. and Koopmans, M. (2017). Editorial Introduction: Special issue on Complex Systems in Education: Questions, methods and implications for practice, Complicity: An International Journal for Complexity and Education, 14(2), 1-6.

$\rightarrow$ Stamovlasis, D. and Tsaparlis, G. (2001). Application of Complexity Theory to an Information Processing Model in Science Education, Nonlinear Dynamics, Psychology, and Life Sciences, 5(3), 267-287.

$\rightarrow$ Stamovlasis, D. and Vaiopoulou, J. (2017). The Role of Dysfunctional Myths in a Decision-Making Process under Bounded Rationality: A Complex Dynamical Systems Perspective, Nonlinear Dynamics, Psychology, and Life Sciences, 21(3), 267-288. 
$\rightarrow$ Steenbeek, H. W. and Geert, P. L. C. van (2013). The emergence of learningteaching trajectories in education: A complex dynamic systems approach, Nonlinear Dynamics, Psychology, and Life Sciences, 17(2), 233-267.

$\rightarrow$ Stylianidou, F., Bagakis, G. and Stamovlasis, D. (2004). Attracting, Developing and Retaining Effective Teachers. OECD Activity. Country Background Report for Greece. Athens: Education Research Centre.

$\rightarrow$ Thom, R. (1975). Structural stability and morphogenesis. New York: Addison-Wesley.

$\rightarrow$ Tonna, M. A., Madalińska-Michalak, J. (eds.) (2018). Teacher Education Policy and Practice - International Perspectives and Inspirations, Vol. 1. Warszawa: Fundacja Rozwoju Systemu Edukacji.

$\rightarrow$ Trombly, C. (2014). Schools and Complexity, Complicity: An International Journal of Complexity and Education, 11(2), 40-58.

$\rightarrow$ Tsiouplis, E. (2016). Investigation of the views of Secondary Education school consultants on the evaluation of teachers according to legislation 152/2013, https://dspace.lib.uom.gr/handle/2159/19656

$\rightarrow$ Tsiouplis, E., Stamovlasis, D. (2019). Rethinking Educational reforms through a complex dynamical systems approach, Northeastern Journal of Complex Systems, 1(1), 1-18.

$\rightarrow$ Tuytens, M., Devos, G. (2018). Teacher evaluation policy as perceived by school principals: The case of Flanders (Belgium), Teachers and Teaching Theory and Practice, 24(3), 209-222.

$\rightarrow$ Van Geert, P. (2011). The contribution of complex dynamic systems to development, Child Development Perspectives, 5(4), 273-278.

$\rightarrow$ Wilson, V. (2012). Research Methods: Focus Groups, Evidence Based Library and Information Practice, 7(1), 129-130. 


\section{Research on Quality of In-Service \\ Teacher Education and Professional \\ Development in Ukraine by TALIS \\ methodology and its Policy Impact}

DOI: 10.47050/66515321.104-129

Oksana Zabolotna, Svitlana Shchudlo

In the present day, teacher education in Ukraine, both pre-service and in-service, is undergoing considerable change within the scope of the New Ukrainian School reform. The Ministry of Education and Science of Ukraine, as the main policymaker, came to the understanding that the reform should be evidence-based and commissioned the Ukrainian Educational Research Association to carry out the All-Ukrainian Monitoring Survey of Secondary School Teachers and Principals, using the TALIS methodology (2017-2018). The research gives insight into the professional development and support of teachers.

The authors present the survey's results on the above-mentioned issues as well as analyze how the survey results are used in policymaking. They conclude that although the reform is introducing a lot of positive changes, in the current Ukrainian educational system, which is too formalised, teachers' professional development is still propelled by external rather than internal motivation; professional development courses that are not diversified enough do not meet teachers' demands; and teachers demonstrate a low degree of awareness of the dynamic $21^{\text {st }}$-century changes that engender teachers' ability to work in a multicultural and inclusive classroom environment.

\section{Keywords: \\ educational policy \\ in-service teacher education \\ teachers' professional development \\ TALIS methodology}




\section{Introduction}

In the present day, teacher education in Ukraine, both pre-service and in-service, is undergoing considerable changes within the scope of the New Ukrainian School reform, which was initiated by the Ukrainian Ministry of Education and Science in 2016. Within the reform, all the educational establishments and the system itself are to be cardinally transformed. The purpose of the reform is to "create a school that will be pleasant to go to and will provide the students not only with knowledge, as is the case now, but also with the ability to apply it in real life. The New Ukrainian School is a kind of school which is pleasant for students to be in. Their opinion is respected here, they are taught to think critically, not to be afraid of voicing their view and be responsible citizens" (New Ukrainian School, n.d.).

To create a favourable educational environment, which is in the focus of the above-mentioned school vision, it is important that teachers are ready to view students as partners. They should provide them with opportunities to express their critical thoughts and to take responsibility for their learning. To ensure that, the Ministry has published methodological materials called New Ukrainian School: Toolkit for teachers (New Ukrainian School, 2017), advising teachers on how to achieve the expected results. Nevertheless, just getting the information is not sufficient for moving towards the New Ukrainian School. It is vital that we hear the voices of Ukrainian teachers and realise their beliefs about the key aspects of the educational reform. For this, we should ask questions of the Ukrainian teachers who are experts in their field and know the school environment on the basis of their daily life. The methods of and approaches to in-service education as well as teachers' professional development are concerned with looking for some measures to raise the prestige of the teaching profession and increasing talented young people's motivation to consider teaching as a career.

\section{The current situation in Ukrainian school education}

To avoid subjectivity and to get a proper idea of Ukrainian education, we would like to view it from different angles. These mainly presuppose taking into account at least three points of view, namely, an external perspective, i.e. from outside Ukraine; an internal perspective, which is provided by teachers and school leadership teams; and the point of view of policymakers. 
When we speak about the external perspective, we mean that of international institutions providing independent expertise, which is often done by analytics and observation, is usually based on short-term data, and is usually straightforward and unbiased. For instance, the World Bank pays attention to some issues affecting Ukrainian schools' sustainability. These are connected with:

1. a lack of adequate facilities, and sometimes a lack of indoor restrooms;

2. outdated teaching methodologies, low morale among teachers, and outdated approaches towards teaching and learning;

3. lessons that are overburdened with theoretical knowledge and dry textbooks dampening motivation and curiosity among students,

4. unofficial payments that are common in education;

5. teachers' low social status, low salaries and a lack of opportunities for personal and professional growth (Kahkonen, 2018).

As a result, "not all Ukrainian citizens enjoy equal access to the quality education that has been guaranteed by the constitution. In fact, too many of the country's schools deepen what is becoming an entrenched cycle of poverty" (ibidem).

According to the OECD's information, we find that "despite having a high literacy rate and high enrolment in primary and secondary education, there is evidence of a skills gap in Ukraine" (OECD, 2012a, p. 10). In addition, "the education system focuses mainly on theory" and "curricula still carry a strong legacy from Soviet times" (OECD, 2012b, p. 11).

So, as can be seen, there are plenty of problems concerning both the physical environment as well as with the teaching itself, which often applies outdated methods that do not contribute to the development of opportunities for personal and professional growth and stifle creativity, dynamism, and motivation.

The Ministry of Education and Science of Ukraine, as the main policymaker, came to the understanding that the reform should be evidence-based and commissioned a TALIS survey from the Educational Research Association as part of the Teacher Project within the large-scale project "Educational Reform: Quality Assessment in the International Context" realised by the Ukrainian Step by Step Foundation with the support of the Ministry of Education and Science 
of Ukraine and Porticus. The first three waves of the Teaching and Learning International Survey (TALIS) were conducted by the OECD in 2008, 2013 and 2018. Ukraine did not participate in them, which deprived it of valuable data that might have contributed to understanding the current situation by comparing its data to those recorded in other countries. Thus, the Educational Research Association got permission from the OECD to use Principal and Teacher questionnaires from TALIS 2013 for the TALIS survey in Ukraine.

\section{The research methodology}

The Ukrainian Educational Research Association conducted the research in February-August 2017. The researched population embraced 201 principals from 201 schools, as well as 3,600 school teachers. The research was conducted in all regions of Ukraine, except for Crimea and the territories in the conflict zone (see Table 1).

Table 1. The Survey Design

\begin{tabular}{l|l}
\multicolumn{1}{c|}{ SURVEY INFORMATION } & \multicolumn{1}{c}{ DESCRIPTION } \\
\hline Project coordinator & Ukrainian Educational Research Association \\
\hline Survey window & February-August 2017 \\
\hline Target group & $\begin{array}{l}\text { School principals and teachers of grades 5-9 from all regions of Ukraine } \\
\text { (government-controlled territories) }\end{array}$ \\
\hline Sampling design & $\begin{array}{l}\text { For schools - multistage sampling: } 1^{\text {st }} \text { stage - stratified, } \\
2^{\text {nd }} \text { stage - random, based on region, location, and type of school } \\
\text { For teachers - one-stage, random }\end{array}$ \\
\hline Achieved sample size & $\begin{array}{l}\text { 3,600 school teachers of grades 5-9 (ISCED 2), } \\
201 \text { principals from 201 schools }\end{array}$ \\
\hline Error & $\begin{array}{l}\text { Simple random sampling error is 1,6\%, school sampling error } \\
\text { with design effect is 2,3\% }\end{array}$ \\
\hline Tools & $\begin{array}{l}\text { Questionnaires for teachers and principals. Time allotted for filling in } \\
\text { was 45-90 min }\end{array}$
\end{tabular}

After the survey, the results were extrapolated on the key reform documents regulating the transformation in teachers' professional development, i.e. On Approving the Concept of the Development of Teacher Education (Ministry of Education and Science, 2018a; hereinafter "the Concept") and On the Roadmap for Implementing the Concept of the Development of Teacher Education (Ministry of Education and Science, 2018b; hereinafter "the Roadmap"). 
The obtained data could be used for answering the following research questions:

1. What should be taken into account in teachers' professional development in implementing the New Ukrainian School reform?

2. In what way(s) are the problems in teachers' professional development addressed in the key documents of the New Ukrainian School reform?

Ukrainian teacher profile. The conducted survey provided data that may be used to describe the Ukrainian teacher profile. Thus, a typical middle school teacher in Ukraine is a 45-year-old female with a Bachelor's or a Master's degree, who has undertaken obligatory teacher training, who feels well-prepared for all aspects of teaching, and who is quite experienced and has a permanent job (see Tables 2 and 3).

If compared to the TALIS 2013 results, on average, the typical Ukrainian teacher is similar to teachers from other TALIS participating countries, though in Ukraine they are older and more experienced.

The average age of Ukrainian teachers in grades $5-9$ is 44,7 , which exceeds the international average in TALIS $2013(42,9)$. The largest share of Ukrainian teachers is in the age group from 40 to $49(29 \%)$, while for other countries it is the same proportion of teachers in the age group from 30 to 39 .

The share of Ukrainian teachers in the age group of 60 and more is $12 \%$, which is twice the international average. Only Estonia (16\%) and Norway $(15 \%)$ have a higher teacher percentage than Ukraine in this age group (Shchudlo, Zabolotna \& Lisova, 2018). In the regional divide, the most considerable differences are observed in the 40-49 age group between Kyiv $(20,4 \%)$ and Central Ukraine $(35 \%)$, and in the 60 -and-older age group between Western Ukraine $(9,1 \%)$ and Kyiv (20\%). In short, if 50 is considered the borderline between working age and possible early retirement age, the most favourable situation is in the central region (68\% of teachers are younger than 50 ), and the least favourable is in Kyiv $(53,1 \%)$, although Kyiv demonstrates a tendency for rejuvenation in its teacher population $(13,7 \%$ of teachers are younger than 30 , whereas in the regions the highest percentage is $5,2 \%$ ).

In general, the share of teachers working after they have reached retirement age correlates with the size of the town (from 9,9\% in villages and small towns with a population of up to 15,000 to $14,7 \%$ 


\begin{tabular}{|c|c|c|c|c|c|c|c|c|c|c|c|c|c|}
\hline & 岕 & $\hat{E}$ & $\begin{array}{l}\frac{\pi}{0} \\
\stackrel{0}{0}\end{array}$ & $\stackrel{\Gamma}{E}$ & $\hat{e}$ & $\begin{array}{l}\stackrel{0}{0} \\
\stackrel{0}{0}\end{array}$ & $\stackrel{\widehat{\sigma}}{\varrho}$ & $\begin{array}{l}\widehat{\widetilde{g}} \\
\stackrel{0}{e}\end{array}$ & $\begin{array}{l}\widehat{f} \\
\stackrel{\varrho}{0}\end{array}$ & $\hat{e}$ & 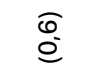 & 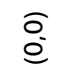 \\
\hline & & 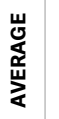 & $\bar{\sigma}$ & $\stackrel{\vec{g}}{\stackrel{g}{q}}$ & 尽 & $\begin{array}{l}\stackrel{+}{\sigma} \\
\dot{\sigma}\end{array}$ & $\stackrel{\overbrace{}}{f}$ & $\begin{array}{l}\stackrel{0}{g} \\
\stackrel{9}{q}\end{array}$ & $\hat{f}$ & $\stackrel{\mathscr{p}}{\tilde{y}}$ & 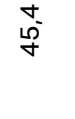 & 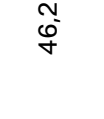 & 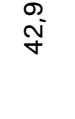 \\
\hline \multirow{13}{*}{ 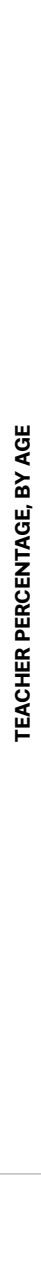 } & & 岗 & 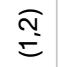 & 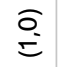 & $\begin{array}{l}\hat{Q} \\
\varphi^{-}\end{array}$ & 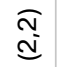 & $\stackrel{\widehat{\alpha}}{=}$ & $\begin{array}{l}\stackrel{Q}{E} \\
=\end{array}$ & $\begin{array}{l}\hat{e} \\
\hat{\varrho}\end{array}$ & $\begin{array}{l}\widehat{\varrho} \\
\stackrel{\varrho}{0}\end{array}$ & $\begin{array}{l}\stackrel{\widehat{Q}}{=}\end{array}$ & $\begin{array}{l}\widehat{Q} \\
\stackrel{E}{E}\end{array}$ & $\overline{\bar{c}}$ \\
\hline & \multirow{2}{*}{$\begin{array}{l}0 \\
\vdots \\
\vdots\end{array}$} & $\stackrel{\circ}{\circ}$ & $\begin{array}{l}0 \\
\text { so }\end{array}$ & $\bar{\sigma}$ & @i & $\stackrel{\leftrightarrow}{F}$ & $\stackrel{0}{\circ}$ & $\stackrel{m}{0}$ & $\stackrel{0}{\risingdotseq}$ & $\stackrel{\circ}{\sigma}$ & 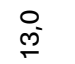 & $\stackrel{\sim}{\leftarrow}$ & $\stackrel{m}{0}^{-}$ \\
\hline & & 岕 & $\begin{array}{l}\text { a } \\
\text { dis }\end{array}$ & 胥 & $\begin{array}{l}\text { E } \\
\text { b }\end{array}$ & $\begin{array}{l}\widehat{\widehat{\alpha}} \\
\stackrel{\underline{c}}{0}\end{array}$ & 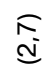 & $\stackrel{\widehat{\rho}}{\underline{d}}$ & $\underset{\Xi}{\tilde{E}}$ & $\underset{F}{\stackrel{J}{E}}$ & $\underset{\mathcal{N}}{\bar{v}}$ & $\underset{\mathbb{N}}{\mathbb{d}}$ & $\begin{array}{l}\widehat{N} \\
\stackrel{\varrho}{\varrho}\end{array}$ \\
\hline & \multirow{2}{*}{$\begin{array}{l}\text { ô } \\
\text { ô. } \\
\text { in }\end{array}$} & $\therefore$ & $\stackrel{\infty}{\stackrel{\infty}{\sim}}$ & 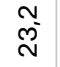 & i্ & $\begin{array}{l}m \\
\stackrel{M}{N}\end{array}$ & $\stackrel{n}{\pi}$ & $\stackrel{\mathfrak{N}}{\underset{N}{N}}$ & 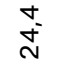 & $\overline{\mathfrak{N}}$ & $\begin{array}{l}\text { 吕 } \\
\stackrel{5}{N}\end{array}$ & 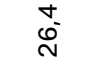 & $\stackrel{\infty}{\mathcal{N}^{\infty}}$ \\
\hline & & 岕 & $\stackrel{\widehat{m}}{=}$ & $\begin{array}{l}\widehat{Q} \\
\stackrel{=}{E}\end{array}$ & $\underset{+}{\stackrel{F}{ \pm}}$ & 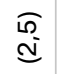 & 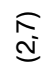 & $\begin{array}{l}\widehat{Q} \\
\stackrel{0}{\tilde{g}}\end{array}$ & $\begin{array}{l}\widehat{a} \\
\stackrel{0}{0}\end{array}$ & 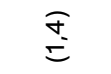 & 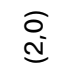 & $\stackrel{0}{=}$ & $\begin{array}{l}\text { ָ̃ } \\
\stackrel{\varrho}{0}\end{array}$ \\
\hline & \multirow{2}{*}{$\begin{array}{l}q \\
+ \\
+\end{array}$} & ஃ & 占 & $\begin{array}{l}\infty \\
\stackrel{\infty}{\infty} \\
\stackrel{\infty}{N}\end{array}$ & ì & 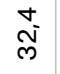 & $\begin{array}{l}\text { 它 } \\
\text { p. }\end{array}$ & 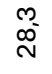 & ০̀ & ণ্ & $\begin{array}{l}\stackrel{L}{\infty} \\
\stackrel{D}{N}\end{array}$ & $\stackrel{\substack{\infty \\
\sim}}{+}$ & 文 \\
\hline & & 岕 & $\begin{array}{l}\stackrel{\varrho}{=} \\
=\end{array}$ & $\underset{\Xi}{\stackrel{\widehat{\Xi}}{E}}$ & $\begin{array}{l}\widehat{Q} \underline{0} \\
\tilde{q}^{-1}\end{array}$ & $\begin{array}{l}\text { J } \\
\text { d }\end{array}$ & 亥 & 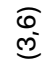 & 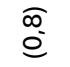 & 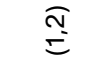 & $\underset{\mathrm{N}}{\bar{v}}$ & 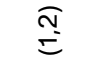 & $\begin{array}{l}\widehat{N} \\
\stackrel{\varrho}{\varrho}\end{array}$ \\
\hline & \multirow{2}{*}{$\begin{array}{l}\text { pे } \\
\text { } \\
\text { pr }\end{array}$} & $\stackrel{\circ}{\circ}$ & $\stackrel{\rho}{\sigma}$ & $\bar{d}$ & 욤 & $\stackrel{0}{\stackrel{N}{N}}$ & 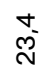 & $\stackrel{m}{\infty_{N}^{-}}$ & $\stackrel{\stackrel{\sim}{N}}{\sim}$ & $\stackrel{\stackrel{L}{D}}{\sim \sim}$ & 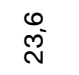 & $\begin{array}{l}\stackrel{0}{ } \\
\infty^{\infty}\end{array}$ & $\stackrel{N}{\stackrel{N}{N}}$ \\
\hline & & 岕 & 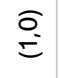 & $\stackrel{\equiv}{E}$ & 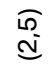 & $\begin{array}{l}\widehat{Q} \\
=\end{array}$ & $\begin{array}{l}\stackrel{F}{E} \\
=\end{array}$ & @্ & $\begin{array}{l}0 \\
\varrho \\
\varrho\end{array}$ & $\stackrel{o}{=}$ & $\stackrel{\widetilde{E}}{E}$ & $\stackrel{o}{=}$ & $\stackrel{0}{0}$ \\
\hline & \multirow{2}{*}{ 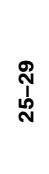 } & $\therefore$ & $\begin{array}{l}0 \\
\infty\end{array}$ & $\begin{array}{l}\stackrel{\rho}{0} \\
\therefore\end{array}$ & $\mathbb{\infty}_{\infty}^{\infty}$ & $\stackrel{\varphi}{\oplus}$ & $\bar{\sigma}$ & $\stackrel{m}{m}$ & $\sigma_{\sigma}^{\infty}$ & $\begin{array}{l}\stackrel{0}{\circ} \\
\stackrel{0}{2}\end{array}$ & $\approx$ & $\stackrel{\infty}{\wedge}$ & $\stackrel{\circ}{\circ}$ \\
\hline & & 岕 & $\begin{array}{l}\widehat{\widehat{\alpha}} \\
\stackrel{\varrho}{\varrho}\end{array}$ & $\begin{array}{l}\tilde{e} \\
\stackrel{0}{0}\end{array}$ & 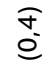 & 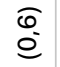 & $\begin{array}{l}\stackrel{F}{E} \\
=\end{array}$ & $\stackrel{\Gamma}{E}$ & $\begin{array}{l}\bar{f} \\
\stackrel{c}{c}\end{array}$ & 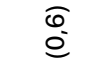 & $\begin{array}{l}\widehat{\varrho} \\
\stackrel{\varrho}{0}\end{array}$ & 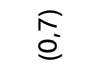 & $\tilde{E}$ \\
\hline & \multirow{2}{*}{$\begin{array}{l}\stackrel{L}{N} \\
\stackrel{2}{5}\end{array}$} & ஃ̊ & $\hat{m}$ & $\stackrel{\sigma}{m}$ & ָூ & 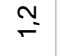 & $\stackrel{0}{\infty}$ & $\stackrel{\sim}{\sim}$ & $\stackrel{\nabla}{m}$ & $\stackrel{L}{\infty}$ & $\stackrel{N}{\sim}$ & $\stackrel{\circ}{+}$ & $\stackrel{g}{=}$ \\
\hline & & & 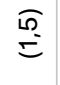 & $\underset{\Xi}{\stackrel{o}{E}}$ & $\begin{array}{l}\bar{m} \\
\stackrel{\text { d }}{0}\end{array}$ & 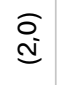 & $\begin{array}{l}\sqrt[1]{0} \\
\stackrel{0}{0}\end{array}$ & $\stackrel{\bar{c}}{\bar{\rho}}$ & 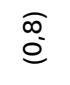 & $\stackrel{\widehat{\widehat{N}}}{=}$ & $\stackrel{\widehat{N}}{=}$ & $\stackrel{\widetilde{E}}{E}$ & 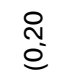 \\
\hline$\frac{\text { z }}{\sum_{0}}$ & & & $\begin{array}{l}0 \\
\infty \\
\infty \\
\infty\end{array}$ & $\underset{\infty}{\bar{\infty}}$ & స્- & $\underset{\infty}{\stackrel{\Delta}{\infty}}$ & 产 & 唉 & $\begin{array}{l}0 \\
\dot{+} \\
\infty\end{array}$ & $\frac{\mathscr{a}}{\infty}$ & $\begin{array}{l}\text { 足 } \\
\text { D. }\end{array}$ & $\begin{array}{l}\infty \\
\infty \\
\infty \\
\infty\end{array}$ & $\stackrel{\overline{0}}{\bar{c}}$ \\
\hline $\begin{array}{l}z \\
\bar{c} \\
\bar{u}\end{array}$ & & & $\stackrel{\infty}{\infty}^{\infty}$ & & \multicolumn{2}{|c|}{ 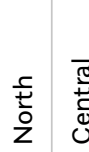 } & 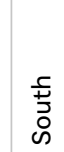 & 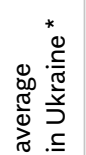 & 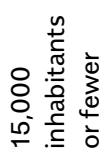 & 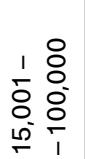 & 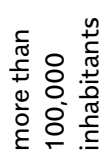 & 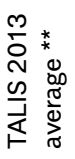 \\
\hline
\end{tabular}


for cities with a population of more than 100,000). The same can be noted in the growing gender disbalance, though the share of women who are younger than 30 constitutes $79 \%$, which is the lowest when one compared to other age groups (the biggest share of $87,3 \%$ is found in the 40-49 age group). Here, we can assume that male teachers dominate in leaving their teaching career early, which leads to further gender disbalance.

There has been some previous research identifying a teacher's age as a determinant for their professional development (Desimone, 2009; de Vries, van de Grift \& Jansen, 2013; Badri, Alnuaimi, Mohaidat et al., 2016). Their results demonstrated that, on average, the extent of teachers' professional development decreased with age. This indicates that, when designing professional development programmes in different regions of Ukraine, this factor should be taken into consideration. Also, there should be a special focus on activities that could prevent male teachers from leaving their teaching career early.

In Ukraine, teachers demonstrate a traditionally high level of formal education which is due to the strict state regulations in this respect. Thus, as the survey demonstrates, the percentage of middle school teachers with Bachelor, specialist or Master's degrees (ISCED levels $5 A$ and 6) in Ukraine is 96,3\% (Table 3), which exceeds the TALIS 2013 average by $5,4 \%$. On the other hand, the share of teachers with a PhD or higher degree is lower compared to the TALIS average (by $0,2 \%$ and $1,4 \%$, respectively). From the regional perspective, there is no significant difference in the levels of teachers' formal education except in the Central and Northern regions where the percentage is somewhat higher (5,7\% and $6 \%$, respectively) (see Table 3 ).

Comparing the levels of formal teacher training in Ukraine with those in the countries participating in TALIS, it is necessary to take into account the differences in the teacher qualification frameworks at different ISCED levels. Although, for instance, the majority of teachers in Flanders, Belgium (85\%) have received formal education to 5B ISCED level, which corresponds to junior specialist in Ukraine, they are qualified teachers, which is sufficient for work at a secondary school. 
Table 3. Teacher Distribution by Highest Level of Formal Education

\begin{tabular}{|c|c|c|c|c|c|c|c|c|}
\hline \multirow{3}{*}{ REGION AND TYPE OF SCHOOL } & \multicolumn{8}{|c|}{ HIGHEST LEVEL OF FORMAL EDUCATION } \\
\hline & \multicolumn{2}{|c|}{$\begin{array}{l}\text { LOWER THAN } \\
\text { JUNIOR } \\
\text { SPECIALIST }\end{array}$} & \multicolumn{2}{|c|}{$\begin{array}{c}\text { JUNIOR } \\
\text { SPECIALIST }\end{array}$} & \multicolumn{2}{|c|}{$\begin{array}{l}\text { BACHELOR } \\
\text { OR MASTER'S }\end{array}$} & \multicolumn{2}{|c|}{$\begin{array}{l}\text { PHD OR DOCTOR } \\
\text { OF SCIENCES }\end{array}$} \\
\hline & $\%$ & SE & $\%$ & SE & $\%$ & SE & $\%$ & SE \\
\hline East & 0,2 & $(0,1)$ & 2,6 & $(0,5)$ & 96,9 & $(0,5)$ & 0,3 & $(0,2)$ \\
\hline West & 0,1 & $(0,1)$ & 3,0 & $(0,6)$ & 96,7 & $(0,6)$ & 0,2 & $(0,2)$ \\
\hline Kyiv & 0,0 & $(0,0)$ & 1,0 & $(0,7)$ & 97,6 & $(1,6)$ & 1,3 & $(1,0)$ \\
\hline North & 0,1 & $(0,1)$ & 1,8 & $(0,6)$ & 98,1 & $(0,6)$ & 0,0 & $(0,0)$ \\
\hline Central & 0,9 & $(0,9)$ & 5,7 & $(1,2)$ & 93,3 & $(0,8)$ & 0,0 & $(0,0)$ \\
\hline South & 0,3 & $(0,3)$ & 6,0 & $(0,8)$ & 93,7 & $(0,8)$ & 0,0 & $(0,0)$ \\
\hline average in Ukraine * & 0,2 & $(0,2)$ & 3,4 & $(0,3)$ & 96,1 & $(0,3)$ & 0,2 & $(0,1)$ \\
\hline middle school & 0,5 & $(0,5)$ & 5,1 & $(1,2)$ & 94,1 & $(1,0)$ & 0,3 & $(0,3)$ \\
\hline secondary school & 0,2 & $(0,1)$ & 2,9 & $(0,3)$ & 96,7 & $(0,3)$ & 0,2 & $(0,1)$ \\
\hline TALIS 2013 average ** & 2,0 & $(0,1)$ & 7,1 & $(0,1)$ & 89,5 & $(0,1)$ & 1,4 & $(0,0)$ \\
\hline
\end{tabular}

* UERA, 2017, *^ OECD, 2014

Table 4 demonstrates the data for how prepared the teachers feel after their formal education. The results are quite close to those provided by teachers from the TALIS 2013 participating countries. With regard to the content of their subject, for example, $92,3 \%$ of Ukrainian teachers feel well or very well prepared (the TALIS 2013 average is $93,2 \%$ ).

In the two other aspects, the percentage of Ukrainian teachers who feel well or very well prepared is higher than the TALIS average with $91,9 \%$ vs $88,9 \%$ in the pedagogy of the subject and $90,9 \%$ vs $88,6 \%$ in classroom practice. It is worth noting that, in comparison with other regions of Ukraine, teachers from Kyiv feel the least well-prepared, which might be attributed to their higher exposure to the challenges of teaching in urban areas and a higher level of self-demand which requires further research. A similar situation is observed in Mexica, Japan and Finland, where at least a quarter of teachers do not feel prepared in all three aspects (OECD, 2014). If viewed from a different 
perspective, this dissatisfaction might be regarded as an internal motivation for professional development and lifelong learning.

Table 4. Preparedness for Teaching after Formal Education

\begin{tabular}{|c|c|c|c|c|c|c|c|c|c|c|c|c|}
\hline \multirow{4}{*}{$\begin{array}{l}\text { REGIONS } \\
\text { AND TYPE } \\
\text { OF SCHOOL }\end{array}$} & \multicolumn{12}{|c|}{ PREPAREDNESS FOR TEACHING } \\
\hline & \multicolumn{4}{|c|}{ CONTENT OF THE SUBJECT } & \multicolumn{4}{|c|}{ PEDAGOGY OF THE SUBJECT } & \multicolumn{4}{|c|}{ CLASSROOM PRACTICE } \\
\hline & \multicolumn{2}{|c|}{$\begin{array}{c}\text { NOT } \\
\text { PREPARED } \\
\text { OR SOMEWHAT } \\
\text { PREPARED }\end{array}$} & \multicolumn{2}{|c|}{$\begin{array}{c}\text { WELL } \\
\text { ORVERYWELL } \\
\text { PREPARED }\end{array}$} & \multicolumn{2}{|c|}{$\begin{array}{c}\text { NOT } \\
\text { PREPARED } \\
\text { OR SOMEWHAT } \\
\text { PREPARED }\end{array}$} & \multicolumn{2}{|c|}{$\begin{array}{c}\text { WELL } \\
\text { ORVERYWELL } \\
\text { PREPARED }\end{array}$} & \multicolumn{2}{|c|}{$\begin{array}{c}\text { NOT } \\
\text { PREPARED } \\
\text { OR SOMEWHAT } \\
\text { PREPARED }\end{array}$} & \multicolumn{2}{|c|}{$\begin{array}{c}\text { WELL } \\
\text { ORVERYWELL } \\
\text { PREPARED }\end{array}$} \\
\hline & $\%$ & SE & $\%$ & SE & $\%$ & SE & $\%$ & SE & $\%$ & SE & $\%$ & SE \\
\hline East & 7,4 & $(1,2)$ & 92,6 & $(1,2)$ & 8,3 & $(1,2)$ & 91,7 & $(1,2)$ & 8,9 & $(1,2)$ & 91,1 & $(1,2)$ \\
\hline West & 7,7 & $(1,2)$ & 92,3 & $(1,2)$ & 7,1 & $(1,2)$ & 92,9 & $(1,2)$ & 8,4 & $(1,2)$ & 91,6 & $(1,2)$ \\
\hline Kyiv & 14,4 & $(3,2)$ & 85,6 & $(3,2)$ & 13,9 & $(3,2)$ & 86,1 & $(3,2)$ & 17,5 & $(3,2)$ & 82,5 & $(3,2)$ \\
\hline North & 6,8 & $(1,2)$ & 93,2 & $(1,2)$ & 6,6 & $(1,2)$ & 93,4 & $(1,2)$ & 7,9 & $(1,2)$ & 92,1 & $(1,2)$ \\
\hline Central & 9,1 & $(2,2)$ & 90,9 & $(2,2)$ & 8,9 & $(2,2)$ & 91,1 & $(2,2)$ & 9,4 & $(2,2)$ & 90,6 & $(2,2)$ \\
\hline South & 4,9 & $(2,2)$ & 95,1 & $(2,2)$ & 9,6 & $(2,2)$ & 90,4 & $(2,2)$ & 9,4 & $(2,2)$ & 90,6 & $(2,2)$ \\
\hline $\begin{array}{l}\text { average } \\
\text { in Ukraine * }\end{array}$ & 7,7 & $(1,2)$ & 92,3 & $(1,2)$ & 8,1 & $(1,2)$ & 91,9 & $(1,2)$ & 9,1 & $(1,2)$ & 90,9 & $(1,2)$ \\
\hline $\begin{array}{l}\text { middle } \\
\text { school }\end{array}$ & 7,1 & $(2,2)$ & 92,9 & $(2,2)$ & 4,3 & $(2,2)$ & 95,7 & $(2,2)$ & 6,4 & $(2,2)$ & 93,6 & $(2,2)$ \\
\hline $\begin{array}{l}\text { secondary } \\
\text { school }\end{array}$ & 7,9 & $(1,2)$ & 92,1 & $(1,2)$ & 9,3 & $(1,2)$ & 90,7 & $(1,2)$ & 10,0 & $(1,2)$ & 90,0 & $(1,2)$ \\
\hline $\begin{array}{l}\text { TALIS } 2013 \\
\text { average ** }\end{array}$ & 6,8 & $(0,2)$ & 93,2 & $(0,2)$ & 11,1 & $(0,2)$ & 88,9 & $(0,2)$ & 11,4 & $(0,2)$ & 88,6 & $(0,2)$ \\
\hline
\end{tabular}

* UERA, 2017, ** OECD, 2014

Ukrainian school profile. The survey evidence describes a typical school as a state or community institution with 345 students and 33 teachers, with 18 students in a class, with 1 assistant staff member for 9 teachers, and 1 school leadership team member for 5 teachers. The school has considerable autonomy in teaching issues, rarely faces issues of vandalism, theft, drugs or alcohol, and enjoys an atmosphere of support, respect and good relationships between teachers and students (see Table 5 and Figure 1). 
Table 5. Quantitative Characteristics of the School

\begin{tabular}{|c|c|c|c|c|c|c|c|c|c|c|c|c|}
\hline & \multicolumn{2}{|c|}{$\begin{array}{c}\text { NUMBER } \\
\text { OF STUDENTS }\end{array}$} & \multicolumn{2}{|c|}{$\begin{array}{c}\text { NUMBER } \\
\text { OF TEACHERS }\end{array}$} & \multicolumn{2}{|c|}{$\begin{array}{c}\text { STUDENT/ } \\
\text { TEACHER } \\
\text { RATIO }\end{array}$} & \multicolumn{2}{|c|}{$\begin{array}{c}\text { TEACHER/ } \\
\text { SUPPORT } \\
\text { STAFF RATIO }\end{array}$} & \multicolumn{2}{|c|}{$\begin{array}{l}\text { TEACHER/ } \\
\text { LEADER- } \\
\text { SHIP TEAM } \\
\text { RATIO }\end{array}$} & \multicolumn{2}{|c|}{$\begin{array}{l}\text { AVERAGE } \\
\text { CLASS SIZE }\end{array}$} \\
\hline & 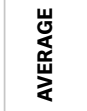 & 㟧 & 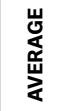 & 岕 & 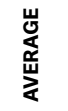 & 㟧 & 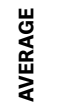 & 岕 & 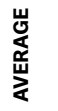 & 岁 & 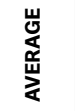 & 㞦 \\
\hline East & 434,6 & $(20,7)$ & 34,6 & $(1,3)$ & 11,8 & $(0,5)$ & 9,5 & $(0,9)$ & 4,0 & $(0,3)$ & 20,6 & $(0,8)$ \\
\hline West & 273,8 & $(16,6)$ & 32,7 & $(0,8)$ & 7,2 & $(0,3)$ & 9,6 & $(0,7)$ & 5,7 & $(0,3)$ & 15,7 & $(0,4)$ \\
\hline Kyiv & 735,1 & $(46,9)$ & 53,5 & $(2,6)$ & 13,4 & $(1,0)$ & 10,4 & $(1,2)$ & 5,4 & $(0,7)$ & 24,3 & $(1,3)$ \\
\hline North & 334,9 & $(26,5)$ & 31,2 & $(1,7)$ & 9,1 & $(0,5)$ & 9,5 & $(1,0)$ & 4,1 & $(0,5)$ & 17,9 & $(0,8)$ \\
\hline Central & 319,1 & $(18,0)$ & 28,4 & $(0,9)$ & 9,1 & $(0,4)$ & 6,3 & $(0,9)$ & 4,6 & $(0,4)$ & 15,9 & $(0,7)$ \\
\hline South & 284,5 & $(22,1)$ & 26,2 & $(0,7)$ & 9,7 & $(0,6)$ & 6,8 & $(1,1)$ & 3,8 & $(0,2)$ & 17,3 & $(1,1)$ \\
\hline $\begin{array}{l}\text { average } \\
\text { in Ukraine * }\end{array}$ & 344,8 & $(8,9)$ & 32,5 & $(0,4)$ & 9,3 & $(0,2)$ & 8,9 & $(0,4)$ & 4,8 & $(0,1)$ & 17,6 & $(0,3)$ \\
\hline $\begin{array}{l}\text { TALIS } 2013 \\
\text { average ** }\end{array}$ & 546,4 & $(4,8)$ & 45,5 & $(0,4)$ & 12,4 & $(0,1)$ & 14,4 & $(0,2)$ & 6,3 & $(0,0)$ & 24,1 & $(0,1)$ \\
\hline
\end{tabular}

The school climate describes the school environment in terms of safety (intimidation or verbal abuse among students, physical injury caused by violence among students, etc.), arriving late at school, absenteeism, cheating, vandalism, use/possession of drugs and/or alcohol, and discrimination (e.g. based on gender, ethnicity, religion, disability, etc.). In addition, the school climate deals with general school culture in terms of the quality of the relationships between the school leadership team, staff, teachers and students.

Figure 1 presents the distribution of teaches at schools who encounter regular cases of negative behaviour (at least once a week). As can be seen, there are no regular cases concerning the use or possession of drugs or alcohol, which goes in line with the TALIS 2013 average $(1,2 \%)$, nor are there cases of theft and vandalism. 
Figure 1. Distribution of teachers at schools encountering regular negative behaviour (at least once a week)

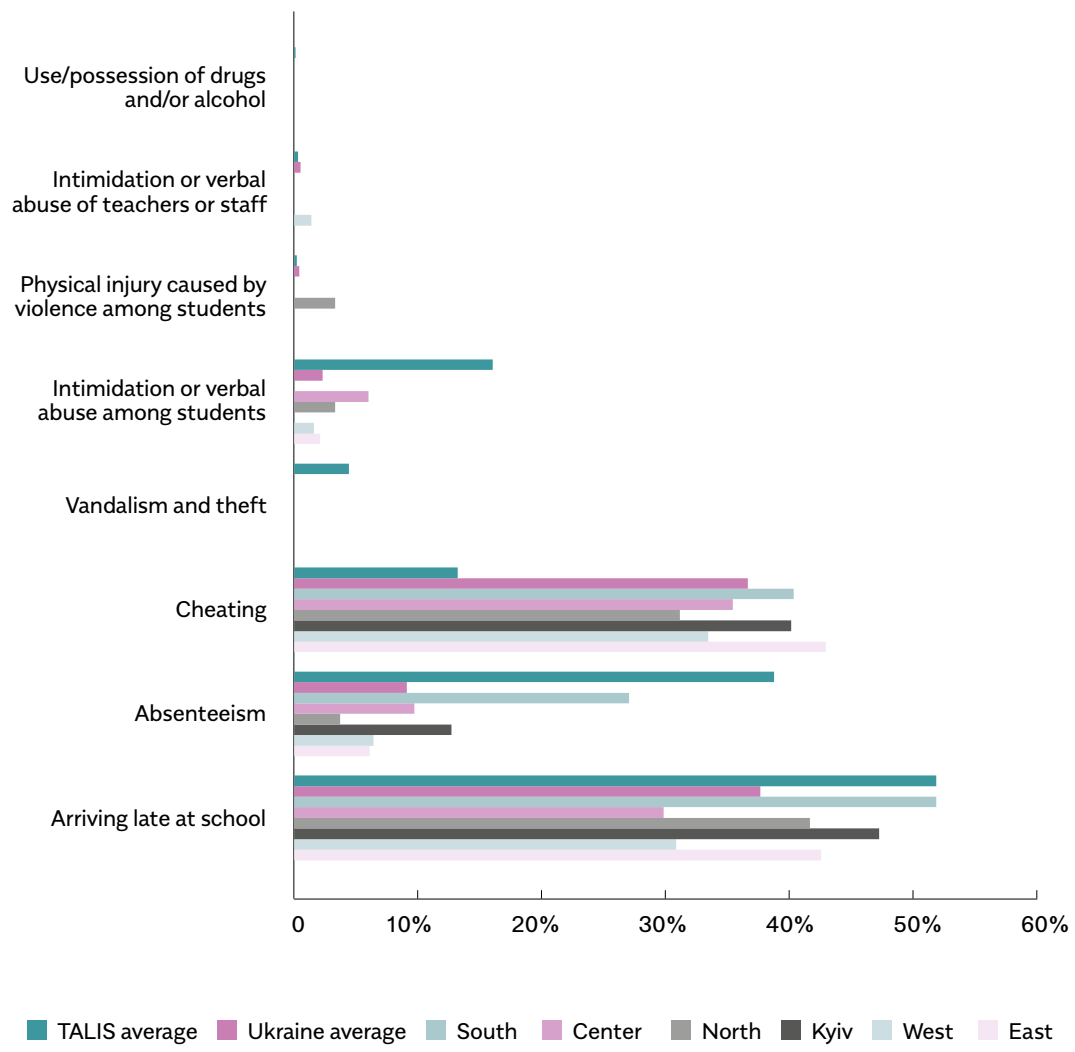

What presents a striking difference is the common practice of cheating at Ukrainian schools that was reported by school principals in all regions, with the most significant presence in the East $(42,9 \%)$, the South $(40,3 \%)$ and the capital $(40,1 \%)$. If compared to the TALIS 2013 average, which is $13,2 \%$, we can conclude that this is a general problem at Ukrainian schools which should be urgently addressed in the New Ukrainian School reform.

There have been some studies examining the association of cheating with aspects of school effectiveness. Researchers have concluded that "reducing the level of cheating is, in turn, an important prerequisite for creating a more equitable allocation of educational opportunities, and 
for preventing individual students from "down-grading" their moral compass during their schooling" (Ramberg \& Modin, 2019, p. 535).

Research has also shown that cheating is not restricted to a certain country or geographical area (Davis et al., 2011; Shariffuddin \& Holmes, 2009). Nevertheless, some studies do focus on international comparisons. One of the few studies that has compared the extent of cheating in exams between nations, based on 7,200 university students from 21 countries, found that the rates and beliefs about cheating differ by country and that countries known to be the least corrupt had the lowest proportions of student cheating (Teixeira \& Rocha, 2010). As Ukraine is the $126^{\text {th }}$ least corrupt nation out of 180 countries according to the 2019 Corruption Perceptions Index (Trading Economics, 2019), we can assume that there might be some interconnection between corruption in Ukraine and cheating as early as at school. As there has not been any research focusing on this connection, it requires further studies. It therefore also requires major attention in the New Ukrainian School reform.

The principals were also asked about their school's needs, and the top problems mentioned by them related to shortages or inadequacies of computers for instruction (Ukraine average $-74,7 \%$; TALIS average $-38,1 \%$ ), instructional materials (e.g. textbooks) $(63,0 \%$ vs $26,3 \%)$, computer software for instruction $(61,2 \%$ vs $37,5 \%)$, and library materials ( $54,7 \%$ vs $29,3 \%$ ) (see Figure 2 ).

A deeper data analysis reveals the schools' needs with a special focus on particular regions. For instance, $85,3 \%$ of the respondents from Western Ukraine work at schools experiencing a shortage or inadequacy of computers for instruction; $73,1 \%$ of teachers from the north of Ukraine report working at schools a with shortage or inadequacy of instructional materials, and $61,4 \%$ also report insufficient internet access. The information coming from school principals should be taken into account in school provisions within the New Ukrainian School reform with a special focus on the regions experiencing the greatest needs. 
Figure 2. Distribution of teachers at schools by need for resources

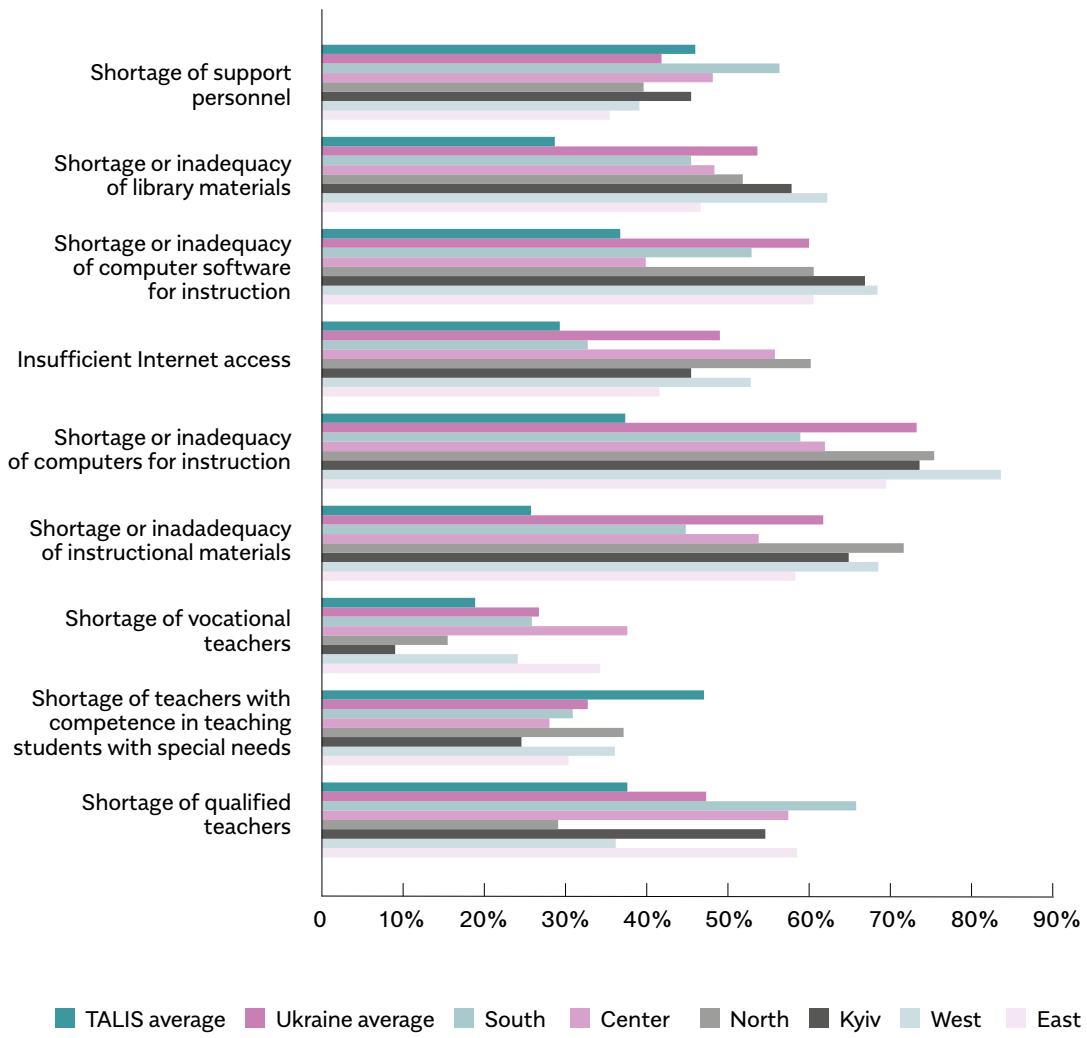

Major differences between data from Ukrainian schools and schools in countries that participated in TALIS 2013. The Ukrainian survey results, if compared to the average obtained from those that participated in TALIS, demonstrate some differences dealing with:

1. a more noticeable gender misbalance with more female teachers;

2. a higher percentage of teachers who are above 50 years old;

3. practically no schools providing an inclusive environment;

4. more support and leadership staff members per teacher, despite there being fewer students, smaller class sizes and fewer students per teacher on average;

5. a greater shortage of qualified teachers; 
6. a shortage of learning materials, computers and software, as well as a lack of internet access;

7. problems with students cheating.

\section{Teachers' professional development impact} as teachers see it

The favourable situation with class sizes and support staff, on the one hand, and the existing problems with teaching and learning, on the other, bring about the question of in-service teacher training and professional development, which is to be in the focus of the Reform.

Table 6. Teachers' professional development support

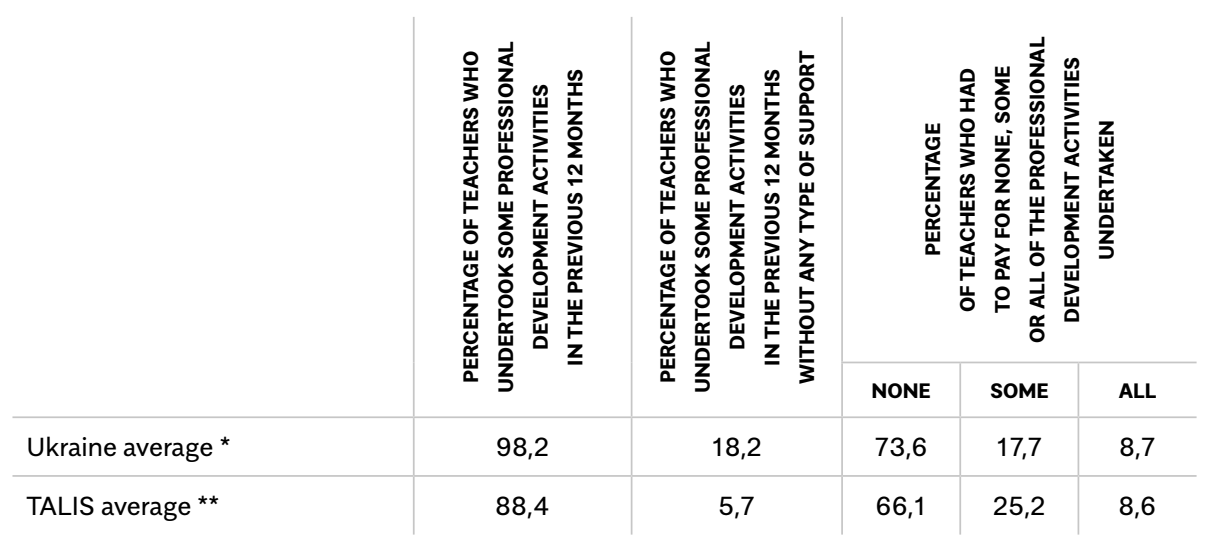

* UERA, 2017, ** OECD, 2014

Data collected during the survey of teachers and school principals indicate that $98.2 \%$ of teachers in Ukraine during the 12 months prior to the survey participated in at least one form of professional development activity. This is almost $10 \%$ higher than the average for TALIS 2013, which proves that much more attention is paid to teachers' professional development in Ukraine (see Table 7).

In Ukraine, the percentage of teachers who report that they have paid for professional development programmes $(8,7 \%)$ is nearly the same as the TALIS average $(8,6 \%)$. The data provided by TALIS 2013 give clear evidence that the percentage of teachers actively participating in professional development programmes is higher 
in the countries providing support to the teachers, which is quite logical. The programmes provided by universities and colleges aimed at giving teachers higher qualification levels usually involve more resources and are therefore fully or partially paid for. In Ukraine, this situation is quite common, as secondary and higher educational establishments receive financing from different sources.

The present research sought information about the types of professional development programmes most often offered to and taken by Ukrainian teachers (see Figure 3).

Figure 3. Types of professional development programmes most often offered to and taken by Ukrainian teachers

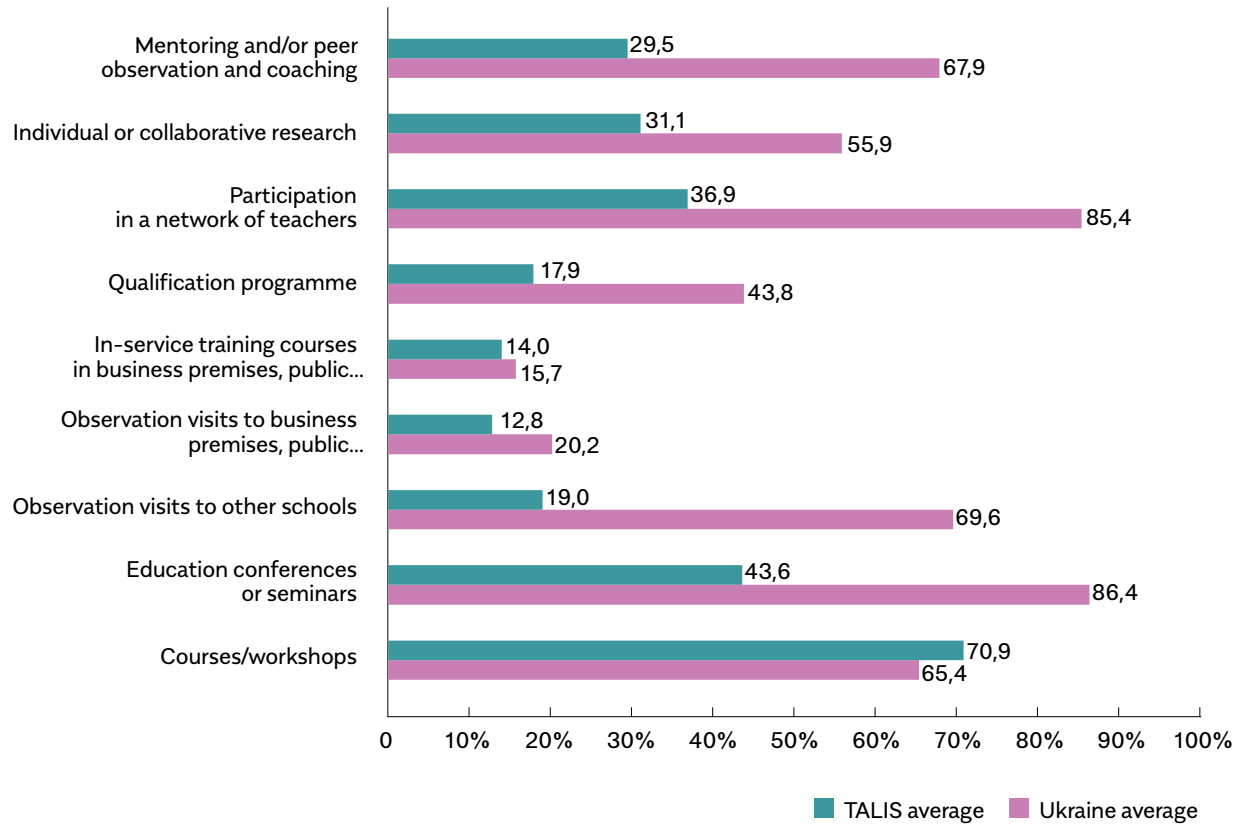

With $86,4 \%$ of teachers reporting their participation in educational conferences and seminars, Ukraine rates very high compared to TALIS countries, where the average is $43,6 \%$. The highest percentage is demonstrated by Croatia (79\%), while there are some countries where the percentage is less than $25 \%$. Rather than be too optimistic, we instead assume that there is a different understanding of what 
an educational conference/seminar is in different countries. In Ukraine, those surveyed might mean any gathering where educational issues are discussed that do not imply either the prior preparation or a presentation of the research carried out by the teachers.

Another common practice in Ukrainian teachers' professional development is their participation in specifically formed networks of teachers $(85,4 \%)$. The percentage is much higher than the TALIS average, which is $36,9 \%$. Such a gap may mean a different understanding of the professional teachers' networks and different degrees of formality in different countries. In Ukraine, teachers are members of so-called methodological unions, which are formal structures that aim at sharing the best educational practices.

As reported by the teachers, mentoring and/or peer observation and coaching, as part of a formal school arrangement, are practised by $67,9 \%$ of Ukrainian teachers, which is high compared to the TALIS average of $29,5 \%$. As mentioned above, less than a quarter of Ukrainian teachers work as mentors, which may mean that such a high percentage is demonstrated due to active peer observation at Ukrainian schools. This is proved by the fact that $69,6 \%$ of Ukrainian teachers report participating in observation visits to other schools.

On the one hand, $55,9 \%$ of Ukrainian teachers claim that they participate in individual or collaborative research on a topic of professional interest and $43,8 \%$ are taking a qualification programme (e.g. a degree programme); on the other hand, Ukraine demonstrates a lower percentage of teachers who have $\mathrm{PhD}$ or higher degrees than the TALIS average.

Another aspect that requires further research is the concept of school-community partnerships for creating opportunities for fostering teacher leaders through their professional development. What the research clearly shows is that there is no real partnership between schools and businesses, public organisations, and non-governmental organisations. The evidence can reinforce this argument, as not many Ukrainian teachers participate in observation visits to their premises $(20,2 \%)$ or in-service training courses organised by business, public organisations, or non-governmental organisations.

Almost all school principals reported that primary vocational socialisation programmes are available in their schools. However, on average, no more than two-thirds of teachers in Ukraine report that 
they participated in such a programme during their first employment as a teacher. There is a similar situation in many other countries. This can be interpreted differently: either teachers are not fully utilising the opportunities available, or their first employment took place at a time when there was no such opportunity. There is a similar situation with mentoring programmes. According to the principals' answers, only $10,8 \%$ of Ukrainian teachers work in schools where there are currently no mentoring programmes, but no more than a quarter of teachers said they took part in them (Shchudlo, Zabolotna \& Lisova, 2018).

In the questionnaire, the teachers were asked about the positive impacts of various aspects of their professional development activities (see Figure 4).

Figure 4. Positive impacts of teachers' professional development activities

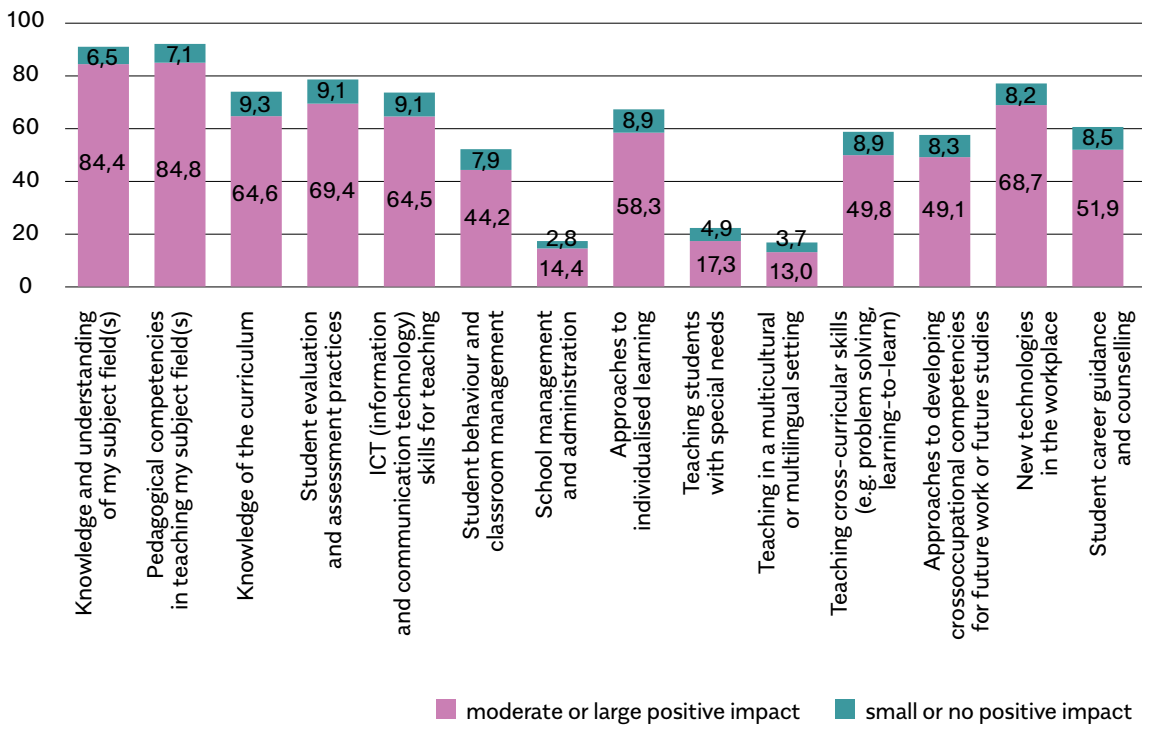

The Ukrainian teachers reported different levels of impact of their professional development activities, varying from 16,7\% (Teaching in a multicultural or multilingual setting) to $92,0 \%$ (Pedagogical competencies in teaching their subject field(s)) (see Figure 4). More than $75 \%$ of respondents confirmed the positive impact 
of the following aspects: knowledge and understanding of their subject field(s) $(90,9 \%)$; student evaluation and assessment practices $(78,5 \%)$; and new technologies in the workplace $(76,9 \%)$. In all these aspects, a higher percentage of Ukrainian teachers gave a positive response than the TALIS 2013 average. Nevertheless, the percentages of Ukrainian teachers who reported the positive impact of school management and administration $(17,2 \%)$, teaching in multicultural and/or multilingual settings $(13,0 \%)$ or teaching students with special needs $(22,2 \%)$ on their professional development are considerably lower than the respective TALIS 2013 averages.

The item dealing with the teachers' underestimation of the role of school management and administration skills in their professional development leads to the assumption that it may be directly related to the low level of school autonomy, which should be focused on by the Reform. The little importance attached by Ukrainian teachers to dealing with students with special needs can be explained by the lack of an inclusive learning environment reported by the majority of the respondents. The lack of interest in teaching in multicultural and/or multilingual settings does not mean that Ukrainian classrooms are homogeneous in terms of nationality or language. On the contrary, the problem came to the surface after the adoption of the Language Article of the Ukrainian Law on Education, which encountered great opposition from national minorities and was sent to the Venice Commission (Shchudlo, Zabolotna \& Medina, 2019). These positions bring about an understanding of the fact that reforms in in-service teacher professional development can and should be simultaneous with the New Ukrainian School reform. On the one hand, without teachers who are competent in dealing with issues of school autonomy, teaching students with special educational needs or teaching in multicultural and multilingual settings, a school can never expect to become an autonomous and inclusive institution that respects human rights. On the other hand, if the school environment does not require these skills from teachers, they might be seen as not attaching any importance to such topics in their professional development programmes. 


\section{Teachers on their professional development: brief evidence for policymakers}

The main issues to consider in the Reform can be listed as follows: initial socialisation programmes; mentoring programmes; partnership with the labour market and a focus on students' practical skills; a focus on students with special needs and better diagnostics; a focus on multicultural school environments; multiple opportunities for teachers' professional development provided by different competing institutions; and schools' autonomy.

The New Ukrainian School reform in action: what is new in teachers' professional development?

The present research gives some food for thought concerning the new practices of Ukrainian schools and Ukrainian teachers who are competent enough to meet the new challenges. First of all, it has demonstrated that, in designing professional development programmes in different regions of Ukraine, their regional peculiarities should be taken into consideration as there are noticeable differences between the schools' provisions and teachers' characteristics and needs. In order to achieve a gender balance or at least narrow the gender gap, there should be a special focus on activities that could prevent male teachers from leaving their teaching career early. In Ukrainian schools, there is also a serious problem with cheating that has never been properly addressed, although it could go further than the educational sphere as there might be some interconnection between corruption in Ukraine and cheating at school. These and other issues demonstrating apparent discrepancies in the data require additional research, which is vital for evidence-based educational policy.

The All-Ukrainian Monitoring survey was commissioned to the UERA by the Ministry of Education and Science of Ukraine as a baseline study for the reform, and the research team consequently published their report (Shchudlo et al., 2018), produced recommendations (Shchudlo et al., 2018) and made all the survey data available (UERA, 2017).

Two years on, we have analysed the key reform documents regulating the transformations in teachers' professional development, i.e. the Concept (Ministry of Education, 2018a), the Roadmap (Ministry of Education, 2018b) and the newly adopted law "On Complete General Secondary Education" (Law of Ukraine, 2020) (see Table 8). 
Table 7. Policy Impact of Research on the Quality of In-Service Teacher Education and Professional Development

\begin{tabular}{|c|c|c|c|}
\hline RESEARCH IMPLICATIONS & $\begin{array}{c}\text { ON APPROVING } \\
\text { THE CONCEPT } \\
\text { OF THE DEVELOPMENT } \\
\text { OF TEACHER } \\
\text { EDUCATION }\end{array}$ & $\begin{array}{l}\text { ON THE ROADMAP } \\
\text { FOR IMPLEMENTING } \\
\text { THE CONCEPT } \\
\text { OF THE DEVELOPMENT } \\
\text { OF TEACHER } \\
\text { EDUCATION }\end{array}$ & $\begin{array}{c}\text { "ON COMPLETE } \\
\text { GENERAL SECONDARY } \\
\text { EDUCATION" LAW } \\
(\mathbf{2 0 2 0 )}\end{array}$ \\
\hline $\begin{array}{r}\text { Initial socialisation } \\
\text { programmes }\end{array}$ & $\checkmark$ & $\checkmark$ & $\checkmark$ \\
\hline Mentoring programmes & $\checkmark$ & $\checkmark$ & $\checkmark$ \\
\hline Educational integrity & - & - & - \\
\hline $\begin{array}{r}\text { Focus on students' } \\
\text { practical skills }\end{array}$ & - & - & - \\
\hline $\begin{array}{l}\text { Partnership with } \\
\text { the labour market }\end{array}$ & - & - & - \\
\hline $\begin{array}{r}\text { Catering for students' } \\
\text { special needs } \\
\text { and better diagnostics }\end{array}$ & $\checkmark$ & $\checkmark$ & $\checkmark$ \\
\hline $\begin{array}{r}\text { Focus on the multicultural } \\
\text { school environment }\end{array}$ & - & - & - \\
\hline $\begin{array}{r}\text { Multiple opportunities } \\
\text { for teachers' professional } \\
\text { development provided } \\
\text { by different competing } \\
\text { institutions }\end{array}$ & $\checkmark$ & - & $\checkmark$ \\
\hline $\begin{array}{r}\text { School autonomy and } \\
\text { teacher leadership }\end{array}$ & - & - & $\checkmark$ \\
\hline
\end{tabular}

Initial socialisation programmes

At the conceptual level, initial socialisation programmes are going to be addressed through an internship, which is an interim stage between pre-service and in-service teacher education. The Concept states that "A newly qualified teacher should take a year as an intern-teacher. During the year they should be consulted by an experienced mentor of the same (or close) subject from the same school. The internship programme is designed by both the intern and the mentor and includes different forms of professional development" (Ministry of Education and Science, 2018a, p. 16). In the Roadmap 
(Ministry of Education and Science, 2018b, p. 4), it was recommended that the pedagogical internship should be introduced for the teachers' initial professional socialisation in the law "On Complete General Secondary Education". The law was adopted in 2020, and according to this law, "The first year of work for a newly-qualified teacher will be a period of pedagogical internship. Within it, he/she will have a mentor who will be obliged to consult the young teacher and help $\mathrm{him} / \mathrm{her}$ in becoming a successful teacher. The mentor will get a $20 \%$ bonus" (Law of Ukraine, 2020).

\section{Mentoring programmes}

According to the Concept, mentoring programmes are becoming a part of teachers' professional development. They involve the best teachers sharing their experiences in the performance of professional tasks. It is considered a priority in the professional development of newly-qualified intern-teachers and ends with their attestation based on a portfolio containing lesson plans, scenarios, and digital educational resources (videos, podcasts, e-books, sites, blogs, tests, etc.) (Ministry of Education and Science, 2018a, p. 18).

The register of teachers who can be mentors is to be made by the State Service of the Quality of Education, based on professional achievements and the document received after passing the teacher certification. Mentors must be motivated by getting bonus payments from the budget (or other funding sources), participating in systematic training and experience exchanges, and providing their expertise in the evaluation of syllabi, educational standards, projects, textbooks, digital resources, etc. The Roadmap contains some practical steps on creating the register of teacher-mentors, though the responsibilities were shifted to the Institute of Educational Content Modernisation and the National Academy of Educational Sciences. Nevertheless, neither of them has published the list yet. In the new law, there are requirements for the teacher-mentor, who "must have at least 5 years' experience in teaching the same or close subject" (Law of Ukraine, 2020, Article 23), and there is information that "based on the principal's decision a teacher-mentor may get a bonus of no more than $20 \%$ of his/her salary which is paid from the school's general payment fund" (ibidem). 
Catering for students with special educational needs

The Concept emphasizes the necessity to train teachers to cater for students' special educational needs (Ministry of Education and Science, 2018a, p. 5) and states that it should be "a part of traditional and other professional development programmes, as well as be included in pre-service teacher or teaching assistant training programmes as preparing to work at special schools and schools with an inclusive educational environment" (ibidem, p. 10).

In the new law, Article 19 is devoted to the education of children with special educational needs and states that "The State and local authorities will create conditions for equal rights and opportunities for students with special educational needs that they might get an education at all levels with the special attention to their individual needs, possibilities, and interests" (Law of Ukraine, 2020). For this, the law regulates the necessity to train specialists, to use the educational forms and methods catering for the individuals' special needs, and to create access and an adaptive physical environment as well as individual development programmes. Article 20, which focuses on inclusive education, emphasizes that "inclusive education is grounded on non-discrimination, taking into account multiple individual needs, [and the] effective involvement of all parties in the educational process" (Law of Ukraine, 2020). It guarantees the right of a person with special educational needs to study in classrooms with an inclusive educational environment and introduces the possibility of getting support from specially trained teaching assistants.

Multiple opportunities for teachers' professional development provided by different competing institutions

Before 2018, the only establishments involved in teacher professional development were regional institutes for teachers' in-service education. Without any competition, the programmes offered by them often tended to be outdated and theory-oriented. However, the Concept introduced the possibility for different institutions to offer alternative licensed programmes of professional development for teachers, which has already added some competitiveness that has resulted in higher quality programmes with the quality assurance system in the process of their licensing and further monitoring. Moreover, the Concept announced the introduction of the so-called "teacher 
professional development voucher" that is viewed as "a guarantee for the teacher's freedom to choose the kind, form and institution for his/her professional development" (Ministry of Education and Science, 2018a).

In the Roadmap, however, no special attention is attached to alternative professional development programmes. The same can be said about the new law, which guarantees teachers the possibility to take professional development courses at regional institutes but only adds a line about the right to choose other options (Law of Ukraine, 2020, Article 51). Nor does it contain information about teacher professional development vouchers.

School autonomy and teacher leadership

Although school autonomy was mentioned in the Concept, there was no information about how teachers should be trained to gain leadership competencies and school management skills. It was only the school's leadership team that was to undergo special training. Article 59 of the new law is devoted to schools' financial autonomy and states that "the school is responsible for the allocation of funds from the money received from the State's budget" (Law of Ukraine, 2020, Article 59). With the reported national money shortage, schools have been given the responsibility to distribute money between training the school's staff; paying salaries, bonuses and other motivational payments; constructing and maintaining the school's buildings; teachers' professional development courses, etc. The benefits of this kind of school autonomy seem somewhat vague if we take into account the fact that Ukrainian schools have been experiencing money shortages even for paying the teachers' regular salaries, which was admitted by President Volodymyr Zelensky (Ukrinform, 2019), to say nothing of covering the other aspects of the budget.

\section{Conclusions}

The current New Ukrainian School reform addresses the key problem areas identified by teachers and school principals in the All-Ukrainian Monitoring Survey of Secondary School Teachers and Principals. The main reform documents take into account the importance of initial socialisation programmes for newly qualified teachers with mentors' support, the vital necessity of catering for students' special educational 
needs, as well as creating multiple opportunities for teachers' professional development to be provided by different competing institutions. Nevertheless, the issues of real school autonomy and teacher leadership still remain underestimated.

Moreover, in the reform documents, some other vital problems are still neglected. These concern the ethical issues that are connected with the common practice of students' cheating, which cannot be solved by accepting an ethical code. The problem goes much deeper and cannot be solved by any formal document. To some extent, it can be explained by the considerable gap between the theoretical education prevailing at Ukrainian schools and the real needs of the labour market. Another concern is how the practice of introducing the legally written issues will be introduced in schools and whether the teachers will actively participate in the process by applying their leadership skills and creativity as the key agents of change.

Probably the most important thing emerging from this research is the finding that it is possible to make productive use of the inconsistencies and doubts arising from comparing national data with data coming from international research and use them for developing common understandings and goals for teachers' professional development.

\section{References}

$\rightarrow$ Badri, M., Alnuaimi, A., Mohaidat, J., Yang, G. and Al Rashedi, A. (2016). Perception of Teachers' Professional Development Needs, Impacts, and Barriers: The Abu Dhabi Case. Sage Open, DOI: 10.1177/2158244016662901

$\rightarrow$ Davis, S.F., Drinan, P.F. and Gallant, T.B. (2011). Cheating in school: What we know and what we can do. West Sussex: Wiley.

$\rightarrow$ De Vries, S., Grift, W. van de and Jansen, E. (2013). Teachers' beliefs and continuing professional development, Journal of Educational Administration, 51, 213-231.

$\rightarrow$ Desimone, L.M. (2009). Improving impact studies of teachers' professional development: Toward better conceptualisations and measures, Educational Researcher, 38, 181-199.

$\rightarrow$ Kahkonen, S. (2018). Why Ukraine's Education System is Not Sustainable, World Bank, www.worldbank.org/en/news/opinion/2018/09/12/why-ukraineseducation-system-is-not-sustainable 
$\rightarrow$ Law of Ukraine (2020). On Complete General Secondary Education [Закон України "Про повну загальну середню освіту"], https://zakon.rada.gov.ua/ laws/show/463-20

$\rightarrow$ Ministry of Education and Science of Ukraine (2018a). On Approving the Concept of the Development of Teacher Education [Міністерство освіти і науки України. Про затвердження концепції розвитку педагогічної освіти], https://mon.gov. ua/ua/npa/pro-zatverdzhennya-koncepciyi-rozvitku-pedagogichnoyi-osviti

$\rightarrow$ Ministry of Education and Science of Ukraine (2018b). On the Roadmap for Implementing the Concept of the Development of Teacher Education [Про план впровадження концепції розвитку педагогічної освіти], https://mon.gov. ua/ua/npa/pro-zatverdzhennya-planu-vprovadzhennya-koncepciyi-rozvitkupedagogichnoyi-osviti

$\rightarrow$ New Ukrainian School: Toolkit for teachers [Нова українська школа: порадник для вчителя] (2017). Kyiv: Pleyady Publishing House [TOВ "Видавничий дім 'Плеяди'"].

$\rightarrow$ New Ukrainian School (n.d.), https://mon.gov.ua/ua/tag/nova-ukrainska-shkola

$\rightarrow$ OECD (2012a). Better Skills, Better Jobs, Better Lives: A Strategic Approach to Skills Policies. Paris: Organisation for Economic Cooperation and Development Publishing.

$\rightarrow$ OECD (2012b). Enhancing Skills through Public Private Partnerships in Education in Ukraine: The Case of Agribusiness. Paris: Organisation for Economic Cooperation and Development Publishing.

$\rightarrow$ OECD (2014). TALIS 2013 Results: An International Perspective on Teaching and Learning. Paris: Organisation for Economic Cooperation and Development Publishing.

$\rightarrow$ Ramberg, J. and Modin, B. (2019). School effectiveness and student cheating: Do students' grades and moral standards matter for this relationship?, Social Psychology of Education, 22, 517-538.

$\rightarrow$ Shariffuddin, S.A. and Holmes, R.J. (2009). Cheating in examinations: a study of academic dishonesty in a Malaysian college, Asian Journal of University Education, 5(2), 99-124.

$\rightarrow$ Shchudlo, S., Zabolotna, O. and Lisova, T. (2018). Ukrainian Teachers and Learning Environment. The results of All-Ukrainian Monitoring Survey of Secondary School Teachers and Principals (by the TALIS methodology) [Українські вчителі та навчальне середовище. Результати Всеукраїнського моніторингового опитування викладання та навчання серед директорів і вчителів загальноосвітніх навчальних закладів (за методологією TALIS)], 
Дрогобич: УАДО; ТзОВ "Трек-ЛТД", http://edreform.mon.gov.ua/obj1. asp?p=oid15913sid0aid80

$\rightarrow$ Shchudlo, S., Zabolotna, O. and Lisova, T. (2018a). Ukrainian Teachers and Learning Environment. The results of All-Ukrainian Monitoring Survey of Secondary School Teachers and Principals (by the TALIS methodology). Executive Summary. Drohobych: UERA www.ussf.kiev.ua/images/ news/2018.02.09/Ukrainian\%20Teachers\%20and\%20the\%20Learning $\% 20$ Environment.\%20Executive\%20Summary.pdf

$\rightarrow$ Shchudlo, S., Zabolotna, O. and Medina, T. (2019). Social and Cultural Discourse of the Language of Instruction of National Minorities in Chernivtsi Region [Соціокультурний дискурс щодо мови навчання національних меншин у Чернівецькій області], Дрогобич: УАДО, ТзОВ "Трек ЛТД", 205 http://sau.in.ua/magazine/socziokulturnyj-dyskurs-shhodo-movy-navchannyanaczionalnyh-menshyn-u-cherniveczkij-oblasti/

$\rightarrow$ Trading Economics (2019). Ukraine Corruption Rank 1998-2019 Data, https://tradingeconomics.com/ukraine/corruption-rank

$\rightarrow$ UERA (2017). Database of All-Ukrainian Monitoring Survey of Teaching and Learning (by TALIS methodology). PRINCIPALS\&TEACHERS_DATA, https://drive.google.com/open?id=1A4ktH72IJkJL6AIJRPgQED1EDKtgiTxv

$\rightarrow$ Ukrinform (2020). Salary debts will be paid to teachers and doctors by the end of the year - President [Зарплатні борги учителям і лікарям погасять до кінця року - Президент], www.ukrinform.ua/rubric-society/2829459zarplatni-borgi-ucitelam-i-likaram-pogasat-do-kinca-roku-prezident.html 


\section{Teaching Quality Assurance \\ Ukrainian and Australian Perspectives}

DOI: $10.47050 / 66515321.130-149$

Nataliya Avshenyuk, Nataliya Seminikhyna

A high level of quality teacher education determines a successful society's development in the era of the knowledge economy. In this regard, most developed countries are placing great emphasis on the related issues. The main objective of the present research is to explore and compare ways of improving quality teaching in Ukraine and Australia by considering annual state reviews and policy directions that have had an impact on quality teacher education in both countries. The findings revealed by the chapter might have wide applicability in enhancing quality teaching in Ukraine as it enters the global education environment.

\section{Keywords: \\ teacher training \\ teacher education reforms \\ quality assurance}




\section{Introduction}

The main objective of our research is to explore and compare ways of improving quality teaching in Ukraine and Australia by considering annual state reviews and policy direction frameworks, the legislative bases that have had an impact on quality teacher education in both countries.

Globalisation has led to greater awareness of the value of specialised knowledge and advanced skills around the world. As a result, the public in many countries has come to demand higher quality at all levels of the education system. The issue of the quality of teacher education has thus been raised. Education professionals express concern over a perceived lack of accountability among teacher education institutions for the actual teaching ability of their graduates. A high quality of provision is one of the core goals of the current reforms in European higher education, and this has led to an increasing demand for quality assurance. The work carried out in this regard at the European level resulted in the European Standards and Guidelines for Quality Assurance in the European Higher Education Area, which were adopted in 2005 (and readopted in 2015). This followed a proposal prepared by the European Association for Quality Assurance in Higher Education (ENQA) in co-operation with the European Students' Union (ESU). The European Association of Institutions in Higher Education (EURASHE) and the European University Association (EUA) are considered as cornerstones for higher education quality assurance due to their implementation of the internal quality assurance system (Loukkola \& Zhang, 2010).

As is well-known, the internal quality assurance system involves the general quality assurance policies, strategies and procedures for the educational activity and quality of higher education at universities. In this regard, most developed countries are placing great emphasis on the related issues. Due to the recent changes in society, from a short-term perspective, professionals who are able to learn throughout life, think critically, set and achieve goals, work in teams, communicate in a multicultural environment and possess other contemporary skills will be the most successful in the labour market.

The findings revealed by the paper might have wide applicability in enhancing quality teaching in Ukraine as it enters the global education environment. 


\section{Australian Approaches to Teacher Training Quality Assurance}

The present study shows that quality teaching in Australia, just like in Ukraine, has been a much-debated national topic for a very long time - a focus of attention for politicians, policymakers, media and the community. According to data presented by the Organisation for Economic Co-operation and Development (OECD) in 2013, 90\% of teachers are satisfied with their work, but only $39 \%$ say that the teaching profession is of public importance. In addition, $47.8 \%$ of Australian teachers have low qualifications for working with students with special needs; $60 \%$ of teachers work in schools where students are late for classes and there is a high level of absenteeism among teachers; $10 \%$ of teachers face bullying from students; and $28.2 \%$ of schools report shortages or inconsistencies in computer equipment, book stock, and Internet access (OECD, 2014).

From this perspective, these data are evidence that educational reform in Australia represents a long-term focus of the government. National policy documents have emphasised quality education for all and improved teacher quality for over 30 years. The gaps in achievement among various groups of learners represent a problem for an education system seeking to achieve national quality benchmarks, standardised levels of teacher quality and common outcomes for all Australian learners. The national response for addressing this situation includes a set of initiatives to standardise teacher quality (Bahr \& Mellor, 2016).

High-achieving countries have stable and effective policies and mechanisms in place to assure the quality of initial teacher education entrants, programmes and programme graduates. These policies and mechanisms determine who gains entry to teacher education, which providers are allowed to train them and who gains full entry to the profession. These policies concern recruitment for entry to teacher education, accreditation of teacher education institutions, and transition and entry to the teaching profession (Ingvarson, Reid, Buckley, Kleinhenz, Masters \& Rowley, 2014).

High-achieving countries have stable policies in place to assure the quality of entrants to teacher education, such as making teaching an attractive career option for high academic achievers, matching supply and demand, and setting high standards for admission to teacher education programmes: 
1. Accreditation of teacher education institutions:

High-achieving countries have regulated teacher education systems in place and rigorous procedures for the accreditation of teacher education programmes.

2. Transition and entry to the teaching profession:

High-achieving countries require and support a period of mentored induction coupled with rigorous assessments of readiness for full entry to the profession (Ingvarson, Reid, Buckley, Kleinhenz, Masters \& Rowley, 2014).

In this regard, the establishment of the following institutions of teacher quality assurance represents four major investments in teacher quality to improve educational outcomes for all Australian learners. This emphasis on teacher quality includes a focus on pre-service teachers and includes a cluster of quality initiatives:

$\rightarrow$ Tertiary Education Quality and Standards Agency (TEQSA) - higher education provisions;

$\rightarrow$ Australian Institute for Teaching and School Leadership (AITSL) - teacher standards;

$\rightarrow$ Australian Curriculum, Assessment and Reporting Authority (ACARA);

$\rightarrow$ Education Services Australia (ESA) - in charge of professional teacher training.

The TEQSA itself is one of four new regulatory and quality arrangements planned for post-secondary education within Australia. These comprise:

$\rightarrow$ Tertiary Education Quality and Standards Agency (TEQSA),

$\rightarrow$ National Register of Higher Education Providers,

$\rightarrow$ Higher Education Standards Framework,

$\rightarrow$ My University website (O'Meara, 2011).

The TEQSA serves as an independent regulative body for post-secondary education to ensure that students receive a high-quality education at any higher education provider. Regulation activities include provider registration, institutional evaluations and quality assurance of international education. The Tertiary Education Quality and Standards Agency Act 2011 (TEQSA Act) established the TEQSA as an agency. 
The TEQSA registers institutions and accredits courses, using the Higher Education Standards Framework (HESF) as a benchmark. The HESF consists of five different standards: provider standards, qualification standards, teaching and learning standards, research standards and information standards. The objectives of the TEQSA are to provide national consistency in the regulation of higher education; to regulate higher education using a standards-based quality framework and principles relating to regulatory necessity, risk and proportionality; and to protect and enhance Australia's reputation for international competitiveness as well as excellence, diversity and innovation in higher education. In addition, it aims to encourage and promote a higher education system that is necessary to meet Australia's social and economic needs for a highly educated and skilled population. Finally, it seeks to protect students undertaking, or proposing to undertake, higher education by requiring the provision of quality higher education and ensuring that students have access to information relating to higher education in Australia (TEQSA, 2011).

To make higher education more available and more attractive, distance education has been heavily promoted. Distance education has been a feature of higher education in Australia for at least 80 years. The geographic size of Australia and the relatively small number of large population centres in previous years meant that, for many, distance education provided the only opportunity to gain a university degree. Traditionally, distance education was text-based, but Australia was an early adopter of new education technologies, and while text-based learning is still important, universities now use a range of delivery modes, including online courses, e-mail, telephone, video-conferencing, web TV, radio and television. Many courses are multi-modal in terms of delivery, and with increasing numbers of metropolitan students, the term "flexible delivery" is now more commonly used than distance education. In 2000, there were a total of 95,360 students studying at Australian universities through distance education arrangements, and 85,284 of them resided in Australia. Distance education students represent just under $14 \%$ of the total university enrolment in Australia. With the growth of online services, on-campus and distance education students can enrol in courses, attend lectures, receive tutorial materials, gain access to libraries and other university services, and submit assignments online. Students studying via distance education 
at Australian universities receive the same degrees as their on-campus counterparts, and degrees obtained following study in this mode receive the same level of recognition as full-time courses from employers and other universities as the basis of admission to further study. Open Learning Australia (OLA) provides alternative higher education and vocational education and training courses. It is owned and operated by an association of universities. One acts as a mediator between students and institutions provider in Australia. It arranges bridging units, vocational education and training/TAFE units, undergraduate units and postgraduate units leading to formal qualifications in the Australian Qualifications Framework.

The Register of Higher Education is officially referred to as the Australian Qualifications Framework (AQF) Register of Recognised Education Institutions and Authorised Accreditation Authorities in Australia (AQF, 2013). This serves as a register of every AQF qualification and the providers accredited to deliver and issue Australian qualifications. The Student Experience Survey (SES), originally known as the University Experience Survey (UES), was created to provide a national framework for collecting feedback on the higher education student experience. The SES focuses on aspects of the student experience that are measurable, linked with learning and development outcomes, and potentially influenced by institutions. The Quality Indicators for Learning and Teaching (QILT) are a suite of government-endorsed surveys for higher education, which cover the student life cycle from commencement to employment. The QILT make available robust, nationally consistent performance data for Australian higher education, helping to drive quality improvement (QILT, 2018).

A consortium commissioned by the Department of Education, Employment and Workplace Relations (DEEWR) designed the UES in 2011. The UES consisted of a survey instrument, the University Experience Questionnaire (UEQ), and a survey methodology (Radloff, Coates, James \& Krause, 2011). The instrument and survey approach was refined in 2012 by the same consortium. From 2013 and 2014, respectively, Graduate Careers Australia and the Social Research Centre assumed responsibility for continuous improvement in the administration of the UES (UEQ, 2019).

In mid-2014, the QILT federal budget measure was introduced. Since 2015, the Social Research Centre has administered the SES 
on behalf of the Australian Department of Education and Training as part of the QILT initiative. QILT include the deployment of a survey research programme aimed at collecting student feedback from current students (the SES), graduates (the Graduate Outcomes Survey) and employers of graduates (the Employer Satisfaction Survey) (QILT, 2018).

In 2015, the UES was renamed as the SES to be inclusive of students enrolled at non-university higher education institutions (NUHEIs) that offered undergraduate-level degree courses. In 2017, the collection was expanded to include postgraduate coursework students for the first time (SES, 2018).

The Australian Institute for Teaching and School Leadership aims to promote a five-point strategy to raise the quality of teaching in all schools for the benefit of every student. This strategy includes national policies for teacher recruitment and preparation.

The Institute has introduced a new set of professional standards for teachers to underpin national reforms. These reforms include the accreditation of pre-service teacher education courses, as well as the accreditation of graduate-level teachers based on a set of effective educator competencies. The National Standards identify what is expected of teachers under three domains of teaching, namely professional knowledge, professional practice and professional engagement.

The Australian Professional Standards for Teachers are a public statement that constitutes teacher quality. They define the work of teachers and make explicit elements of high-quality, effective teaching in $21^{\text {st }}$-century schools that will improve educational outcomes for students. As for the graduate teachers, they are also expected to meet a set of national standards through their successful completion of a nationally accredited programme of initial teacher education. It implies that the successful completion of an accredited programme will equip a graduate with the knowledge and skills to meet common and agreed standards for all Australian teachers (AITSL, 2018).

The development of the Australian Professional Standards for Teachers was enlightened by intensive analysis, knowledgeable information, associate analysis and a review of standards in use by teacher registration authorities, employers and skilled associations across Australia, as well as by important consultations. The method was based upon the work of previous national frameworks and agreements. 
Stakeholder arrangements were developed by territorial institutions, major authorities and teacher regulatory bodies.

In total, 120 single and joint submissions were received from the Federal, State and Territory governments, regulatory authorities, education unions, skilled peak bodies and individual faculties and academics. Following this, the standards were tested across systems, sectors, faculties, and geographical locations. These standards should be an integral part of ensuring quality education in Australian schools.

Education Services Australia (ESA) is a not-for-profit company, owned by all Australian education ministers, which provides some assistance with professional learning needs among both in-service and pre-service teachers. These learning needs include access to relevant teaching resources and the provision of professional learning opportunities to support efforts in teaching or preparing teachers to teach new dimensions of the curriculum. The purpose of this corporation was to strengthen collaboration in order to promote effective curriculum development across Australia. The establishment of the ESA provided a portal for pre-service teachers across Australia to access research to improve their professional knowledge, resources to improve their professional practice, and networks to promote professional engagement. Upon graduation, teachers can continue to engage with the profession. Its strategy statement explains it uses a unique mixture of training and technology information to create and supply solutions that can be used to enhance pupil outcomes and enhance overall performance throughout all schooling sectors. Achieving academic excellence in Australian schools requires strategic initiatives delivered at a countrywide scale that equips each Australian student in each school with the chance to attain their potential. As Australian education's national, cross-sector schooling technology provider, the ESA has the relationships, functionality and track record to take a leading position in driving initiatives for the attainment of this goal. The ESA has also established a capability to mix training and technology expertise to generate and supply options that further Australia's education reform agenda and meet the needs of stakeholders across all sectors. Five strategic pillars provide the aid and capabilities needed to achieve the objectives and focus on the approach's execution. Each strategic pillar builds on the ESA's core capabilities. The pillars are to deliver outstanding tasks and services, disseminate insights 
that support decision making, provide management in schooling records management, develop and preserve countrywide schooling science platforms that amplify entry to and enhance connectivity, and strategically engage stakeholders to set up partnerships that help them to attain their goals (ESA, 2018).

The ESA measures the success of its strategy statement in terms of its impact. It has efficiently executed its strategy statement and contributed to initiatives for improving student outcomes and strengthening teachers' influence, and school communities also had an impact on initiatives delivered on behalf of governments. In addition, the uptake of products and services supplied via the ESA and the use of the ESA's shared platforms were modern options that resulted in increased efficiencies and the effective use of resources, providing more desirable strategies to school managements countrywide.

With the introduction of the above-mentioned in Australia, the recent reforms have led to the successful quality improvement of teacher education and professional development. TALIS results show that:

$\rightarrow 98 \%$ of teachers have higher pedagogical education,

$\rightarrow 97 \%$ of teachers are involved in professional development programmes,

$\rightarrow 51 \%$ of teachers are members of a professional association,

$\rightarrow$ The index of teacher professionalism is 0.2 out of a possible 0.25 (OECD, 2014).

Thus, the above-mentioned initiatives have led to positive changes in teaching quality assurance in Australia.

\section{Education Policies for Teacher Training Quality Assurance in Ukraine}

Australian reforms in teacher education, particularly in teacher quality assurance, are a role model for Ukraine. Educational reforms on teacher quality in Ukraine are needed, as today's Ukrainian schools do not equip pupils with the skills needed for the future. So what are the challenges we face? According to the Minister of Education, firstly, the way of teaching in contemporary Ukrainian schools does not motivate children to learn, and secondly, teachers use mostly outdated teaching methods. At the same time, teachers lack real motivation 
for personal and professional growth. In addition, low social status and low salaries certainly also demoralise teachers. The digital distance between teachers and pupils is growing. Many teachers are just not able to research problems using modern methods, to work with large amounts of data, to make and present conclusions, or to collaborate online on educational, social and academic projects. Teacher issues are currently important considerations for policy agendas because of concerns expressed by teachers themselves about the future of their profession - whether it is sufficiently attractive to talented new entrants, and whether teachers are sufficiently rewarded and supported in their work. As teachers are in daily contact with the students who will potentially form the next generation of teachers, the enthusiasm and morale of the current workforce are important influences on the future supply of teachers.

Radical reforms are needed that will reverse all the negative trends and turn Ukrainian schools into entities able to leverage social equity and consolidation, economic development, and competitiveness. Currently, teacher education in Ukraine is undergoing dynamic reforms. The main principles of state policy in this process are person-centredness, ensuring equal access to education without discrimination, and the development of an inclusive educational environment. Furthermore, the scientific nature of education, the diversity of lifelong learning, the transparency and publicity of managerial decisions, integration with the labour market, and flexibility in choosing the types and forms of education, educational programme, and educational institution are also key considerations (Ministry of Education and Science Ukraine, 2016).

The overall enhancement of the reforms has been accompanied and assured by the introduction of the Law on Higher Education (2014). It prescribes an internal quality assurance system and provides principles for teacher training, a system for monitoring and carrying out periodic reviews of educational programmes, and the annual assessment of higher education graduates. The other equally important factors are the provision of professional development for pedagogical staff, the availability of the necessary resources for students' independent work in each educational programme, the academic integrity of university staff, and preventing and detecting academic plagiarism. As prescribed by the law, the quality assurance system of higher education in Ukraine consists of: 
1. a system to ensure the quality of educational activities at institutions of higher education and the quality of higher education (internal quality assurance),

2. a system of external quality assurance for educational activities at higher education institutions and for quality higher education,

3. a system of quality assurance activities conducted by the National Agency for Quality Assurance in Higher Education (NAQA) and independent agencies.

The internal quality assurance system involves the following procedures and activities:

1. defining principles and procedures for quality assurance in higher education;

2. monitoring and periodic revision of educational programmes;

3. annual assessments of applicants for higher education, research-pedagogical and pedagogical staff of higher educational institutions and regular publication of the results of such assessments on the official websites of higher educational institutions, information stands and any other way deemed appropriate;

4. provision of professional development activities for pedagogical, scientific and scientific-pedagogical employees;

5. ensuring the availability of the necessary resources for the organisation of the educational process, including the independent work of students in each educational programme;

6. ensuring the availability of information systems for effective management of the educational process;

7. ensuring the publicity of information about educational programmes and higher education qualifications;

8. ensuring an effective system of preventing and detecting academic plagiarism in the scientific works of employees of higher education institutions and applicants of higher education.

The internal quality assurance system is managed by the NAQA. This regulator accredits independent agencies for assessing and assuring the quality of higher education in compliance with the requirements of the quality assurance system of higher education, which is approved by the NAQA. 
The external quality assurance system involves the implementation of the following procedures and measures:

1. ensuring the efficiency of the processes and procedures of internal quality assurance of the educational activity of higher education institutions and the quality of higher education;

2. ensuring the availability of a system of external quality assurance procedures;

3. ensuring that decision-making criteria are made public in accordance with the standards and recommendations for quality assurance in the European Higher Education Area;

4. providing accessible and comprehensible reporting;

5. conducting periodic audits of the activity of quality assurance systems and mechanisms of work with the received recommendations.

The quality assurance system of the NAQA and independent quality assurance agencies involves the following procedures and measures:

1. ensuring the availability and efficiency of external quality assurance processes and procedures for higher education;

2. ensuring the availability of sufficient and balanced resources for the implementation of external quality assurance processes in higher education;

3. ensuring the independence of the activities of the NAQA and independent institutions for evaluating and ensuring the quality of higher education;

4. accountability.

The Law of Ukraine "On Higher Education" stipulates the following procedures and measures that define the principles and procedures for quality assurance in higher education: the importance of annual evaluations of higher education applicants, research and pedagogical staff of higher education institutions and the regular publication of the results of such assessments on the official website of the higher education institution; advanced training for pedagogical, research and scientific-pedagogical staff; the availability of the necessary resources to organise the educational process, including the independent work of students, for each educational programme; the availability of information systems for effectively managing the educational 
process; the publicity of information on educational programmes; developing higher education degrees; and ensuring an effective system for preventing and detecting academic plagiarism in the research work of employees of higher education institutions and applicants for higher education.

The NAQA (2018) was established in order to implement the procedures for ensuring higher education quality. It sets requirements for accreditation criteria of educational programmes and institutions. It monitors the quality of the educational process at universities and supervises the scientific and research achievements of the teacher education sector, which determine the ratings of universities in Ukraine. An important factor in the pedagogical education reforms is the development of the qualifications system, which involves the development of the qualifications framework for setting professional and higher/advanced teacher training standards to meet the requirements of pedagogical competencies and applicants' certifications in higher education. The mission of the agency is to become a catalyst for positive changes in higher education in Ukraine and to develop a culture of quality. The agency guarantees the quality of study programmes, promotes and benchmarks quality assurance systems in the universities, and develops standards and criteria of higher education quality assurance on the basis of the best foreign and modern practices.

In 2019, the agency developed and implemented a new accreditation system for higher education programmes. This document defines the main principles and procedures for educational programmes' accreditation. Accreditation is used as a tool for the external quality assurance of higher education in Ukraine and is provided by the NAQA. It is voluntary and is initiated by the institution of higher education. In addition, accreditation is conducted in accordance with the Laws of Ukraine "On Education" and "On Higher Education", as per the Charter of the NAQA. The purpose of accreditation is to determine the quality of educational programmes and the educational activities of this programme, which are defined by the criteria of the "Regulations on Accreditation of Study Programmes in Higher Education".

Accreditation helps institutions of higher education to determine the strengths and weaknesses of educational programmes. Moreover, it provides all stakeholders with information about the quality of the educational programme and the educational activities 
of the programme, thus increasing confidence in higher education in Ukraine and promoting the integration of Ukrainian higher education institutions in order to meet European higher education standards (MONU, 2019).

The accreditation programme also aims to assess the quality of the educational programme. The accreditation of the educational programmes helps to meet standard requirements, as well as the achievement of stated learning outcomes in accordance with the evaluation criteria of quality (EACEA, 2017).

Various criteria are applied to the standards and guidelines for quality assurance in the European higher education system. The criteria are used to prepare information on self-assessment by the institution of higher education for the NAQA, its sectoral expert councils and experts during the accreditation process. An evaluation of the educational programme and its activities is carried out, and each criterion is marked according to a scale of assessment that covers four levels of compliance:

Level " $F$ " - the educational programme and/or educational activities under this programme does not meet the particular criterion, and the identified deficiencies are of a fundamental nature and/or cannot be corrected within one year;

Level "E" - the educational programme and/or educational activities under this programme generally does not meet the particular criterion; however, the identified deficiencies can be eliminated within one year;

Level "B" - the educational programme and educational activities on the programme as a whole meet the particular criterion with defects that are not material;

Level "A" - the educational programme and educational activities under this programme fully comply with the particular criterion, including having innovative component and/or approach.

An institute of higher education can be simultaneously accredited at the same level to two or more educational programmes within the same speciality. The institution of higher education is obliged to promote accreditation and to act in good faith in its relations with the NAQA, its sectoral expert councils and its experts (Kvit, 2019).

In 2017, the Ukrainian Parliament passed the law "On Education", which became the foundation of subsequent educational reforms. The law also encourages professional growth and a European 
structure of the national education system, introduced new principles of content development, the quality assurance system, the National Qualification framework, allows the building of economic relationships in the education system, and implemented the New Ukrainian School project (2017). According to the law, the education system's quality assurance system is made up of an internal quality assurance system, an external quality assurance system, and the quality assurance system of governing bodies and institutions providing external quality assurance (Ministry of Education and Science Ukraine, 2018).

According to the law, the internal quality assurance system in educational institutions may include:

$\rightarrow$ education quality strategy (policies and procedures);

$\rightarrow$ systems and mechanisms for ensuring academic integrity;

$\rightarrow$ publishing criteria, rules and procedures for evaluating students;

$\rightarrow$ publishing criteria, rules and procedures for evaluating the (scientific-)pedagogical activity of pedagogical and research-pedagogical employees;

$\rightarrow$ publishing criteria, rules and procedures for evaluating the management activities of the educational establishment's executives;

$\rightarrow$ ensuring the availability of the necessary resources for the organisation of the educational process, including for the independent work of students;

$\rightarrow$ ensuring the availability of information systems for the effective management of the educational institution;

$\rightarrow$ creating an inclusive educational environment, universal design and smart adaptation in the educational establishment.

The introduction of the "Concept of Pedagogical Education Development" by the Ministry of Education (2018) represents the process of quality teacher education in Ukraine and focuses on the importance of alternative methods of professional teacher education. It is one of the first steps in overcoming the issues and the changing system of teacher quality assurance.

The aim of the concept is to promote and improve pedagogical education by training pedagogical staff from the new generation and providing alternative, modern models for professional and personal teacher development that will become key to the implementation 
of the New Ukrainian School reform by 2029. In general, teacher training should meet public expectations formulated by professional and education standards and take into account global trends and the recommendations of international teacher training organisations. However, there are obstacles to the creation of quality teacher training and professional development systems. These include the dispersion of responsibility between different institutions at different stages of teachers' professional development; problems with the mastery of the selected subject alongside aspects of its teaching; insufficient teacher awareness of the research methods or lack of awareness of the need for them; and insufficient delegation of specific responsibilities between members of the teaching staff.

In some countries, initial teacher education is directly organized and supervised by the Ministry of Education. As other countries have raised the level of teacher training to the post-secondary level, a variety of institutions may offer teacher education programmes. Some programmes are managed by departments or schools within large universities. Other programmes are provided by specialised teacher education institutions, some of which may be private. The growing complexity and independence of teacher education institutions in many countries has led to the need to evaluate their quality of instruction in light of the skills expected of graduates. From this perspective, the accreditation of teacher education institutions or programmes within an institution, particularly in Ukraine, is one of the most important aspects of developing a quality assurance system.

The cross-industry nature of teacher education means that different directions can be taken when preparing for the pedagogical profession.

One of the main tasks of the "Concept of Pedagogical Education Development" is building a modern model of the teaching profession in the context of society's needs, the prospects of national economic development and global technological changes. Policymakers in Ukraine state that teaching staff in educational institutions need to be regulated at the legislative level, based on a combination of high social importance and responsibility and features of permanent employment, mainly relating to those in the public sector. Such a status should balance special requirements for training and the professional activities and improvement of teaching staff with privileges and opportunities. Training principles and pedagogical staff 
need professional improvement regulated by law, and this should be identified through a sectoral system of qualifications. In particular, this law must regulate the activity of institutions of higher education in terms of forming the content of their education and organising the educational process. Furthermore, additional requirements should be implemented for the internal and external quality control of pedagogical education, personnel and inventory technical control. Teacher education in Ukraine requires the introduction of a special state model to support pedagogical education.

An important factor of pedagogical education reform that has been actually going on since 2014 is the formation of a sectoral qualification system that provides professional development and introduces a sectoral qualification framework as well as the development of professional standards, digital competence standards, and a code of ethics for pedagogical employees. Pedagogical reforms set standards for higher and professional higher education based on professional standards that should contain parts in common (between the speciality and education levels) regarding requirements for the pedagogical competence and certification of higher education applicants. The introduction of speciality sections of higher and professional higher education standards determines the structure of educational programmes, the boundary ratio between the cycles in them and the requirements for training. It also sets requirements for programmes of pedagogical internship and teacher qualification exams at a higher education institution or a relevant qualification centre after no less than one year of teaching in secondary education. These requirements are also set for preschool, extracurricular, professional (vocational-technical), professional higher education, and specialised education at appropriate levels.

The importance of defining additional requirements is obvious and can ensure the quality of training and professional development of educators. The internal quality assurance system may also include an assessment of the personal and pedagogical skills and abilities of teachers applying for vocational education, entry-level (short cycle) or the first (Bachelor) level of higher pedagogical education (psychological testing and/or other confirmations of personal and pedagogical abilities). A requirement for teachers who carry out the psycho-pedagogical and methodological training of applicants for teacher education should be introduced with 
training by pedagogical staff and get experience in preschool, secondary, professional (vocational), and adult education institutions. Involvement of experienced teachers of preschool, secondary, extracurricular, and professional (vocational) education in teaching individual courses or training future teachers; combining pedagogical training for candidates with pedagogical activities in the form of voluntary training, internships, dual forms of education, working in holiday periods, parttime work - are recommended.

The external quality assurance system for the training and professional development of teaching staff should additionally involve some experienced employees. Staff from preschool, secondary, vocational and/or extracurricular education (who have not studied or did not previously work at a rated institution) and professional associations' teaching staff and other public associations in the field of education should take part in the accreditation (audit) of educational programmes and institutions.

\section{Conclusion}

At the beginning of the $21^{\text {st }}$ century, efficiency, accessibility and quality became the priority tasks of educational development. Quality education is traditionally considered as an instrument of socio-cultural harmony and economic growth by the world community. Nowadays, no single country in the world is fully satisfied with the quality of its education system. Everyone is looking for innovations that will produce results.

One of the ways that Ukraine can gain a decent place in the international labour market in the era of knowledge and technology is through supporting and respecting evaluations of teaching careers and undoubtedly through enhancing teacher quality assurance. The modernisation of educational programmes should include, in particular, the introduction of a competency-based, student-centred approach to teacher education, thus ensuring the formation of general competences, the acquisition of teaching skills, the development of pedagogical techniques, and the use of ICTs and digital technologies. In addition, the improvement of educational programmes should go along with the strengthening of the practical components of teacher education, the psycho-pedagogical approach, and methodical preparations for practical professional activities. The pedagogy of partnership based on co-operation between students, teachers, 
parents and the public as well as on the principles of inclusive education should be introduced. A significant move would be to build managerial skills with a wide use of ICT and digital technology for its effective operation in conditions of real autonomy of educational institutions, as well as to provide practical training through continuous pedagogical training during preschool, secondary, extracurricular, and professional (vocational) education. In addition, the formation of the socially mature pedagogical personality of the employee should be promoted, along with national identities and tolerance for multiculturalism, a willingness to disseminate these qualities to students, instilling innovation as a way of thinking and a key tool of leadership in public-public partnerships, the perception of the globalisation of educational processes, and competition as a required context of the development of pedagogical education systems.

Continuing efforts to define and promote quality teaching in Australia as well as in Ukraine take place within the development of national frameworks for professional teaching standards that have significant benefits in terms of quality assurance in higher teacher education. Our study has shown the improvement in the quality of pedagogical education in both countries. Common trends of the successful improvement to the quality of teacher education are government regulation, the introduction of pedagogical standards, and the adoption of flexible methods of professional training, development and guidance.

\section{References}

$\rightarrow$ Australian Institute for Teaching and School Leadership (2018). Australian Professional Standards for Teachers, www.aitsl.edu.au/teach/standards

$\rightarrow$ Australian Qualifications Framework (2013). Australian Qualifications Framework, www.aqf.edu.au/sites/aqf/files/aqf-2nd-edition-january-2013.pdf

$\rightarrow$ Bahr, N. and Mellor, S. (eds.) (2016). Building quality in teaching and teacher education - ACER Research, https://mafiadoc.com/building-quality-in-teachingand-teacher-education-acer-research-_5994a06f1723ddcf69a40d58.html

$\rightarrow$ EACEA (2017). Overview of the Higher Education System: Ukraine, https:// eacea.ec.europa.eu/sites/eacea-site/files/countryfiches_ukraine_2017.pdf

$\rightarrow$ ESA (2018). Report of the Review to Achieve Educational Excellence in Australian Schools, https://docs.education.gov.au/system/files/doc/other/662684_tgta_ accessible_final_0.pdf 
$\rightarrow$ Ingvarson, L., Reid, K., Buckley, S., Kleinhenz, E., Masters, G.N. and Rowley, G. (2014). Best practice teacher education programs and Australia's own programs: submitted to Teacher Education Ministerial Advisory Group. Canberra: Department of Education.

$\rightarrow$ Kvit, S. (2019). New Accreditation System, https://naqa.gov.ua/2019/08/newaccreditation-system/

$\rightarrow$ Loukkola, T. and Zhang, T. (2010). Quality Assurance Processes in Higher Education Institutions. Brussels: European University Association.

$\rightarrow$ Ministerstvo Osvity i Nauky Ukrayiny, (2019). Pro zatverdzhennya Polozhennya pro akredy taciyu osvitnix program, za yakymy zdijsnyuyetsya pidgotovka zdobuvachiv vyshhoyi osvity (Nakaz № 977), https://zakon.rada.gov.ua/laws/ show/z0880-19.

$\rightarrow$ Ministry of Education and Science Ukraine (2016). The New Ukrainian School: Conceptual principles of Secondary school reform, https://mon.gov.ua/storage/ app/media/zagalna\%20serednya/Book-ENG.pdf

$\rightarrow$ Ministry of Education and Science Ukraine (2018). New Ukrainian School, https://mon.gov.ua/eng/tag/nova-ukrainska-shkola

$\rightarrow$ O'Meara, J. (2011). Australian teacher education reforms: reinforcing the problem or providing a solution?, Journal of Education for Teaching, 37(4), 423-431.

$\rightarrow$ OECD (2014). TALIS 2013 Results: An International Perspective on Teaching and Learning. Paris: Organisation for Economic Co-operation and Development Publishing.

$\rightarrow$ QILT (2018). A Survey of Current Higher Education Students, www.qilt.edu.au/ qilt-surveys/student-experience

$\rightarrow$ Radloff, A., Coates, H., James, R. and Krause, K.L. (2011). Report on the Development of the University Experience Survey, https://research.acer. edu.au/cgi/viewcontent.cgi?article=1031\&context=higher_education

$\rightarrow$ SES (2018). The Higher Education Student Experience Survey, www.qilt. edu.au/docs/default-source/ses/ses-2019/2019-ses-national-report. pdf?sfvrsn=6486ec3c_10

$\rightarrow$ Tertiary Education Quality and Standards Agency, Act 2011 № 73 (2011). Tertiary Education Quality and Standards Agency, www.legislation.gov.au/ Details/C2017C00271

$\rightarrow$ UEQ (2019). The Higher Education Student Experience Survey, www.qilt. edu.au/docs/default-source/ses/ses-2019/2019-ses-national-report. pdf?sfvrsn=6486ec3c_10 


\section{Teacher Experiences and Perceptions of Collaboration and Peer Support in an Innovative Learning Invironment}

DOI: $10.47050 / 66515321.150-169$

Louise Campbell

The research under discussion here was part of a larger project to investigate teaching and learning in a newly created innovative learning environment in an otherwise traditional secondary school in Central Scotland. By focussing on interview data gathered in relation to collaboration, peer observation and the realities of sharing a large teaching space, as experienced by the participants, this discussion explores what collaborative working entails for the teachers within the context of this project. Planned culture shifts, where teachers have been asked to teach using new strategies in a new and unfamiliar learning space, make emotional as well as pedagogical and practical demands on teachers. It is argued in this paper that the adaptation of practice required by teachers in such spaces makes it an intimidating prospect for some. The implications these findings may have for teacher education and for the support of practising teachers to help them engage in effective peer collaboration are also explored.

\section{Keywords: \\ innovative learning environment \\ teacher collaboration \\ teacher education policy \\ teacher professional development}




\section{Introduction}

Collaborative working is a term that is increasingly pervasive in employment contexts, and one that is becoming prevalent in education too, in recognition of the requirement for formal education systems to prepare young people for the intellectual rigours and complex social expectations of the workplace (Fletcher et al., 2018; Griffin et al., 2012; Holocher-Ertl et al., 2011). Collaborative working is associated with shared thinking with the benefit of combined knowledge and experience. This combinatory characteristic can catalyse creative and innovative problem solving (Craft, 2008; Graesser et al., 2017) and is seen as a desirable and effective way of meeting the challenges of the rapidly changing contexts for work that are the inevitable consequence of technological proliferation (Levi, 2010). It is, in other words, an important competence expected of those entering the workforce. As a consequence, it is a focus of interest for education systems with "process" curricula that seek to prioritise the development of skills over the accumulation of knowledge.

Teacher collaboration has been raised as one route to helping school age learners to build these desirable skills (Baepler \& Walker, 2014; Rytivaara \& Kershner, 2012). There are numerous advantages to teacher collaboration for educators. These include opportunities for professional development (Rytivaara \& Kershner, 2012), reduced feelings of isolation and a heightened sense of engagement with the immediate professional community (Thousand et al., 2006). In their systematic review of 82 studies, Vangrieken, Dochy, Raes and Kynd (2015) found that there were a wide range of additional positive outcomes associated with teachers' collaboration, including increased motivation, improved efficiency, more frequent innovation and the enhancement of professional and technological skills. Clearly, then, collaborative working has much to offer the teaching community.

Yet, in practice, collaborative working amongst teachers remains a work in progress in schools, particularly in relation to the practice of teaching, where a sense of workplace isolation has been cited as a significant cause of teachers leaving the profession (Altieri et al., 2015; Buchanan et al., 2013; Heider, 2005; Paris, 2013). One of the reasons for this may be that collaborative teaching entails the development of a democratic approach to shared responsibility and accountability (Jones et al., 2008) that can cause a measure of cognitive dissonance 
for teachers who have become used to exclusive control over their planning and decision-making. Autonomy and the opportunity to take individualistic and creative approaches to the work of teaching are, it could be argued, key benefits of the job. Another reason may be the structural barriers created by complex timetables and competing workload pressures (Thousand et al., 2006). Human conflict is also a factor that cannot be ignored, with competitiveness and perceived inequities (Vangrieken et al., 2015) impacting teacher motivation to engage with peer collaboration. The tension between apparent benefits and structural barriers is one that has yet to be successfully resolved.

Efforts to encourage teacher education to make moves in the direction of increased professional co-operation and collaboration have aimed to present this as a professional skill that should be amongst the core competences demonstrated by new teachers entering the profession. For example, a key message outlined in the Donaldson Review of teacher education in Scotland (2011) was that teacher professionalism should involve the ability "to work in partnership with other professionals; and to engage directly with well-researched innovation" (ibidem, p. 19). This implies not only engagement with others beyond the school setting but also collaboration with those within it, in order to best meet the needs of learners. The matter of innovation is one that raises a number of further queries. Does this mean innovative pedagogy? New technologies for learning? A need for ongoing experimentation with practice? It is possible that the vagueness of this statement in the Donaldson Review is a deliberate choice to encourage educators to open themselves up to change and professional development in the broadest sense, across the many possible contexts in which educators may find themselves.

One form of innovation, increasingly prevalent in Scottish schools and elsewhere, is the innovative learning environment. The layout of innovative learning environments, which are often larger than standard classrooms, adaptable and digitally connected, is allied with the expectation that they will be used as collaborative spaces for both teaching and learning (OECD, 2013). Scottish education policy advocates for the development of such spaces as part of providing a solid foundation for a curriculum that is designed to facilitate increased learner engagement and thereby, it is implied, higher 
attainment: "Teachers need access to learning spaces which can meet a multiplicity of purposes, for example, whole class teaching, collaborative group work, paired working and independent research based work" (The Scottish Government, 2007, p. 8).

This perceived need for spaces with flexibility to meet a range of purposes has encouraged the development of school designs where the nature of the architecture is seen as an integral part of shaping not only practical matters of usage but also altering pedagogical thinking. "School buildings and facilities are far more than just part of the supporting case for Curriculum for Excellence [the Scottish curriculum for children aged 3-18]. They are at the heart of the whole philosophy and approach to effective learning and teaching and play the fullest part in helping to achieve change for the better" (The Scottish Government, 2009, p. 25).

In other words, school building design is regarded as being not only integral to promoting the curriculum drivers underlying practice in education but also, at least in part, constitutive of them, in the sense of enabling a change in the perceptions of what schools can and should do. The creation of flexible spaces labelled "innovative" or "inspiring" could be seen as an attempt to engage teachers in a process of re-evaluating their practice. It is, as yet, unclear whether these objectives have been meaningfully achieved, though there are a number of studies and research agendas emerging which endeavour to explore precisely this question (Campbell, 2020; Cleveland, 2018; Young et al., 2019). Given the level of financial investment in the creation of these spaces, it could be argued that this research agenda is somewhat overdue.

The research under discussion here was part of a larger project to investigate teaching and learning in a new innovative learning environment in an otherwise traditional secondary school in Central Scotland. By focussing on data gathered in relation to collaboration, peer observation and the realities of sharing a large teaching space, as experienced by the participants, these are explored to identify and examine what working in partnership and engaging directly with innovation entails for these teachers within the context of this project. The implications these findings may have for teacher education and for the support of practising teachers to help them engage in effective peer collaboration are also explored. 
The question guiding this part of the research and the discussion that follows here concerns the participating teachers' experiences and perceptions of collaborative teaching and peer support while working in an innovative learning environment. The intention was to see whether the collaborative intentions of the spatial design were being realised in practice.

\section{The Context of the Study and the Methods Employed}

This research took place in a medium-sized secondary school in Scotland. The school is located in a moderately affluent catchment that is mainly suburban but partly rural in character. The Local Authority bid for funding to create an innovative learning environment and was awarded this funding by the Scottish Government. The motivation for the creation of the space was to enable teachers and learners to explore and experiment with alternative pedagogies and structures for learning as preparation for moving into a new school building that was designed with open, large and flexible spaces, in keeping with the demands of the Curriculum for Excellence (Education Scotland, 2020) and the growing perception that schools need to reflect structural elements of the workplace and help to build the skills that are needed there (The Scottish Government, 2007). The wider purpose of the research was to understand whether or not the innovative learning environment was successfully fulfilling this objective (Campbell, 2020).

The innovative learning environment consisted of three standard-sized classrooms that were opened up to create one large space, where up to 100 pupils could be accommodated at a time. The space was equipped with mobile and flexible furniture, interactive screens and whiteboard walls. The intentions underlying this were to enable the space to be as adaptable as possible to meet the range of teaching and learning needs that might be required by the variety of subjects and departments in the school.

Taking the view that teachers' practice reflects not only their location within particular social, cultural and policy-related situations (Day, 2012; Osborn \& McNess, 2005; Priestley, 2011) but also their uniquely personal perceptions and influences (Beijaard et al., 2000; Campbell, 2019), this investigation took the view that participants would be able to share some sense of their beliefs and insights in relation to working in the innovative learning environment. The perspectives of the participants discussed 
here are considered as representations of experience and thought; inherently subjective but unique and valuable for exactly this reason. While there was no expectation of being able to draw definitive truths from this process, it was hoped that the choices these teachers had made in relation to working in the space, and the reasons they provided for these, would enable a better understanding of the ways in which the space was (or was not) meeting the objectives claimed for it.

One-to-one interviews were undertaken with six teaching staff who volunteered to participate. These participants had a variety of levels of experience of using the new learning space, which had been open for use for almost a full academic year at the time of the interviews. Two of the interviewees had chosen not to be engaged with the space at all. It was considered valuable to explore their reasons for this in order to better understand how to make the space more appealing to teachers who were not using it, as well as to gain an understanding of what the barriers to use were for these teachers. The participants had varying levels of experience in teaching and were teachers of a range of secondary school subjects. Two had been in the teaching profession for fewer than five years. Where extracts from transcripts have been shared, participants' names have been pseudonymised.

Qualitative analysis, utilising inductive strategies to develop and categorise thematic strands within the data, offered opportunities to recognise and value the experiences and thoughts shared by participants. A primary cycle of coding was undertaken to identify core ideas and concerns. This was followed by a secondary coding cycle to draw these together into themes. Four interrelated themes emerged in relation to participants' perceptions of collaboration and peer support in the new learning space. These were (1) planning, (2) control, (3) relationships with learners and (4) visibility. These four themes have been used as stimuli for the exploratory and theoretical discussion that follows here.

\section{Planning for Collaborative Teaching and Learning}

Jack: You hear about interdisciplinary learning and you think, "what an opportunity for a group of geographers, a group of biologists and a group of history students to come together", but I just think that the actual planning behind that is what puts teachers off doing it. 
The issue of planning and the level of detail involved with this (along with the time that such planning would be likely to take) was a clearly identified preventative to collaborative teaching amongst the interviewees. In Jack's transcript extract above, the focus is given to the potential for interdisciplinary learning offered by the space, seeing in the abstract the scope that a large, flexible space could offer for undertaking this kind of learning. However, the scope and scale of the thought that would be needed to enable this collaborative effort to happen is regarded as a significant barrier.

It is possible this may be less a concern related to the space than one that is connected with the implicit border-policing around subject areas that helps to define secondary school teachers' work (Fox, 2010; Hobbs, 2012; Savage, 2012) and the process of their assimilation into the teaching profession at the beginning of their careers (Archer et al., 2012; Fisher \& Webb, 2006; Kyriacou \& Kunc, 2007). Secondary school teachers in Scotland, and many other countries, are qualified as a minimum to degree level in a specialist subject and qualify to teach in this area of specialism. As a result, they see this as part of their professional identity. A lack of confidence in engaging with other disciplines and areas of the curriculum, even with the benefit of colleagues' expertise, presents a cognitively challenging picture, which, when compounded with other challenges such as time constraints and other professional pressures, results in resistance and/or avoidance (Brand \& Triplett, 2012).

The roots of this resistance may also be linked with teachers' memories of the detailed and complex lesson planning required of student teachers, where this becomes a hugely time-intensive aspect of initial teacher education. Lesson planning is seen as vital to professional growth and developing good habits for practice during the period when student teachers are learning the curriculum, the requirements of their subject areas and the pedagogical strategies that support effective learning (John, 2006; Santoyo \& Zhang, 2016). As teachers become more experienced, their planning takes a more abbreviated form. There is a reliance on pedagogical content knowledge, where previous iterations of successful lessons, a recognition of what creates the conditions for effective learning, and the confidence that comes from having ready teaching resources contribute to less time being required for lesson planning (Park \& Oliver, 2008). The prospect 
of returning to the "novice" state, where experience and expertise around some of these areas can no longer be relied upon, is one which understandably appears to have limited appeal.

If it is desirable for teachers to overcome these barriers to extend their professional learning and pedagogical range, then the question becomes one about how this can be more effectively scaffolded to make it manageable, practical and appealing for the teachers involved (Musanti \& Pence, 2010). The hidden barriers to undertaking this kind of collaborative, interdisciplinary work, which is a fundamental concern of education policies and curricula that seek to engage teachers in these strategies, need to be explicitly addressed. There are examples of successful approaches at work internationally (see Havnes, 2009; Stolle \& Frambaugh-Kritzer, 2014) from which lessons might usefully be learnt. These include strategies for educating student teachers via interdisciplinary projects and enabling practising teachers to maintain their individuality and autonomy whilst working within discursive professional communities. These strategies enable teachers to co-operate and share their thinking and motivations as part of their professional learning.

\section{Surveillance, Control and the Challenge to Leadership}

\section{Kira: I said, "How about we do this in the learning space together?" And then before I shut my mouth, I opened it again and said, "No. Forget that", because I remembered the behavioural issues between the two classes. We put them together before and it was horrific.}

For most of the interviewees who had made use of the space, this was confined to booking the space for their own class and using the facilities as appropriate to complement traditional classroom learning. Although the question of collaborative teaching had been raised with colleagues, where this had been considered, it had generally been discounted as unmanageable or impractical, as the extract from Kira's interview transcript above suggests. In Kira's case, there had at least been a previous attempt at collaborative teaching, though by implication it was not a positive experience and was sufficiently 
problematic to dissuade Kira from trying this approach with her colleague a second time.

The matter of classroom control and behaviour management was a conspicuous consideration raised by interviewees. In spite of studies that have shown the value of team teaching for managing students' behaviour (Hayden \& Pike, 2005), the familiar confines of the conventional classroom environment were argued by participants in the present research to offer behavioural benefits in terms of the habitual routines in place in these settings. Moving into a larger, less formal space, with other classes and their different rules and routines, offers the potential for confusion and a variety of associated challenges (physical, social and emotional). The size and shape of the innovative learning space, with areas that made supervision difficult, was considered by some to be unmanageable, though this was not always considered by the interviewees in the context of more than one pair of eyes, where responsibility for behaviour management could be shared. This could be regarded as a consequence of a lack of experience with collaborative practice.

In their explanations about concerns relating to surveillance and control within the space, interviewees seemed to consider their leadership would be compromised. This suggests that shared or distributed leadership was a difficult concept for these teachers to embrace. This is in line with the challenges that have been identified elsewhere (Firestone \& Martinez, 2007; Lahtero et al., 2017; Robinson, 2008). There are issues of workplace culture at play in this context. If conceptions of leadership are tied to single sources of authority, this makes it understandably difficult to conceptualise or create space for shared or team leadership.

As Kira's transcript extract implies, there is also a challenge around the interrelationships between pupils across classes. One of the assumptions guiding the creation of open, flexible spaces for learning is that learners' identities are fluid and able to move between individual and group learning experiences seamlessly, provided there is the right infrastructure and support. However, this perspective does not take into account the idea of classes forming their own social identities (McManus, 2010; Stets \& Burke, 2000) with associated allegiances and antipathies, distinct from other classes at the same age and stage. There can be no simple equation that two classes studying 
the same subject in the same place at the same time will be able to do so without any difficulties. However, this is not to say that new social formations are not possible. Indeed, it is arguable that it is a crucial aspect of the planning process for collaborative teaching and learning to consider how to create bonds between the classes that are coming together for learning so that a new social identity can be formed for the particular purpose of working in a large collaborative space.

In the context of teachers working together, it becomes apparent that curriculum planning for teaching and learning under these circumstances is only one dimension of the necessary preparation required for collaborative practice of this kind (Altieri et al., 2015; Havnes, 2009; Jones et al., 2008; Musanti \& Pence, 2010). Consideration also needs to be given to the catalytic social and behavioural reactions that can take place between individual pupils, between groups of pupils or between pupils and less familiar teachers. The introduction of so many human variables, alongside the no less significant variable of the teaching space itself, creates a daunting prospect for teachers considering the possibility of working collaboratively in a shared and unfamiliar space, though it is by no means an insurmountable obstacle if these challenges are given due consideration as part of the planning process. The importance of valuing positive relationships between teachers and the individuals within their class was also raised as a theme in its own right.

\section{Relationships with Learners}

Jack: I like to have these twenty kids in front of me that I know well, rather than another twenty and another twenty that I do not. You know, it is all about relationships for me, so it is not about technology, and that is what you build up in that little [traditional classroom] area...

An intriguing theme that arose in the data is related to the importance of teacher-student relationships and concerns about the loss of these that might occur with a change in the composition of classes when engaging with collaborative practice in the innovative learning environment with colleagues. For Jack, who shared the comment above, teaching a practical subject, with the relatively small maximum 
class size of twenty entailed in that, is one of the significant benefits of practice. To enlarge the number of students requiring attention through the process of collaboration with other classes and their teachers is perceived to mean the dilution of the time and attention that can ordinarily be given by Jack to his own students. This is equated with an ensuing weakening of the positive relationships that have been built over time in the traditional classroom setting.

The emotional comfort and social strength to be drawn from working within the familiar patterns of interaction and expectation that guide the teacher-student relationship (Dooner et al., 2010) may offer an insight into the reasons for some teachers' lack of engagement with the innovative learning environment even on a solo basis and without the added complexity of teacher collaboration. The space itself, with its key characteristics of openness, flexibility and scale, makes it sufficiently alien to present an unnerving picture to those teachers who place a high pedagogical value on their personal interactions with students. The sense of anxiety is palpable in Jack's comment, where "another twenty and another twenty" are presented as a faceless phalanx of unknown students, distant and potentially overwhelming.

Considering this perspective as tightly tied to personal pedagogical principles raises the issue of how well the teachers who were interviewed understood or had engaged with the forms of pedagogy that are recognised as effective in this kind of space. It has been argued that by setting the student at the centre of her or his own learning, the potential arises to enable and embolden the student to develop autonomous approaches to learning and the intrinsic motivation to make progress with this (Lim et al., 2012). It has also been suggested that empowering the student in this way creates a more positive perception of the learning environment for students (Baepler et al., 2014), as well as contributing to an improved rapport between the students themselves (Baepler \& Walker, 2014). These outcomes are some of the central drivers for the development of flexible learning spaces. Collaborative teaching affords multiple sources of knowledge and skill for students (Little \& Hoel, 2011). It is also argued to provide an important working model of the collaborative skills that process-based curricula ask students to develop (Thousand et al., 2006). There is, therefore, a fundamental philosophical and pedagogical conflict at work here. If teachers' perceptions of the value of their personal and 
professional contribution to the learning process are directly challenged by flexible learning spaces, this becomes a difficult conflict to resolve.

It could be argued that these spaces should, rather, offer the opportunity for teachers to extend their pedagogical range, providing a locus for developing alternative and complementary strategies to support the learning process (Cleveland, 2018; Young et al., 2019). However, for this to be possible, there is a need for teachers to be offered professional development opportunities to enable them to understand the advantages for students and identify appropriate pedagogies to support effective and meaningful teaching and learning in such spaces. While this is not an issue directly related to collaboration, it is one that might be well supported by collaborative practice (Owen, 2015; Stewart, 2014) to enable more hesitant teachers to see effective practice in action or to enable them to experiment with different approaches and assess their learning outcomes.

\section{Visible Teaching and Visible Learning}

\section{Lana: There is a kind of culture in teaching that we have our classroom and we go in and we shut the door, whereas obviously the learning space is absolutely open, you know. There is nowhere to hide from the kids or from other colleagues.}

A sense of performing the work of teaching as a private practice in a private space is one that is implicit in Lana's interview transcript extract above. With a move into the inspiring learning space, the work of teaching becomes much more public, offering opportunities to see and be seen by colleagues as well as other students. While for some this may present a positive challenge, for others it creates a sense of vulnerability that is directly related to their lack of preparedness to engage with the space experimentally to see what affordances it may offer. For some of the participants, being seen while teaching in the innovative learning environment presented no discernible worries, but for others it was a source of anxiety. The potential for making "mistakes", being seen to be less than competent and moving away from the comfort of familiar practice was ample reason to avoid engaging with collaborative practice (or, indeed, any practice) in the space. 
Ironically, in a teaching environment that is designed to promote social interaction and collaborative engagement, this is an area of conflict. Although teaching is regarded as a profession which espouses the need for learning from mistakes, the practical work of teaching appears to be regarded by some teachers as exempt from this. Studies have suggested that, for pupils, seeing teachers modelling the process of learning and growth through their own professional behaviours is a very positive and influential learning process (Jones et al., 2008; Little \& Hoel, 2011; Thousand et al., 2006). However, the act of learning in front of learners may present difficulties for teachers' sense of their role as leaders of learning and the "more knowledgeable other" in the teacher/learner dyad.

The culture of teaching referred to in Lana's transcript extract is one which harks back to the transmission model of teaching, which remains a dominant model in some school contexts. In this version of teaching as a profession, the teacher is the prime source of information and therefore needs to be able to present an unassailably confident and knowledgeable persona. The version of the teaching professional that operates more successfully in innovative learning environments is one that is bound up, instead, with negotiation, a flexible, discursive disposition and openness to possibilities. These attributes are perhaps linked with the need for embracing professional vulnerability and experimental approaches to pedagogy in a collaborative space.

The implied issue raised by Lana's comment is one that has been examined in a number of theoretical explorations of the work of teaching, namely the challenges raised by cultures of performativity and the challenges of being at odds with the dominant discourses at work within the school ecology (Ball, 2003; Biesta, 2009). For teachers, there is a very real possibility that professional embarrassment and dishonour can arise from situations where peer observation is an unusual and unlooked-for dimension of practice.

However, there are varieties of professional culture where there is the conscious development of a much more empathetic and generous community of support (Kennedy, 2016; Owen, 2015). In supportive professional communities of this kind, there is a recognition of a shared continuum of professional development and the sense that there is room for growth for everyone. In these communities, interaction, sharing and observation are common features and ones which are 
regarded as normal. Collaborative practice is, in these situations, much more feasible and desirable, and also offers a suite of benefits for all members of the community. Concerns about loss of face, judgment and failure are not part of the discourse in this form of professional life because dialogues are focused on growth and development rather than outcomes or achievement. There is a need for the ethos underpinning such a community to be embedded in every level of the educational culture, from government, through education policy, to teacher education and through these into all tiers of practice in schools. Without this holistic approach, it is difficult to see how a wholesale engagement with collaborative teaching in spaces such as the innovative learning environment can come to fruition.

\section{Implications}

The aim of this paper was to examine the perspectives of teachers in relation to their willingness to collaborate with peers for teaching in an innovative learning environment. The discussion here has explored four interrelated themes that presented challenges to the participating teachers in their practice. The four themes - planning, control, relationships and visibility - are each significant fields of educational research focus in their own right and therefore offer much scope for further exploration. However, the unique context of the innovative learning environment has offered the opportunity to develop a richer insight into some of these issues, particularly with a view to exploring how best to support teachers in the pursuit of effective and confident collaborative practice in such spaces.

The principal practical implication of this study is that effective and meaningful collaborative teaching requires significant scaffolding and support on the part of teacher managers, local government and national policy makers. Theoretically speaking, the issues presented by the participants in this study suggest there is a significant gulf between the curriculum and policy drivers that seek to embrace collaborative working for teachers and the day to day experiences and perceptions of teachers themselves. There is, undoubtedly, scope for a more streamlined and coherent approach to engaging teachers in this kind of work.

Of the four themes that have been explored in this paper, three are "human" or psychological in nature. Concerns about behaviour 
control and harnessing the power of positive relationships to aid learning are implicitly connected and may be seen as apprehensions about maintaining the boundaries around the interactions and bonds between teachers and pupils within a designated space. In some senses, it is reassuring to know that these are considerations of import to teachers. The matter of teachers being placed in a position of unaccustomed visibility to peers during collaborative teaching and the vulnerability this creates in an unfamiliar space could also be seen as a matter of relationships, insofar as this is a challenge for teachers' sense of self-esteem and self-efficacy (Tschannen-Moran et al., 1998; Woolfolk \& Hoy, 1990). These are social in nature but created, at least in part, in response to either implicit or explicit feedback.

The remaining theme, planning, is one which appears to present teachers with challenges of a predominantly structural nature, with a dependence on teachers being provided with time and opportunity for this work to take place. However, there are also emotional dimensions relating to planning, where taking on the responsibility of working with others to plan collaborative teaching and doing so in ways that can be seen to be effective for learners may be regarded as requiring new and different skills from teachers to those involved with their customary lone practice. The process of planning collaboration opens up individuals' pedagogy, practice and efficacy to scrutiny, and therein lies a source of conflict, particularly in a working context where this kind of scrutiny is not a normal and accepted aspect of practice. In such a setting, it is difficult to escape the perception that peer scrutiny will come loaded with the emotionally hazardous experience of being subjected to peer evaluation and, even more disturbingly, negative judgements.

Taken together, these findings suggest the vital importance of a positive collaborative ethos built into every aspect of school culture. Culture shifts such as those seen in the context of this study, where teachers have been asked to teach in a new and unfamiliar learning space, make emotional as well as pedagogical and practical demands on teachers (Deed, 2015). As has been argued in this paper, the adaptation of practice required by teachers in such spaces (i.e. with the expectation of professional collaboration and visibility to teacher peers) makes it an intimidating prospect for some. There are also issues for teachers' sense of identity and their evaluation of their 
own purpose and role that need to be considered. It is clear that affect has micropolitical dimensions for teachers' practice (Mulcahy \& Morrison, 2017) and for their sense of professional autonomy (Charteris \& Smardon, 2019) that should not be overlooked by those seeking to make changes to teachers' practice and to break with traditional models of teaching. Arguably, by normalising collaboration and developing a culture of mutual support across all the diverse dimensions of teachers' practice, not only for teachers' work in innovative learning spaces, less anxiety about collaborative approaches to practice seems a likely outcome.

It would be remiss not to restate, at this closing stage of the discussion, that in addition to being sites of professional anxiety and personal vulnerability for some teachers, innovative learning environments need to be recognised as sites of policy actualisation that are directly related to managerialist discourses of productivity. Their purpose is to serve the economy by shaping the skills and habits of the future workforce (OECD, 2013; The Scottish Government, 2009; The Scottish Government, 2007). Consequently, there are much wider issues at stake here than those connected with teachers' engagement and choices in relation to their collaborative practice. There are questions here that relate to the spirit and philosophy that guide our beliefs and overarch our approaches to education as a whole. This being the case, there is much scope for further exploration in connection with the issues raised in this paper.

\section{References}

$\rightarrow$ Altieri, E. M., Colley, K. M., Daniel, L. S. and Dickenson, K. W. (2015). Merging Expertise: Preparing Collaborative Educators, The Rural Special Education Quarterly, 34(1), 17-22.

$\rightarrow$ Archer, R., Morgan, S. and Pope, S. (2012). Rethinking partnership in initial teacher education - developing professional identities for a new subject specialist team which includes a joint school-university appointment - a case study in mathematics, https://research.manchester.ac.uk/portal/en/ publications/rethinking-partnership-in-initial-teacher-education--developingprofessional-identities-for-a-new-subject-specialist-team-which-includes-ajoint-schooluniversity-appointment--a-case-study-in-mathematics(a53aac265f97-4f5c-8d2c-24174e8c1f6a)/export.html 
$\rightarrow$ Baepler, P. and Walker, J. D. (2014). Active Learning Classrooms and Educational Alliances: Changing Relationships to Improve Learning, New Directions for Teaching and Learning, 137, 27-40.

$\rightarrow$ Baepler, P., Walker, J. D. and Driessen, M. (2014). It's not about seat time: Blending, flipping, and efficiency in active learning classrooms, Computers \& Education, 78, 227-236.

$\rightarrow$ Ball, S.J. (2003), The teacher's soul and the terrors of performativity, Journal of Education Policy, 18(2), 215-228.

$\rightarrow$ Beijaard, D. D., Verloop, N. and Vermunt, J.D. (2000). Teachers' perceptions of professional identity: An exploratory study from a personal knowledge perspective, Teaching and Teacher Education, 16(7), 749-764.

$\rightarrow$ Biesta, G. J. (2009). Good education in an age of measurement: On the need to reconnect with the question of purpose in education, Educational Assessment Evaluation and Accountability, 21(1), 33-46.

$\rightarrow$ Brand, B. and Triplett, CF. (2012). Interdisciplinary curriculum: an abandoned concept?, Teachers and Teaching, 18(3), 381-393.

$\rightarrow$ Buchanan, J., Prescott, A., Schuck, S., Aubusson, P., Burke, P. and Louviere, J. (2013). Teacher Retention and Attrition: Views of Early Career Teachers, Australian Journal of Teacher Education, 38(3), 112-129.

$\rightarrow$ Campbell, L. (2019). Pedagogical bricolage and teacher agency: Towards a culture of creative professionalism, Educational Philosophy and Theory, 51(1), 31-40.

$\rightarrow$ Campbell, L. (2020). Teaching in an Inspiring Learning Space: an investigation of the extent to which one school's innovative learning environment has impacted on teachers' pedagogy and practice, Research Papers in Education, 35(2), 185-204.

$\rightarrow$ Charteris, J. and Smardon, D. (2019). Dimensions of Agency in New Generation Learning Spaces: Developing Assessment Capability, Australian Journal of Teacher Education, 44(7), 1-17.

$\rightarrow$ Cleveland, B. (2018). Why Innovative Learning Environments? Stories from three schools that helped establish an ongoing space and pedagogy agenda. In: S. Alterator, C. Deed (eds.), School Space and Its Occupation Conceptualising and Evaluating Innovative Learning Environments (pp. 39-65). Leiden: Brill-Sense Publishers.

$\rightarrow$ Craft, A. (2008). Studying collaborative creativity: Implications for education, Thinking Skills and Creativity, 3(3), 241-245.

$\rightarrow$ Day, C. (2012). New Lives of Teachers, Teacher Education Quarterly, 39(1), 7-26.

$\rightarrow$ Deed, C. (2015). A Model of Teacher Adaptation to Open-Plan Settings. In: V. Prain et al. (eds.), Personalising Learning in Open-Plan Schools (pp. 27-41). Rotterdam: Sense Publishers. 
$\rightarrow$ Donaldson, G. (2011). Teaching Scotland's Future: Report of a Review of Teacher Education in Scotland. Edinburgh: The Scottish Government.

$\rightarrow$ Dooner, A.-M., Mandzuk, D., Obendoerfer, P., Babiuk, G., Cerqueira-Vassallo, G., Force, V., Vermette, M. and Roy, D. (2010). Examining Student Engagement and Authority: Developing Learning Relationships in the Middle Grades, Middle School Journal, 41(4), 28-35.

$\rightarrow$ Education Scotland (2020). What is Curriculum for Excellence?, https://education.gov.scot/education-scotland/scottish-education-system/ policy-for-scottish-education/policy-drivers/cfe-building-from-the-statementappendix-incl-btc1-5/what-is-curriculum-for-excellence

$\rightarrow$ Firestone, W. A., Martinez, M.C. (2007). Districts, Teacher Leaders, and Distributed Leadership: Changing Instructional Practice, Leadership and Policy in Schools, 6(1), 3-35.

$\rightarrow$ Fisher, R. and Webb, K. (2006). Subject specialist pedagogy and initial teacher training for the learning and skills sector in England: the context, a response and some critical issues, Journal of Further and Higher Education, 30(4), 337-349.

$\rightarrow$ Fletcher, E. C., Warren, N. Q. and Hernández-Gantes, V. M. (2018). Preparing High School Students for a Changing World: College, Career, and Future Ready Learners, Career and Technical Education Research, 43(1), 77-97.

$\rightarrow$ Fox, K. (2010). "Belonging" as a subject specialist: challenging the barriers, Teacher Education Advancement Network Journal, 1(2), 1-16.

$\rightarrow$ Graesser, A. C., Kuo, B.-C. and Liao, C.-H. (2017). Complex Problem Solving in Assessments of Collaborative Problem Solving, Journal of Intelligence, 5(2), $1-14$.

$\rightarrow$ Griffin, P., Care, E. and McGaw, B. (2012). The Changing Role of Education and Schools. In: P. Griffin, B. McGaw, E. Care (eds.), Assessment and Teaching in $21^{\text {st }}$ Century Skills (pp. 1-15). Dordrecht: Springer.

$\rightarrow$ Havnes, A. (2009). Talk, planning and decision-making in interdisciplinary teacher teams: a case study, Teachers and Teaching: Theory and Practice, 15(1), 155-176.

$\rightarrow$ Hayden, C. and Pike, S. (2005). Including "positive handling strategies" within training in behaviour management: the "Team-Teach" approach, Emotional and Behavioural Difficulties, 10(3), 173-187.

$\rightarrow$ Heider, K. (2005). Teacher Isolation: How Mentoring Programs Can Help, Current Issues in Education, 8(14), 1-7.

$\rightarrow$ Hobbs, L. (2012). Examining the aesthetic dimensions of teaching: Relationships between teacher knowledge, identity and passion, Teaching and Teacher Education, 28(5), 718-727.

$\rightarrow$ John, P. D. (2006). Lesson planning and the student teacher: re-thinking the dominant model, Journal of Curriculum Studies, 38(4), 483-498. 
$\rightarrow$ Jones, M., Michael, C., Mandala, J. and Colachico, D. (2008). Collaborative Teaching: Creating a Partnership between General and Special Education, The International Journal of Learning, 15(7), 203-207.

$\rightarrow$ Kennedy, A. (2016). Professional learning in and for communities: seeking alternative discourses, Professional Development in Education, 42(5), 667-670.

$\rightarrow$ Kyriacou, C. and Kunc, R. (2007). Beginning teachers' expecations of teaching, Teaching and Teacher Education, 23, 1246-1257.

$\rightarrow$ Lahtero, T. J., Lång, N. and Alava, J. (2017). Distributed leadership in practice in Finnish schools, School Leadership \& Management, 37(3), 217-233.

$\rightarrow$ Levi, F. (2010). How technology changes demands for human skills (OECD Education Working Paper No. 45), www.oecd.org/education/skills-beyondschool/45052661.pdf

$\rightarrow$ Lim, F. V., O'Halloran, K.L. and Podlasov, A. (2012). Spatial pedagogy: mapping meanings in the use of classroom space, Cambridge Journal of Education, 42(2), 235-251.

$\rightarrow$ Little, A. and Hoel, A. (2011). Interdisciplinary Team Teaching: An Effective Method to Transform Student Attitudes, Journal of Effective Teaching, 11(1), 36-44.

$\rightarrow$ McManus, J.E. (2010). Social identity and ability grouping in a secondary school. [Doctoral Thesis, Institute of Education]. University of London, https://ethos.bl.uk/ orderdetails.do?uin=uk.bl.ethos.534896

$\rightarrow$ Mulcahy, D. and Morrison, C. (2017). Re/assembling "innovative" learning environments: Affective practice and its politics, Educational Philosophy and Theory, 49(8), 749-758.

$\rightarrow$ Musanti, S. I. and Pence, L. (2010). Collaboration and Teacher Development: Unpacking Resistance, Constructing Knowledge, and Navigating Identities, Teacher Education Quarterly, 37(1), 73-89.

$\rightarrow$ OECD (2013). Innovative Learning Environments. DOI: 10.1787/9789264203488en

$\rightarrow$ Osborn, M. and McNess, E. (2005). The Cultural Context of Teachers' Work: Policy, Practice and Performance. In: N. Bascia, A. Cumming, A. Datnow, K. Leithwood, D. Livingstone (eds.), International Handbook of Educational Policy. Springer International Handbooks of Education (pp. 507-525), Dordrecht: Springer.

$\rightarrow$ Owen, S. (2015). Teacher Professional Learning Communities in Innovative Contexts: "Ah Hah Moments", "Passion" and "Making a Difference" for Student Learning, Professional Development in Education, 41(1), 57-74.

$\rightarrow$ Paris, L.F. (2013). Reciprocal Mentoring: Can it Help Prevent Attrition for Beginning Teachers?, Australian Journal of Teacher Education, 38(6), 136-158. 
$\rightarrow$ Park, S. and Oliver, J. S. (2008). Revisiting the Conceptualisation of Pedagogical Content Knowledge (PCK): PCK as a Conceptual Tool to Understand Teachers as Professionals, Research in Science Education, 38(3), 261-284.

$\rightarrow$ Priestley, M. (2011). Schools, teachers, and curriculum change: A balancing act?, Journal of Educational Change, 12(1), 1-23.

$\rightarrow$ Robinson, V. M. J. (2008). Forging the links between distributed leadership and educational outcomes, Journal of Educational Administration, 46(2), 241-256.

$\rightarrow$ Rytivaara, A. and Kershner, R. (2012). Co-teaching as a context for teachers' professional learning and joint knowledge construction, Teaching and Teacher Education, 28, 999-1008.

$\rightarrow$ Santoyo, C. and Zhang, S. (2016). Secondary Teacher Candidates' Lesson Planning Learning, Teacher Education Quarterly, 43(2), 3-27.

$\rightarrow$ Savage, J. (2012). Moving beyond subject boundaries: four case studies of crosscurricular pedagogy in secondary schools, International Journal of Educational Research, 55, 79-88.

$\rightarrow$ Stets, J. E. and Burke, P. (2000). Identity Theory and Social Identity Theory, Social Psychology Quarterly, 63(3), 224-237.

$\rightarrow$ Stewart, C. (2014). Transforming Professional Development to Professional Learning, Journal of Adult Education, 43(1), 28-33.

$\rightarrow$ Stolle, E. P. and Frambaugh-Kritzer, C. (2014). Putting Professionalism Back into Teaching: Secondary Preservice and In-Service Teachers Engaging in Interdisciplinary Unit Planning, Action in Teacher Education, 36(1), 61-75.

$\rightarrow$ The Scottish Government (2007). Building Excellence: Exploring the Implications of the Curriculum for Excellence for School Buildings. Edinburgh: The Scottish Government.

$\rightarrow$ The Scottish Government (2009). Building Better Schools: Investing in Scotland's Future. Edinburgh: The Scottish Government.

$\rightarrow$ Thousand, J., Villa, R.A. and Nevin, A. (2006). The Many Faces of Collaborative Planning and Teaching, Theory Into Practice, 45(3), 239-248.

$\rightarrow$ Tschannen-Moran, M., Woolfolk Hoy, A. and Hoy, W. K. (1998). Teacher Efficacy: Its Meaning and Measure, Review of Educational Research, 68(2), 202-248.

$\rightarrow$ Vangrieken, K., Dochy, F., Raes, E., Kyndt, E. (2015). Teacher collaboration: A systematic review, Educational Research Review, 15(15), 17-40.

$\rightarrow$ Woolfolk, A., Hoy, W. (1990). Prospective Teachers' Sense of Efficacy and Beliefs about Control, Journal of Educational Psychology, 82(1), 81-91.

$\rightarrow$ Young, F., Cleveland, B., Imms, W. (2019). The affordances of innovative learning environments for deep learning: educators' and architects' perceptions, Australian Educational Researcher, 46(5), 1-28. 


\section{The Role of Graphic Organisers in Iearning and Ireaching}

DOI: $10.47050 / 66515321.170-184$

Marine H. Arakelyan

This chapter aims to describe the significance of various graphic organisers not only in teaching but also in learning cycles across the course continuum. They are effective instructional tools to enhance students' creativity, innovative mindset and higher-level thinking and to integrate previously-acquired knowledge with the existing proportion of the learnt schemata. Moreover, the implementation of different graphic organisers as useful visual tools in different modes, at various levels, and across all skills and subject domains fosters active learning and effective teaching under different circumstances to identify alternative learning opportunities and achieve various accessible and measurable learning outcomes as an integral part of the curriculum. The chapter also reveals not only the advantages of graphic organisers' incorporation into our teaching and learning phases, but also possible disadvantages that might occur while graphic organisers are used in a learning task.

In this paper, a further effort is made to illustrate the impact and importance of e-portfolio implementation as an interactive and effective device containing multiple graphic organisers to foster learning/ teaching styles and strategies, reflection, and awareness in both teachers and students.

\section{Keywords:}




\section{Introduction}

In all stages of language learning, the process is presented as a multilayered, continuous and interesting procedure. This paper is aimed at illustrating the value of various graphic organisers in teaching and learning cycles across the course continuum as effective instructional tools. There is no doubt that these powerful tools assist students with realising their departure point before starting their learning journey through the content, where they are at that specific moment and where they are planning to reach (Boudah, Lenz, Bulgren, Schumaker \& Deshler, 2000).

As useful teaching tools, they can be used for all types of students (e.g. mixed-ability classes, gifted students or those with special needs) in all stages of the learning process and within every discipline (EFL, Social Studies, Math, Research, IT, Assessment, etc.).

According to Gallavan and Kottler (2007), graphic organisers are practical methods of great importance because a large proportion of information can be simplified as per the requirements and the students' level and presented by serving multiple curriculum-oriented purposes from different perspectives.

This makes learning a more manageable, meaningful, achievable and enjoyable task, especially for students with special needs (Gallavan \& Kottler, 2007). The above-stated features have a clear connection with the ones that have been determined, revealed and demonstrated in various settings throughout my learning/teaching experiences.

\section{The Importance of Sharing Experiences}

For today's classroom, the incorporation of graphic organisers as a set of different teaching techniques and strategies and as effective learning tools provides students with more control over the content with all its components within a learning task and facilitates both their understanding of the assigned activities, their own learning styles and modes and their awareness of their inner strengths and weaknesses.

The effective use of these tools also assumes to foster students' ownership of the presented information and their active involvement in all cycles of an acquisition process where students internalise what they are learning with all the connections between the concepts and paths, sometimes adjusting them to their own ways of perception and emphasising the most significant parts of the provided information in a brief and logical order (Bromley, DeVitis \& Modlo, 1995). 
In the meantime, teachers should take into account the need for differentiating their teaching strategies and the ways and methods of how to implement graphic organisers not only for language teaching and learning but also for enhancing higher-order thinking skills. It is obvious that the use of graphic organisers in any phase of a learning or teaching cycle can have a positive backwash effect on students' active engagement and comprehension. This will lead to a productive phase of student-student and teacher-student interactions where all the participants are involved in meaningful and purposeful learning. Thus, according to various researchers (Hutchinson, 2007; William, 2005), the effective use of graphic organisers positively impacts and enhances all strata of students' active learning processes and academic performance, including students with learning disabilities.

\section{Applications of Different Graphic Organisers}

Various phases of any learning cycle take time, as students mainly perceive new elements of knowledge by questioning the known and the unknown and observing multifaceted components of authentic information embedded into in-class and out-of-class learning tasks.

It is assumed that in order to understand newly-formulated information throughout a learning cycle, either the information must be broken down into manageable and achievable chunks so that students can easily spot and infer, even indirectly, stated relationships between the separate ideas, or it must be organised to filter core pieces of information, based on which any student can align the associated concepts/ideas with their background schemata.

Hence, being universal in nature, graphic organisers appear to be valuable devices that facilitate the comprehension of various instructions, make the invisible meanings of the concepts visible and enhance student learning no matter the extent of the students' cognitive maturity, types of learning styles and strategies, or prior experience of their engagement in the learning cycle. Moreover, it is believed that students should feel free to experiment and take risks while increasing their ability to think and to take responsibility for their own learning. Thus, being powerful tools, once teachers use graphic organisers in any phase of instruction, it is inevitable that students' learning will improve (Hall \& Strangman, 2002). It should be noted at this point that even though different terminology is used, such as story, concept or mind 
maps, cognitive and advanced organisers or concept diagrams, they will all be referred to here as graphic organisers.

To get the whole picture, it is essential to mention that there are many ways to classify graphic organisers. As stated by Bromley et al. (1995), graphic organisers are classified into four basic types, based on how the represented information is arranged. However, regardless of the chosen method of representation, graphic organisers are considered to be more effectively implemented and better instructional tools if they are clear and straightforward with plain instructions focusing only on the core information (Boyle \& Yeager, 1997; Egan, 1999). More specifically, the first of the categories is called cyclical as it displays the sequence of events or organises numerous pieces of information in a process without stating the exact beginning and ending. The second category is called conceptual, due to the fact that it indicates how a core concept is supported by relevant facts, evidence and characteristic features. The third type is known as sequential. It shows the relationship between an essential concept and sublevels of the features such as cause-effect and problem-solution.

Hierarchical organisers belong to the fourth category. They may be especially useful tools when the students' aim is to perceive the relationships between diverse parallel ideas and their relationship with a larger concept or an idea as well as the chronological order of different events within the timeframe. They also help students to correctly keep track of details, activate their prior perception(s) of the concept and prevent them from the confusion of which details are associated with which main idea. Thus, various types of graphic organisers within each of the above-mentioned categories such as Venn diagrams, fishbone maps, flowcharts, timelines, rubrics, spider maps, and matrices can illustrate both simple and complex information based on either a single concept or multiple/parallel concepts.

It is very likely that the integration of various organisers into learning enables students to create semantic maps and story maps to facilitate and enhance reading comprehension (Hutchinson, 2007). Moreover, the incorporation of graphic organisers into learning enables students to develop concept-associated structures, store newly-perceived pieces of information and align them with previously-gained schemata for comprehension and assessment purposes that emphasize a stronger sense of ownership of their own work. 
In the meantime, teachers elaborate new graphic organisers to evaluate students' understanding of the provided information (Hutchinson, 2007) for research projects or other specific learning tasks for which the purpose, assessment type and learning outcomes to be met are clearly stated. These tools facilitate both student-guided and independent learning through active interaction and meaningful learning where students pose thoughtful questions in order to arrange, comprehend, retain and internalise new pieces of information for further use (McKnight, 2010; Hutchinson, 2007).

Needless to say, this will foster students' higher-order thinking, such as critical and analytical thinking skills, which will make them more successful and independent learners. Furthermore, while using cause-effect, KWL, web clusters, compare-contrast, Venn diagrams and other thought-provoking graphic organisers, students become capable of visualising general concepts and breaking them down into manageable, meaningful and specific ideas that will push them a step closer to becoming better decision makers and problem solvers, triggering other soft skills into their everyday life. Hence, the various applications of graphic organisers across different subject areas, skills and levels create a positive backwash effect on student-teacher and student-student interactions, leading to the enhancement of students' learning.

During teaching/learning cycles, due to the multiple advantages of these instructional tools, they can be used within any stage of a planned lesson and in various ways (as a warm-up activity to generate ideas or a wrap-up), based on the purpose of the lesson and the learning outcomes required to be achieved by its end. More specifically, they can be used across language and content area acquisition stages not only individually but also in large groups. It has been described (Merkley \& Jeffries, 2000) that, through these effective devices, teacher-directed instruction is transformed into student-directed instruction where the emphasis is on students' metacognitive skills in general that can be used in different situations.

Ellis (2004) suggested a number of steps to follow. First, the teachers should explain to students exactly how the organiser is used and what is required to be done, and allow the students to create their own graphic organisers by focusing only on essential information. In this way, the teachers will facilitate students' learning on both how content 
is organised and how graphics work in the domain of visual strategies. Afterward, modeling can be taken on board to reveal all the challenges and subtleties of how to implement the preferred method, which will be followed by guided practice.

In light of this, both the teacher and students can come up with many possible ideas on how to complete the graphic organiser meaningfully and purposefully as an overall class objective. There can also be small group practice, where the students may learn from their peers through observing other effective and interactive approaches to the same procedure. Moreover, students may be assigned some thought-provoking tasks on graphic organisers in groups to trigger their accountability for a better result as well as strengthen their communication skills. Finally, students can deal with the organiser by themselves, but they should be given support and constructive feedback if necessary.

All these steps will make students more confident in getting enrolled in independent practice and using various graphic organisers. As soon as the students master the skill and perceive the whole array of the usage of these tools, they will generate their own graphic organisers, web clusters, diagrams and concept/mind maps. Though students will have independence in creating and completing graphic organisers, the teacher must follow this sequence for each type or format introduced and encourage the students to reveal the relationships between the ideas/concepts and identify the information contained and the learning outcome behind the task.

Each of the above-enumerated components can be incorporated into teaching and learning practices across all the areas of the EFL setting. Thus, depending on the objectives of the class, the teacher's goal for a specific lesson and its nature, and the learning styles of the students engaged, the application of graphic organisers can be different: to write an essay or reports, to prepare briefs and outlines, to take notes on major issues or main ideas from lectures or internet sources, to make an outline for project work or a planned presentation, or to organise relevant information to study for an exam or for a graded-reader book review.

It is worth stating that these various skill-oriented graphic organisers are considered to be powerful instructional tools that make student learning more enjoyable, meaningful, and sustainable. Moreover, due 
to the above-mentioned reasons, the scope of graphic organiser-related research still remains an ongoing path of inquiry for various scholars.

Another important thing to note is that when students are given flexibility and clarification on the purposeful and meaningful use of graphic organisers, they can use numerous graphic organisers corresponding to their learning styles, needs and levels of intelligence. In addition, there is tangible evidence of the positive influence of graphic organisers on students' better comprehension of a large chunk of new information and completion of complex tasks (Ellis, 2004).

As a result, students are able to generate concept-associated structures or create images in their minds to uncover multilayered aspects of the content, store newly-acquired information in their long-term memory, align it with previously-obtained knowledge, reveal conceptual relationships, graphically depict the overall representation of similarities and differences, causes and effects, problems and solutions, and discuss and evaluate relevant relationships between content and sub-content, main idea and supporting details (McKnight, 2010).

\section{Challenges with Graphic Organisers}

There may be a number of challenges while finding out the most effective ways of implementing graphic organisers across skills, levels and subject domains. It is obvious that graphic organisers must not be overused since the students may become stressed or bored because the process of graphic organiser completion can be time-consuming and may negatively impact students' creativity.

It should be said that not enough research has been done with detailed investigations on the types of graphic organisers to be incorporated in overall comprehension, specifically in the reading dimension, and the type of students who benefit most from the specific use of these visual devices. This means that in some situations, possible drawbacks might occur while incorporating graphic organisers in a learning task. For example, note-taking may decrease when students learn new material by applying graphic representations. Consequently, students may lack a comprehensive guide while revising the material, which may affect their academic performance.

Another shortcoming is closely related to giving constructive feedback on a particular task or situation-related graphic organiser. 
Creating some criteria or a rubric to assess graphic organiser completion is supposed to be time-consuming. Teachers mostly implement graphic organisers to foster brainstorming, discussions, explanations of complex ideas, and active engagement. However, they do not tend to make corrections and give comments on each student's organiser when it is complete. As a result, the student may miss out on the chance to receive valuable feedback.

Being teachers, we always plan our lessons with the intention to maximise student engagement in the class, make it interesting and interactive, and achieve the learning outcome(s) by the end of the class. As the teacher has the needed flexibility to flow from one topic to the next and can answer questions, this may lead students to another part of the context in different domains of teaching and learning.

In addition, when the class teachers use graphic organisers as a review tool, they are of great significance, as they help students recall important facts on various features and concepts. On the other hand, arranging information from a written text, an audio conversation, a lecture or a writing prompt on an organiser, such as a Venn diagram, can allow students to visualise how something is similar, different or the same. They can see all this information on one sheet of paper so they do not need to take pages of notes to study at home, making it less frustrating and confusing.

According to Drapeau (2009), graphic organisers are instructional tools that can be implemented for all types of students in all phases of the learning and teaching process. Thus, the use of these effective tools will foster the methods of students' creativity and develop more meaningful and active learning experiences at various stages of the learning cycle, accompanied by higher-order competencies.

All in all, there is no single technique or approach that can be applicable to every student. Therefore, the maximum level of acquisition can only be derived if teachers are well equipped with the ability to use the strategy in an appropriate way, typical of the level of the students' proficiency.

\section{Interaction through Graphic Organisers}

The use of different types of graphic organisers in the EFL setting can effectively contribute to the creation of a wider learning/communicative environment in which the students are encouraged to reveal their 
competences, enrich their English vocabulary, acquire English language skills and unfold their self-concept in an interactive way. The employment of the best practices of gained knowledge construction, vocabulary improvement, structured information creation, story demonstration, essay writing and other techniques is designed to prove that students are given the opportunity to interact not only with each other and with the teacher, but also with the given content or information with the explicit intention of decoding all the aspects of the concept or content.

In terms of the advantages of different applications of graphic organisers, it is worth mentioning that they can be used in numerous ways to improve the overall comprehension of EFL learning skills, which makes them challenging and primary tools in all EFL classrooms.

One of these helpful visual tools is concept maps, which permit students to concentrate on the exact concepts essential to boosting meaningful learning cycles and thorough comprehension. According to Cesarone, a concept map is a "chart-based graphic that describes a concept and its various relationships, with general concepts at the top, supporting concepts at the bottom, and lines showing the connections between the concepts" (2007, p. 191).

This approach enables students to elaborate a new proportion of information to the existing schema. It is undeniable that the students will then have ample practice in the basic skills required to master verbal and written English. Cesarone (2007) suggested that concept maps could be implemented to foster the overall comprehension of the students with learning disabilities, as these students encounter enormous hardship in expressing themselves and connecting ideas.

Furthermore, this helpful technique can be used to evaluate the students' perception of the provided information by asking them to create their own concept maps/web clusters by means of activating their background schemata, bridging it to the newly-perceived knowledge and making the existing relationships between concepts and ideas more explicit and integrated (Novak \& Cañas, 2006). In addition, the students participate in giving different viewpoints and judgments on authentic tasks by interacting with their prior schemata through understanding how the information content of one sentence links in meaning with the content of the following one (Merkley \& Jeffries, 2000). 
In light of this, students will further make tangible progress in their achievements when lessons are interactive, interesting, and varied. Furthermore, this promising learning setting highlights the necessity for EFL teachers to integrate and implement graphic organisers as visual tools when students are pushed to acquire more understanding about each other, their own self-concept, and the world through the medium of a new language. However, the effectiveness and positive backwash effect of any kind of instruction will be rooted in teachers' constructive skills and knowledge in the development and implementation of graphic organisers (Hutchison \& Padgett, 2007).

It is necessary to note that graphic organisers remove a lot of words involved in prewriting and, through the use of pictures, they force students to make constructive connections among and between the ideas. Figuring out how the piece of writing fits together and flows is the foundation for any good writer. When students can see how ideas are placed into an order, writing is far less frustrating and can actually become something they greatly enjoy doing.

With one diagram, they have all the information they need to know about a particular topic. It can make the learning process a much more enjoyable endeavor for all types of students at all levels. Furthermore, graphic organisers can be implemented while conducting a lecture, no matter whether the class is a large first-year class or a smaller higherlevel course.

Taking into account the students' learning strategies and styles, teachers can use multifaceted graphic organisers in a lecture in different ways for explicit and implicit purposes. First, teachers could use them to prepare their instruction with a more simplified approach. Second, they could use them as a visual aid for students in a large class to guide the talk in a sequence and by topic or in a skill-oriented manner. In teaching reading skills (Merkley \& Jeffries, 2000), graphic organisers allow both the teacher and students to keep an overview of what the topic of discussion is at all times. Moreover, graphic organisers could be used to narrow down many ideas, written in a linear format, into key topics that the teacher would like to discuss in class. Having only the key words or topics that the teachers would like to explain allows the students the freedom to discuss these topics in a structured format without having rehearsed instruction. 
In hindsight, it is crucial to note why graphic organisers are considered as a primary tool for language learning. Graphic organisers resemble networks and allow students to add or alter their background knowledge by seeing the key conceptual connections rather than facts and contradictions between existing knowledge and newly perceived information. Other techniques used to assist students with visualising the general concept and breaking it down into manageable, meaningful, and specific ideas are mind maps or concept maps. As for the incorporation of KWL (Know, Want to Know, Learnt) charts into EFL teaching/learning, this tends to activate students' prior knowledge of a topic or a concept as well as encourage students' active learning, constructive interaction and research skills.

Furthermore, they are helpful and thought-provoking as a pre-reading strategy when reading expository texts, and may also serve as an assessment tool of what students have learnt during a unit of their study. Various implementations of graphic organisers in a reading class make the content area digestion a much more enjoyable and efficient endeavor, as it facilitates students' most complex learning cycles within the content perception in order that they can acquire all of a text's information with its hierarchical arrangements in one graphic organiser. As a result, the students can identify the main ideas and make the desired connections within one diagram. They align all the information-related components and reveal the multilayered interrelationships of various ideas and their logical connections between and among higher and lower order concepts (Alvermann, 1986; Barron, 1979; Hutchinson, 2007).

It is worth mentioning that the explicit purpose of the incorporation of these effective instructional tools in the reading class is to boost students' reading comprehension of the entire meaning of the text by decoding the clues as well as the hidden or directly stated relationships throughout the context. Therefore, while conducting a brainstorming phase to develop a story map, the students reveal their awareness of their current level of understanding and then try to advance themselves. By establishing appropriate scope-related knowledge and pushing their deductive and inductive reasoning skills forward in their minds, students implement various ways of building up enduring understanding. This makes them more autonomous and motivated. 


\section{Graphic Organisers within an e-Portfolio Framework}

There is valuable practice regarding the implementation of graphic organisers within the frame of the e-educational domain, more specifically in an e-portfolio, as one of the most interactive tools to enhance learning and teaching. This can be considered as one of the best platforms for a constructive virtual teacher-student dialogue and students' active participation in multilayer learning through an interactive graphic designer. This is due to the efficient process throughout which the e-portfolio helps to facilitate collaboration and interaction between students and a teacher. It also assists learners in obtaining regular feedback from a teacher through the addition of their comments to individual portfolio items, as well as defining students' weak and strong sides for further learning and improvement.

The aim of the use of the student e-portfolio is to teach and encourage students to organise the flow of their thoughts into further work, to record and learn new vocabulary and to become independent learners. This means that students can be responsible for their own learning by reflecting on it in an e-portfolio domain. It is worth highlighting that in an e-portfolio platform, pre-designed templates of different components are used as a way to scaffold student portfolio activities.

One of the valuable features of using an e-portfolio as an interactive learning and teaching platform is that students may reuse their e-portfolio components (e.g. an academic calendar, a can-do checklist, learning goal statements, reflection forms, self-study and vocabulary logs) throughout their learning journey. They can revisit the same tasks to assess, self-evaluate, make necessary changes according to the comments made by a teacher, and self-reflect at any time. It is evident that time management is an indispensable requirement to be met for any e-portfolio task in order to get a high mark because students have to meet the assigned deadlines for different components.

As a result, graphic organisers incorporated into an e-portfolio domain are intended to assist students in developing their study habits and becoming more autonomous in any learning task. Thus, students learn how to plan their time, find solutions to the problems they have in their study and organise their work effectively, which is why it is important to be aware of their learning styles in any given situation 
and recognise patterns within an e-portfolio framework as well as for them to reflect on their own learning.

\section{Conclusion}

To sum up, regarding the multiple benefits of the use of graphic organisers, they have become a so-called umbrella term containing a range of effective learner-centred tools and instructional strategies that can be applied on a more frequent basis depending on teaching objectives and learning outcomes to be achieved. This may contribute to students' better academic performance on various stages and in different types of formative and summative assessments (Marzano et al., 2001).

Moreover, graphic organisers as described by Drapeau (1998) are aimed at enhancing students' higher-level thinking and cognitive skills by encouraging the process of brainstorming, generating new ideas, aligning them with their background schemata, and classifying, comparing, contrasting, sequencing, synthesising as well as visualising how parts are connected to the whole, which leads to a thorough comprehension of the correlation(s) between ideas, facts and specific operations.

Another tangible benefit of the use of these instructional tools is to support teachers to differentiate a mode of instruction, based on the students' needs and the content being learnt, to understand multilayered concepts (Hall, Kent, McCulley, Davis \& Wanzek, 2013). This will open communication channels among peers and teachers, giving everyone involved a voice.

Encouraging new ways of multiple intelligence is one of the most important advantages of a graphic organiser that has become a vital tool to get students engaged in class activities during which they need an open mindset to think critically about a particular topic based on previously acquired knowledge.

It is believed that not all students are aware of their own learning capacities or know how to foster interaction without being afraid of making mistakes. On the advantages of graphic organisers, Drapeau (1998) emphasizes that they expand students' understanding of divergent complex concepts by visualising general concepts and breaking them down into manageable, tangible and specific ideas. Thus, with the help of the interaction between graphic organisers, 
skill elaboration and active engagement in learning tasks, these tools have become a priority of the educational improvement agenda in the EFL setting.

\section{References}

$\rightarrow$ Alvermann, D. E. (1986). Graphic organisers: Cueing devices for comprehending and remembering main ideas. In: J. F. Baumann (ed.), Teaching main idea comprehension (pp. 210-226). Newark: International Reading Association.

$\rightarrow$ Barron, R. R. (1979). Research for the classroom teacher: Recent developments on the structured overview as an advance organizer. In: H. L. Herbert, J. D. Riley (eds.), Research in reading in the content areas: The fourth report, Syracuse: Syracuse University Reading-Language Arts Center.

$\rightarrow$ Boudah, D. J., Lenz, B. K., Bulgren, J. A., Schumaker J. B. and Deshler, D. D. (2000). Don't water down! Enhance content learning through the unit organizer routine, Teaching Exceptional Children, 3, 48-56.

$\rightarrow$ Boyle, J. R. and Yeager, N. (1997). Blueprints for learning: Using cognitive frameworks for understanding, Teaching Exceptional Children, 29, 26-31.

$\rightarrow$ Bromley, K., Irwin-DeVitis, L. and Modlo, M. (1995). Graphic organisers: Visual strategies for active learning. New York: Scholastic Professional Books.

$\rightarrow$ Cesarone, B. (2007). Concept mapping in early childhood and primary education, Childhood Education, 83, 191-192.

$\rightarrow$ Drapeau, P. (1998). Great teaching with graphic organisers. New York: Scholastic.

$\rightarrow$ Drapeau, P. (2009). Differentiating with Graphic Organisers: Tools to Foster Critical and Creative Thinking. Thousand Oaks: Corwin Press.

$\rightarrow$ Egan, M. (1999). Reflections on effective use of graphic organisers, Journal of Adolescent \& Adult Literacy, 42, 641-645.

$\rightarrow$ Ellis, E. (2004). Q\&A: What's the big deal with graphic organisers?, www. graphicorganisers.com/Sara/ArticlesAbout/Q\&A\%20Graphic\%200rganisers. pdf

$\rightarrow$ Gallavan, N.P. and Kottler, E. (2007). Eight Types of Graphic Organisers for Empowering Social Studies Students and Teachers, Social Studies, 98(3), 117-128.

$\rightarrow$ Hall, C., Kent, S. C., McCulley, L., Davis, A. and Wanzek, J. (2013). A New Look at Mnemonics and Graphic Organisers in the Secondary Social Studies Classroom, Teaching Exceptional Children, 46(1), 47-55.

$\rightarrow$ Hall, T. and Strangman, N. (2002). Graphic organisers. Wakefield: National Center on Accessing the General Curriculum. 
$\rightarrow$ Hutchinson, C. B. and Padgett II, B. L. (2007). How to create and use analogies effectively in teaching science concepts, Science Activities, 44, 69-72.

$\rightarrow$ Marzano, R., Pickering, D. and Pollock, J. (2001). Research-based strategies for increasing student achievement. Classroom instruction that works. Alexandria: Association for Supervision and Curriculum Development.

$\rightarrow$ McKnight, K. S. (2010). The Teacher's Big Book of Graphic Organisers: 100 Reproducible Organisers that Help Kids with Reading, Writing, and the Content Areas. San Francisco: John Wiley \& Sons.

$\rightarrow$ Merkley, D. M. and Jeffries, D. (2000). Guidelines for implementing a graphic orgamar, The Reading Teacher, 54, 350-357.

$\rightarrow$ Novak, J. D. and Cañas, A.J. (2006). The Theory Underlying Concept Maps and How to Construct Them, www.stanford.edu/concept_maps

$\rightarrow$ Williams, J. P. (2005). Instruction in reading comprehension for primary-grade students: A focus on text structure, The Journal of Special Education, 39, 6-18. 


\section{School Social Work and Inclusion \\ of Refugee Students in Greek Schools \\ Teachers' Perspectives and Experiences}

DOI: $10.47050 / 66515321.186-210$

Irene Katsama, Stefania Bakirtzi

This chapter studies the issue of integrating diversity into primary education and, in particular, focuses on the case of refugee students. It aims to explore the views and perceptions of teachers on issues arising in the school environment that either complicate, obstruct, or enhance the student integration process. The present study explores the crucial contemporary issue of the integration of refugee students into education following recent legislative reforms of intercultural education in Greece and the European Union.

\footnotetext{
Keywords:

diversity

education

inclusion

integration

refugee students

school social work
} 


\section{Diversity and integration in education}

Education contributes significantly to the integration and promotion of social cohesion. As stated in the Convention on the Rights of the Child, every child has the right to attend general education, regardless of race, ethnicity, or mental, physical, psychic or other ability (United Nations, 1989, p. 3). The distinction between students with or without disabilities, natives or foreigners, is formally unaccepted, as schools focus on the common features that students share and the positive effects of any kind of diversity in interaction.

In regard to the term diversity, the question that arises is: Different from whom or from what? Diversity refers to any personal, physical, or demographic feature (such as skin colour, gender, or ethnic origin), while in a deeper context, it refers to attitudes, values and beliefs. More generally, the term has appeared in the literature since the 1970s, when it referred to minorities and women in the workforce (Karanikola \& Pitsou, 2015).

In the modern scientific discourse, the terms difference and diversity usually refer to students who are different from those described by the literature as mainstream (Boethel, 2003).

In a multicultural environment such as a school, an understanding of the distinction between us and the other person, that is, the realisation of identity versus diversity, is necessary for the understanding of relationships. Diversity is a philosophical and anthropological term that identifies the other person (Soulis, 2008; Kandylaki, 2009), highlighting that the other person may be the imaginary other. This can be the opponent, the enemy, or even the cherished, the desirable. As the images of us and one's self are formed at an early age through education, school is an important factor in influencing or altering students' perception of diversity.

In education, a certain class or school population does not necessarily mean a heterogeneous group of students. On the other hand, the term diversity tends to be used for any group of students, however homogeneous it may be, in which most members do not reflect the main characteristics of the broader group (Keil et al., 2007).

Legislation against discrimination on the grounds of racial or ethnic origin, religion, age or sexual orientation has significantly affected educational policies combating discrimination in Europe. According to Article 13 (2000), the European Union has adopted two 
anti-discrimination directives: one on the implementation of equal treatment, irrespective of racial or ethnic origin, which prohibits racial discrimination in the fields of employment, education, social security, health care and access to goods and services, and a second on the formulation of a general framework for equal treatment in employment and occupation on the grounds of religion or belief, age and sexual orientation.

The role of teachers in the management of discrimination becomes essential for the inclusion of students in school and, thus, society on equal terms. With teachers' contribution, the participation of students bearing any kind of diversity in school can enable them to become active members and explore the environment according to their interests and needs. They can also engage themselves in the process of discovery through collaboration with others and develop their personality in an area that cultivates "acceptance, respect, interaction and creativity" (Kontogiannis, 2012, p. 273). The above-mentioned core values are prerequisites for inclusive education.

According to Mel Ainscow and Susie Miles (2009, p. 8), "inclusion or inclusive education" is the "education that refers to all students regardless of their abilities or weaknesses as a result of gender, social order, nationality and of their ability". Inclusion is a complex and dynamic process with multiple educational, political, and social extensions. The term inclusion is often confused with other terms such as integration, from which it can be a conceptual development without, however, identifying with them. The difference is that integration refers to the way certain groups, such as students with disabilities or different linguistic, religious or social minorities, can attend general education, while inclusion focuses on developing the quality of education provided in school so that all students can attend (Soulis, 2008, p. 53).

Inclusive education aims to ensure that all students are welcomed at schools in their neighbourhood in order that they can attend regular classes. Necessary changes need to be made for refugee students to be effectively integrated into the school community since schools have to meet the needs of those students and enable their participation in all aspects of school life (Soulis, 2008). In summary, inclusion refers to "how we develop and design our schools, classes, programmes and activities so that all students learn and participate together" (Inclusion BC, n.d.). 
As Athina Zoniou-Sideri and Evdoxia Deropoulou-Derou argue (2012, p. 17), "inclusion is a way to gain the effective participation of all students throughout the activities of general education". However, continuous and daily efforts are required, with many challenges and constant changes in attitudes and practices that often engender the exclusion of diversity from education. Inclusion is based on empowerment, participation in small groups, the development of collective action, and the enhancement of co-operation among all students. The purpose of the above-mentioned actions is to utilize all students' knowledge, personal experiences, feelings and thoughts, aiming at the cultivation of mutual understanding, the exploration of different ways of managing such issues as co-operation or conflict resolution, the motivation of creativity and the encouragement of the active engagement of all students in the learning process. Equally important are the systematic monitoring and support of all students and their needs at the educational level, their work and their social environment.

Regarding refugee students, the Greek Ministry of Education and Religious Affairs has, as a basic principle, the promotion of measures aimed at educational equality, the elimination of inequalities experienced by students who speak their native language and the assurance of equal opportunities in education for all students in the context promoted by the principles of intercultural education. According to the Government Gazzette (63A/21.09.2016), the objective of the Zones of Educational Priority (ZEPs) is "the equal integration of all students in the education system through the operation of supportive actions" in order to improve learning outcomes.

\section{Refugee Students attending Greek Schools}

Many children, irrespective of the status of their parents, are studying at all levels of education in Greek facilities. In 2016-2017, when 22,000 refugee children were in the country, 800 reception classes were facilitated within public schools, each including 10 to 20 pupils aged between 6 and 15 years. They were offered a 4 -hour programme on the Greek language, mathematics, computer science, music, art, theatre and gymnastics (Buchanan \& Kallinikaki, 2018).

According to the Ministry of Education (2017), during the 2017-2018 school year, 1,000 schools across Greece accepted refugee children, 
while 30 kindergartens operated within the refugees' accommodation structure. Specifically, there are "an estimated 2,493 children aged 6-16 who live within the urban fabric (in apartments or hostels) and have already been enrolled in schools throughout Greece at all levels of education. More than 2,360 are estimated to be school-age children (6-16 years old) living within the Inland Refugee Accommodation Structures" (Ministry of Education, 2017). Children aged 6-16 who attended last year's reception classes will join this year's public school morning program. Consequently, 211 teachers have enrolled for 600 reception classes that operate in the morning while 36 permanent teachers of the primary and 33 teachers of the secondary education systems have been appointed to the position of Refugee Training Coordinator1.

About 12,000 refugee children attended Greek schools during the 2018-2019 school year. Aiming to ensure access to school for refugee children staying on the Greek islands, the Regional Education Directors highlighted the positive experiences they have gained in these specific regions (Greek City Times, 2019).

Nevertheless, as the UNHCR (2019) declares, "Refugee children face increased challenges in enrolling at school globally, but their right to education should be safeguarded. The school is a safe space that gives them opportunities for empowerment, while helping integrate into the societies that welcome them". Therefore, the process of enrolling refugee students in Greek schools has encountered many difficulties and obstacles, as several parents' associations throughout Greece have opposed the integration of refugees into the education system, and a number of those associations have protested against refugee students' inclusion and refused to accept them into schools, claiming religious and cultural differences.

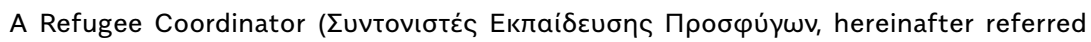
to as an SEP) is a teacher designated to each refugee hosting centre. The number of SEPs depends on the number of refugee residents. The RTCs recommend measures for the proper functioning of the educational units and address issues related to: (1) informing the residents of the host centre of the need for education as a basic means of social inclusion, (2) the implementation of the educational policy of the Ministry of Defence, (3) recording the pupils attending the educational units by age and other criteria, (4) monitoring and coordinating the training provided by all GOs and NGOs, as well as observing quantitative and qualitative elements of the educational actions of other institutions, and (5) the recording of service needs (naftemporiki.gr, 2016). 
In particular, parents seem to claim that the gap between the different cultures is so big that the settlement of immigrants in certain areas would cause problems of adaptation. In some cases, parents' associations highlighted that the quality of education will negatively affect Greek students. Therefore, according to the above view, all refugee students should be excluded from the general education system and their placement in educational groups should be within the "hotspots"2.

The separation of refugee students from the rest of the general population, apart from conflicting with a child's statutory rights, also promotes an exclusionary situation in refugee settlements (United Nations, 1989). In this situation, school social workers manage or work on preventing problems of marginalisation and social exclusion, aiming at the promotion of inclusion in education for all students.

\section{School Social Work and the Inclusion of Diversity in Education}

The need for planning and implementing interventions that aim at the management of diversity at schools appears more than necessary. Internationally, social work has a broad scope of practices in all grades of education. The tradition and culture of each country affect practices of social work. Recently, a connection between social work, social pedagogy and school social work has been implemented in countries such as the United Kingdom, France, Germany and the Netherlands (Lorenz, 2008; Hatton, 2008). Kieron Hatton (2008) underlines the significance of creativity as a strategy for the improvement of services provided at schools and emphasises the cultivation of personal and social skills through their participation in social workgroups. Personal development, self-esteem improvement and social inclusion all contribute to the promotion of children's mental health.

School social work interventions are based on theoretical approaches (critical social work, anti-oppressive) that support and promote the rights of minority students, refugees and immigrant children (Kallinikaki, 2011; Kandylaki, 2010). 
Most school social work interventions are based on systems theory, as it takes into consideration the interaction between the individual and the environment. Social work interventions address the needs of all parts of the school community - students, parents and teachers - while also bearing in mind all the interactions and influences the external environment brings into the school community (Katsama \& Bourbaki, 2017).

Systems theory underlines the complexity and diversity of individuals and systems, as they "interact continuously for mutual coexistence" (McMahon, 1996, p. 27). Looking at certain contexts, instead of considering whether the environment has an influence on the individual or the individual has an influence on his or her environment, the question is whether the person is part of his or her environment (Dimopoulou-Lagonika, 2011).

\section{Research Methodology - Purpose and Objectives}

The present research explores how teachers perceive, experience, symbolise, and adopt behaviours towards the inclusion of diversity in education. Its purpose is to explore the views of teachers on issues that arise in the school environment and whether they complicate or enhance and promote the integration process of all students. Emphasis is given to the ways in which teachers contribute to the inclusion of students in their school. Furthermore, the ways in which collaborations between school social workers and teachers can contribute to the effective inclusion of students in education and the community are also explored.

Four research questions were formulated for the exploration of the subject:

1. What are teachers' perceptions concerning inclusion and in what way/how do they work on students' inclusion in the classroom?

2. How do teachers perceive school social workers and how informed are they about their role?

3. In what ways could social workers' and teachers' collaborations contribute to the inclusion of diversity in the school environment?

4. How could inclusive education and co-operation between teachers and social workers contribute to the social integration of groups (refugee students)? 
As already mentioned, in-depth interviews were the main research tool and semi-structured questions were designed accordingly. Pieria, a district of 126,698 people (as of 2011) in the north of Greece, was selected as the target area, as it received a large influx of refugees during 2017. They live in apartments in the centre of the city of Katerini as well as in outlying villages and have attended regular schools in the wider area since September 2017 (Alfavita, 2016; PierikiAlithia, 2017).

Seven primary education teachers participated in the research. Their selection was based on purposive sampling, and their profiles are as follows:

1. A primary school teacher who works in an integration class.

2. A teacher who works in a kindergarten integration class attended by two refugee students.

3. A teacher who works in a primary school in Katerini (with two refugees in their class).

4. The director of a primary school in Pieria that has taken in many refugee students.

5. An SEP (Primary Education) working in the Administrative District of Pieria.

6. An SEP (Secondary Education) working in the Administrative District of Pieria.

7. A teacher who works in a kindergarten integration class attended by four refugee students.

\section{Data Analysis}

The produced data derived from recording and transcribing the interviews (consent for which was given by the respondents). Five individual subject areas resulted from the thematic analysis process and are presented and analysed in turn below, with accompanying quotes from the participants and references to their interview number 3 :

Inclusive education through integration with the community:

(1) Sense of belonging as the first step for social integration,

(2) Organisation of events at school. numbers were assigned to them in the interviews. The numbers are represented in the text as No. 1, 2, 3, etc., where "No." is the interview number. The gender of the participants is not mentioned since there was only one male teacher involved in the research, and making mention of the participants' gender could reveal the identity of the male teacher. 
$\rightarrow$ Teachers' contribution to inclusion: (1) Preparation of class and teachers' lifelong learning, (2) The use of art as a universal method of communication.

$\rightarrow$ The role of school social work in inclusion: (1) Counseling and support when managing difficult cases, b) Interdisciplinary cooperation when supporting the student.

$\rightarrow$ Obstacles and difficulties: (1) Crowded classes and students' different needs, (2) Linguistic and religious diversity as a constant challenge, (3) Vulnerability of refugee students.

$\rightarrow$ Benefits of integrating diversity into education: (1) Sense of acceptance by the community, (2) Sensitisation to diversity.

\section{Inclusive education through integration with the community}

\section{Sense of belonging as the first step for social integration}

Including diversity at school can contribute to socialisation and community integration. The following quote is a representative one:

When the child attends school he or she feels that he or she is also part of society... I saw that during the school break, the new children were a group by themselves... Now I see that they have started playing with the rest of the children, all together [...] so they slowly become part of the society in which they live, they become a group with the rest of the children, while at the beginning they were a group by themselves due to the language barrier. [Interview No. 1]

In this context, the inclusive education of refugee students in general education classrooms seems to contribute to the elimination of prejudices and stereotypes. It might take time, but all members of the group can learn to co-operate and coexist with diversity.

\section{Attention is now more and more focused on special education and refugees. The important thing is to get the refugee children to know our customs, our school and the Greek students so that both sides can socialise. This, however, can only be achieved with inclusion... [Interview No. 5]}


Bringing all children together, regardless of the difficulties, eventually leads to mutual interaction and connection or even the alteration of stereotypes and prejudices.

\section{Organisation of events at school}

As the participants mentioned, one way that could help groups integrate into the community is to initiate in-school and out-of-school activities and events with the involvement of families. School social workers can assist in organising events aimed at increasing awareness of diversity, bringing together schools, families and communities.

The social worker, with their close contact with the families, will be able to help integrate refugee kids into school so as to organise welcome events [taking place at the school facilities], or an event in regard to ethics and customs or even a cooking event, with both Greek and refugee families preparing meals. I think that this could, in collaboration with social workers, connect the families. [Interview No. 3]

School is a microcosm of society, and if, for example, an event takes place at school, organised by a social worker, and if this event is able to attract parents, then this is I think the "magic touch" in order to bring people together. [Interview No. 5]

The organisation of events and the involvement of all families in school seem to be factors that contribute to socialisation and therefore the elimination of prejudice.

\section{Teachers' contribution to inclusion}

\section{Preparation and lifelong learning}

All respondents agree that teachers are crucially important to students' life in the classroom as they spend many hours with them. In particular, they argue that a lot of preparation is required for the inclusion of students. As argued by one respondent, teachers must "prepare" the classroom and, depending on the situation, devote some time to talking to the rest of the children about diversity. 
The main thing is the reception of the new students. This means that the teacher, prior to the children's arrival, must do some preparatory work. He or she must explain that the new students will not be able to speak Greek since they come from a foreign country and that they have been through some unpleasant situations. This will help raise awareness in children since whatever happens in society also becomes part of the school, and therefore of the classroom. [Interview No. 6]

Preparation is needed on behalf of teachers so as to differentiate and personalise their teaching. More efforts and responsibilities are needed from their side so as to have the desired result. [Interview No. 3]

It appears that it is necessary for teachers to adjust their teaching methods so that all students can follow them and participate in their class. According to the above, inclusive education does not concern only the presence of the refugee students in the school environment but also their interaction in the lesson during the teaching process.

An important prerequisite for groups' integration into school seems to be the lifelong learning education of teachers. According to one respondent, teachers' education is necessary not only for the benefit of the refugee students but also for other social groups that may exist in society and be part of a regular class (e.g. Roma students).

I believe it is necessary for us to be educated in certain fields [not just] in this respect, but also in how to engage with other social groups... [Interview No. 2]

\section{The use of art as a universal method of communication}

According to the respondents' views, the use of arts and group games seem to be appealing to all students. Art in education can contribute to developing students' confidence, developing their own personal skills and creativity, which are more important for the smooth integration of the child into school and classroom (Robinson, 1992).

I invest emotionally on children, at least I try to... I want them to express themselves by organising a theatrical play. I think it is a good start to get a kid to express itself. So, this is where we 
should start from [...] a play, some reward, whatever seems to help children. [Interview No. 2]

The importance of implementing school art therapy for the development of self-esteem is underlined by Nikolaos Tsergas (2014). Programmes designed to address children's needs in poor and deprived areas and which aim at preventing school drop-out rates, developing social skills, creating a sense of belonging, improving their performance and enhancing conditions to ensure school success have adopted art therapy techniques (Sutherland, Waldman \& Collins, 2010).

In this context, music, visual arts and theatrical education are mentioned by the respondents as alternative methods of emotional expression for students.

Classes of art, music and theatre contribute a lot to integration... School is not only about Greek language and mathematics, it is also about motion, a theatrical play or music [...] all these give the joy of inclusion and a sense of belonging to children. [Interview No. 4]

The use of colour and music is also very useful... numbers, one could do something with numbers, as these are common to everybody.

[Interview No. 6]

\section{The role of school social work in inclusion}

In this section, teachers underline the role of school social workers in integrating students into their school.

\section{Counseling and support in managing difficult cases}

According to one respondent, school social workers should support teachers and co-operate with them closely.

Social workers could make suggestions to teachers regarding children's integration into the classroom [...] and also support the management of various children's behaviour... [Interview No. 1]

The following respondent, who appears to share the same view, describes counseling as a way to manage challenging situations appearing in class. 
To be by my side so as to advise me, to manage some diverse children's cases, as he or she-as an expert-knows how to handle them... I cannot know everything, it is impossible... [Interview No. 2]

It seems that teachers separate educational issues from those of behaviour, which are more of a task for social workers. In addition, it is noteworthy that the respondent uses the term expert to describe the social worker, which indicates the necessity of having social workers in education and the need for someone to have "authority" and expertise with regard to specific cases.

There must be a social worker, at least one or two, per school. I believe their expertise will primarily help us, the teachers, who do not have the knowledge of approaching children from another point of view. [Interview No. 3]

The respondents also focused on the differentiation of the social worker's role from that of the teacher: the latter is more interested in teaching and learning while the former focuses more on the approach and management of "sensitive issues" (Kandylaki, 2010).

Social workers approach some situations quite differently; we, as teachers, are interested in learning and teaching. You [the social worker] approach more sensitive issues, i.e. I believe you have a supporting role, you approach children in a different way... [Interview No. 6]

\section{Interdisciplinary co-operation when supporting the student}

Two participants precisely described the specific role of the social worker in education:

Co-operation with a social worker will enable us to approach the family and to be able to integrate the child into society in better ways, I believe in the connection of school with society and the social worker. [Interview No. 3] 
worker, all problems arising in class are mentioned, and the social worker gives solutions... [Interview No. 4]

Researchers have claimed that the school social worker is a "bridge" between the school, families and the community. They suggest that the school social worker can open the window of communication with parents and contribute to contacts and communication among teachers, families and children (Kallinikaki, 2015; Kandylaki, 2009; BoydWedd, 1996). Teachers expecting social workers "to give solutions" demonstrates their need to co-operate with other professionals for the better management of certain cases arising in their class.

As the teachers suggested, school social workers, in collaboration with the school's principal and teachers, may be able to identify the issues that need to be addressed.

So, the more people deal with children and who are qualified to do so, the better they can form an interdisciplinary team. It is better than being by myself, as a teacher. [Interview No. 5]

The school social workers, along with teachers, will be able to evaluate each case better during a school day. [Interview No. 4]

\section{Obstacles and difficulties}

In the following section teachers underline the obstacles and difficulties they come across.

\section{Crowded classes and different students' needs}

When you are in sixth grade, for example, you can see that students have reached a particular educational level. When a new student comes who does not understand the language and must attend the sixth grade, you have to deal with this child to teach him or her the basics... Each educational class lasts for 45 minutes, and classes are attended by 25-28 children. How much time does a teacher really have to deal with each child separately, how much time does he or she really have to deal with a refugee who doesn't know the language? [...] How much time can he devote to doing his job in the right way and basically not being unfair to anybody since the goal is equality? [Interview No. 6] 
The teachers' despair is evident, as they need support to handle the multiple different cases and needs of students.

The teacher needs a lot of help and support as there are far too many children in the classroom [...] however, every year, the less the number of children, the better the situation is, and this year I do not have any "difficult" cases, unoriented, or disruptive children in the classroom. Last year I had four and I was living in chaos, "fighting with the beasts". They were all supposed to be mainstream kids [...] if the social worker cannot intervene in such cases, who can really help me? Do I have to do everything by myself? [Interview No. 2]

At this point, it is worth mentioning the use of the phrases "difficult cases" and "I was living in chaos, fighting with the beasts". Both phrases show the teacher's tension and how difficult it is to handle such situations, while at the same time highlighting the necessity of having social workers at school to handle such cases, seeing as the teachers themselves feel "helpless".

These participants' views are confirmed by Villa et al. (1996), whose research data suggests that teachers who teach small groups of 15 to 21 students express more positive views about inclusive education compared to those who teach in more crowded classrooms, that is, from 22 to 30 students.

\section{Linguistic and religious diversity as a constant challenge}

The fear of diversity also appears in the words of the participants when they express their stress and anxiety about the reaction of native students' parents (reactions that were described earlier in this chapter) to the integration of refugee children into the classroom.

You do not really know how parents of children who attend regular education will react when they see a refugee child in the classroom. Everyone has his or her prejudices and racism is part of our lives [...] and that is exactly the part one needs to manage best, how the rest of the parents will accept the child. [Interview No. 5] 
The above-mentioned view is confirmed by Dominelli (1998), who highlights that racism causes problems both in minority groups that are culturally and racially diverse as well as in majority groups.

Another respondent highlighted the difficulty with the rest of the class accepting the new students in the classroom:

\section{Children consider the class as their own and they perceive new} students as intruders, as something foreign entering their class, and certainly the foreign element, when coming from another country or ethnicity, another culture or another language, makes the situation more difficult. [Interview No. 6]

The use of the words "intruders" and "foreign" and the phrase "the foreign element [...] makes the situation more difficult" are typical and are expressions that hide deeply structured prejudices and stereotypes towards diversity, coexisting with fear. Some of the respondents also seem to use the word "different" while others use the term "new students" in order to define or refer to the refugee children, reproducing, in a subconscious way, discrimination patterns.

Particularly interesting is the fact that differences such as culture, language and religion are seen as factors of difficulty in teachers' views. Language is an important factor contributing to difficulties, since communication is the main principle of social interaction. Given this, it is almost impossible to capture a social interaction that does not involve communication (Hogg \& Vaughan, 2010). Based on the above, a different language can be an obstacle to communication, since misunderstandings can occur between a teacher and a student:

These kids represent a new element, that is why we do not understand their language. It is possible that one of them says something and I will not understand. I might be doing something wrong for a child... [Interview No. 1]

What seems to worry the respondents is the possibility of causing further harm to students. The lack of an interpreter leaves teachers "exposed", leading to misunderstandings that might further isolate students from their teachers. Different languages, other than being 
a barrier to communication, could also be a cause of prejudice and stereotypical behaviours towards different groups.

There are a lot of difficulties, let us not try to sugar-coat the situation. For teachers, a different language constitutes a major obstacle. For younger children, it is much easier to communicate with their peers in non-verbal ways. As for the older children, this is not the case [...] and one can also see how isolated those kids are in the classroom... [Interview No. 3]

This view seems to be supported by Whorf (1956), who referred to the term "linguistic relativity". According to this theory, language determines thought, and people who speak different languages might see the world in a different way and basically live in different cognitive worlds (Hogg \& Vaughan, 2010, p. 704). Nevertheless, the respondents mainly refer to the realistic and practical obstacles a different language sets, rather than the conceptual ones. It seems that a different language is a major obstacle for almost all the respondents, who have tried to find ways to initiate communication with children. The significance of non-verbal communication is stated in the following quote. As well as the different languages, the students' different religion is also considered as an obstacle by teachers.

Another problem is [...] of course the issue of religion. It is a very important one. Students are not obliged to pray, to follow our rituals, but at the time of prayer in the morning they all stand in line. They may not follow it, but they try to understand. [Interview No. 4]

Challenges [...] are [...] religious ones [...] I see that children, not all of them, have some issues regarding this part... for example, the fact that they do not want to attend and be present at the time of prayer. They could just stand nearby, because all school announcements are made after prayers. We have got the tradition of starting every morning with prayers, and then the announcements from the principal follow... [Interview No. 3]

Students may not be obliged to participate in prayers; however, they should stand in line and "try to understand". In the same context, 
the respondent argues that children's attendance during prayers is a necessity, since all announcements are made after the prayers, and this is why their presence is considered important. In both cases, the language used during the prayers and when the principal makes the announcements is Greek. Language was mentioned as a difficulty, but despite the fact that these students do not understand Greek, it seems that no action has been taken for them to listen to announcements in their own language.

\section{The vulnerability of refugee students}

Teachers express the view that, in some cases, certain behaviours of students at school are difficult to manage. They mention aggressive attitudes and isolation, attributing both behaviours to the children's past traumatic experiences "in times of war".

\section{A difficulty for refugee children is what they carry with them.}

That is, the dark look in their eyes. It is not because their soul is dark, it is because they have been through many experiences. Seeing a child, one can often think that he or she is aggressive. One cannot judge why he or she is aggressive, or why he or she has a dark look in his or her eyes, or what this child carries with him or her. These obstacles, which then lead to behavioural difficulties, aggression, etc., appear in both young and older children. [Interview No. 3]

These children have lived in times of war, in difficult situations. They often have anger and an aggressive attitude towards other students. [Interview No. 4]

It seems that the respondents are sensitive to the emotional state of the children and are aware of the traumatic experiences they suffered in their countries. They are trying to understand their behaviour and put it into its proper context. Aggressiveness is a universal way to communicate anger and despair, and maybe it is a way for the children to get through all the changes and challenges of their new life. Research has shown that exposure to war-related traumatic events contributes to mental health disorders and, in some cases, to longterm psychopathology in children and adolescents (Lustig et al., 2004; Betancourt \& Williams, 2008). Nevertheless, it seems that problems 
concerning interpersonal relationships are attributed only to the refugee students, and they should also be examined in the context of their relationship with other students and teachers.

The difficulty teachers face with handling the aggressive cases of refugees is evident. It also seems that teachers have difficulty with managing "sensitive issues" that arise in the school environment.

\section{Benefits of integrating diversity into education}

The results of the data analysis mentioned two factors as benefits of the integration of diversity: (1) a feeling of acceptance by the community, and (2) sensitisation to diversity.

\section{Sense of acceptance}

According to teachers, the benefits of involving all students in education are linked to the quality of their school life.

\section{First of all, children who are part of inclusive education are accepted and recognised. For me, all children certainly have the right to be accepted by the school community. [Interview No. 1]}

The participation of all students (in spite of their diversity) in school positively contributes to strengthening their self-esteem as learners. This can only happen through their acceptance and recognition in the school environment (Katsama \& Bourbaki, 2017).

\section{It is not only the new child who gains but also the other ones, it is a two-way link that affects both sides individually as well as the group of students in a holistic way, and this is what we try to do, including me. If children in the class are helped by the mainstream children, they will feel accepted. [Interview No. 5]}

Through such a process of inclusion, it seems that children learn to co-operate with each other and help one another, resulting in them feeling accepted by their peers.

\section{Sensitisation to diversity}

Interaction can work positively to raise awareness of the community as a whole. The students' interaction in the school area gives them 
an opportunity to manage stereotypes and prejudices and, with the teacher's contribution, to become more aware of diversity.

We learn to collaborate and not to look at others strangely just because they are different, since this is the secret to softening all differences, all hatred, all tension... [Interview No. 2]

In my opinion, the first and most important benefit for people is to change their values, to figure out what is around us and how to deal with situations. I think the benefit that Greek students gain from the inclusion of refugees in education is much greater than the one refugees gain. I think the main thing is for children to be able to see what is happening in the world. [Interview No. 3]

Stereotypes and prejudices are cultivated in children from an early age. In this respect, it is necessary to handle stereotypes and prejudices in the field of education to prevent future separating behaviours (Nesdale, 2001). As the respondents wisely mentioned, the modification or even change of values seems necessary, although this is quite a demanding and difficult procedure.

\section{Conclusion}

The present chapter focused on the strengths of and obstacles to the integration procedure of refugee children in general education, based on teachers' views and perspectives.

Teachers reported the importance of sensitising the rest of the classroom (sensitisation to diversity) as well as highlighting the necessity of their own preparation for welcoming new students through the modification of their teaching strategy and lifelong learning.

Regarding the role of the school social worker in integrating diversity into education and the school community, the respondents expressed the need for close co-operation with social workers in regard to managing difficult situations in the classroom. According to them, the role of school social workers could positively contribute to connecting families with the school and the community. The collaboration between school social workers and teachers could contribute to the latter having the best possible contact with the children and their families. The respondents concluded that the expertise of school social workers 
can also contribute to children's effective inclusion in the classroom and in the school.

Crowded classes, combined with differing educational needs, emerged as obstacles. In this context, the limited time available for teachers, combined with a plethora of different individual needs, makes the management of the situation difficult. It appears that teachers are required to handle issues that are far removed from the school curriculum, and according to the produced data, it is preferable for these to be handled in co-operation with social workers who have the necessary expertise and professional experience. Teachers referred to such issues as managing parents' stereotypes and prejudices towards new students, incidents of domestic violence, and the violent behaviour of refugee students due to past war experiences.

According to the respondents, the language barrier prohibits communication with the students, while the different religion makes students' participation in the time of prayer difficult, both resulting in the exclusion of children from their morning briefing on school events.

With regard to integrating diversity into education, there are multiple benefits. On the one hand, there is the "sense of acceptance" and belonging that the new students feel as a result of inclusive education, and on the other hand, there is the fact that the rest of the students learn to live and collaborate by overcoming stereotypes and prejudices. Thus, all groups are prepared for positive interactions in adult life.

The school needs to be able to integrate students coming from vulnerable groups of the population. In these cases, however, the school needs support from social workers, as both individual and community integration is required.

Inclusive education programmes should be designed with a clear vision, inspired by values and principles such as acceptance and respect, based on human rights, ensuring equal opportunities in education for all students in the sense of equal, dignified and non-discriminatory access to the right of education.

It seems that teachers are challenged to reconsider their values not just personally but socially as well. During the current research, they expressed their feelings with honesty, demonstrating at the same time their deep interest in and genuine care for all students. They also did not hesitate to admit their need for support, realising the responsibility of the school as a key institution of inclusion. 
Due to the new circumstances at their schools, they adopt an attitude of flexibility in how they perceive the new and the different (religions, rituals, languages, dress codes, attitudes, etc.) and try to cultivate a sense of acceptance, respect, and openness within the students.

It is crucial that the core values of human rights and social inclusion are embodied by school communities, teachers and school professionals. The above-mentioned elements, which are derived from the current data analysis, constitute strong values that need to be integrated into daily practice at schools. A great challenge for teachers and school professionals is to develop and adopt changes in order to be able to manage diversity with acceptance, respect, interaction and creativity. As noted by one respondent, "whatever happens in society also becomes part of the school, and therefore of the classroom", and this quote aptly summarises the significance of the interaction between schools and the contemporary social reality.

\section{References}

$\rightarrow$ Ainscow, M. and Miles, S. (2009). Developing inclusive education systems: How can we move policies forward?, www.ibe.unesco.org/fileadmin/ userupload/COPs/Newsdocuments/2009/0907Beirut/ DevelopingInclusive/ EducationSystems.pdf

$\rightarrow$ Alfavita (2016). ELME Pieria: Refugee Accommodation Center

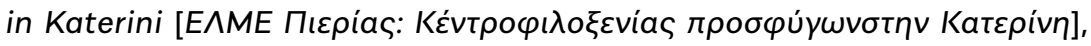
www.alfavita.gr/ekpaideysi/176824_elme-pierias-kentro-filoxenias-prosfygonstin-katerini

$\rightarrow$ Betancourt T. S. and Williams T. (2008). Building an evidence base on mental health interventions for children affected by armed conflict, International Journal of Mental Health, Psychosocial Work and Counseling in Areas of Armed Conflict, 6(1), 39-56.

$\rightarrow$ Boethel, M. (2003). Diversity. School, Family \& Community Connections. Austin,: Southwest Educational Development Laboratory.

$\rightarrow$ Boyd-Webb, N. (1996). Social Work Practice with Children. New York: The Guildford Press.

$\rightarrow$ Buchanan, A. and Kallinikaki, T. (2018). Meeting the needs of unaccompanied children in Greece, International Journal of Social Work, 61(5), 1-49.

$\rightarrow$ Dimopoulou-Lagonika, M. (2011). Social Work methods: From Individual

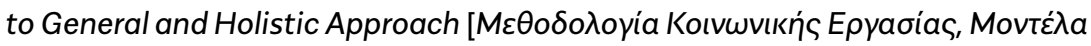




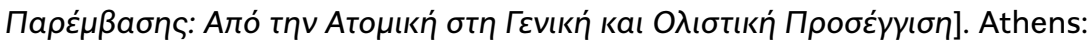
Topos Publications.

$\rightarrow$ Dominelli, L. (1998). Anti-racist Social Work. Palgrave: Macmillan.

$\rightarrow$ European Union. (2000). Council Directive 2000/43/EC of 29 June 2000 implementing the principle of equal treatment between persons irrespective of racial or ethnic origin, https://eur-lex.europa.eu/LexUriServ/LexUriServ. do?uri=CELEX:32000L0043:en:HTML

$\rightarrow$ Greek City Times. (2019). More than 12,000 refugee children attended Greek public schools, https://greekcitytimes.com/2019/05/31/more-than-12000refugee-children-attended-greek-public-schools/

$\rightarrow$ Hatton, K. (2008). New Directions in Social Work Practice. Exeter: Learning Matters.

$\rightarrow$ Hogg, M.A. and Vaughan, G.M. (2010). Social Psychology. Athens: Gutenberg.

$\rightarrow$ Inclusion BC (n.d.). What is Inclusive Education?, https://inclusionbc.org/ourresources/what-is-inclusive-education/

$\rightarrow$ Kallinikaki, Th. (2011). Introduction to Theory and Practice of Social Work

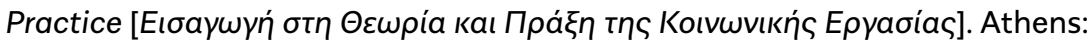
Topos Publications.

$\rightarrow$ Kallinikaki, Th. (2015). Evaluation of social work practice in educational

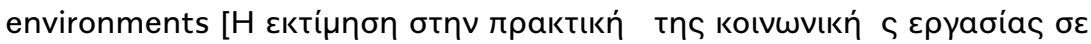

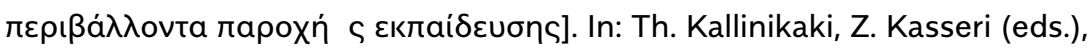

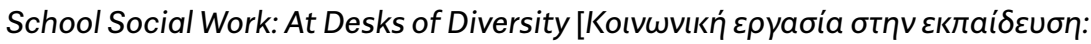

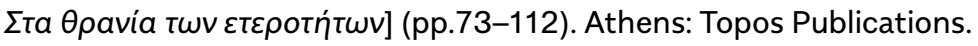

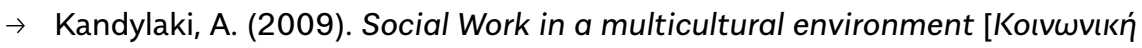

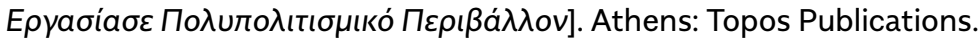

$\rightarrow$ Kandylaki, A. (2010). Qualitative research concerning sensitive issues in social

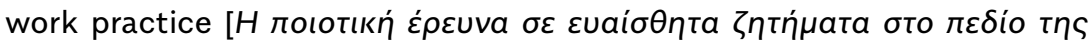

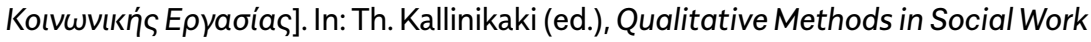

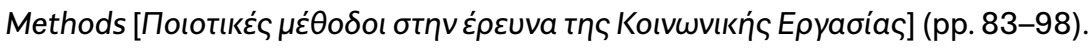
Athens: Topos Publications.

$\rightarrow$ Karanikola and Z., Pitsiou, X. (2015). Outline of the actions of the Ministry of Education with regard to protection of cultural diversity in Primary and Secondary Education. A qualitative study of the thematic analysis of the annual reports of the Ministry of Education to the National Commission for Human

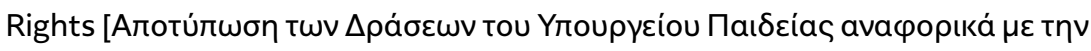

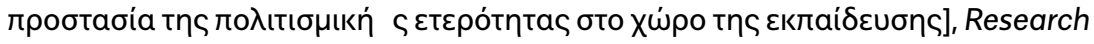
in Education Laboratory of Pedagogical Research and Educational Practices Department of Preschool Education Sciences, 4, 128-151. 
$\rightarrow$ Katsama, I. and Bourmpaki, E. (2017). Bullying in primary education. A social work intervention with students, Journal of Education and Social Policy, 4(3), 98-111.

$\rightarrow$ Keil, M., Amershi, B., Holmes, S., Jablonski, H., Lüthi, E., Matoba, K., Plett, A. and Unruh K. (2007). International Society for Diversity Management, www. idm-diversity.org

$\rightarrow$ Kontogiannis, A. (2012). Art and creative expression in special education

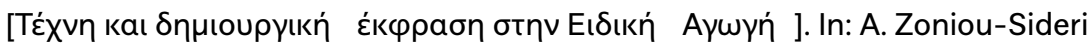

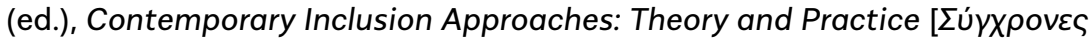

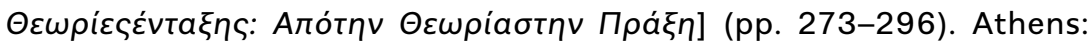
Pedio Publications.

$\rightarrow$ Lorenz, W. (2008). Towards a European Model of Social Work, Australian Social Work, 61(1), 7-24.

$\rightarrow$ Lustig S. L., Kia-Keating M., Knight W.G., Geltman P., Ellis H. and Kinzie J.D. (2004). Review of child and adolescent refugee mental health, Journal of the American Academy of Child \& Adolescent Psychiatry, 43(1), 24-36.

$\rightarrow$ McMahon, M.O.N. (1996). The General Method of Social Work Practice: A Generalist Perspective. Boston-London: Allyn \& Bacon.

$\rightarrow$ Ministry of Education (2017). "2017-2018: All refugee children in school"Interview of the Deputy Secretary General of the Ministry of Education,

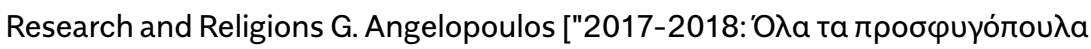

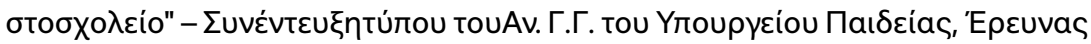

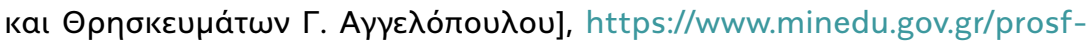
ekpaideusi-m/30920-18-10-17-2017-2018-ola-ta-prosfygopoula-sto-sxoleio

$\rightarrow$ Naftemporiki.gr (2016). The decision to establish reception structures for

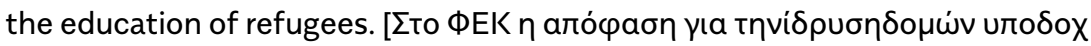

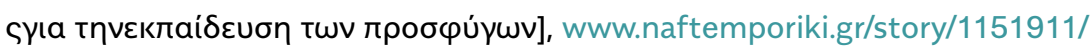
sto-fek-i-apofasi-gia-tin-idrusi-domon-upodoxis-gia-tin-ekpaideusi-tonprosfugon

$\rightarrow$ Nesdale, D.(2001). Social identity and the development of children's group attitudes, Child Development, 72(2), 506-517.

$\rightarrow$ PierikiAlithia (2017). The "village" of immigrant-refugees was inaugurated

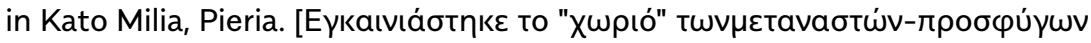

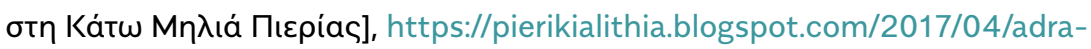
refuges-katomilia.html

$\rightarrow$ Robinson, M. (1992). Mastery learning in public schools: Some areas of restructuring, Education, 113(1), 121-126. 
$\rightarrow$ Soulis, S. G. (2008). A school for all. From Research to Practice: The pedagogy

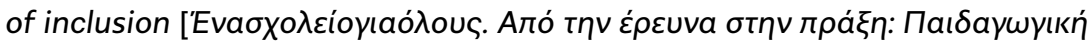

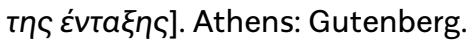

$\rightarrow$ Sutherland, J., Waldman, G., Collins, C. (2010). Art Therapy Connection: Encouraging Troubled Youth to stay in School and Succeed, Journal of the American Art Therapy Association, 27(2), 69-74.

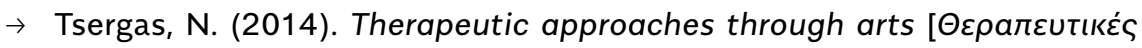

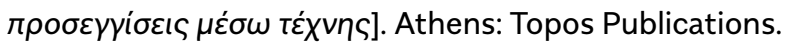

$\rightarrow$ UNHCR (2019). The Global Report, www.unhcr.org/the-global-report.html

$\rightarrow$ United Nations (1989). Convention on the Rights of the Child. Treaty Series, Vol. 1577, www.refworld.org/docid/3ae6b38f0.html

$\rightarrow$ Villa, R., Thousand, J., Meyers, H., Nevin, A. (1996). Teacher and administrator perceptions of heterogeneous education, Exceptional Children, 63, 29-45.

$\rightarrow$ Whorf, B. L. (1956). Language, thought and reality. Cambridge, MA: MIT Press.

$\rightarrow$ Zoniou-Sideri, A., Deropoulou-Derou, E., Vlachou, A. (2012). Disability and Education Policy. Critical Approach in Special and Inclusive Education [Avarnpía

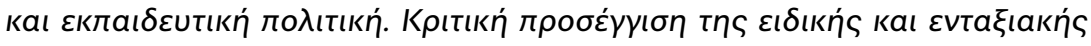
$\varepsilon \kappa \pi a i ́ \delta \varepsilon \cup \sigma \eta \varsigma]$. Athens: Pedio Publications. 


\section{Expressing a Sense of Readiness about Research Inquiry \\ In-service Teachers After a Master's Course}

DOI: $10.47050 / 66515321.212-237$

Maria Antonietta Impedovo

This paper discusses teachers' sense of "readiness" and what learners know, can do and value between learning and the work setting after attending an international Master's course. To explore this process in an international setting, individual interviews and focus groups were set up with students from two programmes of an international Master's course and narrative data collected at the end of each programme and one year later. The participants were 16 in-service teachers -12 men and 4 women - with an average age of 39, who came to Europe from four African countries (Zimbabwe, Lesotho, Burkina Faso, and Namibia) and Vanuatu (South Pacific islands). The collected data were qualitatively analysed with a category system from three readiness perspectives: conceptual, procedural and dispositional readiness. Exploring the sense of readiness contributes to the field of teachers' professional development and agency-promoting leadership.

\section{Keywords:}

research inquiry

attitude

readiness

internationalisation

teacher training 


\section{Introduction}

Globalisation has increased the internationalisation of education. International teaching courses are characterised by cultural plurality and they have great potential for a teacher's professional learning (Oolbekkink-Marchand, Hadar, Smith, Helleve \& Ulvik, 2017; Lai, Li \& Gong, 2016). A transcultural professional development programme for teachers could stimulate and support the teacher's professional growth (Hoare, 2013), promote transformational learning and make explicit cultural discursive practices (Smith, 2009). However, these international programmes can also be fraught with a predominant one-way perspective and limited knowledge about local resources, opportunities and constraints (Montgomery, 2014). Maximising the benefit of an international teacher's professional learning, it does not depend exclusively on the quality of the training but also on the active engagement of the participants (Edwards, 2015; Priestley, Biesta \& Robinson, 2012) and their capacity to reconcile knowledge between learning and working. This process of the reconstruction and reconciliation of the learning and working settings can be particularly difficult in the international context, especially for under-privileged teaching staff (Djerasimovic, 2014). To explore this active process of the mediation of knowledge in international settings, we have adopted the concept of "readiness", which is interpreted by Billet (2015) as what learners know, can do and value in learning and working. In particular, we focus on the sense of readiness about a specific domain of knowledge that is developed in an international training programme, which has to be adopted in a work setting characterised by social and cultural diversity.

In the first two sections, we will briefly review the theoretical framework related to the research inquiry attitude in professional learning, with a focus on the concept of readiness (Billett, 2015; Billett, Wärvik \& Choy, 2018). Next, we will describe the main study of 16 African in-service teachers who came to Europe to attend an international Master's course, which is oriented to develop a research inquiry attitude. We consider that exploring the teacher's readiness can contribute to understanding more deeply the processes of becoming an agentic teacher, and we aim to find ways to support this development (Kumpulainen \& Lipponen, 2012). 


\section{Expanding Teachers' Professional Learning with a Research Inquiry Attitude}

The current international change in education calls for new competencies and dispositions from teachers, as recognised by the national and international policy and research literature (Bates, Swennen \& Jones, 2011). Teachers' competences are moving beyond boundaries and meaning-making, and they have significant implications in participating in the changes to society and school systems (Renshaw, 2016).

Professional learning is even more critical to schools' sustainable improvement in developing countries. In recent years, many of these countries have seen a resurgent emphasis in educational policy on teacher professionalism and autonomy in place of highly prescriptive curricula and strict regimes of inspection and control (Sahlberg, 2012). For example, the UNESCO programme called 'Education for All' (EFA) faces the challenges of providing quality training to all teachers within a poorly resourced education system. However, Hardman, Ackers, Abrishamian and O'Sullivan express concerns about "the dangers of international agencies urging developing countries to adopt 'best practices' concerning teacher professional development that ignore the everyday realities of the classroom, and the motivations and capabilities of the teachers to deliver such reforms" (2011, p. 670).

Considering teachers as agents of change (e.g. in curriculum-making, see Oliveira, 2012; Priestley, Edwards, Miller \& Priestley, 2012), the individual teachers' capacities for learning new knowledge are significant sources for professional learning. Following this idea, the perspective of teachers as researchers is an interesting point of view that supports the trend that enacts school reform by sustaining teachers' leadership and autonomy in their works (Girod \& Pardales, 2001). This perspective considers the dual demands of being both a reflective teacher and also a researcher who contributes to knowledge development (Cochran-Smith, 2005; Dobber, Akkerman, Verloop \& Vermunt, 2012). Adopting a research inquiry attitude mobilises new skills, demands explicit efforts and commitment from teachers, and asks teachers for a new engagement in challenging traditional practices. According to Billet (2015), the learners' readiness shapes their ability to engage productively in activities and interactions, in training and working, and in learning from these experiences. 


\section{Between learning and working: readiness to engage knowledge in action}

Readiness comprises what individuals know, can do and value. Already used in Piagetian (1968) theories of child development, Billett (2015) applies the concept of learner readiness to the healthcare setting. In a sociocultural constructivist account, the learning is mediated by the kinds of activities in which learners engage as afforded by the social world. Consequently, readiness refers to the individual's abilities to engage with and learn effectively from what they experience, shaping the scope of their learning potential. As proposed by Billet (2015), the point is how learners (i.e. students, apprentices, workers) come to make sense of what they are experiencing, construe meaning from it and learn through it. Specifically, the author proposes that there are three broad dimensions of readiness associated with the knowledge required for practising healthcare professions, which are as follows:

1. Conceptual, factual, propositional (what one knows): this readiness is about being able to make these links and associations thanks to the repertoire of experiences to form purposeful associations and linkages. Thanks to this kind of experience, conceptual associations might arise.

2. Procedural readiness (what one can do): this is the capacity to achieve goals, such as in healthcare work when taking blood. In this case, readiness is likely derived from having had sufficient experience in taking blood samples to perform that procedure without recourse to conscious engagement in that task.

3. Dispositional readiness (what one values): this is the level of occupationally-related dispositions required when drawing upon and utilising knowledge effectively when, for instance, interacting with patients.

According to Billet (2015), these dispositions are central to how individuals elect to engage in these activities, and they also mediate the kind of effort that the individuals exercise in their thinking and acting and, therefore, their learning. Hence, engaging in authentic activities that require the deployment of these three forms of knowledge interdependently is important: "How, for what reasons, and by what degree individuals elect to engage in goal-direct activities is central to what they do and learn" (Billet, 2015, p. 4). This readiness is related 
to teacher agency, which concerns the awareness or experience (Hilppö, 2016) that shapes what teachers do, how they think about what they do, and what they think they will be within their profession. Agentic utilisation and crafting of experiences are crucial for successful professional learning and development (Goller \& Billet, 2014).

In this paper, we are interested in exploring the teacher's sense of readiness. By this term, we mean the attitude expressed by the teachers about how they expand knowledge thanks to their repertoire of experiences (what they know), their attitude about their capacities to achieve goals from having had sufficient experience (what they can do), and their attitude about the level of occupationally-related dispositions required to draw upon and utilise this experience.

Taking this interpretation into consideration, we will investigate the sense of readiness about research inquiry developed by African in-service teachers on an international Master's course through their narratives. This paper contributes to the discussion on how the research dimension is integrated into initial and continuing teacher education courses and what approaches and strategies can be used to integrate theory and practice (Flores, 2017). We explore the personal perspectives of the teachers while also considering the need to see what these are, how teachers engage personally with their professional learning, and how new practices are sustained (Impedovo, 2016).

\section{Aim}

This research aims to find out:

$\rightarrow$ Which sense of readiness is expressed by the teachers' accounts about a specific domain of knowledge developed on a formative training programme?

$\rightarrow$ How is the sense of readiness modulated by teachers between the learning and the work settings?

Taking into consideration the theoretical framework presented above, we will investigate the sense of readiness about research inquiry developed by African in-service teachers on an international Master's course. We hypothesise that the in-service teachers' sense of readiness about the research inquiry attitude acquired during their formative training will shape their attempts to implement this attitude in their daily local work. 
To explore how this engagement starts at the end of their Master's course and evolves after it, the design of this study proposed that teachers were interviewed twice: once at the end of the course and a second time a year later. However, these data do not catch the teachers in action but only the attitude expressed by the teachers during the interviews. For this reason, we explore the 'sense' of their readiness and not their readiness in action.

\section{Participants}

The participants were made up of 16 in-service teachers from two programmes of the same Master's course.

The first programme of the Master's (2014/2015) was attended by a class of nine in-service teachers (six men and three women), and the second programme (2015/2016) had a class that was composed of seven in-service teachers (six men and one woman). They all agreed to be involved in this research project. They all had a bachelor's degree in Educational Science with different levels of school teaching experience in their respective countries. The average age of the participants was 39 (ranging from 30 to 50). All of them spoke English as a second language (with different levels of fluency), except for one, who mainly spoke French. Fifteen of them came from four African countries (Zimbabwe, Lesotho, Burkina Faso, and Namibia), and the other came from Vanuatu (South Pacific islands). In all these countries, the teacher's position is characterised by a low status and educational reforms of their education systems are needed (Haßler, Hennessy, Cross, Chileshe \& Machiko, 2015). Reforms are also required to sustain teachers' professional development (Jansen, 2001; Samuel \& Stephens, 2000; Smit \& Fritz, 2008; OECD, 2014). They all received an international fellowship to attend a two-year, full-time international Master's in Educational Research in Europe. A summary of the participants' information is given in Table 1. 
Table 1. Participants of the two programmes of the international Master's

\begin{tabular}{|c|c|c|}
\hline & FIRST PROGRAMME & SECOND PROGRAMME \\
\hline Gender & Male $=6 ;$ Female $=3$ & Male $=6 ;$ Female $=1$ \\
\hline Country & $\begin{array}{l}\text { Zimbabwe }=3 ; \text { Lesotho }=5 \\
\text { Burkina Faso }=1\end{array}$ & $\begin{array}{l}\text { Namibia }=3 ; \text { Lesotho }=1 ; \\
\text { Zimbabwe }=2 ; \text { Vanuatu }=1\end{array}$ \\
\hline Previous degree & Educational Science (bachelor level) & Educational Science (bachelor level) \\
\hline Language & English $=8 ;$ French $=1$ & English $=7$ \\
\hline
\end{tabular}

The Master's degree

The first part of the Master's course was organised at a Belgian university and the second part at a French university, supported by a European fellowship, for an Erasmus Mundus Joint Master's Degree in Educational Research. This Master's course aimed to improve teaching skills in science education research and to develop a positive research attitude. The Master's course includes training on research methodologies in science education, with a focus on new technology education in teaching. Specifically, the main subjects of the course were: methodology of research, statistics, innovative educational approaches in science education, and the use of educational technology in the classroom. The first part of the Master's had a focus on educational technology, and the second part focused on the quantitative and qualitative methodology of research. To obtain the official qualification, the teachers had to present a final research dissertation that was based on data collected in their local school.

The author of this paper was a teacher on the French part of this Master's course, which allowed for following the second half of the teachers' professional learning process. In the end, the teachers had to prepare a final dissertation that focused on the introduction of technology in teaching and learning practice. Consequently, they collected data in their local contexts during a period spent at home to finalise their work. They continued to work with their supervisor to complete and support their final work. Considering the international nature of the Master's, this course allowed them to improve their professional teaching career and opened up other opportunities for them to obtain new jobs in their home countries. 


\section{Data Collection}

In this paper, we examine two programmes from the same Master's. In both, the teachers were contacted at the end of the Master's course, when they had just finished their training and were about to return to their respective countries. They were then interviewed a second time one year after the end of the Master's.

In the first programme (2014/2015), each participant was interviewed individually and each interview lasted 30 minutes on average. The semistructured interviews were composed of 31 questions (see Annex 1), which were video-recorded and transcribed. Besides the biographical and professional profile (composed of 12 questions), the interview covered two main topics:

$\rightarrow$ Training courses and ongoing research activities (10 questions), which included the topic chosen for their research thesis, their expectations and difficulties related to the learning course and their research activities.

$\rightarrow$ The participants' future projection of how they would use the research skills that they had learnt during the course (9 questions), which included how the teachers saw themselves after the course, projections of the research skills and knowledge acquired into their school, and their relationship with their local communities.

At the end of the second programme (2015/2016), the data were collected based on the same protocol; that is, through in-depth discussions of the participants' research skills and activities.

In both programmes, the same interview was repeated one year after the completion of the Master's. By this time, the participants had already submitted their final dissertation based on data collected in their local schools, obtained their official qualification and were living in their respective countries. This second interview contained eight questions that focused on the two main topics considered in the first interview: training courses and their use of the research skills learnt (see Annex 2). The interviews were conducted via Skype with subsidiary asynchrony chats conducted when needed.

The data collection methods chosen aimed at stimulating the reflections of the participants to obtain richer data from which 
to extrapolate the teachers' sense of readiness in applying the research inquiry attitude between learning and working in the classroom.

\section{Data Analysis}

An initial overview of all the data (interviews and videos) was carried out by two researchers to familiarise themselves with the corpus of data. During this phase, the extracts considered as capable of giving insights about the teachers' sense of readiness were selected and, later, themes connected to expressions of their sense of readiness were identified (Charmaz, 2006; Mayring, 2004; Neuendorf, 2016). This circular process was oriented by the theoretical framework. Specifically, the themes were examined in reference to Billet's three dimensions of the concept of readiness (2015), as viewed from the perspective of knowledge: (1) conceptual, (2) procedural and (3) dispositional. At the same time, three temporal dimensions were also considered:

$\rightarrow$ the sense of readiness before completing the Master's degree,

$\rightarrow$ the sense of readiness right after completing the Master's degree, and

$\rightarrow$ the sense of readiness one year after completing the Master's degree.

The first two dimensions of the teachers' thoughts were collected during the first round of interviews. The last was collected during the second round of interviews. As such, there were three temporal dimensions but only two rounds of interviews.

These were traced directly from the teachers' accounts. Consequently, for each dimension, there are three sub-categories related to the temporal perspectives (see Table 2). 
Table 2. Codebook of the Sense of Readiness

\begin{tabular}{|c|c|c|c|}
\hline DIMENSION & DESCRIPTION & SUB-CATEGORIES & EXAMPLE \\
\hline \multirow{3}{*}{$\begin{array}{l}\text { Sense } \\
\text { of conceptual } \\
\text { readiness }\end{array}$} & \multirow{3}{*}{$\begin{array}{l}\text { expand knowledge } \\
\text { thanks to my repertoire } \\
\text { of experiences } \\
\text { (what I know) }\end{array}$} & $\begin{array}{l}\text { before } \\
\text { the Master's }\end{array}$ & $\begin{array}{l}\text { "I want to use this } \\
\text { technology in my teaching". }\end{array}$ \\
\hline & & right after & $\begin{array}{l}\text { "I am ready and I have } \\
\text { something new in mind". }\end{array}$ \\
\hline & & one year on & $\begin{array}{l}\text { "It opened my eyes towards } \\
\text { the use of technology". }\end{array}$ \\
\hline \multirow{3}{*}{$\begin{array}{l}\text { Sense } \\
\text { of procedural } \\
\text { readiness }\end{array}$} & \multirow{3}{*}{$\begin{array}{l}\text { capacity to achieve } \\
\text { goals from having had } \\
\text { sufficient experience } \\
\text { (what I can do) }\end{array}$} & $\begin{array}{l}\text { before } \\
\text { the Master's }\end{array}$ & $\begin{array}{l}\text { "Previously, I just waited } \\
\text { and I was frustrated". }\end{array}$ \\
\hline & & right after & $\begin{array}{l}\text { "Now we can play } \\
\text { an important role, we will } \\
\text { implement simulations } \\
\text { in our classrooms". }\end{array}$ \\
\hline & & one year on & $\begin{array}{l}\text { "I am helping some } \\
\text { colleagues with how } \\
\text { to do research". }\end{array}$ \\
\hline \multirow{3}{*}{$\begin{array}{l}\text { Sense } \\
\text { of dispositional } \\
\text { readiness }\end{array}$} & \multirow{3}{*}{$\begin{array}{l}\text { level of occupationally- } \\
\text {-related dispositions } \\
\text { required to draw upon } \\
\text { and utilise } \\
\text { experience } \\
\text { (what I value) }\end{array}$} & $\begin{array}{l}\text { before } \\
\text { the Master's }\end{array}$ & $\begin{array}{l}\text { "In my country, there is not } \\
\text { motivation. I do not have it". }\end{array}$ \\
\hline & & right after & $\begin{array}{l}\text { "Research really can help } \\
\text { teachers with teaching } \\
\text { approaches so they can } \\
\text { help the students better". }\end{array}$ \\
\hline & & one year on & $\begin{array}{l}\text { "I would like to engage } \\
\text { myself more in research } \\
\text { projects". }\end{array}$ \\
\hline
\end{tabular}

Considering the exploration of the sense of readiness in the teacher narrative, discursive and linguistic indicators of the agency have been identified (action verb, reference to a personal or collective action).

In line with Billet (2015), we consider these three dimensions separately but as interdependently related, and they are not exclusive categories. The two researchers compared their outcomes and discussed controversial cases (about 30\%) with a third researcher. Once a total agreement on the data's interpretation had been reached, they selected the most representative cases for each category to be reported and discussed in this paper is a qualitative process (Bryant \& Charmaz, 2007). 
In the next section, the findings of the study are presented. The data of the two programmes are grouped and presented according to the three categories and sub-categories reported above.

\section{Findings}

For each section, we analyse the three categories concerning the three temporal sub-categories considered (i.e. before the Master's, right after the end of the Master's, and one year on from the end of the Master's) with the use of extracts from the teachers' interviews. The first section discusses the participants' accounts of their sense of conceptual readiness.

Sense of Conceptual Readiness

Before the Master's

In general, the teachers expressed a need for professional development and learning. This personal need was related to the desire to help students improve their performance and to indirectly affect colleagues and, more generally, the community to which they belonged. Therefore, the teachers saw the Master's as a source of knowledge and methods to help them to renew their role as teachers, as in the following extract:

I would like to know how to approach this net-generation with new teaching methods. For that reason, I choose to go on with my studies and return to deal with this challenge. [Extract No. 1]

Teachers are ready to engage in learning and training for their professional development for different reasons. Technology knowledge is particularly considered to improve teaching in modern society, a feeling that all the teachers expressed. This confirms their need for new knowledge and content to deal with changes in modern African society.

Right after the end of the Master's

The training course activated new potential practices of teaching and the teachers' involvement in research generated new knowledge. When new knowledge is acquired, this starts to intertwine with implications for their teaching practices. In the following extract (No. 2), the teacher explored the potential link between her future action of doing research, 
possibly thanks to the experience she had acquired, and the impact on her students:

When you are a teacher you use the knowledge that you know and use the results you just had. But as a researcher, you have to read what other people have done, what other people have to teach you, how you can use this and then you can expand. My students will be better now. I will try to stay in research. Oh yes, I am ready and I have something new in mind. [Extract No. 2]

The course enriched her vision of teachers and she projected herself as a researcher with a new modality of practices, such as reading educational and scientific literature and taking part in discourses in the educational community. The knowledge acquired by the teachers is seen to be directly linked with the knowledge and performance of the students. She considered that engaging in research, with a focus on both knowledge acquired and knowledge still to be appropriated, will help to improve her own students' performance.

One year on

One year on from the end of the Master's, the teachers still valued and considered the knowledge they had acquired, which had been adapted and tested in different pedagogical solutions. Teacher values, particularly the global opportunity given by the Master's, had been exposed to a new culture, a new educational system and new content that stimulated their professional growth, as in these two extracts:

Being exposed to ideas, education systems in Europe has helped me to realise not to stick to an education system as a fixed body but to discover new ideas that flow into the classroom for the best results. [Extract No. 3]

To improve my teaching methods and to be open-minded in other areas of life. Research has helped me to keep searching for ways to improve or to possess new skills in my current occupation and any other work-related areas. [Extract No. 4] 
One year on from the end of the Master's, it is the teachers' global experience in Europe, in its totality, that has shaped their new conceptual perspectives about education, pedagogy and national practices. Teachers, apart from the pedagogical implications, evoke their engagement to become more oriented to a social perspective. Their conceptual readiness is oriented towards activating their knowledge to solve general problems in their African community, such as the penury of teaching resources and the poor quality of science laboratory tools. The teacher's role has been re-conceptualised and enriched with a new commitment and important implications (albeit still generic) for the social community.

\section{Sense of Procedural Readiness}

Before the Master's

The teachers recognised they could not act as active teachers in their work because they were demotivated for different reasons, such as the poor resources available and the absence of support. In Extract No. 5 , the teacher is clearly stating that she was waiting for something - it is not clear what - that did not arrive, which made her frustrated. Indeed, frustration and a lack of motivation were the basis of passive action that made it impossible for the teachers to change their teaching strategies.

\section{Previously, I just waited and I was frustrated. [Extract No. 5]}

Their willingness to act under new practices was inhibited by the absence of new stimuli, which would subsequently be filled by the Master's course.

Right after the end of the Master's

The teachers felt that they could do research thanks to the new tools they had acquired. They were ready to act in new ways and with an activated sense of procedural readiness for research inquiry, as the following extract testifies:

\section{If I come back home now, I will teach, I think, I will see research differently. If you see a problem in your classroom, maybe the students are not learning, so you have to ask yourself, why are}


the students not learning? If you decide to do such a research you will be able to find an answer. So, for this reason, research can be done. It can help. [Extract No. 6]

The teacher in this extract feels ready to apply their acquired knowledge in the new context, imagining scenarios of intervention. This knowledge is active in terms of organising new pedagogical activity and doing research, which expresses their sense of readiness in applying a research inquiry attitude.

The teachers were also aware that peer collaboration has the potential to transform teaching practices. They often referred to the concrete planning to share their expertise with other colleagues involved in the research. For example:

\section{When I go back to my school, I will organise a series of workshops for my colleagues, as well as in the neighbouring school. [Extract No. 7]}

This sort of collective action is considered valuable in supporting changes in teaching practices. In general, teachers had begun to evaluate the benefits of the acquisition of research skills, which extended their traditional action space. Indeed, some generic implications of their doing research in the school-for the benefit not just of the classroom but also of society - began to emerge:

\section{I will do research and be able to resolve more problems.}

[Extract No. 8]

However, this procedural readiness is, at the same time, generic and over-optimistic about the implication of teachers' research on the local community.

One year on

The teachers still claim to apply and consider the knowledge they acquired about research inquiry and that this has led to some stable and significant changes in their practices. Indeed, some practices are well assimilated in their daily activities, as shown in this extract: 
I have identified what type of students I have in class, detected the learning style that suits their learning needs. [...] Since I have activated the students' curiosity in the classroom, learning is effective, and I can tell that students have gained a lot from the different types of teaching methods I have prepared for each lesson. [Extract No. 9]

Here, the teacher is attempting to build a network with his colleagues in his local context. There is an active effort to create a shared repertoire with colleagues for the common goal of improving the performances of the students.

The teachers' actions also include going on with their research, for example:

I am currently working on the publication of my research paper. [Extract No. 10]

As shown in this extract, great emphasis is placed not only on what can be taken from the research but also on the potential to contribute to research. Consequently, one year after the end of their Master's course, the teachers are still dealing with research, which can open new possibilities for their career and the quality of their teaching.

Sense of Dispositional Readiness

Before the Master's

The teachers expressed a sense of frustration in their dispositional readiness, considered as the level of occupationally-related dispositions available for them to draw upon and with which they could utilise their knowledge effectively (i.e. what they value). They characterised the existing activity as a failure, and many had lost their motivation to continue to work. In the following extract, a teacher refers to the sense of frustration they experienced: 
In this extract, the teacher realises the absence of personal engagement as a consequence of economic depression and passivity from the country-level educational institutions.

Right after the end of the Master's

At this stage, the teachers' sense of dispositional readiness in applying research inquiry is active, with high expectations and a positive bias about educational research, as in the following example:

\section{I mean to find a way to teach in a limited situation. Only} true research can improve the situation. [Extract No. 12]

As we can see, taking part in the course has given a powerful boost to breaking away from previous practices and finding new solutions to overcome obstacles. Teaching is seen as a space in which to apply and experience new strategies, while research is seen as a space to find new resources, solutions, and problem-solving insights. However, despite this positive disposition, some of the teachers were also aware of the obstacles and slowness of social transformation, as seen in this extract:

\section{Another concern is the situation of the internet. We have already downloaded the simulation programmes, but we are still worried because so far we cannot access the internet freely. [...] I am aware that this will be a challenge at home. [Extract No. 13]}

The problems with the lack of technology were a shared concern for the teachers who would have liked to introduce some innovations into their teaching practices. Their continued belonging and access to the research communities were seen as crucial for enacting these changes.

\section{One year on}

The teachers affirmed that becoming a teacher is generally easy in their respective countries of origin. However, teaching is described as a low paid profession with limited social status and with few opportunities for professional learning. One year after the end of the Master's, 
the experience was still central to their professional development, as seen in this extract:

The Master's of Research was a journey that changed my profession. [Extract No. 14]

Apart from recognising the value of the Master's in its entirety, this teacher expresses that their future disposition was strongly oriented towards research. However, while the Master's course had helped them to take new actions to improve their skills and take opportunities, one year later, the teachers seem to be struggling individually for professional growth. For example:

I would very much love to continue research in education.

Educational science in my country still needs a lot of research

to improve the education system. If I am given a chance, I would like to continue doing research. [Extract No. 15]

Positive in their research-oriented dispositions in the final interview one year after finishing their Master's course, teachers are looking for new opportunities to pursue a path of professional growth.

\section{Discussion}

The purpose of this paper was to look into teachers' sense of readiness about a specialist domain, which is the research inquiry attitude. In the following, we discuss the narrative data obtained at the end of the Master's and one year on in the light of the three categories considered.

The category "sense of conceptual readiness" shows the ability of the teachers to make new conceptual links about teaching practices thanks to the repertoire of experiences acquired during their Master's course. Beforehand, the teachers felt the need for new knowledge to adapt their job to the demands of the students and society. This absence leads to the difficulty of keeping up with their habitual way of working while also considering the lack of motivation, resources and new strategies to deal with young students. These teachers had started to search for new actions and opportunities, 
such as the learning opportunities of the Master's course. One year on, the teachers expressed the importance of the Master's as a moment in which they felt 'charged' with the new knowledge desired.

The category 'sense of procedural readiness' is characterised by an inhibition of action before the course. At the end of the Master's and one year on, the teachers had introduced some changes into their role as teachers, revising their working practices with more use of technology in the classroom, although always while dealing with limited resources. At the same time, the teachers were willing to engage in shared reflections about potential social transformation thanks to their actions.

The category "sense of dispositional readiness" is characterised at the end of the Master's with a renewed personal commitment towards the profession. By the end of the course, the teachers were willing to stay in research activities (such as publishing papers). This engagement is considered as a personal and professional advantage but, for some of them, also has the social implication of contributing their countries.

The three categories and sub-categories help us to see in detail the journey from learning to work made by the teachers in their process of professional development until one year after the end of their Master's. This process and its related experiences help us to see how the knowledge is "digested" over time with different levels of attention from their side (attention to specialist knowledge at the beginning of the course and more global at the end, with a wider appreciation of the Master's) in sedimentation of the learning done.

The peculiar cultural and economic situations in the countries the teachers came from seeming to shape the elaboration of their knowledge in evaluating the teaching profession and the possible projection of actions to perform at a personal and social level. Indeed, the teachers mentioned their adaptation between the learning done and the features of their contexts, shaping their ability to implement innovative teaching practices, and, concerning their procedural and dispositional readiness, discussed sharing in colleagues' experiences, proposing new solutions in the classroom and so on. The research inquiry attitude thus shaped new possibilities of pedagogical and professional action for these teachers.

Considering the international context between Africa and Europe, we feel that this study may open a discussion about how to transfer the conceptual, disposition and procedural readiness acquired 
in an international training arena to local practices, where challenges could be found in daily working life, such as for our sample of teachers. The study of readiness and senses of readiness in teaching practices helps us to deeply explore the transition between learning and practice and the agentic role of the teacher in these revisions of knowledge.

Indeed, supporting the ability to introduce and use new knowledge, practices and innovations in a specific context is what it means to be an agentive teacher. Agency, which is here conceptualised as an individual or collective willing to act, is an integral part of a teacher's professionalism and involves the capability to conceive broad educational visions and meanings that give a long-term purpose to the work (Toom, Pyhältö \& Rust, 2015). Specifically, the teachers' agency is here conceptualised as the opportunity, will and skill to act upon, influence and transform activities and circumstances in their professional lives (Emirbayer \& Mische, 1998). Specifically, the teachers' sense of agency concerns the awareness or experience (Hilppö, 2016) that shapes what teachers do, how they think about what they do, and what they think they will be within their profession. Considering teachers' agency related to their capacity to act combined with the contingencies of the environment within which such action occurs (Biesta \& Tedder, 2007) and their senses of conceptual, procedural and dispositional readiness thus help us to decode what the teachers know, do and value.

\section{Conclusions}

In this chapter, we have explored a group of teachers' senses of readiness about their research inquiry attitudes after attending an international Master's course. From a methodological point of view, in exploring the sense of readiness of in-service teachers, this paper is limited because it considered a small number of respondents. Nevertheless, the case study considered allowed patterns to emerge (Zittoun, 2016). Indeed, self-narratives are a powerful instrument to explore the subjective point of view about professional learning and development, as well as changes related to the acquisition of a research inquiry attitude. At the same time, we are aware of the complexity of the concept and the difficulties in the operationalisation of the sense of readiness. Further research is needed in this direction, considering the small amount of current literature about the concept of readiness 
and senses of readiness; for example, research may aim to see readiness in direct action or constraints in the introduction of innovations into local communities, considering that instructional practices are generally highly institutionalised (Bridwell-Mitchell, 2015). More broadly, the paper contributes to the field of teachers' professional development and agency-promoting leadership (Vähäsantanen, Paloniemi, Hökkä \& Eteläpelto, 2017). Teachers may become aware of their agency thanks to their professional learning, how it affects their professional experiences, and how it may affect students' learning. Meanwhile, future research may shed light on how to support agency in a changing context (Rajala \& Kumpulainen, 2017) and how to actively use learning to have a real impact in the work setting.

\section{References}

$\rightarrow$ Bates, T., Swennen, A. and Jones, K. (2011). Teacher educators - a professional development perspective, The Professional Development of Teacher Educators, 1, 7-19.

$\rightarrow$ Billett, S. (2015). Readiness and learning in healthcare education, Clinical Teacher, 12, 1-6.

$\rightarrow$ Billett, S., Wärvik, G. B. and Choy, S. (2018). Concepts, Purposes and Practices of Integration Across National Curriculum. In: S. Choy, G.-B. Wärvik, V. Lindberg (eds.), Integration of Vocational Education and Training Experiences (pp. 327344). Singapore: Springer.

$\rightarrow$ Bridwell-Mitchell, E. N. (2015). Theorizing teacher agency and reform: How institutionalized instructional practices change and persist, Sociology of Education, 88(2), 140-159.

$\rightarrow$ Bryant, A. and Charmaz, K. (2007). Grounded Theory Research: Methods and Practices. In: A. Bryant, K. Charmaz (eds.), The Sage Handbook of Grounded Theory (pp. 31-57). Los Angeles: Sage Publications.

$\rightarrow$ Charmaz, K. (2006). Constructing grounded theory: A practical guide through qualitative analysis. London: Sage Publications.

$\rightarrow$ Cochran-Smith, M. (2005). Teacher educators as researchers: Multiple perspectives, Teaching Teachers, 21(2), 219-225.

$\rightarrow$ Djerasimovic, S. (2014). Examining the discourse of cross-cultural communication in transnational higher education: from imposition to transformation, Journal of Education for Teaching, 40(3), 204-216. 
$\rightarrow$ Dobber, M., Akkerman, S. F., Verloop, N. and Vermunt, J. D. (2012). Student teachers' collaborative research: Small-scale research projects during teacher education, Teaching and Teacher Education, 28(4), 609-617.

$\rightarrow$ Edwards, A. (2015). Recognising and realising teachers' professional agency, Teachers and Teaching: theory and practice, 21(6), 779-784.

$\rightarrow$ Emirbayer, M. and Mische, A. (1998). What Is Agency?, The American Journal of Sociology, 103(4), 962-1023.

$\rightarrow$ Flores, M. F. (2017). Practice, theory and research in initial teacher education: international perspectives, European Journal of Teacher Education, 40(3), 287-290.

$\rightarrow$ Girod, M. and Pardales, M. (2001). "Who am I Becoming?" Identity Development in Becoming a Teacher Researcher. Paper presented at the Annual Meeting of the American Educational Research Association, Seattle, WA, 10-14 April.

$\rightarrow$ Goller, M. and Billett, S. (2014). Agentic behaviour at work: Crafting learning experiences. In: M. Goller, S. Paloniemi, Discourses on professional learning (pp. 25-44). Dordrecht: Springer.

$\rightarrow$ Haßler, B., Hennessy, S., Cross, A., Chileshe, E. and Machiko B. (2015). School-based professional development in a developing context: lessons learnt from a case study in Zambia, Professional Development in Education, 41(5), 806-825.

$\rightarrow$ Hardman, F., Ackers, J., Abrishamian, N. and O'Sullivan, M. (2011). Developing a systemic approach to teacher education in sub-Saharan Africa: Emerging lessons from Kenya, Tanzania and Uganda, Compare: A Journal of Comparative and International Education, 41(5), 669-683.

$\rightarrow$ Hilppö, J. (2016). Children's sense of agency: A co-participatory investigation. Doctoral thesis. University of Helsinki, Helsinki.

$\rightarrow$ Hoare, L. (2013), Swimming in the deep end: transnational teaching as culture learning?, Higher Education Research \& Development, 32(4), 561-574.

$\rightarrow$ Impedovo, M.A. (2016). In-service Teachers' Sense of Agency after Participation in a Research Master Course, International Journal of Educational Psychology, 5(3), 281-307.

$\rightarrow$ Jansen, J.D. (2001). Image-inning teachers: Policy images and teacher identity in South African classrooms, South African Journal of Education, 21(4), 242-246.

$\rightarrow$ Kumpulainen, K. and Lipponen, L. (2012). Harnessing funds of knowledge in dialogic inquiry across formal and informal learning environments. In: P. Jarvis, M. Watt (eds.), The Routledge international handbook of learning (pp. 112-125). New York: Routledge. 
$\rightarrow$ Lai, C., Li, Z. and Gong, Y. (2016). Teacher agency and professional learning in cross-cultural teaching contexts: Accounts of Chinese teachers from international schools in Hong Kong, Teaching and Teacher Education, 54, 12-21.

$\rightarrow$ Neuendorf, K. A. (2016). The content analysis guidebook. London: Sage Publications.

$\rightarrow$ Mayring, P. (2004). Qualitative content analysis, A companion to qualitative research, 1, 159-176.

$\rightarrow$ Montgomery, C. (2014). Transnational and transcultural positionality in globalised higher education, Journal of Education for Teaching, 40(3), 198-203.

$\rightarrow$ OECD (2014). Reviews of Vocational Education and Training A Skills beyond School Review of South Africa. Paris: Organisation for Economic Co-operation and Development Publishing.

$\rightarrow$ Oolbekkink-Marchand, H. W., Hadar, L. L., Smith, K., Helleve, I. and Ulvik, M. (2017). Teachers' perceived professional space and their agency, Teaching and Teacher Education, 62, 37-46.

$\rightarrow$ Oliveira, A. W. (2012). Teacher agency in the performance of inquiry-oriented science curriculum reform, Cultural Studies of Science Education, 7, 569-577.

$\rightarrow$ Piaget, J. (1968). Le point de vue de Piaget, International Journal of Psychology, 3(4), 281-299.

$\rightarrow$ Priestley, M., Biesta, G. J. J. and Robinson, S. (2012). Understanding teacher agency: The importance of relationships, Paper presented at the Annual Meeting of the American Educational Research Association, Vancouver, Canada, 13-17 April.

$\rightarrow$ Priestley, M., Edwards, R., Miller, K., Priestley, A. (2012). Teacher agency in curriculum making: Agents of change and spaces for manoeuvre, Curriculum Inquiry, 43(2), 191-214.

$\rightarrow$ Rajala, A. and Kumpulainen K. (2017). Researching Teachers' Agentic Orientations to Educational Change in Finnish Schools. In: M. Goller, S. Paloniemi, Agency at Work. Professional and Practice-based Learning (Vol. 20, pp. 311-329). Cham: Springer.

$\rightarrow$ Renshaw, P. (2016). On the notion of worthwhile agency in reformist pedagogies, Learning, Culture and Social Interaction, 10, 60-63.

$\rightarrow$ Samuel, M. and Stephens, D. (2000). Critical dialogues with self: Developing teacher identities and roles - a case study of South African student teachers, International Journal of Educational Research, 33(5), 475-491.

$\rightarrow$ Sahlberg, P. (2013). The most wanted: Teachers and teacher education in Finland. In: Teacher education around the world (pp. 15-35). New York: Routledge. 
$\rightarrow$ Smith, K. (2009). Transnational teaching experiences: an under-explored territory for transformative professional development, International Journal for Academic Development, 14(2), 111-122.

$\rightarrow$ Smit, B. and Fritz, E. (2008). Understanding teacher identity from a symbolic interactionist perspective: two ethnographic narratives, South African Journal of Education, 28(1), 91-101.

$\rightarrow$ Vähäsantanen, K., Paloniemi, S., Hökkä, P. and Eteläpelto, A. (2017). An agency-promoting learning arena for developing shared work practices. In: M. Goller, S. Paloniemi (eds.), Agency at work: An agentic perspective on professional learning and development (pp. 351-371). Cham: Springer.

$\rightarrow$ Zittoun, T. (2016). Modalities of generalization through single case studies, Integrative Psychological and Behavioral Science, 51(2), 171-194. 


\section{Annex 1}

The first interview that was done at the start of the programme

Autobiographical and professional profile

1. Gender

2. Age

3. Nationality

4. What was your last academic qualification?

5. What is your subject of teaching?

6. How many years of teaching have you done?

7. In which school do you work?

8. Why did you choose to be a teacher? How do you become a teacher?

9. What are the basic elements to be a teacher?

10. Do you think that there were significant turning points in your professional career? Which?

11. When and why did you decide to improve your professional skills?

12. Who supported you in this decision?

Learning course and ongoing research activities

1. Why and how did you choose the topic of your research thesis?

2. What is your main expectation in doing your research?

3. What are the main difficulties in organising your research?

4. Is this the first time that you have done research?

5. What role do your supervisor and colleagues have in your research?

6. Do you consider your previous experience as a teacher when doing your actual research? If yes, how?

7. What kind of new technology do you use for doing your research?

8. Do you use some online social networks or websites to connect with other researchers or teachers?

9. Do you think you have developed skills while doing your research? If yes, can you give some examples?

10. Do you like to do research in education? 
Projection of skills acquired in future activities

1. Do you think your experience during the Master's will be useful in your future teaching activities? In what way?

2. Do you think your experience during the Master's will be useful for your future students? In what way?

3. Will you share your experience of learning and research with other teachers in your school? If yes, in what way?

4. Do you think you will continue to improve your skills? If yes, how?

5. Do you feel confident to start new research in your local school in the future?

6. Will you use new technology to improve your research skills? If yes, which technology?

7. According to you, do teachers need to develop research skills? Why?

8. What is the attitude of your school about research activities?

9. What kind of relationship is there between your school and your local university? 


\section{Annex 2}

Interview Protocol

1. After more than a year since the end of your international Master's course, are you still interested in your research topic?

2. On returning to your country, did you share the results of your research with colleagues/students or other schools? In what way?

3. In your opinion, what is the most important contribution of your research in your school and/or community?

4. Do you think that doing your research has had an impact on your teaching practices? In what way?

5. Have you published, or do you plan to write, articles about your research?

6. Are you involved in new research projects?

7. Do you intend to improve your professional skills? In what way? 


\section{Teacher Training Project \\ An Attempt to Devise an In-service Training \\ Programme for English Language Teachers}

DOI: $10.47050 / 66515321.238-254$

Meretguly Gurbanov

Today, English has attained a different role other than as a second or a foreign language; it has become a primary medium of international communication around the world. The increase in its use leads naturally to a demand for people with a good knowledge of English. As a result, English language teaching (ELT) has become a part of basic education, an important business and a major part of educational policy. Thus, English language teacher training has become an important issue. However, the in-service teacher training programmes that have been employed at various times are often not fully successful in providing systematic opportunities for continuing education, skills and career development. Consequently, continuous teacher education (CTE) has recently regained attention in the field of foreign language teaching (FLT). This revival of interest in teacher development has led researchers, policy makers, and leaders to seek programmes in which teachers could be educated in recent methods of FLT. In this scope, the Ministry of Education of Turkmenistan adopted the Conception of Foreign Language Teaching and Learning (the Conception) in December 2017. Throughout the Conception, a CTE programme for foreign language teachers using national and international experience was highly recommended. This chapter aims to propose an inservice teacher training programme. It also tries to present techniques of conducting CTE as a part of in-service teacher training and suggests ways to implement them for English language teachers.

\section{Keywords:




\section{Introduction and Background of the Project}

If you give people fish, they will eat for a day; if you teach them how to fish, they will eat for a lifetime.

proverb

By the 1950s, countries around the world had placed an emphasis on English language teaching (ELT) as an important requirement of education (Collins, 2010). Also, in countries where English is not an official language, the importance of English as an international language has been widely recognised. As a result, ELT has become a part of both secondary and tertiary education systems in countries where English is used as a foreign language. In such contexts, teachers face challenges because of school environments (Alibakhshi \& Dehvari, 2015). In such cases, teachers might become frustrated and less effective (Murray, 2010). Therefore, professional development activities can solve some of these problematic issues (Bailey, Curtis \& Nunan, 2001).

In the age of advancement in education, the term 'professional development' (PD) may be used in reference to a wide variety of forms of specialised training, formal education, or advanced professional learning methods intended to help administrators, teachers, and other educators improve their professional knowledge, competences, skills, and effectiveness. When the term is used in education contexts, it may range from a one-day conference to a two-week workshop to multiyear advanced degree programmes. They may be delivered in person, face-to-face or online, during the school day or outside of normal school hours, or through one-on-one interactions or in groups. Participants might even be given a few days or months of official leave. Within this period, teachers' PD has moved beyond a series of simple, in-service workshops and expanded into a more organised system of continuing education. Engaging in PD models shows that one is a lifelong learner who is willing to adapt and make the necessary changes within the professional environment to produce more successful outcomes. In order to have successful outcomes, teachers must continuously evaluate not only their students but also their personal practices within the learning environment. Continuing professional development (CPD) keeps teachers up to date with the latest changes and developments 
in new curriculum resources, teaching methods and techniques and more. The best professional development is continuing, experiential, collaborative and connected to and derived from working with students. Regardless of their roles, teachers should think that there are sets of skills that they need to develop, as there is no boundary to professionalism. Every situation may provide opportunities for the development of teachers. There are many experiences that allow for teacher development, such as career discussions, mentoring, workshops, online learning, debates with colleagues and work shadowing. All of these and more can enable teachers to improve what they do, why they do it and how they do it. CPD is integral to a successful career and impactful research. Identifying teachers' CPD needs can happen as a planned process or spontaneously as a response to deficiencies in teaching skills or knowledge. To help facilitate teachers' learning and develop their skills in these areas, at a time and in a way that suits them, the Turkmen National Institute of Education (NIE), under the Ministry of Education, conducts PD courses for foreign language teachers in various institutions throughout the year. The NIE monitors and checks the feedback on training courses. In December 2017, the Conception of Foreign Language Teaching and Learning (hereinafter 'the Conception') was adopted by the Ministry of Education. Since then, many activities have been carried out. One of the most important activities was a call for a continuous teacher education (CTE) programme, which was repeatedly mentioned throughout the Conception. This programme should include sessions on teacher effectiveness, teacher professionalism, and other important stages of teacher development. This process led to developing an approach to the management of innovation through the present in-service teacher training project. This project aims to propose in-service teacher training programmes using national and international experiences. This would be a combination of local (i.e. Turkmen) experiences with those of teachers from around the world. The current research aims to use the scientific and literary works of national and international scholars to suggest modifications to in-service teacher training programmes. This paper consequently tries to present techniques of conducting CTE that are a combination of national and international experiences and suggests ways to implement this for foreign language teachers. 


\section{Problem statement}

As English is an international language, it has been selected as a compulsory subject for students of all levels. The general goal of teaching English is to equip students with the required level of language to help them communicate effectively and successfully in various situations. The essence of a teacher is to help students to become successful learners. This is why it may be so hard for educators to look at themselves to see what they can improve upon. Teacher training in EFL contexts is quite challenging compared to the same process in the target language community, where preservice teachers' exposure to the language environment is not limited to the institutional setting.

Many teachers often complain because they believe that students are not successful communicators in English. Teachers feel helpless and they wish to change the situation. The present researcher believes that the problem is not because there are no knowledgeable teachers, but rather that it is a problem of teachers' practices. Teachers are, more often than not, spending every minute in class explaining several language items and neglecting the importance of providing students with chances to use the language. They have problems with what to teach, how to teach and why. Therefore, this study will try to deal with these problems and will offer several activities through a wellorganised action plan, as the practical planning of actions is often the more calm and manageable approach in such cases.

\section{Purpose of study}

This project aims to use the scientific and literary works of national and international scholars to suggest modifications to in-service teacher training programmes. This paper consequently tries to present techniques of conducting CTE that are a combination of national and international experiences and suggests ways to implement this for foreign language teachers. It is hoped that the findings and outcomes of this project will be helpful in reaching the goals of the Conception.

\section{Review of the Literature}

A professional educator is always learning and honing their craft. They are on an endless journey where they are always looking for new ideas or teaching strategies, ways to improve their skills, or new information 
that will help their students to succeed. It takes a lot of hard work and effort to be a professional educator. "It requires effort to go that extra mile for the students who need it and it takes patience to continually grow and truly understand your craft as a teacher" (Cox, 2019).

The Organisation for Economic Co-operation and Development (OECD) adopts a broad definition of teachers' PD as "activities that develop an individual's skills, knowledge, expertise and other characteristics as a teacher" (2009, p. 49). Rose and Reynolds, citing Day, provide another definition of teachers' PD:

Professional development consists of all natural learning experiences and those conscious and planned activities which are intended to be of direct or indirect benefit to the individual, group or school, which contribute, through these, to the quality of education in the classroom. It is the process by which, alone and with others, teachers review, renew and extend their commitment as change agents to the moral purpose of teaching; and by which they acquire and develop critically the knowledge, skills and emotional intelligence essential to good professional thinking, planning and practice with children, young people and colleagues throughout each phase of their teaching lives (Day, 1999, p. 4, cited in: Rose \& Reynolds, n.d., p. 219).

\section{Methods of the Study}

This study aims at exploring EFL teachers' opinions of CPD and the CPD activities they engage in to develop professionally. Therefore, in attempting to investigate and interpret the meaning of CPD from the participants' perspectives within the researched context, the researcher is getting the benefits of a mixed method. Mixed method studies attempt to bring together qualitative and quantitative methods. In this mixed method study, the researcher conducted a series of semi-structured interviews with a small number of participants and also carried out a large-scale survey. This kind of integration of qualitative and quantitative methods helped the researcher to collect first-hand data for this project, which is the first of its kind.

\section{Participants}

Groups of both male and female teachers of English as a foreign language (TEFL) were selected by local education authorities and sent to central institutions. They teach at public schools all around the country, though 
their years of teaching experience are varied. As it is an ongoing study, the number of participants is increasing as groups are continuously coming and going after each two-week training seminar. They are graduates of higher education institutions and vocational education schools who have studied in and out of the country. The main reason for including such a wide selection of fresh and experienced full-time teachers is to be able to generate a broad range of perceptions, insights, and experiences of CPD.

\section{Data Collection}

The relevant data for this ongoing study is being collected directly from both male and female participants through informal interviews and surveys. The participants come to seminars, the duration of which is two weeks or two months. The sizes of the groups are from around twenty to twenty-five. These instruments help the researcher deeply explore EFL teachers' perspectives of CPD and the CPD activities they are engaged in. Hence, these instruments help to understand the problems beyond students' underperformance. As it is an ongoing study, the results will be published in a future paper.

\section{Aims and Objectives}

The cycle of in-service teacher training aims to enhance the professional and knowledge levels of the English language teachers in Turkmenistan through achieving the following objectives:

1. Exchange knowledge and professional experiences, opinions and findings, and discuss mechanisms of inspiring the performance level of teachers;

2. Inform the in-service English language teachers of the latest international publications in the fields of English language teaching and learning methods;

3. Present and follow the latest developments, modern technologies and leading practices in the field of English language education;

4. Highlight the importance of scientific research conducted by the researchers and academicians and enhance the overall performance of English teachers;

5. Guide self-development and develop English language education by using contemporary scientific methods and techniques; 
6. Promote a culture of innovation, openness, creativeness, novelty and leadership in English language teaching;

7. Train and inspire qualified personnel as regional English language trainers to work at local educational institutions and on the Train the Trainers programme.

\section{Research Questions}

A research project cannot be imagined without research questions. In order to reach the above-mentioned objectives, there are a set of research questions. The main research question of this project is English Language Teaching in Turkmenistan: Why? What? How? When? This is followed by various sub-questions that also need to be covered:

1. What is a good teaching method?

2. What is an effective teaching and learning process?

3. Do the teachers have a particular style or approach to teaching the English language?

4. What are the factors that make you unique as an English teacher?

5. What does a teacher expect from his/her students and vice versa?

6. What do teachers do for their CPD or CTE?

7. How often do English teachers use educational tools and technologies in their classes?

\section{How does the project operate?}

Keeping English as their working language, the following events are also planned to be held within the scope of the project:

1. Periodic workshops, seminars and training on various topics concerning teaching the English language for secondary school teachers based on a planned series of significant themes.

2. Seminars for English language instructors of higher education institutions.

3. Popularise the best papers and experiences through electronic and print publications.

4. Facilitate and strengthen the production of high-quality research from Turkmenistan relevant to the Turkmen ELT community.

5. Investigate and document current ELT theories and practices in Turkmenistan using full-bodied research. 
6. Facilitate and encourage the establishment and maintenance of active research links between ELT professionals and policy makers within Turkmenistan.

7. Exhibit the research and methodological publications related to English language teacher education.

The events of the project are open to future English language teachers too.

\section{What can this project offer to English language teachers?}

The professional development of English language teachers will take place through seminars and workshops throughout the project as well as national and international events with well-known speakers from both overseas and various parts of Turkmenistan. Throughout the project, the researcher will attend international teacher education and development conferences and other teacher training seminars, bring international experience to Turkmenistan and share it with Turkmen English language teachers. This project will provide a forum in which English language teachers can exchange ideas, share problems and find solutions to issues of classroom teaching. Finally, in an effort to unite all English language teachers working in secondary schools in Turkmenistan, our action plan must take into account opportunities that may arise to co-operate with other teachers that are not part of this project.

\section{Suggested Activities}

The following categories of activities are suggestions for meeting the needs of teachers' capacity building:

1. Collaborating with other teachers to examine case studies of student work and development;

2. Participating in courses and other learning opportunities;

3. Coursework linked to the improvement of instructional technique or content knowledge;

4. Coursework for more advanced certification;

5. Curriculum and materials planning and development;

6. Participating in formal programmes of peer coaching or participation in peer reviews; 
7. Participating in PD activities or other school-college teacher development partnerships;

8. Training to become an examination "assessor" or test development committee member.

\section{Preliminary Findings}

This project actively started in November 2019. A list of expected findings for in-service teacher training programme project has been systematically identified. These are:

1. To develop the competencies and skills needed for the professional development of teachers;

2. To enable them to organise competency-based and commitment-oriented professional programmes;

3. To enable them to develop pedagogy relevant to English language education;

4. To acquire an understanding of the needs and problems of teachers;

5. To develop skills related to classroom management;

6. To develop competencies of curriculum development and material preparation;

7. To develop their capacity for examination, analysis, interpretation, and communication of educational ideas;

8. To develop capabilities for self-directed and life-long learning;

9. To enable them to understand the relationship between local attitudes, modern technology and education;

10. To enable them to undertake meaningful educational research.

\section{Expected Implications}

The researcher would like to undertake this project as postdoctoral research work, and he can guide a few self-motivated, open-minded, research-oriented teachers who are curious and keen on professional development for their PhD studies. He also would like to use and document the gathered data as a postdoctoral dissertation.

Another target is to establish an Association of Turkmen English Language Teachers, which will undertake all activities related to English language teaching in provinces of the country. One more point is to organise national and international conferences where local and 
international experts and English language teachers can mingle, discuss related issues and share their valuable experiences.

\section{Research Limitations}

This teacher training project is an in-service training programme for English language teachers who are serving at public schools. For that reason, it is limited to school-level English language teachers. However, other foreign language teachers who are proficient in English may also attend and avail the benefits of the project.

\section{Action Plan}

The project's action plan summarises the steps which we will follow to answer the inquiry question(s) outlined in this study. The action plan makes it clear what needs to be done, who is doing what, and when these things will be done, as well as the costs. While it takes time to create, it ultimately saves time and guides us to achieve the goals we intended.

An action plan allows everyone involved to understand what we intend to do on a term-by-term basis. It enables us to keep track of what we are doing, to inform our checkpoint reporting and to respond to what we are learning. It is also a working document and can be modified if we find that a different course of action is likely to be more effective.

Within the framework of this action plan (see Annex 1), some schools would be selected as experimental and control groups. They would take part in this project with teachers, students and their teaching-learning processes. The feedback from teachers will help in preparing better strategies. The researcher, in the first step, will conduct surveys and tests under the general topic "Me and my English classes". There are language proficiency tests and teacher knowledge tests to check their educational background. Surveys will help to gather and interpret data on English language teaching.

\section{Conclusions and Recommendations}

In-service teacher training aims to improve the quality of teachers who are already engaged with teaching. This project, through in-service training programmes, aims to increase teachers' efficiency in public schools. It is expected that trained teachers will improve their English language teaching knowledge and skills, and it is also hoped that this 
improvement will raise the quality of English teaching at schools. Furthermore, teachers can change their classroom practices by providing more opportunities for students to actively engage in learning, which will result in better student learning. These expectations suggest that teacher training may be effective in improving student learning and that teachers' motivations may play a role in facilitating its effects. In the present study, through the preliminary findings, it has been illustrated that good teaching methods and techniques performed by teachers help students to question their preconceptions and motivate them to learn by putting them in a situation in which they come to see themselves as the authors of answers and the agents of responsibility for change and improvement.

The action plan for this project (see Annex 1) was planned for six terms, beginning with gathering additional information on the skills and knowledge that teachers have through test and questionnaires. It proposes workshop sessions on topics ranging from teachers' theoretical knowledge to skills in English language teaching. There are practical sessions on curriculum design and materials production. As this project is limited to English language teachers at public schools, there are some additional recommendations for them:

1. Develop abilities for evaluating educational programmes and designing learning materials;

2. Enable teachers to acquire the capability to organise in-service continuing education programmes;

3. Promote the global perspective of educational development with special reference to local situations;

4. Enable them to appreciate and adopt emerging communication technology and innovative practices in the local context;

5. Develop qualifications for EFL teachers who want to improve their English language teaching skills, knowledge and confidence;

6. Enable them to have a developed understanding of teaching methodology through assessed teaching practice;

7. Enable them to have a developed understanding of the principles underlying language learning and teaching;

8. Enable them to have the ability to identify learners' needs and monitor and evaluate their progress;

9. Enable them to have developed insights into and awareness of language form and function in the classroom; 
10. Organise periodic in-service training programmes for teachers, educational administrators, and other educational staff;

11. Prepare outlines and printed materials for local training programmes;

12. Participate in the preparation of textbooks, education materials, and educational programmes.

\section{References}

$\rightarrow$ Alibakhshi, G. and Dehvari, N. (2015). EFL teachers' perceptions of continuing professional development: A case of Iranian high school teachers, PROFILE Issues in Teachers' Professional Development, 17(2), 29-42.

$\rightarrow$ Bailey, K.M., Curtis, A. and Nunan, D. (2001). Pursuing professional development: The self as source. Boston: Heinle \& Heinle.

$\rightarrow$ Collins, A.B. (2010). English-medium higher education: Dilemma and problems, Eurasian Journal of Educational Research, 39, 97-110.

$\rightarrow$ Cox, J. (2019). Professional Development Tips for Teachers, www.teachhub. $\mathrm{com} /$ professional-development-tips-teachers

$\rightarrow$ OECD (2009). Creating Effective Teaching and Learning Environments: First Results from TALIS. Paris: Organisation for Economic Co-operation and Development, www.oecd.org/edu/school/43023606.pdf

$\rightarrow$ Rose, J. and Reynolds, D. (n.d.). Teachers' Continuing Professional Development: A New Approach, International Congress on Effectiveness and Improvement, 219-240.

\section{Annex 1}

\section{Provisional Action Plan}

Inquiry question: What is a good teaching method? What is an effective teaching and learning process? Do the teachers have a particular style or approach to teaching English? In what ways can teachers apply and practice new techniques in their classrooms to increase success? 

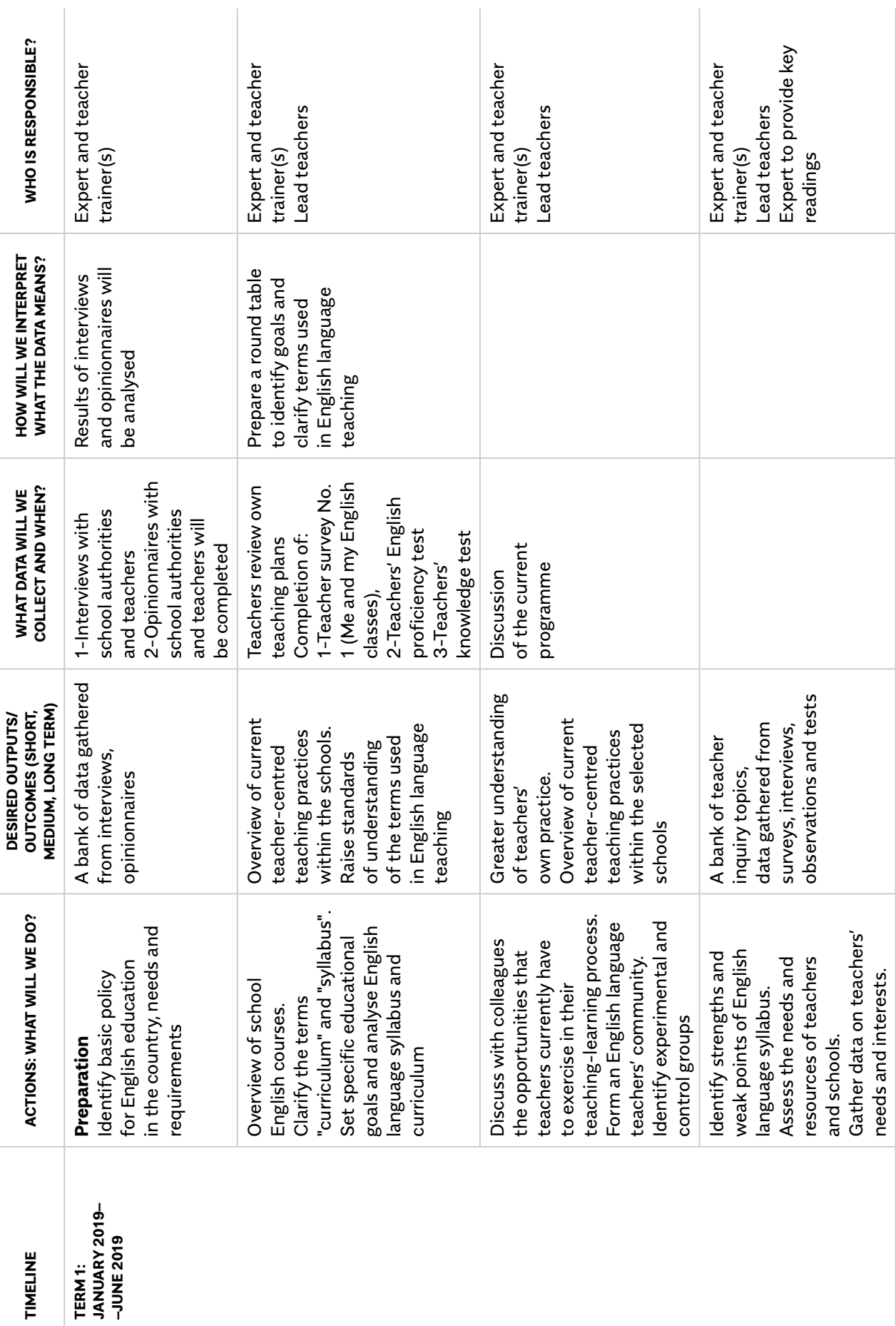


\begin{tabular}{|c|c|c|c|}
\hline 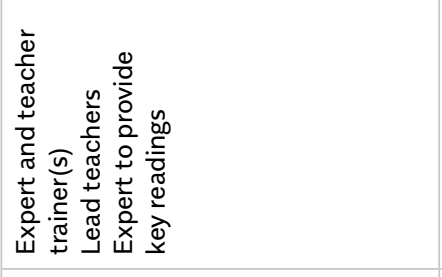 & 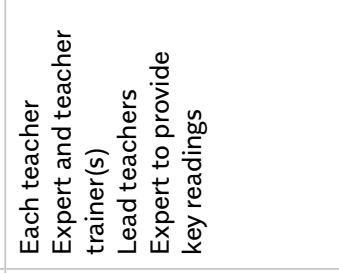 & 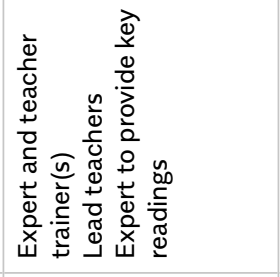 & 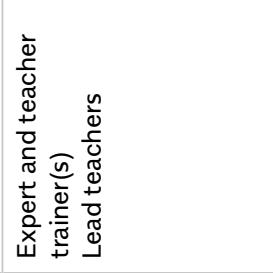 \\
\hline & 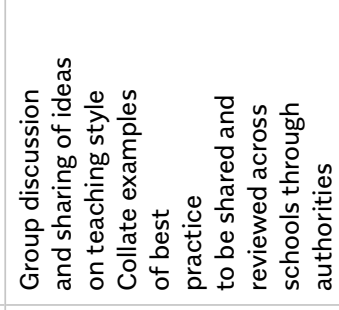 & 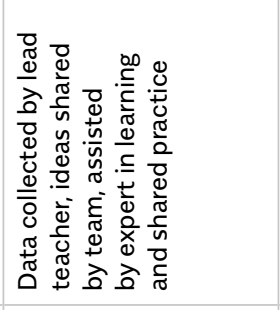 & 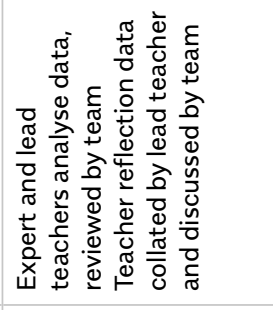 \\
\hline & 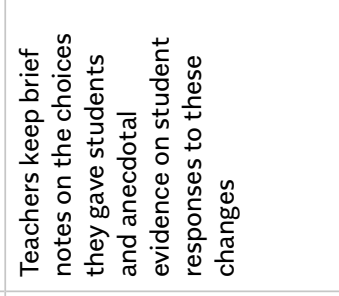 & 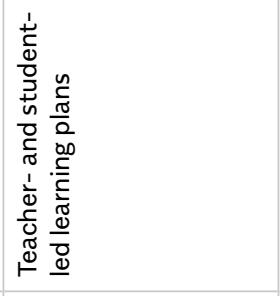 & 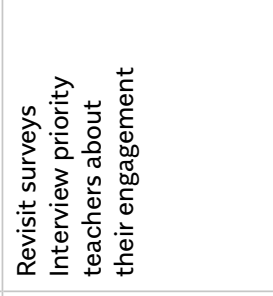 \\
\hline 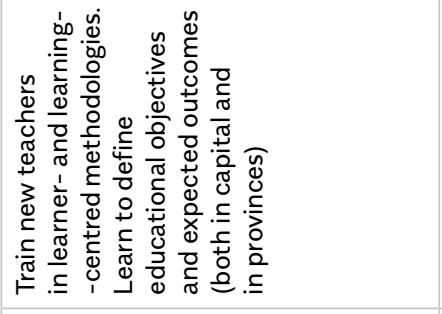 & 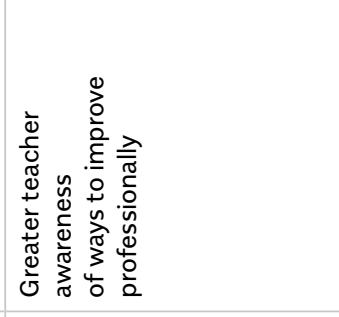 & 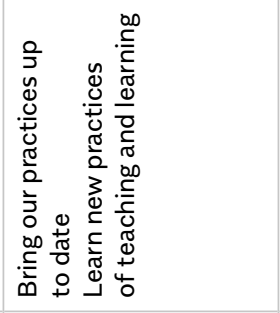 & 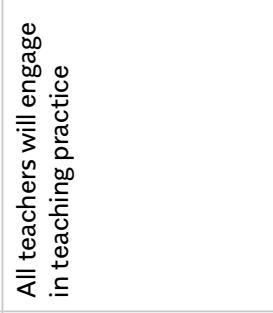 \\
\hline 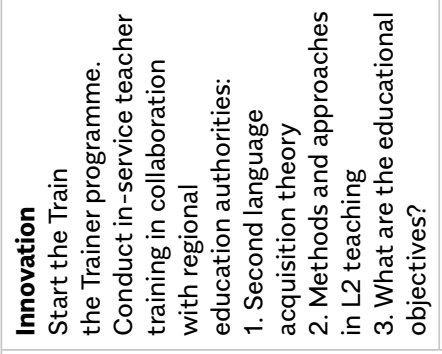 & 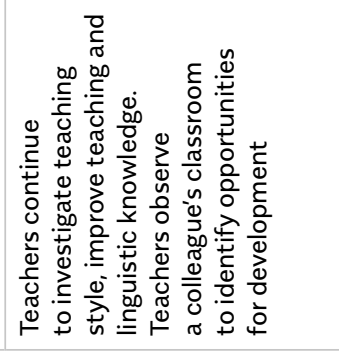 & 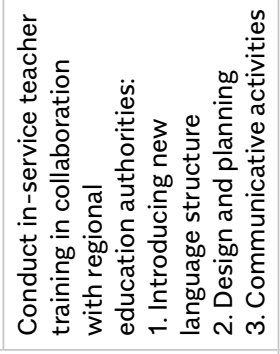 & 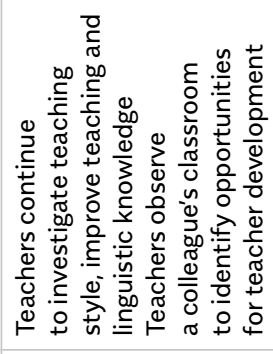 \\
\hline 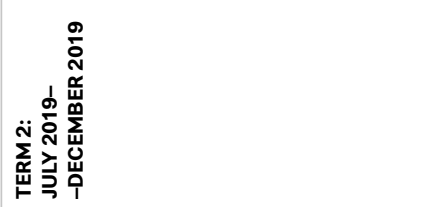 & & & 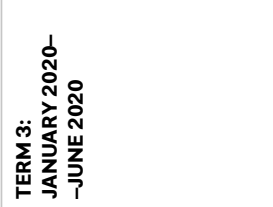 \\
\hline
\end{tabular}




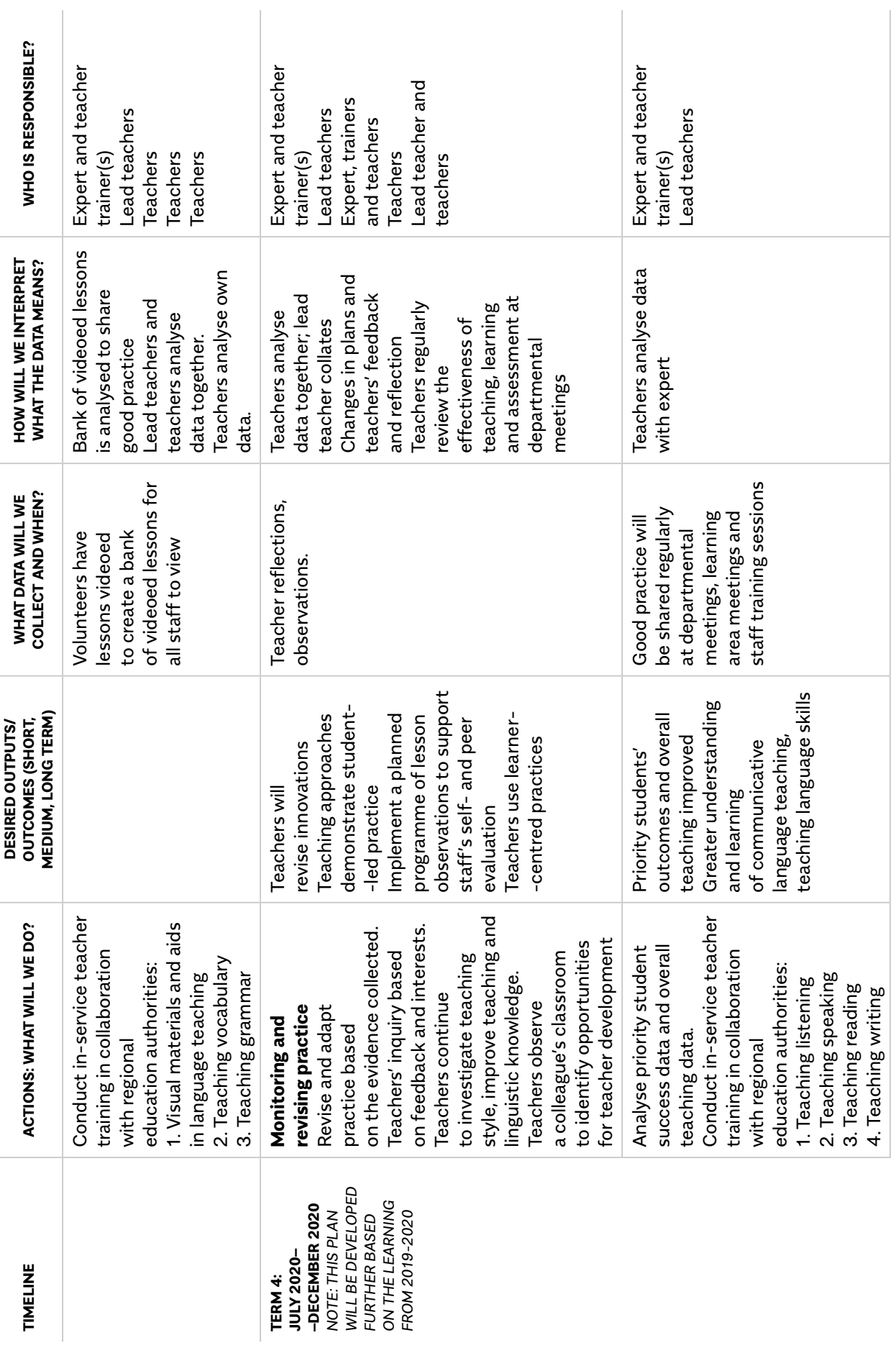




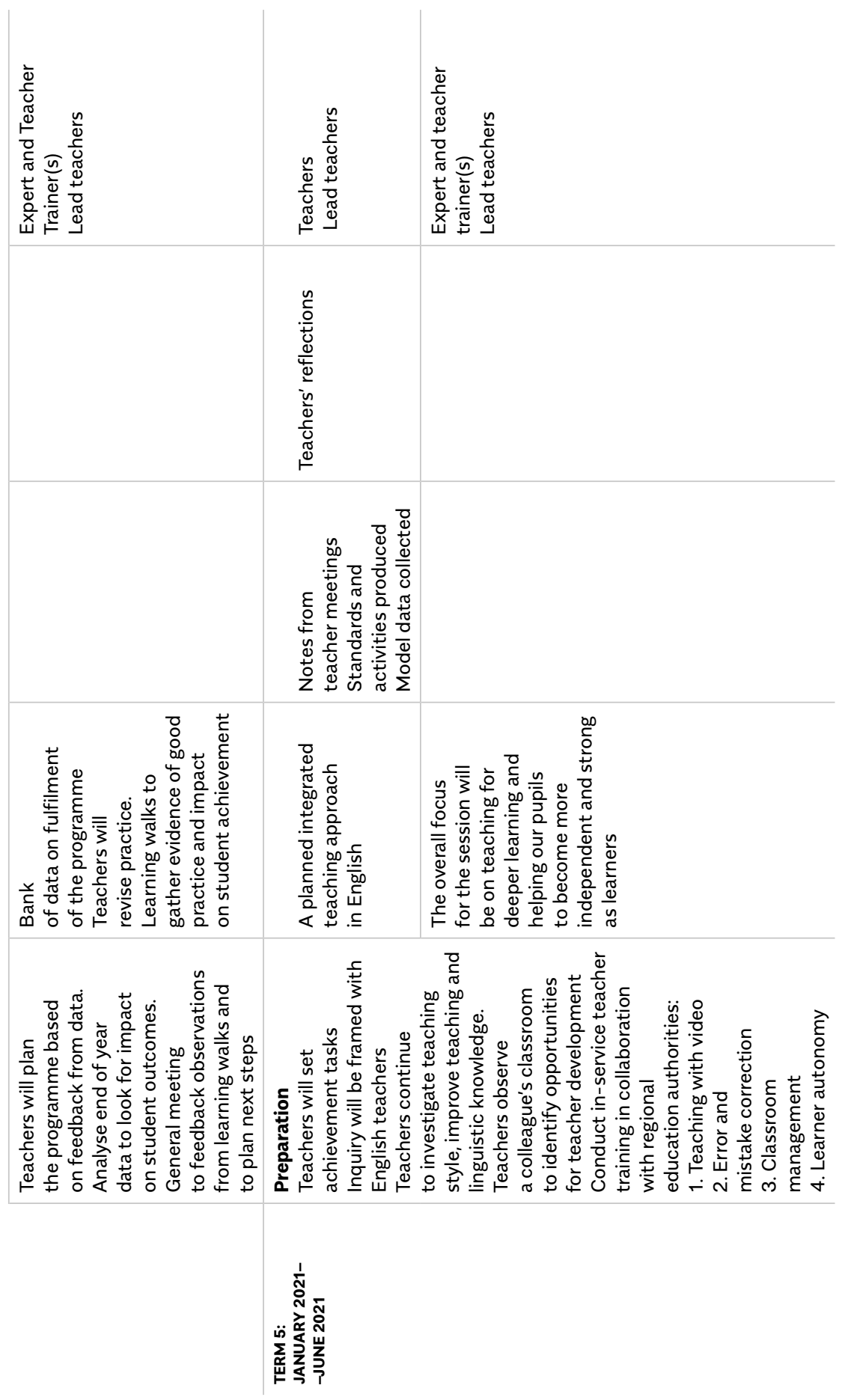



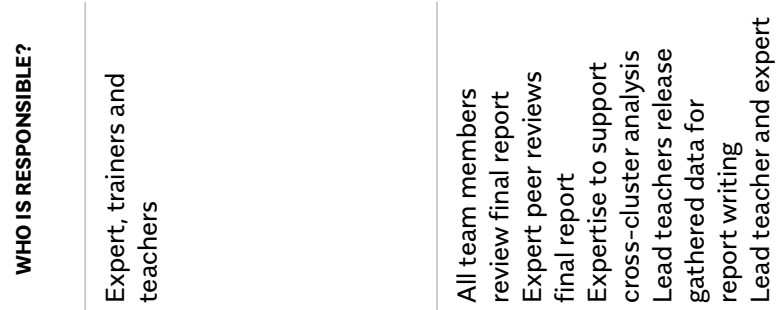

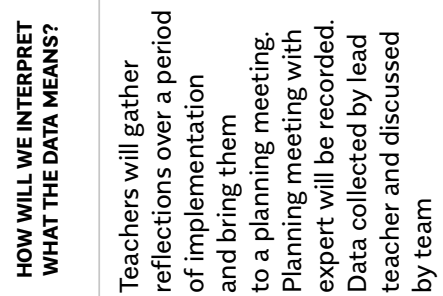

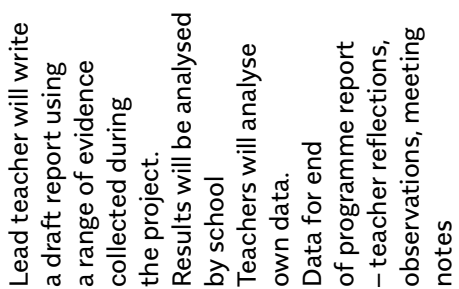

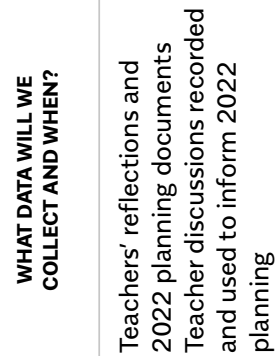

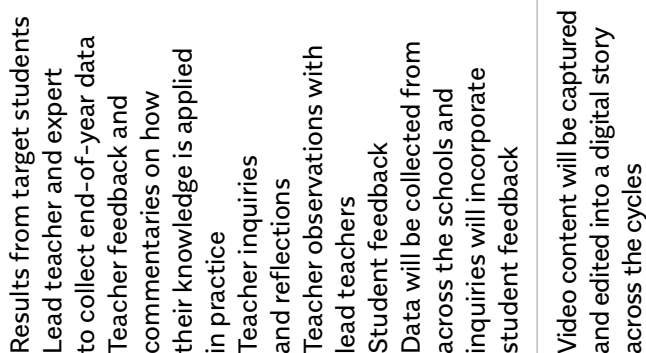

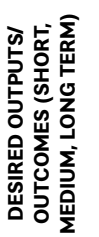

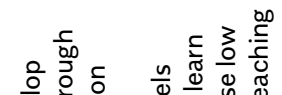

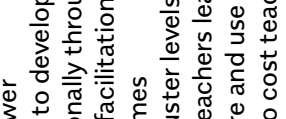

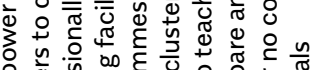

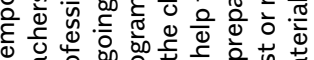

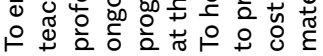

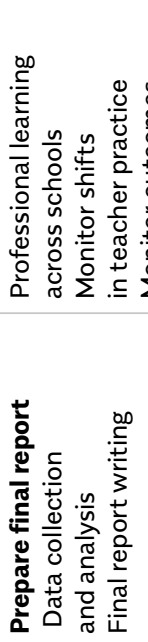

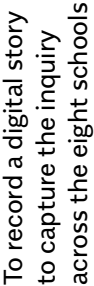

范

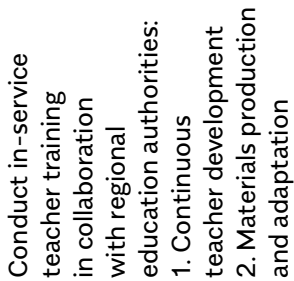

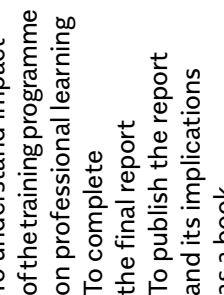

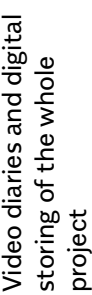

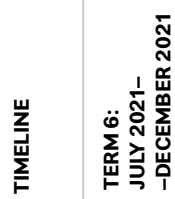

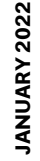




\section{English Language 'Teachers' Cognition \\ in Foreign Language Reading Instruction \\ in Slovak Upper Secondary Education \\ Interpretative Research}

DOI: 10.47050/66515321.256-278

Martina Šipošová

(Language) teacher cognition has been acknowledged as playing a crucial role in (language) teachers' lives due to the fact that it influences their subsequent behaviour, decisions and classroom practices. Although research studies in teacher cognition in developing reading skills are scarce, the author of this article analyzes their conceptually and methodologically diverse designs and research findings as a basis for her further research in this field, taking into account the Slovak educational context and its peculiarities. Thus, the article deals with examining English language teachers' cognition in developing reading in Slovak grammar schools, since reading skills are one of the four skills which are intensively developed in the EFL classroom and finally evaluated by taking a Maturita test. Teachers' beliefs, attitudes and personal practical knowledge are significant factors that have an impact on their classroom practices when developing students' reading comprehension skill. The author presents research findings based on a qualitative research paradigm (in-depth interviews as a research tool) carried out with five qualified English language grammar school teachers.

\section{Keywords: \\ grounded theory \\ paradigm model \\ reading skills \\ Slovak upper secondary education \\ teacher cognition}




\section{Introduction}

The complex issue of teacher cognition has been elaborated and investigated since the 1990s. This inclusive term embraces the complexity of teachers' lives and refers to the unobservable cognitive dimension of (language) teaching. Due to the fact that (language) teachers' cognitions are highly influenced by their own prior experience of learners, they may suppress the impact of pre-service education in influencing what (language) teachers really do in their classrooms. With regard to the contextual factors, (language) teachers' cognitions interact bi-directionally with teachers' experience and classroom practices. The volume of research into language teacher cognition in foreign language reading instruction has been focused on a variety of concepts regarding teachers' beliefs and practices (e.g. Graden, 1996; Johnson, 1992; Kuzborska, 2011; Richardson et al., 1991) as well as teachers' practical knowledge (e.g. Meijer et al., 1999, 2001; Rahmany et al., 2014; Yu, 2011). Obviously, teachers' beliefs, attitudes and personal practical knowledge are significant factors that have an impact on their classroom practices when developing students' reading comprehension skills.

Reading, in its broadest sense, can be defined as "the ability to draw meaning from the printed page and interpret this information appropriately" (Grabe \& Staller, 2013, p. 3). It is a complex skill since it is best developed in association with writing, speaking as well as listening activities. Tandlichová (2001, p. 133) defines reading as "a multifaceted, complex skill made up of a number of psychological, physical, and social elements". Grabe $(2009$, p. 74$)$ adds that it is also defined as "a combination of text input, appropriate cognitive processes, and the information that we already know". Similarly, Carrell, Devine and Eskey (2012) state that reading is dependent on the interactions among three types of knowledge - linguistic, schematic and background knowledge. Reading is an important communicative skill developed in the classroom as well as a significant aspect in the process of language acquisition as opposed to language learning. According to Repka and Šipošová (2017, p. 36), reading is a significant skill because the whole process of learning a foreign language moves from "comprehension to production", i.e. it begins with a receptive understanding of the language which is subsequently followed by a productive use of the language items. 
Additionally, due to the fact that reading is accomplished without the writer's presence, the reader has sufficient time to process the text and comprehend its message. Consequently, reading is considered a relatively easy skill in comparison with listening, speaking or writing, and it is not very difficult to achieve a high level of proficiency. Eskey and Grabe (2006) claim that reading requires a high degree of grammatical control and a large-scale development of vocabulary in order to achieve fluency.

Based on the fact that teachers' cognitions - in particular, teachers' attitudes and beliefs about developing students' reading skills - significantly influence their teaching style and behaviours in a classroom, the aim of the following interpretative research is to enrich the scope of research results focused on examining this complex issue.

\section{Language teacher cognition}

According to Borg (2003, pp. 81-86), language teacher cognition is an inclusive term that embraces the complexity of teachers' lives; it refers to the unobservable cognitive dimension of teaching. He emphasises that studies of language teacher cognition examine what second and foreign language teachers, at any stage of their careers, think, know, or believe in relation to various aspects of their work and which additionally, but not necessarily, entail the study of classroom practices (both preactive and interactive decision-making) and of the relationship between cognitions and these practices. A key point in the emergence of teacher cognition research came in 1975 when the National Institute of Education (NIE) in the USA concluded in their report that "it is obvious that what teachers do is directed in no small measure by what they think [...] The question of relationships between thought and action becomes crucial [...] Thus, an understanding of how teachers cognitively construct the reality of teaching and learning remains central to the achievement of NIE's overall goal of developing the means to improve the provision, maintenance, and utilisation of high quality teaching personnel".

Although the study of teacher cognition is generally characterised by a multiplicity of labels, among which we can find such concepts and notions as personal pedagogical systems, pedagogical principles, theories for practice, routines, conceptions of practice, pedagogical knowledge, personal practical knowledge images, theoretical beliefs, 
images, practical knowledge, maxims, the culture of teaching, pedagogical reasoning, personal theories, specific pedagogical knowledge, and BAK (beliefs, attitudes, knowledge), it is obvious that identical terms have been defined in different ways and different terms have been used to describe similar (or even the same) concepts. This terminological ambiguity in English leads to even more ambiguity when translating the concepts into Slovak (or Czech), where we can find to some extent synonymous expressions, e.g. "pedagogické myslenie učitel'a", "učitel'ovo chápanie výučby", "učitelovo pojetí výuky", "učitel'ova individuálna koncepcia vyučovania", and "subjektívne teórie učitela" (grounded in German as "Subjektive Theorien").

There are overlaps between numerous labels (concepts) leading to a unifying framework for understanding language teacher cognition, as depicted in Figure 1 (reproduced from: Borg, 2006). The diagram outlines relationships suggested by mainstream educational research between language teacher learning (both through schooling and professional pre-service and in-service teacher education, so-called professional coursework) and classroom practice, including practice teaching. Obviously, as can be seen from Figure 1, the core category "language teacher cognition" stands in relation to three categories which outline the basic three-level relationships with the core category, i.e. language teacher cognition and teachers' prior language learning experience (schooling), language teacher cognition and both pre-service and in-service teacher education (professional coursework) and language teacher cognition and classroom practice (including practice teaching), which is strongly influenced and shaped by contextual factors (i.e. the social and institutional contexts of classrooms). Moreover, a great deal of attention (for more information, see Borg, 2003,2006 ) has been paid to the issue of teacher cognition in relation to teaching different language skills (mainly reading and writing) and language means/systems (mainly grammar, vocabulary and pronunciation). Although research studies carried out in ESL (English as a second language) contexts far outweigh those carried out in EFL (English as a foreign language) contexts, research in EFL contexts has boomed recently. 
Figure 1. Language Teacher Cognition

Personal history and specific experience of classrooms which define preconceptions of education (i.e. teachers, teaching)

\author{
May impact on existing \\ cognitions, especially when \\ unacknowledged, \\ these may limit its impact
}

professional coursework
Beliefs, knowledge, theories, attitudes, assumptions, conceptions, principles, thinking, decision-making
LANGUAGE

TEARCHER

COGNITION
About teachers, teaching learners, learning, subject matter, curricula, materials, activities self, colleagues, assesment context

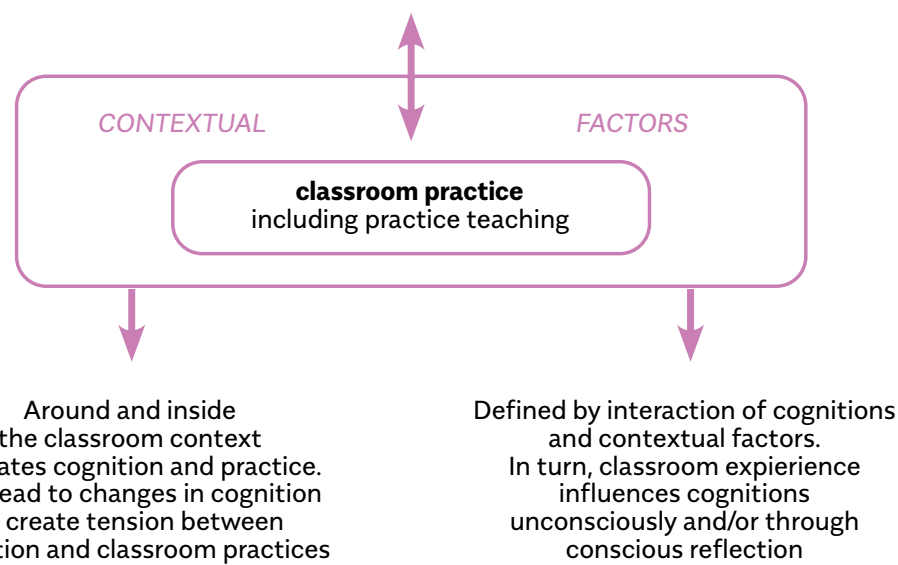

Source: Borg, 2006, p. 283.

\section{Literature review}

The decade between 1990 and 2000 saw an increased number of research studies aimed at examining language teacher cognition, teachers' beliefs, and teachers' practical knowledge, in particular. The cognition of teachers teaching English to non-native speakers became a widely explored issue. Two main areas have been focused on since the 1990s, namely grammar and literacy instruction, including writing and reading. We intend to outline particular research studies focused on reading instruction carried out after 1990 as well as more recent studies published since 2000 . 
Johnson's (1992) research aim was to examine the extent to which language teachers possess beliefs about second language teaching and learning that influence their approaches and practices in a classroom. The research was carried out among $30 \mathrm{ESL}$ teachers from suburban and urban areas of New York. The data were gathered via a Multidimensional TESL Theoretical Orientation Profile, consisting of an Ideal Instructional Protocol, a Lesson Plan Analysis Task, and a Beliefs Inventory, in order to determine the extent to which these $30 \mathrm{ESL}$ teachers possessed theoretical beliefs about second language learning and teaching. Ideal Instructional Protocols were coded as skill-based (reading activities involved extensive oral practice and tended to emphasise appropriate pronunciation over meaning and writing activities in which words and/or phrases were first drilled orally and then written as patterned-practice), rule-based (reading activities in which the meaning of the text was derived through the study of grammatical structures and writing activities which were designed for practising and applying grammar rules in meaningful contexts), and function-based approaches (reading activities which focused on the concepts or ideas within the text and context-rich writing activities where students were encouraged to express their ideas without paying attention to grammatical correctness) towards second language teaching. The second task presented teachers with three separate instructional lesson plans, each designed to teach the same grammatical concept (modals; can, will, may, might), but each also reflecting one of the three methodological approaches (skill-, rule- or function-based). Teachers were asked to read each lesson plan carefully and select one which best reflected their own beliefs about second language teaching. Upon completion of this task, teachers were assigned either a skill-, rule- or function-based code, based on the type of lesson plan they had selected. Finally, a Beliefs Inventory contained 15 statements, which represented each of the methodological approaches towards second language teaching (five statements per approach). Teachers were asked to read all 15 statements and select five that most closely reflected their own beliefs about second language learning and teaching. Teachers were assigned a percentage score based on the number of skill-based, rule-based, and function-based statements they selected. As Johnson (ibidem, p. 87) emphasises, a multidimensional TESL Theoretical Orientation Profile was designed to gather information about teachers' 
theoretical beliefs across three separate measures. All three measures on the profile were administered during a 20 - to 30 -minute private meeting between the researcher and each teacher. The data were subsequently analysed. The research results indicate that the majority of the researched ESL teachers (60\%) possessed clearly defined theoretical beliefs that consistently reflect one particular methodological approach (function-based approach) towards second language teaching. As the author points out, this finding is consistent with the changes and innovations in language teaching that occurred in the late 1950s. That is, the skill-based approaches of the 1950s and 1960s were overshadowed by a rise in rule-based approaches in the 1970s, followed by function-based approaches, which were popularised during the 1980s (Stern, 1983). The dominance of the function-based theoretical orientation may represent the overwhelming popularity of this approach among ESL teachers in the 1990s. In the second phase of the research, which was aimed at determining the extent to which ESL teachers' instructional practices are consistent with their theoretical beliefs, three secondary-level ESL teachers identified as having different theoretical orientations were observed. A careful analysis of transcribed classroom observations revealed that literacy instruction was consistent with each teacher's theoretical orientation. Furthermore, ESL teachers with different dominant theoretical orientations provided strikingly different literacy instruction. Overall, Johnson's study supports the notion that ESL teachers teach in accordance with their theoretical beliefs and that differences in theoretical beliefs may result in differences in the nature of literacy instruction. However, as the author admitted, many further research questions appeared during the research, so additional inquiry was essential. The author openly admitted the research limitations, in particular the fact that it did not take into consideration several other aspects (social, cultural, political, etc.) which influence teachers' beliefs. Thus, Johnson (1992, pp. 83-108) considers the findings of the study as a good basis for further investigation.

Kuzborka's (2011) qualitative study was focused on investigating the belief system of English for Academic Purposes (EAP) teachers regarding their teaching of reading to advanced learners of English in the context of a state university. The research sample consisted of eight language teachers (teaching practice varied from 8 to 24 years) from a Lithuanian state university. All teachers from the research 
sample had been teaching advanced learners. This need stemmed from the fact that the language teaching and learning at the university was essentially text-based, with a number of activities based on these texts. English teachers are required to develop students' academic and professional communicative competence, enabling them to effectively communicate in academic and professional contexts. The data were collected via lesson observations, video-stimulated recall followed by a semi-structured interview and document data analysis. The observations were accomplished within three successive lessons per teacher, each of which was 90 minutes in length. All the lessons were audio- and video-recorded and subsequently analysed for events concerning activities related to the teaching of reading. The video tapes served as a stimulus for the teachers who, while watching, recalled their thought processes at that time and subsequently explained what they were doing or thinking. The author noted that the stimulated recall sessions were accomplished in Lithuanian in order to reduce stress and encourage teachers to answer freely and openly. The data were transcribed and later analysed by applying a combination of inductive and deductive approaches, which were coded and the codes then clustered into categories. The research findings indicate that the teachers of the research sample taught in a way that was in accordance with their theoretical beliefs. Furthermore, the results pointed out that the teachers' approach was predominantly skill-based with its focus on vocabulary, reading aloud and translation of texts. The texts used by the teachers were mostly assigned for homework and reading in a classroom was carried out with little or no prior preparation or discussion. The research also revealed that the teachers lacked knowledge of alternative and innovative instructional practices for reading, owing to little or no previous participation in such specific training. For these teachers, moving beyond the traditional approach to reading instruction will require access to alternative approaches. As Kuzborska (2011, p. 122) emphasises, in order to address these concerns, preparatory programs in Lithuania can provide teachers with a firmer background in the reading process and in an appropriate second language (L2) reading instruction methodology. But, most importantly, beliefs towards reading and reading instruction first need to change. Similarly to the previous research by Johnson (1992), Kuzborska (2011, p. 122) also openly calls for more research on EAP 
teachers' beliefs and practices in the area of reading instruction in order to further advance our knowledge of how EAP teachers think and act and how we can better bridge the gap between practice and research. Nevertheless, she stated that even though her research was conducted within the specific context of Lithuania, its findings and recommendations could be relevant for the professional development of teachers in general.

While the previous two studies examined the relation between teachers' beliefs and their classroom practices concerning teaching reading, the following studies are aimed at the exploration of the teachers' personal practical knowledge about teaching reading comprehension in English. The aim of the research study conducted by $\mathrm{Yu}$ (2011) was to describe and illustrate the content of 13 (2 males and 11 females, teaching experience varied from 3 to 14 years) teachers' personal practical knowledge about teaching reading comprehension to non-English majors at a university in China. It also examined similarities (shared knowledge) and differences in teacher knowledge and potentially relevant background variables. As the author points out, teachers' personal practical knowledge is the knowledge of teachers which is principally known and produced by teachers themselves. Greatly inspired by Meijer, Verloop, and Douwe (1999), the study used a questionnaire and an interview. Meijer, Verloop, and Douwe provided a system of categories of teachers' practical knowledge about teaching reading comprehension in their study: (1) subject matter knowledge, (2) student knowledge, (3) knowledge of student learning and understanding, (4) knowledge of purpose, (5) knowledge of curriculum, and (6) knowledge of instructional techniques. The study by $\mathrm{Yu}$ (2011) included these six categories in the design of the questions in the questionnaire. The questionnaire was distributed to the research subjects via e-mail. After the analysis, the questionnaire was subsequently followed by interviews. The interviews were informal and conversational in their nature, carried out via the chatting software QQ with each teacher separately, and they were recorded. As Yu (2011) states, shared knowledge in these teachers' practical knowledge about teaching reading comprehension could not be found. Instead of belonging to the same category of teachers, as he presupposed, the teachers could be classified into three groups: subject matter-oriented 
teachers (little clear knowledge about students in general and how students work; for them, teaching reading is seen as the training of skills), student-oriented teachers (detailed knowledge about students; they think text selection is a kind of strategy to motivate students), and student learning-oriented teachers (clear knowledge about both the subject matter and students in general; they select texts and design their lessons based on goals that have to be achieved in lessons). Moreover, six potentially relevant background variables were discussed in this study, in particular, personal characteristics, personal experiences and teaching context, teaching experiences, prior education and reflections on teaching, also based on the study by Meijer et al. (1999). By matching the six background variables to the responses of the teachers, three patterns in potentially relevant background variables were developed: professional growth teachers, student-centred teachers, and authority-maintaining teachers. Similarly to previous studies, the author admits that reliable generalisationss of teachers' knowledge about teaching reading cannot be made because of the small sample in the study. Therefore, $\mathrm{Yu}(2011$, p. 55) suggests further research to investigate a larger group of teachers to achieve more generalised results.

The research carried out by Rahmany, Hassani, and Fattahi (2014) aimed at investigating teachers' individual practical knowledge about teaching reading comprehension to engineering major students. The first part of the study searched for a shared category among the categories of practical knowledge (based on Meijer et al., 1999) and isolated the unshared parts. The second part examined the unshared parts in order to see whether the differences were significant or not. The research sample consisted of 36 English for specific purposes (ESP) teachers (18 teachers had a Master's degree and 18 had a doctoral degree) from Payame Noor University of Kermanshah, Islamic Azad University of Kermanshah and Razi University of Kermanshah. The research tool was a questionnaire consisting of 10 closed questions with three choices offered and six categories of practical knowledge based on Meijer et al. (1999). The questionnaire was distributed in person or via e-mail. The research results of the first part showed the teachers did not have any shared practical knowledge. The result of the first part of the study showed the knowledge of student learning and understanding category had the greatest 
diversity in the responses and the student knowledge and knowledge of purpose had the lowest. The results of the second part revealed that there was a significant difference in the overall categories of practical knowledge. This was mostly due to the significant difference in the knowledge of purpose and knowledge of curriculum categories. The teachers in the study tended to reflect on their teaching in a way that maintained the focus of their practical knowledge, e.g. teachers focusing on the subject matter category tended to think that subject matter is an important issue in their teaching. Similarly, teachers who focused on the student knowledge category believed that knowledge of the students (age, sex, level, personality, etc.) should be taken into account prior to teaching. The Master's-holding teachers in the study, in contrast to the doctorate-holding teachers, put a different emphasis on different categories of practical knowledge, focusing more on the knowledge of purpose and knowledge of curriculum categories. The reason for this difference might be due to the fact that the Master's-holding teachers tended to be more conservative than the doctorate-holding teachers. They focus mostly on the required textbook and the given syllabus and try to follow the syllabus exactly as written. On the other hand, the doctorate-holding teachers do not mostly follow the given syllabus exactly as stated. They prefer to design their own teaching material rather than use the materials recommended by authorities, such as textbooks. They also do not focus on the final exam as much as the Master's-holding teachers. However, the relationship between a teacher's practical knowledge and their teaching methods was not examined. Rahmany, Hassani, and Fattahi $(2014$, p. 457) suggest that further research should be carried out to investigate this issue. Another issue that could be investigated is whether a teacher's practical knowledge affects the learning process of the learners.

We have presented a basic overview of research conducted worldwide within the past 20 years in the relevant field. The methods used to collect the research data varied - both quantitative and qualitative methods were used. Despite all our efforts, however, we could not find any relevant research studies conducted in the Slovak educational context. Thus, in order to fill the gap, we designed the following qualitative research study. 


\section{Qualitative Study}

Research design - research subjects

This qualitative study was designed within the framework of qualitative research methodology, applying the grounded theory approach. The data for it were obtained through in-depth interviews. Boyce and Neale (2006) identify in-depth interviewing as a qualitative research technique that involves intensive individual interviews with a small number of respondents to explore their perspectives on a particular idea, programme, or situation. The research subjects were selected based on purposive sampling. Smith, Flower and Larkin (2009) recommend purposive sampling for participants who are selected because they share particular characteristics and experiences. Thus, the common features characterising our research subjects were as follows: all of them were qualified EFL teachers (faculties of education graduates) whose teaching practice varied from 5 to 10 years and who were all teaching English at the upper secondary level (grammar schools). The research study was carried out from November 2018 to February 2019. The group of research subjects consisted of five subjects (females). The in-depth interviews were held in a friendly atmosphere in the participants' respective staff rooms. The 25 - to 30-minute interviews were recorded, transcribed and coded.

\section{Methodology and data collection tools}

For the purpose of this study, we chose a qualitative methodology, specifically, the application of the grounded theory approach. Kostrub and Šipošová $(2015$, p. 202) claim there is a significant need to apply qualitative research in the educational context, especially when analysing learner performance in the teaching and learning process. According to Kostrub (2019, p. 19), "qualitative investigation represents a consistent and complex approach to subjective and intersubjective realities as legitimate objects of scientific knowledge". Stake (2010) stresses the fact that qualitative research has moved social research away from cause-and-effect explanations and towards personal interpretation. Kostrub (2016) emphasises the fact that qualitative research relies heavily on interpretive perceptions through the planning, data gathering, analysis and conclusion of the study. Following our decision to explore this issue through a qualitative analysis, we created 
a theory that would express, enlighten and interpret the beliefs, opinions and attitudes of EFL teachers about teaching reading in the EFL classroom. To achieve this goal, we applied the grounded theory approach, which, according to Strauss and Corbin (1990, p. 12), is "derived from the data, systematically gathered and analysed through the research process".

Grounded theory has a systematic procedure and is defined by identifying important words with the goal of providing many theoretical codes (often called labelling), coding the material leading to the creation of basic categories and variables for the theory, and, finally, constructing the theory as a set of statements between categories and variables. These acts often coincide and are mutually created as one influences the other. They are also often referred to as the open, axial and selective coding process. According to Strauss and Corbin (1990), initial coding is often said to fracture the data, whereas axial coding reconnects the data in ways that are conceptually more abstract. Selective coding, as the last part of the work with the data, focuses on actualising the core category in a highly abstract conceptual manner. Hence, they provide a fundamental analytical technique which breaks data into fragments that are later clustered into relevant concepts. These concepts are categorised according to a common criterion. By common criterion, we mean subcategories that belong to subsidiary categories of the core category, which is the central phenomenon of the research. Strauss and Corbin (1990) stress the importance of locating the core category. Categories stemming from coding are the crucial parts of the consequent theory. The naming of particular levels of coding is sometimes ambiguous. The aforementioned concepts or labels are sometimes referred to as properties. They see this procedure as the key to success, in this case, the key to a consistent theory. The central category provides a base for other categories as well as a base for a new theory. It could be any core category from the paradigm model, depending on the relations between categories for each particular piece of research. The entire theory is usually explained on the basis of this category. The final theory is usually consistently presented in two ways, verbally and complementarily displayed in the form of schemata (paradigm models), diagrams or concept maps. The grounded theory methodology allows the elaboration of a story line, which is based on the paradigm model. 
Thus, the story is simply a descriptive narrative about the central phenomenon of the study and the story line is the conceptualisations of this story (abstracting). When analysed, the story line becomes the core category while subsidiary categories are related to the core category, according to the paradigm model, the basic purpose of which is to enable the researcher to think systematically about the data and relate them in complex ways.

Strauss and Corbin (1990) recommend a paradigm model, which comprises all of these categories and can be identified as follows: Causal Conditions $\rightarrow$ Phenomenon $\rightarrow$ Context $\rightarrow$ Intervening Conditions $\rightarrow$ $\rightarrow$ Action/Interaction Strategies $\rightarrow$ Consequences.

In the model, causal conditions are events that lead to the development of a phenomenon. The phenomenon is defined as the core category (i.e. the central idea, event or happening). Context refers to the particular set of conditions and intervening conditions, the broader set of conditions, in which the phenomenon is couched. Action/interaction strategies refer to the actions and responses that occur as a result of the phenomenon, and finally, the outcomes of these actions and responses are referred to as consequences.

Since qualitative researchers have special concerns regarding the validity as well as reliability of the research results, it was important to utilize more research tools. The process of triangulation, which refers to the application and combination of several research methods in the study of the same phenomenon, adds depth to the data that are collected. Fusch, Fusch, and Ness (2018, p. 22) distinguish four types of triangulation: data, investigator, theory and methodological. According to the authors, methodological triangulation can be within method or between methods (also known as across methods), although the generally understood type is within method, such as multiple sources of data found within one design, e.g. triangulating data from multiple data collection methods (interviews, focus groups, observations, etc.). Thus, by combining in-depth interviews and unstructured observations, we hoped to overcome the weakness or intrinsic biases of the data in order to increase the credibility and validity of the research results. We carried out observations of two lessons taught by each of the research subjects. We focused on teachers' classroom practices, teaching style, behavioural patterns and interactions, as well as the overall classroom dynamics. 


\section{Aim of the study}

The aim of this research study was to examine the influence of EFL teachers' cognition on teaching reading comprehension in upper secondary education. Thanks to our deep professional understanding of the teaching profession, we focused on examining and interpreting English teachers' beliefs, attitudes, opinions and reading instruction practices, which are interrelated and therefore influence each other.

\section{Research questions}

RQ1: What are the teachers' beliefs and attitudes about developing reading skills?

RQ2: What classroom practices do English language teachers use while teaching reading?

RQ3: What changes related to teaching reading have English language teachers made since they started teaching?

In order to capture the essence of the research subjects' views on this issue, we deliberately decided to ask several in-depth questions which allowed for a variety of answers. The interviews were held in a semi-structured manner, i.e. we had prepared some questions concerning particular issues in advance. However, during the interviews (25-30 minutes long), we flexibly asked a vast range of ad hoc questions in order to clarify the issues which emerged.

In-depth interview questions

Q1: Why did you become an English language teacher?

Q2: How do you teach reading comprehension in your classes? Could you tell me about the pre-reading, during-reading and post-reading activities you use with your students?

Q3: What kinds of materials do you use when developing reading skills in your classes?

Q4: What is your personal attitude towards reading comprehension and its teaching?

Q5: What do you remember from your early teaching experience? What are the differences between the techniques you used when you started teaching and the techniques you currently use?

Q6: What was your own experience as a learner of English at school? Q7: What do you think the attitude of your students is towards English language and reading comprehension? 


\section{Answering research questions}

RQ1: What are the teachers' beliefs and attitudes about developing reading skills?

Based on the research findings and observations, our research subjects believe that reading comprehension undoubtedly plays a significant role in the process of English language learning. However, they see that reading is pushed aside and more attention is devoted to other communicative skills (listening, speaking and writing). The research subjects believe in the importance of being able to read original English texts and the necessity to master reading as a life skill. They also recognize higher requirements for and demands on the learners and the fact that the texts found in course books are not sufficient. Their beliefs about the learners' attitudes about reading significantly influence the way they approach developing reading skills in the EFL classroom. In other words, a research subject who believes that learners' attitudes are rather negative has the tendency to think that the learners are lazy and ignore reading activities; as a result, this leads to falling back on the use of true/false activities, translation, and reading aloud in the classroom. If the teacher believes that the learners' attitudes towards reading are positive, s/he is more likely to use additional, authentic materials and choose more sophisticated activities. All of our research subjects feel very positively about developing reading skills. They claim they like reading and attempt to make it attractive for their learners. The research subjects do not consider reading difficult, and despite the fact that they are aware of the challenges associated with it (it can be time-consuming, requiring learners' undivided attention, which is difficult during the lesson), they attempt to stress the positive features of reading. Moreover, they agree that the teacher's attitude influences the way $s / h e$ teaches and that there is a huge difference between a teacher who is truly committed and a teacher who is just punching the clock.

RQ2: What classroom practices do English language teachers use while teaching reading?

Based on the teachers' answers and observations, the research subjects use student-centred teaching to a great extent. They personalise the selection of texts to their students' needs and interests, they ask students about their own experience, they encourage them to express 
their opinions and attitudes, and they attempt to help them relate the content of the texts to their own lives. However, they also favour traditional teaching methods - much of the classroom work is still dependent on a course book - and engage in stereotypical activities, such as true/false tasks, translation to and from the mother tongue, and reading aloud. To provide an overall picture, the following are particular examples of activities. In the pre-reading stage, the research subjects use activities such as brainstorming, descriptions of pictures, small group work discussions, guessing content from the title or headline and vocabulary activities (pre-teaching of new words). During the reading stage, the research subjects claim that they do not use any specific activities and the students just read the text. One of the research subjects indicated that students were occasionally asked to focus on a certain pronoun and to find the noun it referred to or to fill in the missing words in a sentence. In the post-reading stage, the research subjects use questions and discussions to a great extent, answering teachers' questions, true/false activities, and determining keywords to summarise content. The research also proved that the research subjects lacked methodological knowledge concerning the during-reading stage.

RQ3: What changes related to teaching reading have English language teachers made since they started teaching?

According to our research subjects' answers, the changes in their approach primarily concern the usage of a course book. They claim that, as novice teachers, they had the tendency to rely on course books without using supplementary texts. It made them feel more comfortable and confident since the course books provided ready-made lesson plans and activities. Nowadays, they use supplementary materials and authentic materials. The research subjects also claim that they stick strictly to the texts and do not use alternative follow-up activities. They also state that they gradually changed their approach as they acquired more teaching experience. They also note that workshops and seminars have a certain impact in terms of implementing new techniques. Their approaches as novice teachers were strongly influenced by stress combined with a lack of teaching experience and confidence. Furthermore, the research subjects attributed certain changes to a rapid increase in learners' requirements 
resulting from developments which are changing from year to year. As a result, the teachers are forced to adapt to the changes and adjust their teaching techniques accordingly.

\section{The Paradigm Model Interpretation}

With regard to the grounded theory methodology, we elaborated a story line based on the paradigm model (English teachers' cognition in reading instruction in Slovak upper secondary education). A story is simply a descriptive narrative about the central phenomenon under study, and the story line is the conceptualisations of this story (abstracting). When analysed, the story line becomes the core category while subsidiary categories are related to the core category, according to the paradigm model, the basic purpose of which is to enable the researcher to think systematically about the data and relate them in complex ways (see the Methodology section above for further details on the paradigm model).

As can be seen from Figure 2, the paradigm model represents a visual interpretation of the research findings. As mentioned before, it consists of six pivotal categories. In order to distinguish particular relationships among the given categories, one-way or two-way arrows are used, depending on whether the relationship is reciprocal or not. The small solid-line arrows express strong relations and small dashed-line arrows denote weaker relations (i.e. depending on the frequency of occurrence). Long dashed-line arrows leading from supporting and paralysing strategies are utilised to emphasise certain consequences which are under their influence. To start with the broadest category of context, this represents the set of conditions in which each of the categories takes place.

Within the framework of our research, two main categories for context were created, namely personal conviction (subcategories: responsibility and prejudices) and situational conditions (subcategories: requirements of the Slovak curriculum and institutional factors). These categories represent sets of conditions in which our research subjects taught and in which our research was conducted. The influence of context is depicted by a thick solid line surrounding the rest of the categories since its impact is markedly strong.

The intervening conditions, presented as socio-cultural factors, include five subcategories. Our research subjects are aware 
of the development of the current era and the changes that have to be implemented into their teaching since learners are more demanding nowadays. They also admit the importance of English in present-day society is undeniable since the learners are surrounded by English not only at school but in their everyday lives. The research subjects also consider technological development as significant. They claim that it is easier to find additional materials for learners nowadays due to internet access. It was also revealed that the teachers' motivation plays a significant role, and this is conditioned by internal and external factors.

As a result of the intervening conditions, causal conditions occur. They are presented as schooling (subcategories: pre-service education, previous teachers' influence, seminars and course) and stress and frustration (subcategories: fear, personal preference of age group). As is apparent from the model, causal conditions directly influence action/interaction strategies and subsequently lead to the development of the phenomenon. The research has revealed that the choice of strategies, approaches or techniques is influenced by teachers' own schooling and experience, particularly their pre-service education. Moreover, the influence of their previous teachers plays a significant role. The category of stress and frustration was saturated with codes which also condition the choice of particular strategies, but rather negatively, e.g. a fear of the time allotted for reading activities and a fear of working with older learners.

The category of action/interaction strategies is divided into two subcategories, which reflects the fact that the choice of strategies is directly influenced by the causal conditions. These are presented as supporting (subcategories: personalisations, individualisations) and paralysing strategies (subcategories: stereotyped activities, translating into mother tongue). This resulted in the division of the model into two parts. As aforementioned, the outcomes of action/interaction strategies are referred to as consequences. While supporting strategies result in utilising teachers' activation practices (subcategories: learner-centred teaching, supporting autonomous learning, use of authentic materials) in a classroom, paralysing strategies lead to the resignation of teachers (subcategories: slavish use of course books, learners' disinterest). In this case, certain aspects of traditional teaching were noticed during the observations, e.g. slavish use of the course book. 
Figure 2. Paradigm model

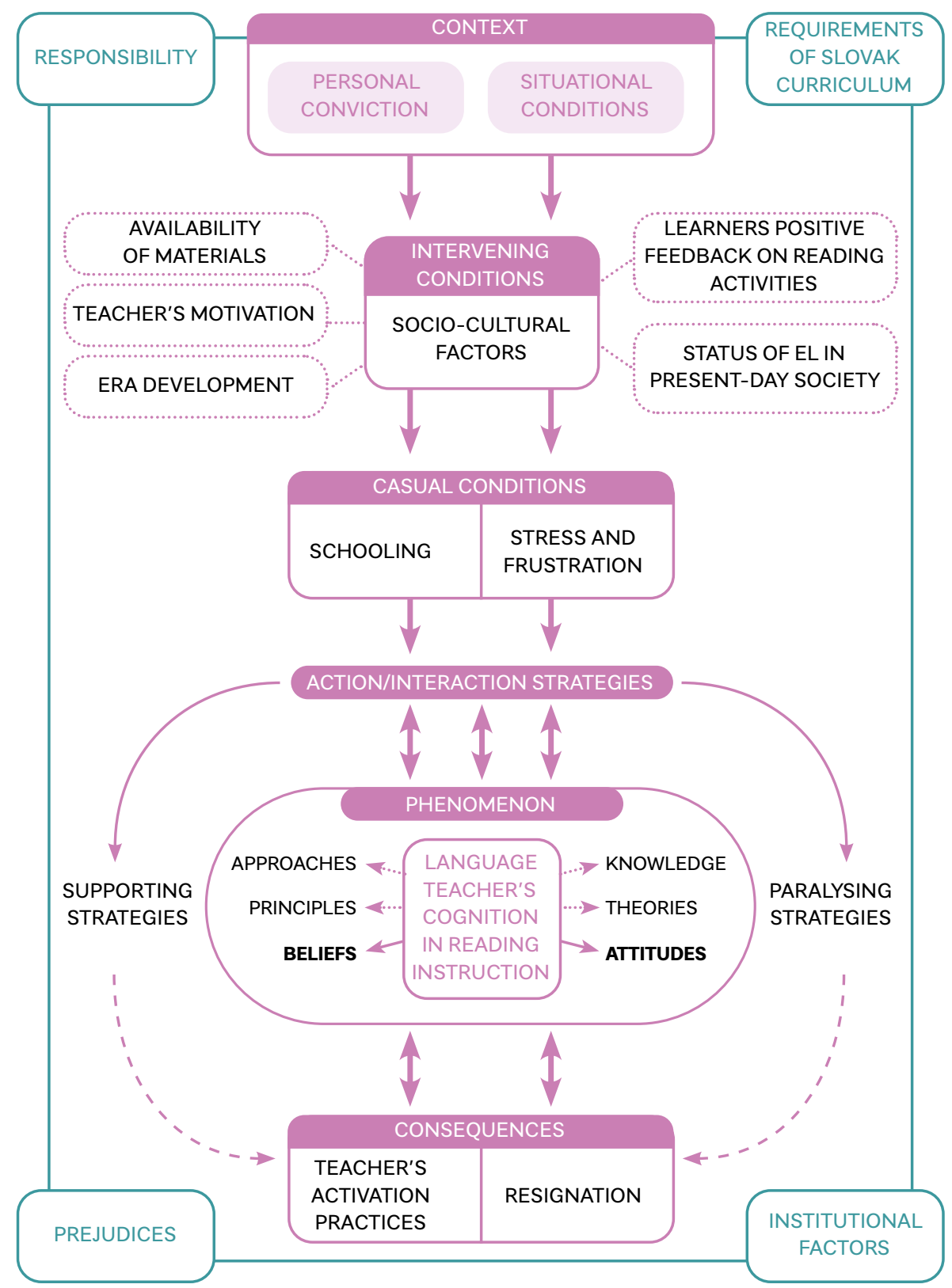

Source: author's elaboration. 
The last category of the paradigm model, the core category and the key concept at the same time, is the phenomenon. The phenomenon is guided by action/interaction strategies but also influences them at the same time. Similarly, the consequences both result from the phenomenon and influence the phenomenon at the same time. The mutuality of the relations among these categories is displayed via big two-way arrows. The phenomenon, identified as language teachers' cognition in reading instruction, was saturated with teachers' beliefs and attitudes about reading instruction. As is apparent from the paradigm model, principles, approaches, knowledge, and theory codes also occur. These codes are based on the analysis of the verbatim transcripts and notes taken during the observations. However, they were not saturated enough to create a category. On the other hand, it was necessary to include them in the model, hence they are represented by short dashed-line arrows.

\section{Conclusion}

In essence, our research findings shed light on the issue of teacher cognition in reading instruction. The presented research shows that there are many significant aspects that play crucial roles in the process of developing English language teachers' cognition. Since generalisations is not accepted by many researchers as the purpose of qualitative, interpretative research, our research concern with the opinions, beliefs and attitudes of EFL teachers about developing reading in upper secondary education leads us to the following conclusion, notwithstanding the fact that it cannot be generalised to the overall upper secondary English language teacher population.

Our research subjects' attitudes about reading instruction appear to be positive. They express their passion for reading in general and their attempts to make it attractive for the learners. Nevertheless, the importance of teachers' beliefs is even stronger. Their classroom performance depends on what they believe in. Their beliefs are connected with prejudices they possess about the learners, in particular, their age characteristics and their attitudes towards reading. This results in the resignation of the teacher and their use of the same stereotyped true/false and translation activities over and over again. On the other hand, their beliefs also have a positive impact which results in them implementing student-centred teaching, in which the focus is shifted 
from teacher to learners and which is based on personalisations and individualisations. The teachers are enthusiastic about using authentic materials and various sources for the texts. To conclude, teachers' beliefs significantly impact their classroom practices, and their performance depends on what happens in their minds, i.e. what they believe in. Therefore, we consider these research results important for trainee, novice and expert teachers alike. All of them have to be aware of their own mental constructs, which significantly influence their classroom practices.

\section{References}

$\rightarrow$ Borg, S. (2003). Teacher cognition in language teaching: A review of research on what language teachers think, know, believe, and do, Language Teaching, 36(2), 81-109.

$\rightarrow$ Borg, S. (2006). Teacher cognition and language education: Research and practice. London: Continuum.

$\rightarrow$ Boyce, C. and Neale, P. (2006). Conducting in-depth interviews: A guide for designing and conducting in-depth interviews for evaluation input. Watertown: Pathfinder International.

$\rightarrow$ Carrell, P. L., Devine, J. and Eskey, D. E. (2012). Interactive Approaches to Second Language Reading. Cambridge: Cambridge University Press.

$\rightarrow$ Eskey, D. E. and Grabe, W. (2006). Interactive Models for Second Language Reading: Perspectives on Instruction. In: L. Carrel, J. Devine, D. E. Eskey (eds.), Interactive Approaches to Second Language Reading (pp. 223-238). Beijing: World Publishing Company.

$\rightarrow$ Fusch, P., Fusch, G. E. and Ness, L. R. (2018). Denzin's Paradigm Shift: Revisiting Triangulation in Qualitative Research, Journal of Social Change, 10(1), 19-32.

$\rightarrow$ Grabe, W. (2009). Reading in a Second Language: Moving from Theory to Practice. Cambridge: Cambridge University Press.

$\rightarrow$ Grabe, W. and Stoller, F.L. (2013). Teaching and Researching Reading ( $2^{\text {nd }}$ ed.). New York: Routledge.

$\rightarrow$ Graden, E. C. (1996). How language teachers' beliefs about reading are mediated by their beliefs about students, Foreign Language Annals, 29, 387-395.

$\rightarrow$ Johnson, K. E. (1992). Learning to teach: Instructional actions and decisions of preservice ESL teachers, TESOL Quarterly, 26, 507-535.

$\rightarrow$ Kostrub, D. (2016). Základy kvalitatívnej metodológie. Bratislava: UK v Bratislave.

$\rightarrow$ Kostrub, D. (2019). The inspiration by qualitative methodology in pedagogical research. Horn: Verlag Ferdinand Berger \& Söhne. 
$\rightarrow$ Kostrub, D. and Šipošová, M. (2015). A Qualitative Research Paradigm - a Tool to Enhance the Development of Pedagogical Science and Interpersonal Understanding in the Field of Human Behaviour, Komunikacja w edukacji: język w komunikacji, 3, 197-206.

$\rightarrow$ Kuzborska, I. (2011). Links between teachers' beliefs and practices and research on reading, Reading in a Foreign Language, 23(1), 102-128.

$\rightarrow$ Meijer, P. C. Verloop, N., Douwe, B. (1999). Exploring language teachers' practical knowledge about teaching reading comprehension, Teaching and Teacher Education, 15, 59-84.

$\rightarrow$ Meijer, P. C., Verloop, N., Douwe, B. (2001). Similarities and differences in teachers' practical knowledge about teaching reading comprehension, Journal of Educational Research, 94, 171-184.

$\rightarrow$ National Institute of Education (NIE) (1975). Teaching as clinical information processing. ( Panel No. 6, National Conference on Studies in Teaching). National Institute of Education, https://files.eric.ed.gov/fulltext/ED111807.pdf

$\rightarrow$ Rahmany, R., Hassani, M. T., Fattahi, H. (2014). Teachers' Individual Practical Knowledge about Teaching Reading Comprehension, Journal of Language Teaching and Research, 5(2), 452-459.

$\rightarrow$ Repka, R., Šipošová, M. (2017). The Teaching of Communicative Skills to Slovak English Language Learners. Bratislava: Z-F Lingua.

$\rightarrow$ Richardson, V., Anders, P., Tidwell, D., Lloyd, C. (1991). The relationship between teachers' beliefs and practices in reading comprehension instruction, American Educational Research Journal, 28, 559-586.

$\rightarrow$ Smith, J. A., Flower P., Larkin, M. (2009). Interpretative Phenomenological Analysis: Theory, Method and Research. London: Sage Publications.

$\rightarrow$ Stake, R. E. (2010). Qualitative Research: Studying How Things Work. New York: Guildford Press.

$\rightarrow$ Stern, H. H. (1983). Fundamental concepts of language teaching. Oxford: Oxford University Press.

$\rightarrow$ Strauss, A., Corbin, J. (1990). Basics of qualitative research: Grounded theory procedures and techniques. New York: Sage Publications.

$\rightarrow$ Tandlichová, E. (2001). Text pri rozvijaní komunikačných zručností vo vyučovaní anglického jazyka. Bratislava: Univerzita Komenského.

$\rightarrow$ Yu, H. (2011). Exploring Teachers' Personal Practical Knowledge about Teaching Reading Comprehension in English: A Study of Teacher Knowledge at a University in China. Kristianstad University, Sweden, www.diva-portal.org/ smash/get/diva2:426266/fulltext01 


\section{Teaching a Second Language \\ to Young Learners \\ A Theoretical Approach}

DOI: $10.47050 / 66515321.280-301$

Jenny Johana Izquierdo Casadiego,

Olesya Parakhina

Every year, more people are aware of the importance of being multilingual. Early childhood is the best period for language acquisition.

There are four language skills: speaking, listening, reading, and writing. When a preschooler is learning a second language, the objective is to improve these skills along with developing the child's personality.

The "best" programme for teaching second languages to young learners is still an open question, however. The current theoretical approach will expose some methods that modern educators use to introduce preschool children to a second language.

A multisensory approach is supported in the theory of multiple intelligence and learning styles. This approach proposes teaching children through their individual learning styles, such as auditory, visual, tactile, and kinesthetic. The multisensory approach to teaching preschoolers a second language recognizes that every child is capable of learning, allowing every individual to acquire knowledge according to their characteristics.

\section{Keywords:}

\section{learning styles}

multisensory approach

preschoolers

second language

young learners 


\section{Introduction}

Language is a natural skill of a person - it allows us to express our needs and emotions or transfer culture and traditions to new generations. Starting to learn a second language at an early age is one of the most essential abilities as all cognitive resources are available for it (Diez, 2010). In the early years, the brain is predisposed to new knowledge; with the right approach, a child can manage different languages because the brain can generate more neural connections for them. According to Montessori and Bofill (1986), the mind of a child can absorb language from their environment. If a preschooler has access to different languages in the natural environment, they will absorb them.

While a child is learning a native language, they can also learn and understand a second and even a third one at the same time (Montessori \& Vera, 1918). The sensitive period in which children are at the preschool age is the right time for gaining experience in a second language. Sensitive periods are defined by Montessori and Vera as "windows of opportunity", allowing children to develop deeply in a certain field of knowledge. Learning vocabulary is easy for them, and adults can give a child natural access to these possibilities of knowledge.

According to Lomakina and Laer (2014), preschoolers in an English class should have interest in the new language. They should not feel stressed or discomforted. The teacher, parents and a speech therapist should decide if a preschooler is ready to learn a new language and determine how they feel during the lesson time, i.e. whether they are developing or if some kind of stress is being generated.

Creating a motivational environment for children allows them to develop interest in a second language, and using different strategies and programmes lets a preschooler feel that another language is something natural, fun, interesting and enjoyable. As such, the use of music and games is recommended. Using rhymes is favorable for creating an excellent psychological climate and reducing psychological stress, as it increases the emotional tone and keeps children interested in learning a second language. It is possible to use them as relaxation or physical activities at any stage of a lesson when children need a discharge that relieves stress and restores their ability to work (Chakhchakhova, Tolstykh \& Ansimova, 2016).

International experts (e.g. Diez, 2010; Medina, Melo \& Palacios, 2010; Polo Torres, 2005) argue that the best age to start to learn languages 
is preschool age. According to these findings, children can recognize different languages and "use" a second language alongside their own. The scientific explanation for this phenomenon is that in the first years of a child's life, the neural connections of the brain are only beginning to develop and the vocal cords are adjusting to tune and strengthening in order to produce any sound; consequently, a child can speak any language naturally.

Russian experts, e.g. Sholpo (1999), Koryakovtseva (2010), Lomakina and Laer (2014) and Vorobyeva (2011), have also pointed out the positive impact of English on developing a preschooler's personality. Doctor of Education Milrud (2014) authored the "English to school" manual, used for teaching English to the children of the preschool age, to promote children's intellectual development, accelerate their speech development and form essential elements of social competence. Learning English helps their early integration into the multicultural space of the modern world, reinforces their communicative skills in interactions with teachers, parents, and classmates, trains universal cognitive activities, and prepares them for their school education (Lomakina \& Laer, 2014).

What method will help the child learn a second language is still an open question. Various methods and approaches have been developed related to teaching second languages to children. Since getting into the deep world of a language is a long-term process, motivation and interest are crucial to continuing this development.

\section{Language acquisition}

The language acquisition occurs spontaneously. In their interaction with their social environment, a child absorbs words and sounds, which are later associated with objects, feelings, and situations. The study of language development must take into account that learning to speak is not only learning how to pronounce and combine sounds but also how to use words and understand how they get a meaning in a particular context.

According to Montessori and Bofill (1986), the study of language in infancy is a natural process during which the brain absorbs information, which allows children to learn knowledge about the world around them. In a natural and healthy environment, the child listens to sounds that will later become words and sentences with meaning. Over time, this 
information makes sense, and the classification of actions, objects, feelings, and abstract concepts occurs. Afterward, the child naturally understands how the language works and, thus, can use all aspects of the language, such as grammar rules, phonetics, pronunciation, etc. (Lněničková \& Chocholatá, 2015).

Behaviourism, as a psychological theory, affirms that language has a function in the child's environment, and as this language is reinforced by their environment, the child must use it as a communication tool. According to Skinner (1957), a person develops language through associations; the child correlates the object that they see with the word that they hear. The environment contributes to this by allowing the child to satisfy their needs through language. Vygotsky claimed that language develops in interaction with its environment and for a communicative purpose (López Maján, 2018).

Chomsky says that the ability to acquire a language is innate, meaning that the human being is born with the ability to understand and acquire any language. This ability is called universal grammar, which is a set of rules that all the languages in the world share and which allows them to be learnt in a short period of time by a child, since they were born with the ability to understand these rules and assimilate them.

\section{Cognitive Theory}

Cognitive theories declare that the development of language is the result of previous cognitive development. In other words, cognitive development is responsible for language development. This theory is represented by several authors who have various positions:

1. For Vygotsky and the Russian school, language is the main element responsible for cognitive development (Oyarbide, 2004);

2. For Piaget and the Geneva school, language depends on learning and other competencies for its development (ibidem);

3. For Bruner and the Harvard school, language is the most powerful amplifier of human faculties and is considered the principal instrument in the cultural transmission of such faculties (ibidem). 
Piaget, being the most significant representative of cognitive development, defined language learning in four stages. For him, each stage is the result of the interaction between the maturity of the organism and the environment.

The first stage is from birth to 8 months, prior to the child's first words. The child tries to communicate through crying, gestures and the sounds of babbling unintentionally. The next period goes from 8 to 24 months, during which they increase their vocabulary to a range of 40-50 words and two-word phrases begin to appear (Piaget, 1981).

In the preconceptual stage of symbolism, which goes from the age of 18 months to 4 years, the child begins to give meaning to everything around them. Then there is the intuitive stage that goes from the age of 4 years to 7 and a half years. At this time, the child abandons symbolism and begins to understand reality; this presents improvements in their social behaviour. For example, they start using intuition to solve problems and begin to form more complex structures, e.g. verbal complements and relative and coordinated sentences (ibidem).

According to Vygotsky and his book Thought and Language (1934), a language is a decisive factor in the formation of mental processes. In order to analyze the higher psychological functions, it is necessary to investigate how the organisation of mental processes is influenced by language. Similarly to Piaget, he was interested in the effect of communication on the development of thought (Lucci, 2011).

Vygotsky pointed out that language has two functions: external communication with others and the regulation of internal thoughts. According to him, during the first years of life, a connection is generated between the thought and the language and together they mutually develop throughout one's lifetime (ibidem).

The preschool age (from 3 to 7 ) is characterised by improving pronunciation and phonemic perception, e.g. vocabulary increases and abstract speech and retelling skills appear. Children over the age of 7 continue to improve their grammar, writing and reading skills. This stage does not have strict age boundaries, as it is dependent not only on the environment but also on the individual child's mental constitution and personal characteristics (Tkachenko, 2016).

The acquisition of language requires the activation and development of interaction with the environment. Every child should 
be in an environment which contributes to their development and facilitates their language learning. Thus, interaction with more than one language does not interrupt the child from the full acquisition of their native language. The presence of two languages is in fact useful for the child because it allows the second language to develop naturally as well as the native one (Alvares, 2010).

Therefore, preschool education has a particularly significant role, during which time the child expands his/her world, meanings, vocabulary and linguistic structures with the all-new situations around them. It also creates the need in them to talk about different topics and explore diverse ways of using language. It is consequently interesting to teach second languages in preschool; the objective of these classes is to create an environment where a child can speak as freely they do in their native language.

\section{Language skills (listening, speaking, reading, writing)}

Language ability comprises four areas: writing, reading, speaking and listening. These are areas that a child develops in a healthy environment. However, when a person is studying a second or third language, developing abilities in these areas should be planned carefully by teachers, and it is necessary for them to prepare classes aimed at developing each of these language skills.

Listening: This is the first skill to be stimulated and developed. At the first moment of life, a child begins a lengthy period of "muteness", as Montessori illustrated in 1918, but the children are not just silent: they are listening actively to the sounds around them. Over time, this allows them to understand and start repeating familiar sounds. This is the first step in acquiring language (Lněničková \& Chocholatá, 2015).

At the first moment of hearing a language, it is normal not to distinguish one word from another and instead to perceive a continuous noise that seems meaningless. Every language has its own musicality; for example, some languages are low pitch and others are high pitch. This is why a person should have time for auditory adaptation to the segmental and suprasegmental characteristics of a new language, which are accent, rhythm, and intonation (Hernández, 2016).

Various nursery rhymes have been made for preschoolers that introduce the child to new languages in an interesting and natural 
way. Songs and poems are the main educational tools in the early childhood. Music, poems, rhymes, and songs allow children to improve their language skills (Martin, 2017). Rhymes are easier for the brain to remember; therefore, when teaching second languages, the use of nursery rhymes is an indispensable tool in every class.

With a good level of listening skill, a person should be able to perceive and understand the speech of the teacher and their classmates, understand the main content of uncomplicated authentic audio and video texts related to different communicative types of speech, and recognise context and significant and necessary information (Ageeva, 2018).

With preschoolers it is expected that they can understand rhymes, simple commands, routine words and phrases that a teacher uses every day, for example, if preschoolers are colouring it is expected a child is able to ask their groupmates to pass a particular colour in the second language.

Speaking: Speaking allows us to express feelings and thoughts. Speech and thought are interconnected. This is the basis for communication with our environment and the people around us. The main period of speech perception is from birth to 3 and a half years (Diez, 2010). Speech development in children is easier than in adults since their phonetic system is still developing. This enables the child to speak and repeat new vocabulary naturally, the same as a native speaker.

To develop this skill, the teacher needs to prepare activities that allow the child to be confident in talking, repeating, and expressing thoughts. Games and methods using dialogues and silences are useful for this purpose. The teacher can prepare games that encourage the children to verbally express simple questions and answers related to a proposed topic.

Reading: Reading is a complex skill. The task of the teacher is to associate the sounds with which the children are familiar with writing signs. When they can understand these, they have the power to provide information with meaning. Reading allows us to amplify our language not only in our reading, but also in our speaking, writing, and cognitive skills. By reading, people learn vocabulary, different grammatical components and concepts, and new information. 
A person with an appropriate level of reading skills in a language is supposed to read authentic texts of different genres and styles (Ageeva, 2018). At the preschool age, a child learns to associate sounds with graphic signs set for the native language, studies the letters of the alphabet, and builds words that indicate objects and situations around them. Reading is a process in which a child receives information from written characters (Ghaffari, Kashkouli \& Sadighi, 2017). In Russia, teachers traditionally wait until the child has a good knowledge of their own alphabet. When preschoolers aged 5-6 can read simple Russian phrases, they can start to learn other alphabets, for example the English one, then associate it with the related sounds.

Writing: The sensitive period for writing begins around the age of 3 and a half years and lasts up to the age of 4 and a half years. A 4-year-old child should be ready to write. This is the period of the formation and development of motility (Ghoneim \& Elghotmy, 2015). Writing serves as an additional means of communication besides speaking. At this point in life, the child learns to correlate words and concepts that they already know with a written representation.

Writing in kindergarten is a very sensitive subject. Children with a different alphabet in their mother language (as in Russia) could learn English letters by drawing them on paper. It is convenient for younger preschoolers (age 3-4) to stimulate fine motor skills with different hand activities, and with older preschoolers (age 5-6), it is possible to introduce writing in English. They can repeat what the teachers show them on a board or in a book, but it is important that the teachers monitor if the children understand what they are writing.

Different methods for the development of these communication skills have been searched for throughout the history and evolution of the educational technologies. Searching for the "right method" for teaching a second language has been the concern, historically, not only of teachers but also, and particularly, linguists, speech therapist and psychologists.

The work of these professionals in these years of methodological search allows us to know that this ideal method does not exist and will never exist. However, it is important to know the different methods that do exist in order to know the diversity of approaches that have been implemented through history and use and adapt the best of these to specific circumstances. 


\section{Second language teaching methods}

Language teaching distinguishes between general and specific, traditional and contemporary methods, and the literature has documented a number of methods and approaches designed to teach second languages. Some of the methods are grammar-translation, natural, conversational, direct, active, audio-lingual, audio-oral, situational, audiovisual, structural, suggestopedia and the method of silence, and the total physical response. Each method is distinguished by having its own approach, design and procedure for the activities for the promotion of language learning (Richards \& Rodgers, 2014).

\section{Grammar-Translation Method (GTM)}

As the name implies, this technique (the traditional form of language teaching, which dates back to the teaching of Latin and Greek) focuses on learning grammar and translation skills. It is based on learning a set of rules and grammatical exceptions that manifest themselves logically and are observable in written texts. Grammar learning is deducted, and the rules are presented, studied and practiced through translation exercises.

Although it is a frequently used method, its use is not recommended for preschool because it requires a basis for understanding the logic of the mother tongue, and children at this age have not yet deciphered this logic (Richards \& Rodgers, 2014).

The direct method

The direct method, developed by Maximiliano Berlitz and Gouin Francoise in the $19^{\text {th }}$ century, represented an improvement in the method of grammar-translation. This approach encourages direct connections between meanings and objects in the student's mother tongue and the second language without translation. Teachers and students use the second language exclusively in class, and the new material is demonstrated through actions or images (Richards \& Rodgers, 2014).

This method can be used in preschool, especially if the children are younger (age 3-4), since they are learning concepts. For older preschoolers, a little more care is required, especially if they are working in groups, since it may be stressful for them to be in the context where their mother tongue is not used as a linker with the second language. 


\section{A natural approach}

The foundations of this method were presented by Terrell and Krashen in 1983. For them, there is a clear difference between acquisition and learning. The main objective is the understanding of meanings. This method supports the theory that exposure and immersion in the target language are more important than the students' written production (Krashen, 1982). The acquisition theory on which this method is based is innatism, which gives the students a leading and highly active role. Grammar is reduced to a minimum (Sánchez, 2010).

This method has proven to be a big success in the kindergarten and schools (international schools) where children are immersed in a second language from the toddler age, where the aim is that all interactions with adults are in the second language. The child then grows with full access to this second language, obtaining as a consequence the total dominion of all the areas of language (writing, reading, speaking and listening).

For those who only have access to the second language in classes a couple of times a week, this method can be applied to generate the environment in which activities, such as games, manual activities, physical activities and others, allow natural interactions.

\section{Other approaches}

Nowadays, games, songs, and storytelling are frequently used in teaching languages. Moreover, in preschool education, the game method is the most actively used. At an early age, children love to play to develop their personality as well as their learning, cognitive, social, and motor skills. Games allow the child to improve physically, emotionally and mentally. By playing, the child is more involved in the proposed activities, and learning becomes more effective. The game should be a methodological component in language learning in kindergarten to help communication skills such as oral and written expression, comprehension and reading develop. In addition, playing creates an atmosphere where the child feels comfortable and motivated (Ghaffari, Kashkouli \& Sadighi, 2017).

The effectiveness of the game method has been shown by Madarsara, Youhanaee, Barati and Nasirahmadi (2015) in the research with Persian children who studied English as a second language. A group that studied with games remembered vocabulary better than the group where games 
were not used as a pedagogical strategy. It should be highlighted that the games should be used for a purpose; in teaching English as a second language, the game should be planned and oriented to teach a specific topic or study certain vocabulary. In places where a child is in a second language environment, it is also possible for them to play freely with some background music.

The total physical response (TPR) method proposed by Asher (2010) involves dance, mimic and dramatic movements of the body to learn vocabulary during lessons. According to Canga (2019), this teaching method is effective. He used it to teach English to children in Malaga and claims that this method contributes to learning the target language effectively.

The TPR method could be used for working with young children. The teacher should choose a series of children's songs that include simple acts and moves, and show them vocabulary in combination with these simple moves; as the result of these fun and interesting songs, children who join in and perform this physical activity can remember the words and link them when they are presented in other contexts (Martin, 2017).

The use of technology in teaching is becoming a necessity. For the study of second languages, parents and teachers use technology as a tool to help them in the learning process. Technological tools should only be considered as part of the learning method. Their use should be planned and focus on a specific goal. Even though it is possible to find apps, games, music, and videos for children and adults to learn languages on cell phones and computers (Gilakjani, 2012), language is based on human interaction, and this cannot be replaced with interactions with a machine. A child needs social relations to develop a language. On technological devices, the vocabulary is limited, and in human interactions, language is infinite.

The use of storytelling in preschool is a traditional method. Children love to listen to different stories, and this could also be used as a technique for learning a second language, e.g. reading stories with illustrations or other visual elements that are clear and full of color, in addition to providing a very pleasant moment for everyone. Children like to hear stories that are already familiar to them, so re-reading the stories repeatedly is fantastic for reviewing vocabulary and syntactic structures in a cozy and familiar environment. 
Apart from stimulating their imagination, reading in English allows children to develop the fundamental listening skills by hearing new words and grammatical structures.

Setyarini, Soleimani and Akbari (2011) used storytelling as a teaching technique. Their findings show that storytelling is a proper technique for teaching because preschoolers learnt English more enthusiastically. The preschoolers claim that this meant they could memorise the new vocabulary more easily. It also created a joyful atmosphere because the children were totally involved in it through listening, reading and creating their own story.

The craft (hand work) approach, also called manual work, requires a greater degree of mental work, since understanding must first be cultivated, then practical intelligence and, finally, skills must be acquired through construction and exercise. Imitation is both skillful and mechanical, but understanding of the activity is also needed. Crafts are commonly used in a preschool context, so involving them in second language classes could bring advantages for fine motor skills, cognitive and language development.

Crafts are beneficial from the points of view of both children and adults. Children love them because using crafts is usually a fun and relaxed activity for them, and at the same time they will be developing creativity and personal relationships, and they will undoubtedly reach a higher level in fine motor skills. The latter is related to the development of intelligence and memory and the reduction of stress (García \& Sanchez, 2013).

Crafts, of course, should be connected with the learning subject, and it is expected that they should be $90 \%$ completed by the child. The objective in a language class is not that the child has a beautiful craft to show to their parents, but that they can use the language while they are interacting, asking for paper with a certain colour, crayon, pencil, glue, etc. Also, the craft works to link the child with the rest of the activities. For example, a class could start with a song about animals, then proceed to some activity that involves acting like some animals, some storytelling about the animals, and end with a simple craft of an animal. Then the craft will be linked with the whole theme.

In accordance with the previously presented theoretical approaches, we want to propose a method that can be used to teach second languages to preschool children. This method uses a multisensory 
approach; consequently, it is necessary to be familiar with such concepts as: multisensory learning and teaching, the theory of multiple intelligences, and multisensory learning styles.

\section{Multisensory Learning and Teaching}

The concept of "multisensory" includes two words: "multi" from the Latin multum (many) and "sensory" from the Latin sensus (perception, feeling, sensation). According to this theory, people have diverse types of perception, thinking, and memory that could have certain sets of abilities: visual-spatial, musical-rhythmic, logical-mathematical, kinesthetic, naturalistic, linguistic, etc. This approach uses tasks that include music, sounds, songs, images, real objects, and motor activities. Regular change of tasks, focusing on different channels of perception, help to keep each preschooler involved during the lesson. By activating the senses, students develop the ability to concentrate, keep their attention, and keep language information in their long-term memory (Balashova, 2016).

Research by neuroscientists related to the field of education brings relevant conclusions about how the human brain processes and combines information. Thus, it is necessary to consider the natural predisposition or orientation of the brain to learn, which functions as a stimulator of learning processes (Jensen, 2004). This postulate emphasizes the relevance of developing meaningful educational practices based on what the student perceives as learning in interaction with their environment. It is important that learning takes place along multisensory paths, which provide an enabling environment for a diverse learning experience (Cañas \& Chacón, 2015).

In 1993, Howard Gardner put forward the theory of multiple intelligences. His work broadened the notion of what intelligence is. He believes that there are diverse types of intelligence. In training-teaching situations, according to Gardner, we often emphasise only verbal and linguistic intelligence. He suggests that people have a wide range of intelligence.

Gardner identifies eight types of intelligence: linguistic, musical, logical-mathematical, spatial, naturalistic, bodily-kinesthetic, interpersonal, and intrapersonal. Although he believes that these eight types are interconnected, he also suggests that separate areas 
of the brain are allocated for each type. Applying this theory offers students more learning opportunities.

Multisensory learning occurs when more than one sense is used to retrieve and store information. Such learning is divided into four types: auditory, visual, tactile, and kinesthetic (Suryaratri, Prayitno \& Wuryani, 2019). Multisensory education notes that each child has diverse styles of learning and gives each child the opportunity to succeed under their personal characteristics, presenting the same information from the four above-mentioned approaches.

The learning style theory proposed by Rita and Kenneth Dunn in 1978 is a method of perceiving and processing information in educational situations. Learning styles are defined as general approaches, namely, global, analytical, auditory, and visual. Students use these styles when learning a new language or any other subject. The style used determines the way the student perceives the learning environment and interacts with and responds to it. The learning style could be defined as characteristic cognitive, affective, social, and physiological behaviour, which provides a stable indicator of how students perceive, interact with and respond to the learning environment (Mackeracher, 2004).

There are four main learning styles, represented in Graphic 1: visual, auditory, tactile and kinesthetic.

Figure 1. Learning styles

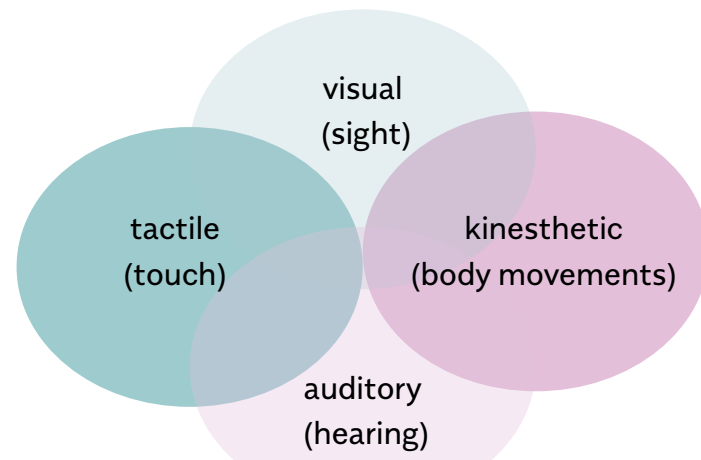


Visual learners

Visual learners think in pictures and learn much better with visual images. They depend on the teacher's non-verbal signals, such as body language. Sometimes visual learners prefer to sit in front, facing their groupmates. They also make descriptive notes on the material presented. Visually-learning children like well-organised material that allows them to find patterns and associate symbols with familiar objects so they can make mental pictures and conserve them in the brain (García \& Sánchez, 2013).

\section{Auditory learners}

These learners discover information by listening to and interpreting information using pitch, emphasis, and speed. They gain knowledge from reading aloud in a group and may not have a complete understanding of written information. The child of this type benefits from music, repeating content, reading aloud, and explaining what they need to other children or their peers (Suryaratri, Prayitno \& Wuryani, 2019).

\section{Kinesthetic learners}

Kinesthetic children learn best with an active and direct approach. These learners prefer interactions with the physical world. Most of the time, kinesthetic learners have difficulty reaching a goal and can lose concentration. Children with kinesthetic types of learning need to move their bodies in order to concentrate and learn. Examples include body movements that indicate a concept or manipulating objects that represent the concepts they are being taught (Gilakjani, 2012).

Tactile learners

Tactile learners should be able to use their hands, touching all objects around them. It is important for them to have information about the texture, temperature, consistency or even weight of the object of study in order for them to keep and understand the information deeply. These learners enjoy having different sensorial experiences; they notice the varied materials of clothes, for example, and the touched experience lets them predict the quality of an object (García \& Sánchez, 2013). 


\section{Multisensory teaching}

Multisensory teaching means using a technique that permits the child to learn through more than one sense. Common techniques are teaching through sight or hearing (visual or auditory). The child used sight for looking at text and pictures or reading information on the board. Hearing is used to listen to what the teacher says. Difficulties with tracking or visual processing may affect the child's vision.

Sometimes, the child's auditory processing may be weak. The solution to this difficulty is to involve the use of more senses, e.g. the use of images (visual), touch (tactile) or movement (kinesthetic). This will help the brain develop tactile and kinesthetic memories to hang on to, as well as auditory and visual ones.

Students with learning difficulties often struggle in the areas of reading, spelling, writing, listening comprehension and expressive language. Multisensory techniques enable students to use their personal areas of strength to help them learn. They can range from simple to complex, depending on the needs of the student and the task at hand. The multisensory approach can be applied to young children, children with special needs, and learners with dyslexia or disabilities (Fister, Stevenson, Nidiffer, Barnett \& Wallace, 2016).

In the classroom, most children understand the material better when more than one method is used. For example, when children learn about oranges, the teacher first talks about and explains the characteristics of oranges and how they grow. Later, the children can inspect, touch, smell and taste oranges, and they can also divide into two groups and count the number of seeds so they will have diverse experiences of one concept. In multisensory instruction, children convey information through such things as touch, movement, vision and hearing. Table 1 presents some examples of techniques that can stimulate each sense. 
Table 1. Multisensory Techniques

\begin{tabular}{|c|c|}
\hline VISUAL TECHNIQUES & AUDITORY TECHNIQUES \\
\hline $\begin{aligned} \rightarrow & \text { Text, pictures, posters, toys, } \\
& \text { projection screens, computers, } \\
& \text { flashcards } \\
\rightarrow & \text { Use of color for highlighting and } \\
& \text { organising information or imagery } \\
\rightarrow & \text { Graphic organizers, } \\
& \text { outlining passages } \\
\rightarrow & \text { Student-created art, images, videos } \\
\rightarrow & \text { Real objects }\end{aligned}$ & $\begin{array}{l}\rightarrow \text { Recordings } \\
\rightarrow \text { Poems } \\
\rightarrow \text { Music and songs } \\
\rightarrow \text { Reading a story (Storytime) }\end{array}$ \\
\hline $\begin{aligned} & \text { TACTILE TECHNIQUES } \\
& \rightarrow \text { Use of toys } \\
\rightarrow & \text { Use of textures (sand, finger paint, } \\
& \text { different papers, pastes) } \\
\rightarrow & \text { Modeling materials (clay } \\
\text { and sculpting materials) } & \text { Experiences of touching real objects }\end{aligned}$ & $\begin{array}{l}\text { KINESTHETIC TECHNIQUES } \\
\rightarrow \text { Action games involving moving } \\
\text { the body, arms, legs, head, etc. } \\
\rightarrow \text { Dancing to songs } \\
\text { related to the concepts }\end{array}$ \\
\hline
\end{tabular}

The multisensory method of teaching English as a second language is effective because children associate the second language with the perceptions and sensations they experience. This is a form of instruction that improves children's learning because it is based on meaningful and experiential learning. Education is perceived as a constructive and responsive process in which children play an active role.

The multisensory approach has been used in different countries for teaching English as a second language, and, through a comparison of test results, has been shown to be more effective than the traditional method in a case study in Jordanian schools. In 2012, Sereen Jubran concluded that students were more engaged in learning when they were given a chance to use all their senses. Furthermore, she added, using a multisensory approach is a powerful tool (Jubran, 2012).

Sanchez and Garcia (2013) created a programme in a kindergarten using a multisensory approach in teaching a second language to younger preschoolers, based on the Visual-Auditory-Kinesthetic model. They found that the learning process is conceived naturally and spontaneously; this model allows a teacher and a child to work 
on different topics and contexts, creating an ideal environment for the meaningful acquisition of the language.

In Russia, the use of the method is described by some authors, e.g. Voloshko (2014), who combined the multisensory approach with the tandem method in an international group with Russian and British preschoolers aged from 4 to 6 years in a summer camp. During this time, pictures and bilingual presentations were used, and cinema time with cartoons in Russian and English was also organised. In addition, there were creative activities (fairy tales and poems) relating to Russian and British culture, traditions and customs. At the end of the course, the preschoolers staged fairytales in Russian and English. The result was that the use of the multisensory approach helped to involve students in communication and made the learning process more accessible and effective.

\section{Conclusion}

In the modern world, knowledge of a second language is becoming a necessity. But how to learn and how to teach a second language is still being studied by experts. Over the years, specialised methods have developed. These often use songs, videos, poems and repetition games, and many also include body movements, such as the TPR method, which involves a person in actions beyond hearing and verbal repetition.

With children, the use of the game as a teaching method is vital, because with the help of this activity the child develops holistically, and if this activity is used by the teacher for a specific purpose, the child receives this information pleasantly and feels more connected to the process of participating and learning. Using technology in education is a tool that cannot be ignored; it is a useful way in which children can learn in a fun manner, but it should be utilised as an oriented tool and for a planned purpose. A language is learnt and improved with human interaction, not just with machines.

Language comprises four main areas - speaking, listening, reading and writing - and these are developed by children with their families and in the school environment. However, when teaching a second language, the teacher should plan actions that allow their students to improve in each of these areas.

The best way to learn a second language is still an open question. The various methods and techniques are still being researched. Among 
these techniques is the multisensory approach, which aims at supplying information by stimulating various sensory paths so that the brain can assimilate it efficiently.

The framework of the multisensory approach implies that children study and assimilate information in diverse ways: considering the theory of multiple intelligence, each child has the mental and physical capabilities for more productive work in various fields of knowledge. The multisensory method has been used in kindergarten for various purposes, and it has also been used to help children with learning difficulties. It has proved to be effective, and its principles are used in other methods (Montessori, cited in: Tello Puente, 2017). It is intended for children to study the environment using all their senses.

The uses of different methods for teaching second languages at the preschool age have been studied to consider how a child can be connected with a new language in a more effective way. It can be stressful for a child to be in the environment with a language that is not used in their daily life, in which case the teacher should connect the child with the language in a way that motivates them to learn new vocabulary and easily relate it to the concepts that they already know from their mother tongue. Using the multisensory method in teaching second languages allows the child to learn a new language, similar to learning their native language, as it allows them to be involved in the new vocabulary through doing different activities as well as receive information from various communication channels (visual, auditory, kinesthetic, tactile), allowing the brain to memorize and store information effectively. More research still needs to be done in order to further our understanding of the issues.

\section{References}

$\rightarrow$ Ageeva, A. V. (2018). The Relevance of Teaching English to Preschoolers and The Corresponding Difficulties in The Work of Teachers [in Russian]. In: National Priorities of Modern Russian Education: Problems And Prospects (pp. 94-98), https://Elibrary.Ru/Item.Asp?ld=36696409

$\rightarrow$ Alvarez, M. V. (2010). El Inglés Mejor A Edades Tempranas, Pedagogía Magna, 5, 251-256.

$\rightarrow$ Asher, J. J. (1966). The Learning Strategy of The Total Physical Response: A Review, The Modern Language Journal, 50(2), 79-84. 
$\rightarrow$ Balashova, V. V. (2016). Multi-Touch Technology in English Classes [in Russian]. Paper presented at the Modern Forms Of Organization Of Educational Activities conference. Moscow Region, Serpukhov, www.pedopyt.ru/conference_notes/7.

$\rightarrow$ Birchenall, L. B. and Müller, O. (2014). La teoría lingüística de Noam Chomsky: del inicio a la actualidad, Lenguaje, 42(2), 417-442.

$\rightarrow$ Canga, A. A. (2019). El Método De La Respuesta Física (Tpr) Como Recurso Didáctico Para El Aprendizaje Del Inglés En Educación Infantil, Revista Iberoamericana De Educación, 60(3).

$\rightarrow$ Cañas, L. Á. and Chacón, C. T. (2015). Aportes De La Neurociencia Para El Desarrollo De Estrategias De Enseñanza Del Inglés, Acción Pedagógica, 24(1), 52-61.

$\rightarrow$ Chakhchakhova, E. A., Tolstykh, V.V. and Ansimova, K. A. (2016). Development of Children's Creative Activity in English Lessons [in Russian]. In: Actual Problems of Pedagogy: Materials of the VII international conference (pp. 14-17).

$\rightarrow$ Diez, V. Á. (2010), El Inglés Mejor a Edades Tempranas, Pedagogía Magna, 5, 251-256.

$\rightarrow$ Dunn, R. and Dunn, K. (1978). Teaching students through their individual learning styles: A practical approach. Reston: Prentice Hall.

$\rightarrow$ Fister, J. K., Stevenson, R. A., Nidiffer, A. R., Barnett, Z. P., Wallace, M. T. (2016). Stimulus Intensity Modulates Multisensory Temporal Processing, Neuropsychologia, 88, 92-100.

$\rightarrow$ García Marulanda, K. and Sánchez, V.A. (2013). El Taller De Inglés: Un Acercamiento Significativo Al Aprendizaje De Una Lengua Extranjera Fundamentado En El Modelo Visual-Auditivo-Kinestésico En Niños De 4 Años De Una Institución Privada, http://ridum.umanizales.edu.co:8080/jspui/handle/6789/895

$\rightarrow$ Gardner H. (1993), Frames of Mind: The Theory of Multiple Intelligences. New York: Basic Books.

$\rightarrow$ Ghaffari, M., Kashkouli, S. M. and Sadighi, F. (2017). Montessori And Conventional Teaching Methods In Learning English As A Second/Foreign Language: An Overview, Journal of Applied Linguistics and Language Research, 4(5), 209-218.

$\rightarrow$ Ghoneim, N. M. M. and Elghotmy, H. E. A. (2015). The Effect of a Suggested Multisensory Phonics Program on Developing Kindergarten Pre-Service Teachers' Efl Reading Accuracy and Phonemic Awareness, English Language Teaching, 8(12), 124-143.

$\rightarrow$ Gilakjani, A.P. (2012). Visual, Auditory, Kinaesthetic Learning Styles and Their Impacts on English Language Teaching, Journal of Studies in Education, 2(1), 104-113. 
$\rightarrow$ Hernández, V. (2016). Fonética En Ele: Los Elementos Suprasegmentales Y Su Aplicación En El Aula, Doctoral dissertation, Universidad de Oviedo, http://hdl. handle.net/10651/37647

$\rightarrow$ Jensen, E. (ed.) (2004). Brain-Compatible Strategies. Thousand Oaks, CA: Corwin Press.

$\rightarrow$ Jubran, S. (2012). Using Multi Sensory Approach for Teaching English Skills And Its Effect On Students' achievement at Jordanian Schools, European Scientific Journal, 8(22).

$\rightarrow$ Koryakovtseva, O. V. (2010). Methods of teaching English to pre-school children, Doctoral dissertation. Moscow: Moscow State Linguistic University.

$\rightarrow$ Krashen, S. D., Kerrell, T. D. (1983). The natural approach: language acquisition in the classroom. Oxford: Pergamon.

$\rightarrow$ Lněničková, I. and Chocholatá, M.J. (2015). Montessori Language Teaching: Materials Analysis and Evaluation, Master's thesis. Brno: Masaryk University, Https://ls.Muni.Cz/Th/166802/Pedf_M/Diplomova_Prace_Lnenickova_Aeh7l.Pdf

$\rightarrow$ Lomakina, G.R. and Laer, A.A. (2014). Early Learning of a Foreign Language: Pros and Cons, Young Scientist, 20, 597-599.

$\rightarrow$ López Maján, A. (2018). La Enseñanza Y Aprendizaje De Una Segunda Lengua En Educación Infantil: El Caso Del Español, Http://Uvadoc.Uva.Es/ Bitstream/10324/31644/1/Tfg-O-1325.Pdf

$\rightarrow$ Lucci, M. A. (2011). La propuesta de Vygotsky: la psicología socio-histórica, Profesorado. Revista de currículum y formación del profesorad, 10(2), 1-11.

$\rightarrow$ Mackeracher, D. (2004). Making Sense of Adult Learning. Toronto: University of Toronto Press.

$\rightarrow$ Martin, K. (2017). The Impact of Song And Movement on Kindergarten Sight Word Acquisition, https://rdw.rowan.edu/etd/2489/

$\rightarrow$ Medina, M., Melo, G. and Palacios, M. (2013). La importancia del aprendizaje del idioma inglés a temprana edad, Yachana Revista Científica, 2(2).

$\rightarrow$ Milrud, R. P. (2014). Teaching English In Preschool Education: The Experiment Continues, Education - Foreign Languages, 11, 34-46.

$\rightarrow$ Montessori, M. and Bofill, M. (1986). La mente absorbente del niño. México: Diana.

$\rightarrow$ Montessori, M. and Vera, P. (1918). El método de la pedagogía científica: aplicado a la educación de la infancia. (No. 371.4 Montessori). Barcelona: Casa Editorial Araluce.

$\rightarrow$ Oyarbide, M. A. (2004). Jerome Seymour Bruner: de la percepción al lenguaje, Revista Iberoamericana de Educación, 34(1), 1-19.

$\rightarrow$ Piaget, J. (1981). La teoría de Piaget, Infancia y aprendizaje, 4(sup2), 13-54. 
$\rightarrow$ Polo Torres, M. L. (2005). Bilingüismo en la edad preescolar, Bachelor's thesis. Universidad del Azuay, http://dspace.uazuay.edu.ec/bitstream/ datos/728/1/05137.pdf

$\rightarrow$ Richards, J. C. and Rodgers, T. S. (2014). Approaches and methods in language teaching. Cambridge: Cambridge University Press.

$\rightarrow$ Sánchez, M. Á. M. (2010). Aproximación histórica a la enseñanza de lenguas extranjeras, Aula, 16, 137-154.

$\rightarrow$ Setyarini, S., Soleimani, H. and Akbari, M. (2011). Storytelling: An innovative language learning for English young learners, http://a-research.upi.edu/ operator/upload/pros_ui-itm_2011_setyarini_innovative_language_learning. pdf

$\rightarrow$ Sholpo, I. L. (1999). How to teach a preschooler to speak English: A textbook on the method of teaching English for pedagogical universities, colleges and colleges in the specialty "Teacher of a foreign language in kindergarten" [in Russian]. St. Petersburg: Special literature.

$\rightarrow$ Skinner, B. F. (1957). Verbal Behavior. New York: Appleton-Century-Crofts.

$\rightarrow$ Suryaratri, R.D.,Prayitno, E.H. and Wuryani, W.(2019). The Implementation of Multi-Sensory Learning at Elementary Schools in Jakarta, Jurnal Pendidikan Usia Dini, 13(1), 100-113.

$\rightarrow$ Tkachenko, A. S. (2016). Features of Teaching English To Preschool Children, Youth Scientific Forum: Humanities, 11, 167-170.

$\rightarrow$ Tello Puente, M. A. (2017). Método Montessori En El Proceso De Enseñanza Aprendizaje En El Idioma Inglés, En Los Estudiantes De Inicial 2, En La Escuela Albany Junior School, Bachelor's thesis. Universidad Central Del Ecuador, www.Dspace.Uce.Edu.Ec/Handle/25000/11108

$\rightarrow$ Voloshko, M. O. (2014). Multisensory Approach in Teaching English To Children Of Preschool And Primary School Age In The Framework of A Collective Tandem Course [in Russian]. Innovative future of Pedagogy and psychology: collection of articles. Collected papers International scientific and practical conference. Ufa: Aeterna Research Center, https://elibrary.ru/download/ elibrary_22541759_59833657.pdf.

$\rightarrow$ Vorobyova, O. I. (2011). Methodological aspects of teaching English in preschool institutions [in Russian], https://lib.vsu.by/xmlui/handle/123456789/4573 


\section{Promoting Quality in Teaching through Moving into Hinglish-medium Instruction}

DOI: $10.47050 / 66515321.302-324$

Melanie Ellis

In many contexts in higher education, there is an increasing trend for institutions to offer courses with English as the medium of instruction (EMI), which presents particular challenges for the prospective teacher. This case study tracks five university lecturers in Poland preparing to begin teaching EMI courses. A course to support their English was offered as part of a project to develop the teaching competences of university staff. Based on data from transcripts of interviews and questionnaires, the study investigates the relationship between how the teachers teach in their own language and in English, the decision-making process as they plan an EMI course, their perception of the language course, and whether the move towards EMI enhances the overall quality of their teaching.

The findings demonstrate that the preparation process to start EMI is highly individual. Deciding what to teach and how is a complex process related to the participant's self-efficacy in English and their concerns about student response and language skills. The course planning has promoted deep reflection on the teaching/learning process. There are suggestions that this will also bring about changes in teaching in the national language. In short, the move towards EMI has the potential for raising quality in teacher education.

\section{Keywords:}

English-medium instruction

planning process

self-efficacy

teaching quality 


\section{Introduction}

Within the European Community, the Europe 2020 Strategy placed a premium on the mobility of staff and students, partnerships between institutions of higher education, and the internationalisation of programmes and courses with the goal of "enhancement of the quality of teaching and learning" (CHE Consult et al., 2014, p. 143). The 2014 report on the impact of the Erasmus programme (ibidem) found that staff involved in mobility, either those visiting or those being visited, strongly felt that the experience had indeed improved the quality of teaching and learning. The 2019 report (CHE Consult et al., 2019) added that staff involved in Erasmus were found to employ more modern teaching methods, including the use of digital media, and introduce innovative curricula. Yet internationalisation, in the form of offering programmes through English as a medium of instruction (EMI), which is defined as "the use of the English language to teach academic subjects (other than English itself) in countries or jurisdictions where the first language (L1) of the majority of the population is not English" (Dearden, 2015, p. 2), has a longer history than this. It was introduced at the University of Maastricht as long ago as 1987 (see Wilkinson \& Zegers, 2008). Initially a topic of interest in Europe, it has now become a global concern (Dearden, 2015).

Reasons for a move towards internationalisation in European higher education institutions (HEIs) can be traced to the Lisbon 2000 strategy, which aimed for countries to encourage at least $40 \%$ of young people to have completed higher education by 2020, with a view to raising the competitiveness of the $\mathrm{EU}$ as a world economy. The 1999 Bologna declaration created a European Higher Educational Area (EHEA), across which staff and young people were intended to be able to move freely. Falling birthrates mean that HEls have to compete for undergraduates, and this has contributed to what Coleman (2006) calls the "marketisation" of these institutions. In order to be attractive for international students, HEls need to offer courses in accessible languages and English is dominant in this respect. In a report on the extent of EMI in Europe (Wächter \& Maiwurm, 2015), it was found that the largest number of programmes are in Scandinavia and the Baltic countries, followed by other countries of northern Europe (the Netherlands, Switzerland, Germany), with notably fewer such programmes in the south of Europe. In the period between earlier 
reports (Maiworm \& Wächter, 2002; Wächter \& Maiworm, 2008) and the 2015 study, the overall number of EMI programmes increased substantially. MA level programmes dominate, and are found particularly in HEls which award PhDs.

\section{Theoretical background}

EMI has been the subject of a substantial amount of research (see review article by Macaro et al., 2018). A number of concerns have been identified in the literature (examples given here focus only on Europe and Turkey). These include the attitudes of lecturers and students towards the introduction of EMI (e.g. Dearden \& Macaro, 2016; Earls, 2016); difficulties faced by lecturers (language proficiency, see e.g. Campagna, 2016; Guarda \& Helm, 2017; Werther et al., 2014); methodology (Klaasen \& de Graaf, 2001; Aguilar \& Rodriguez, 2012); student responses to the introduction of EMI, in particular regarding difficulties faced with English (e.g. Airey, 2011; Basıbek et al., 2014; Doiz, Lasagabaster \& Sierra, 2011; Napoli \& Sourisseau, 2013); and the question of whether EMI improves student English language skills (e.g. Aguilar \& Munoz, 2014; Hellekjaer, 2010).

Several studies have looked at ways of supporting university staff engaged in EMI. One of the areas of concern is that of the language proficiency of staff in EMI (Lasagabaster, 2018). Klaasen (2008) describes how courses offered in a Dutch HEl initially focused solely on developing the English skills of lecturers, but over time researchers understood the need to devote attention to the pedagogical skills needed to allow the internationalisation of courses. Guarda and Helm (2017), in an Italian context where lecturers had been pushed into EMI regardless of their skills in English, reported on a course to develop the academic language skills of those engaged in EMI through a focus on pedagogical skills in order to help the university achieve its goal of internationalisation. This same study also found that staff reported the course promoted reflection on the nature and quality of teaching. Doiz, Lasagabaster and Sierra (2011) found that staff engaged in EMI perceived that it had positive benefits for their personal and professional development.

Some studies link the question of lecturers' language skills with the language skills of students. Flowerdew, Miller and Lee (2000) found that Cantonese lecturers, aware of their students' difficulties with 
English comprehension, attempted to compensate for this by switching languages, a policy only possible if the lecturer and all their students shared a common language. Airey (2011) found that the lecturer becoming aware of the need for students to comprehend is a key factor in successful EMI lecturing, more important than the lecturer's language skills. Erkin and Osam (2015) found that low levels of student language proficiency reduced the level of comprehension of lectures, despite efforts from the lecturer to accommodate for this. They conclude that "the instructional process in the native language and the foreign language (English) are significantly different" (p. 193) and stress that this fact needs to be made clear to those engaged in EMI. In an observational study, Jiang, Zhang and May (2019), in an HEI in China where the aim of EMI is not only to teach the subject but also to develop student skills in English, found that teaching staff focused primarily on the content; however, they also adopted various strategies to support student understanding through, for example, the use of visual support. Students' level of language proficiency was seen as an inhibiting factor in the effectiveness of the process, with a need for additional language for specific purposes seen as a requisite.

To date, it appears that there have been no studies that explore the planning and decision-making processes of university teachers before they begin to work in EMI. The study described here aims to address this gap.

The notion of quality in higher education

As this study is based in Europe and the course it features took place thanks to EU funding, it seems appropriate to look to the European Commission (2013) report on "Improving the quality of teaching and learning in Europe's higher education institutions" to gain an understanding of how quality is perceived in this context. In the introduction to this report, Commissioner Androulla Vassiliou stresses that quality higher education is important "to produce the critically-thinking, creative, adaptable graduates who will shape our future" (p. 4). From the report, we learn that the goal is a co-constructive approach to learning with students as partners in the process, where students are actively engaged in reaching deeper levels of understanding and have opportunities to analyze the latest research from across the world in order to "develop academic literacy and both subject 
specific and generic skills which they can apply immediately in the real world, especially in the labour market" (p. 19). Courses and activities are to be problem- or research-based, feature work in groups or teams and promote critical thinking (p. 72).

\section{Research context}

The internationalisation of HEls is a priority for Poland (Bobko, 2016) in the face of a falling number of Polish students due to demographics. Data from 2017 (Siwiński, 2017; GUS, 2018) indicate a rising number of foreign students, standing at $5.63 \%$ of the student population. In some universities, foreign students now represent around $5-6 \%$ of the total number, with the largest group of students coming from Ukraine.

This paper concerns a project, funded from the EU Structural Fund, which aimed to raise the teaching competences of staff at a Polish university. In particular, it aimed to support young researchers (aged up to 35) in their preparation to teach subject courses through the medium of English. An enrollment requirement was that participants would teach a minimum of 30 hours of course(s) through English in the semester following the end of the course and submit the course syllabus as documentation. Participants were taught English in micro-groups of three, 70 hours of group English classes taught by two tutors (one British, the other Polish) who shared the teaching hours, plus 15 hours of live online individual tutorials, similarly divided between the tutors. Other parts of the project included focus on innovations in methodology, but these are not the subject of this paper.

\section{Research design}

This is an ethnographic case study of five tertiary lecturers in different fields preparing to teach courses through the medium of English. The researcher was a participant in the process, being the British tutor who taught half of the language course and conducted half of the individual consultations. During these the researcher also used her experience as a teacher educator and her experience in course and materials design. The analysis in this paper consequently offers both etic (researcher/observer) and emic (participant-tutor) perspectives. The broad aims were to explore the planning process undertaken by the participants in the course. Specifically, the study set out to find answers to the following questions: 
1. What is the relationship between how teachers work in their own language (L1) and how they plan to work in English?

2. What did the teachers decide to teach in English? Why? What influenced the process?

3. How did teachers evaluate the preparation-to-teach-in-English process?

4. Is there evidence that the preparation process affects the overall quality of their teaching?

\section{Participants}

The participants were post-doctoral members of the university staff, aged 34-36, with teaching experience ranging from 3.5-11 years. There were four women and one man. Four of the five had volunteered for the programme, whereas the fifth had been asked to join. The selection process seems to have focused on the individual's research profile rather than their language competence, which varied considerably, particularly in terms of spoken language ability. They represented diverse disciplines: mechanical engineering; biology; political science; geography (teacher education); and artificial intelligence. The brief was that the language course should be at level $\mathrm{C} 1$ on the Common European Framework, which was challenging for two of the participants.

\section{Data collection}

Participants gave their informed consent to take part in the research. Throughout the course, the researcher kept a log in which notes and reflections were made. Materials submitted by participants as part of the course planning process were collected, including the course syllabuses they prepared. Online individual consultations took place on Skype, during which written messages were used to correct language and give feedback. These messages were then included in the research log.

At the end of the course, participants were asked to complete an online questionnaire, in either English or Polish, with open questions, which was done by three participants. Questions were arranged in four areas: yourself as a teacher now (teaching in own language (L1), beliefs about, attitudes and approach to university teaching, self-efficacy); moving towards teaching in English (planning process, decision making, comparison between teaching in English and in L1); course plans (aims, 
approach, criteria for choice of what to teach and how); and evaluation (role of individual consultations, how they were used and why, readiness to teach in English, self-efficacy, impact of process of preparing to teach English on self as a teacher in general, on teaching). Course members also agreed to take part in semi-structured interviews in the two groups in which they had been taught. These were conducted in English. Each of these lasted 90 minutes and were recorded and then transcribed. Two participants took part in one interview and three in the other.

\section{Research Methodology}

Potter and Hepburn (2012) stress the importance of how interviews are designed, carried out and analysed and the impact of this on the validity of qualitative data. Bearing this in mind, explicit statements are made here about the role of the interviewer and the specific context in which the interviews took place, and statements made on the basis of the interview data are supported by verbatim quotations. Nickerson (1998) warns of the dangers of confirmation bias, whereby the researcher extracts only data which are perceived as supporting preconceived views. For this reason, a grounded theory approach was taken (Strauss \& Corbin, 1998) by reading and re-reading the transcripts and creating codes. First, the general areas outlined in the questionnaire were identified and then, within these, more detailed codes were created, comparing and contrasting them across the responses to trace patterns.

While the semi-structured interview followed the same broad outline as the questionnaire, the responses were much longer, and in places participants interacted with each other and/or with the interviewer, discussing the views expressed. Where, for reasons of language limitations, a participant's response was not transparent, the researcher rephrased what had been said in clearer language, using markers such as "If I understood correctly you are saying that..." and "Do you mean that...?" for confirmation or correction by the interviewee, with the aim of ensuring the message was clear. In this context, therefore, we follow Holstein and Gubrium (2003), who state that the views expressed in an interview are co-constructed as a result of interactions between the interviewer and interviewee(s). These may differ from the views an individual interviewee might express in a questionnaire. 


\section{Findings}

Teaching in L1

Describing their current teaching in their specialist areas in their L1, the participants fall roughly into two groups: those who teach by lecturing to introduce theoretical concepts, followed by classes during which practical work is done based on exercises, and those who actively engage the students in the construction of theoretical knowledge, followed by group problem-solving tasks. There are, however, differences in the first group (3 teachers), where one participant (biologist) explains: "I try to bring the knowledge to the students in an attractive way so that they feel the usefulness of this knowledge in their own lives", while another (artificial intelligence) protests that giving a 90-minute lecture is not effective, as the students "go to sleep... because there is a lot of information, it is not useful for them". This same teacher, however, loves classes: "I love learning by doing, so [I mean] if they have lots of exercises, or the exercise that they need to improve their knowledge". In short, there is evidence that while traditional transmission of knowledge through lectures is standard practice for the first group, one of the lecturers tries to introduce information in ways to make it more understandable for the students and a second is critical of the lecture as a mode of learning. Within the second group (2 teachers), one teacher (mechanical engineer) explains "I am trying to engage students to actively participate", describing that this takes place through spontaneous dialogue with them in the form of questions and answers. The other teacher (political scientist) works with text: "we discuss it and try to find examples". Students then "have to solve the problem connected with [the text] and they have small group work to summarise knowledge".

Asked in one of the interviews if lectures were needed in a modern university, both participants were strongly in favour, explaining that before a student is able to search for information effectively on their own they need a foundation, on the basis of which they are able to discern which information is relevant or reliable. A second argument given was that the lecturer acts as a mediator who helps students interpret new information, modelling ways in which the student can then work on their own and thus serving as a guide. This suggests that viewing the lecture simply as a vehicle for the transmission of knowledge appears to be a misleading over-simplification. 
In terms of self-efficacy, four of the participants declared (in the questionnaire or in the interview) that their $\mathrm{L} 1$ teaching is rated positively by their students, while the remaining teacher did not answer this question.

Moving towards teaching in English: the planning process

Participants were able to choose what they were going to teach in English. On an administrative level there were problems, as all course syllabuses are required to be submitted and approved at the start of the academic year, yet a project requirement was that 30 hours should be taught in English in the second semester, which required a new, revised syllabus that the regulations did not allow. The students enrolled were all Polish and the courses had not been promoted as being English-medium, which some of the lecturers anticipated could cause difficulties. These issues proved to be one of the deciding criteria in choosing what to teach in English. The question of how students would react was a recurring theme in the discussion. (The following extracts are taken from the interviews where participants spoke in English, and this is reproduced as near to verbatim as possible, with any additions marked with [...] These represent translations when words were given in Polish, or corrections that were felt to be needed to make the text intelligible.)

\section{[1] I want to introduce [a] mixed course in English and in Polish so some parts of my classes will be in English, maybe some parts in Polish, but I think this is dependent on the students' level in English and also what they want because I can not [...] I can not force them.}

This teacher rationalizes the need to use English on the grounds that the latest research is only accessible via articles published in English, and that if a text is presented in the original language, supported with a glossary, then it is logical that discussions about it should also be in English. She also explains the process by which she will justify her use of English to the students:

[2] I think we can create some need for students to develop themsel[ves] in English, they know, they [find out] new words, specific words. In the future for them [it] will be easier, [they will] 
more understand, so I can [explain to] them why they need this language and [why] some part of the course is in this language.

Her colleague, by contrast, was less optimistic, based on her experience from a previous year when she used a text in English in one of her classes which led to an official complaint from a student. She also cites the very low take-up of elective classes in technical English, indicating the reluctance of students to develop their English skills. (This teacher finally decided to meet the project requirement whilst away as a visiting lecturer in Jordan.) The two teachers considered alternative approaches in the Polish context to accommodate the students' lack of English proficiency or resistance: e.g. giving a lecture in Polish with slides in English, lecturing in English with slides in Polish, or lecturing in English with a summary at the end in Polish.

The next criteria noted in the data are that of how the lecturer perceives their level of English and their sense of self-efficacy in the language. This is highly individual and does not always correspond with their actual level of proficiency, as perceived by the tutor.

[3] I feel a lot of limitation of my language, so when I want to say something very specific, very - the context of what I want to say is very important - so sometimes I think about this what I have to say, but I do not go deep to the knowledge of something - so I feel the limitation of my language.

Another teacher describes the challenge of coping with content and language simultaneously:

[4] In Polish when I speak about some process I can imagine this in my mind and I speak in Polish and I understand this process well [...] but when I start to think in English about this process it is hard to me to be on the first step, on the second step, then think about this, think about the first steps and think in English to be correct, so I use lots of diagrams. [Researcher: So it is almost as if it is too much in your head at the same time?] Yes, yes! So when I have this diagram I have some information - for example, [the] first step is this, written on this diagram, and it helps me to speak about it. 
This teacher has found a strategy to compensate for her language difficulties: using visual support in the form of a labelled diagram. She believes this helps her by reducing the cognitive load and leaving her mental space to focus more on her English.

Another teacher spoke about her sense of self-efficacy in English:

[5] It is hard to use this language because I want to be perfect and I am not perfect. It is hard to speak in English when you feel that you are not enough good... I am afraid of speaking in English...

The final extract is from a teacher who has considerable experience in working on European projects with international partners so feels comfortable in her everyday use of English, but had reservations about using English in class, both on account of her own skills and also due to concerns about the students. She has found a solution:

[6] I want students to work by their own with sources, one of which they will search for, one of them I will give them, this will be English language sources. They will work on it in English and then in the end there will be discussion [...] there will be some individual actions they will take, so it will be all in English, so it will be quite a challenge, but I already discussed it with them and half of them is, are terrified, but I make them sure that they will receive the materials to have a chance to [familiarise themselves] with them... So I calm them that it is not a competition whose language is best [...] the goal is to use English language sources without any boundaries and achieving higher goals because of it.

Deciding on plans for a course

The decision-making about what to teach in English was a process which involved the criteria outlined above, which then had to be mapped onto the specifics of the subject being taught and the format - lecture or class. Participants appeared to start with an expectation that there would be no difference between how they would teach in English and how they teach in Polish, as expressed here: "I think [I will teach in] the same way, because it is working in Polish, so why does not [...] [it] working in English? We only change the language, yes?" This teacher initially thought of giving a lecture in English to explain the workings 
of a computer program. It was not until she tried to rehearse part of this live during an online consultation that she became aware she was not familiar with the English version of the program, so lacked terminology in English, and did not know the specific language to give instructions for using the program. In other words, what she had assumed would be easy because she found it easy in Polish turned out to be a challenge in English. She continues:

[7] So I think now it is not a good idea to explain how this program works. I think a normal lecture where some theory and then this exercise for them will be [a] better idea ... because when I forget something I can see on this slides.

Another teacher, aware of their language limitations, initially thought of introducing English only in one-to-one classes:

[8] Because I know what I have to do with this student, I put my attention only on one person and we will conduct what I know, what is for me very automatic, and I can put my attention only on English, and only on one person.

This appears to echo the cognitive load issue mentioned by a different participant earlier when trying to describe a process in English (extract 4). Here, the teacher feels that having to teach a class, think about students, think about the content and how to explain it in English would be too much to deal with all at once. This teacher, however, went on to explain that she now felt more confident and less concerned about making mistakes and so decided on a mixed language course (see extract 1).

Other planning decisions were pragmatic:

[9] I chose the classes that will be about the technology of the computer, writing code and engineering calculations, it is based on new software that was created in the United States and also the technology and the knowledge ... was developed mostly in the United States, so I have got lots of books about it in English, so it will be easier to me to prepare it in English. And the form I choose, it means the mini-lecture or talk, it is because I am not 
quite satisfied with the level of my English... sometimes it is quite difficult for me to say something when I have not prepared it... not maybe learning it by heart, but knowing what I want to say. I have got some problems with spontan[eous] talk.

Another teacher feels that her course is already challenging for the students as it involves developing critical thinking skills to analyze scientific texts and writing academic articles based on source texts: "They are terrified about everything [...] I am talking about, so that is why I do not feel I can use English on this course". Instead, she chose to prepare a course for students/visiting lecturers on Erasmus visits which introduces them to Poland, using authentic sources in English: "I am quite sure that I can find a lot of sources about our country... so I can use these sources and I can discuss with people about other countries, that is why I choose this kind of course".

In the final extract in this section, a teacher views the opportunity to teach in English as a lever for change:

\section{[10] I discovered that most of the department's text books for} didactics are about 30 years old, near my age, so we really need to refresh it, so it is a good opportunity... I am going to add lots of new literature [in English] to the syllabus.

\section{Evaluation}

The participants all declared that they had made progress in their English and felt more confident about using it for speaking, and in particular were less concerned about making mistakes. Despite this, they all felt there was still further development needed before they could achieve the goals they had set for themselves. They attributed the change in confidence to the amount of practice they had had, the very small groups, and the intensity of the course. The individual consultations were perceived as playing a key role in the process. The participants decided how they wanted to spend this time:

[11] I did what I think that was necessary to do, it is mean to check if I am fluent in the oral presentation... I chose some topics that were strongly connected with the subject I wanted to present to my students... I said some things and it assured me ... that I did 
it correctly. What is your opinion about that? [Researcher: Sure, I could understand you and I am not an engineer!]

Another teacher used the time to discuss her ideas for materials and for classes:

[12] Sometimes showing these materials and getting your feedback was also useful for me to analyse, is it the correct thing, or should I use another tool? And also your advices connected with choosing the resources was very important for me, so I spent [the time] as I wished, working on courses, and somewhere in the background, during all of our discussion[s], [my] speaking skills have improved.

For the participants for whom English was more challenging, the individual sessions had a particular impact:

[13] We talk about my topics, yes, I checked myself what I can say in English, and I saw that in some parts I have problems with words, but I also saw that when I speak to you about interesting for me things I do not remember that I speak in English and I speak to you.

For this participant, the challenge of communicating ideas became more important than her worries about the language, and the sense of satisfaction when she was able to get these ideas across boosted her confidence in speaking in English. Her colleague experienced something similar when trying to explain the contents of an article she had just read:

[14] I was not prepared because I found this information the day before... I was really shocked about this article, for me it was really news, it was better for me than when I talked to you about my thesis and I love my thesis, I am really attached to it.

In her excitement about the innovation described (creating a computer animation from a single photograph), she became so absorbed in trying to explain to me how it worked that she spoke spontaneously in English. Earlier, she had evaluated her attempt to tell me about her doctoral thesis as "a tragedy because I can not find these words to explain this 
simplest thing in English", describing a process which suggested she was first thinking in Polish and then trying to translate these thoughts into English. She found that in the individual sessions "I do not have time to think in Polish" as if she did not speak there was silence, which moved her to speak at once as she felt awkward about it.

The participants felt differently about the extent to which they were ready to teach in English, as described in the section on the planning process. Their feelings related primarily to their sense of self-efficacy, while concerns about student reactions were dealt with in terms of the methodological approach they decided to take, their decisions about which language to use, the amount of visual support they opted for, and the materials and tasks they chose. The two participants who felt unable to resolve issues with students made decisions to teach alternative courses to non-Polish students.

There was also some indication that the participants had been influenced by some of the activities they experienced during the language classes, such as having to give prepared mini-lectures to their colleagues, watching short educational films as an introduction to a topic, or doing problem-solving tasks in a group. The concept that input material could be divided into parts, prepared by different students and then explained to others in a group was also adopted. This had not been anticipated in the language course design and happened spontaneously.

One of the teachers described how her approach to teaching in English would be different from the approach she had taken so far when teaching in Polish:

[15] My students will suffer, because I discovered that they are pretty lazy, because - I found the reason - because we read a lot, we research a lot and what we do is serving things to students. I can see that during the learning process that we focused on, on making exercises but based on knowledge, [it is] like "I will show you this this this, I will explain you this this this" and then you are making an exercise on knowledge that I served you and it makes them a bit lazy... the English course [...] will have an impact on my students for sure, that I will push them harder to look for sources, to build knowledge from information, also from English language sources, that will not be only my job to work for it and serve... I think so, that 
I have to add this point on any course, to make them, to force them to think wider about different things [...] so my goal to expand their boundaries it is, I am sure it will keep on, it is also going to change in the other classes too.

The process of reflection has led this teacher to understand that she has been working in transmission mode, "serving" things to her students, who, as a result, are passive or complacent ("a bit lazy"). In planning the course in English, she determines to move to a more student-centred approach and is aware this could be painful for the students, who will need to be pushed to take a more active role. Interestingly, she declares that this change will not only apply to the new EMI courses but to all the classes she teaches.

\section{Discussion and conclusion}

If we consider the way the teachers describe their approach when teaching in their L1 (Polish), we can see that while several of the teachers have a transmission approach, there is also a concern for the students in terms of how the information can be packaged or explained to make it more comprehensible for them. There is already a dual focus on the content and on the students, and not on the content alone. As Airey (2011) pointed out, it is awareness of the need for students to comprehend when classes are conducted in English that is the key to successful EMI. It seems to be a natural extension for these teachers to carry this concern over when they start to consider how they plan to teach in English.

The decision process likewise has a dual focus: the teacher and the students. For the teacher, the concern is their English proficiency, not in the abstract, but as a medium by means of which they need to communicate with and reach their students. For the individuals whose teaching style is highly language-dependent, such as the biologist, who described selecting ways to link the new ideas with the students' everyday lives, or the mechanical engineer, who uses a Socratic questioning technique to activate students and guide them to an understanding of complex new concepts, the move to English is viewed as limiting. It appears to be limiting as these two teachers feel they do not yet have the flexibility in English, which they have in their L1, to spontaneously adapt and respond, without preparation, to the needs 
of students in the moment. This 'limitation' is not purely linguistic, it relates to their persona as a teacher. The language skill, for these teachers, is equated with the efficacy of how they teach. The biologist accepts that she is not yet able to teach in English as she feels she needs to be able to, and so seeks a mixed language compromise. In conversation she later explained that she saw this as a transitionary stage, believing that as her proficiency developed she would be able to change her teaching, but not yet. The second teacher, the engineer, also described having to find a temporary alternative way to teach in English until he feels he is sufficiently fluent to teach in the way he wants. He explains he has chosen a safe compromise, where he prepares the material he wants to explain and rehearses it to feel comfortable. To facilitate this, he uses source texts in English, which is not new as he used them himself earlier, but he mediated the content into Polish to explain it to the students. Now he does not intend to do all the work of mediation but rather to share responsibility for this with the students. He will support them in this process by creating a bilingual glossary and adding his own English explanation, but the students will have the text in the original and work to understand it for themselves.

The text as a tool for mediation between languages also appears in extracts (6) and (15), where the same teacher describes her approach. The text will not only support the students in the language change but will also be used to introduce a more student-centred approach to teaching, with the learners active in the co-construction of knowledge based on their engagement with the text and related tasks. The decision-making process about what to teach and how emerges as complex and situated. For each of the teachers, there are personal beliefs and assumptions, pedagogical aims and the relationships between themselves, the students and the content material to consider.

An additional factor which appeared from the interviews is that the participants have formed a close-knit community, not only within the micro-groups which they were in for the language classes but also across the groups. There are discussions going on outside the classes, information is being shared, and how each has decided to tackle the course planning issue is known to the others. In short, they have created for themselves a community of practice (Lave \& Wenger, 1991). During the interviews, these discussions continued, with one 
participant, for example, trying to persuade another that they were under-estimating their language proficiency and were able to teach in English without difficulty. This serves to indicate the deeply personal investment entailed in the move into EMI and how strongly individual it is. That the participants felt the need to form a community in the face of this challenge seems to underline this. Guarda and Holm (2017) also found that staff members reported finding the opportunity to discuss pedagogical issues welcome and innovative and expressed a desire to continue contact beyond the training course.

A final point to make is the use the participants made of the language course itself as a source of ideas for pedagogical approaches. Although not part of the course design in this instance, it is worth considering for future courses to support teachers in EMI. Support courses should not take the form of lectures, but involve participants in active learning, using a variety of ways of interacting with input material, using different media and task-based pair or group activities. It seems that this methodology does not necessarily need to be made explicit to be taken up by participants.

The preparation to teach in English process was evaluated positively by the participants, who particularly affirmed the intimate size of the groups and the fact of having two different tutors, one of whom was British and also a teacher educator. The way in which the individual consultations were used depended on the participant, which also seemed to be a strength. They were used variously - to discuss and plan classes (2 participants), to have additional language practice (1) or to rehearse parts of lectures (4). The individual sessions appeared to have a particular impact on those for whom communicating in spoken English was still challenging. This may have been exacerbated by the fact that it was synchronous online communication, but audio only. Although screens could be shared for materials to be discussed, faces could not be seen. This was to do with technical limitations of the internet connections. This is a much more demanding medium than face-to-face communication where there is additional information from non-verbal gestures. The role of an English language specialist in supporting the subject teacher was also found to be helpful by Klaasen and Graaf (2001), while Lasagabaster (2018) suggests going a step further and having team-teaching with a tandem of a subject specialist and a language teacher working together. The additional 
aspect here of the language specialist also having teacher education experience and course/materials planning expertise appeared to facilitate discussions of pedagogical approaches. Guarda and Helm (2017) introduced a course to discuss pedagogical issues relating to EMI through the medium of English, which seems a promising design worth further exploration.

The final question to discuss is whether the process of preparing to teach through the medium of English affects the overall quality of teaching of these teacher-participants. If we consider teaching quality as it is defined in the EU 2013 report, we note several features which are found in the data. There appears to be a growing sense of the need to share responsibility for the teaching/learning process with the students. There is a desire expressed to encourage students to engage with research literature in English in order to develop the skills needed to do this for themselves. The use of resources in English is also seen as a way to obtain a wider perspective and a deeper understanding. The teacher-participants themselves also expressed an awareness that the process of being able to teach in English is the way ahead for their personal and professional development, to become globally mobile in their profession, and also to enable the institution to achieve its aim of internationalisation.

Clearly the language course, in particular the individual consultations and the community of practice the participants formed, led them to reflection and deep thinking about pedagogical approaches. The planning process is closely linked with teacher cognition. The decisions teachers make about what and how to teach depend on their personal beliefs about teaching and learning and assumptions about students, grounded in experience. In addition is what Shulman (1986) describes as pedagogical content knowledge, the knowing what to teach, how and why in the particular context. While these teachers already have expertise in the teaching of their subjects in their own language, the challenge now is to develop an extended view of pedagogical content knowledge which encompasses the additional challenge of the medium of a new language. This medium challenges both the teacher and their students. It appears that the process described here has given the teachers space and time to begin to devise possible ways to find themselves in this new role. They have been supported in this process and have supported each 
other. Each participant has found a response they feel is acceptable for themselves and accommodates their particular teaching persona, even if it may only be a transitory stage in a process-of-becoming. This has been a profound experience for all involved and without doubt will impact on how these teachers work in the future. The very fact of reflecting deeply on what we do carries within it the seeds of change and the potential for improvement.

\section{References}

$\rightarrow$ Aguilar, M. and Munoz, C. (2014). The effect of proficiency on CLIL benefits in Engineering students in Spain, International Journal of Applied Linguistics, 24(1), 1-18.

$\rightarrow$ Aguilar, M. and Rodríguez, R. (2012). Lecturer and student perceptions on CLIL at a Spanish university, International Journal of Bilingual Education and Bilingualism, 15(2), 183-197.

$\rightarrow$ Airey, J. (2011). Talking about teaching in English: Swedish university lecturers' experiences of changing teaching language, Iberica 22, 35-54.

$\rightarrow$ Basıbek, N., Dolmacı, M., Cengiz, B. C., Burd, B. C., Dilek, Y. and Kara, B. (2014). Lecturers' perceptions of English medium instruction at Engineering departments of higher education: A study on partial English medium instruction at some state universities in Turkey, Procedia-Social and Behavioural Sciences, 1819-1825.

$\rightarrow$ Bobko, A. (2016). Position of the Ministry of Science and Higher Education on the situation of foreign students in Poland [Stanowisko MNiSW na temat sytuacji studentów z zagranicy w Polsce], www.pw.edu.pl/Aktualnosci/ Stanowisko-MNiSW-na-temat-sytuacji-studentow-Z-zagranicy-w-Polsce

$\rightarrow$ Campagna, S. (2016). English as a medium of instruction. A 'resentment study' of a micro EMI context. In: S. Campagna, E. Ochse, V. Pulcini, M. Solly (eds.), 'Languaging' In and Across Communities: New Voices, New Identities. Studies in Honour of Giuseppina Cortese (pp. 145-168). Bern: Peter Lang.

$\rightarrow$ CHE Consult, Brussels Education Services, CHE, Compostela Group of Universities and Erasmus Student Network (2014). The Erasmus Impact Study: Effects of mobility on the skills and employability of students and the internationalisation of higher education institutions. Final report to the European Commission. Luxembourg: Publications Office of the European Union.

$\rightarrow$ CHE Consult, Directorate-General for Education, Youth Sport and Culture (European Commission), ICE consulting (2019). Erasmus+ Higher 
Education Impact Study Final Report. Luxembourg: Publications Office of the European Union.

$\rightarrow$ Coleman, J. A. (2006). English-medium teaching in European Higher Education, Language Teaching, 39(1), 1-14.

$\rightarrow$ Dearden, J. (2015). English as a medium of instruction- a growing phenomenon. London: British Council.

$\rightarrow$ Dearden, J. and Macaro, E. (2016). Higher education teachers' attitudes towards English: A three country comparison, Studies in Second Language Learning and Teaching, 6(2), 3-34.

$\rightarrow$ Doiz, A., Lasagabaster, D. and Sierra, J. M. (2011). Internationalisation, multilingualism and English medium instruction. World Englishes 30(3), 345-359.

$\rightarrow$ Earls, C. W. (2016). Evolving agendas in European English-medium higher education: Interculturality, multilingualism and language policy. Basingstoke: Palgrave Macmillan.

$\rightarrow$ Erkan, A. and Osam, N. (2015). English-medium higher education: A case study in a Turkish university context. In: D. Slobodanka, A. K. Hultgren, C. Jensen (eds.), English-Medium Instruction in European Higher Education (pp. 177-200). Boston/Berlin: Walter de Gruyter.

$\rightarrow$ European Commission (2013). Report to the European Commission on Improving the quality of teaching and learning in European higher education institutions. Luxembourg: Publications Office of the European Union.

$\rightarrow$ Flowerdew, J., Miller, L. and Li, D. C. (2000). Chinese lecturers' perceptions, problems and strategies in lecturing in English to Chinese-speaking students, RELC Journal, 31(1), 116-138.

$\rightarrow$ Guarda, M., Helm, F. (2017). 'I have discovered new teaching pathways': The link between language shift and teaching practice, International Journal of Bilingual Education and Bilingualism, 20(7), 897-913.

$\rightarrow$ GUS (2018). Higher education in the academic year 2017/2018 (preliminary data) [Szkolnictwo wyższe w roku akademickim 2017/2018 (dane wstępne)], https:// stat.gov.pl/files/gfx/portalinformacyjny/pl/defaultaktualnosci/5488/8/5/1/ szkolnictwo_wyzsze_w_roku_akademickim_2017-2018_dane_wstepne.pdf

$\rightarrow$ Hellekjaer, G. O. (2010). Assessing lecture comprehension in Norwegian Englishmedium higher education, Language Use and Language Learning in CLIL Classrooms, 7, 233.

$\rightarrow$ Hahl, K., Järvinen, H. M. and Juuti, K. (2016). Accommodating to Englishmedium instruction in teacher education in Finland, International Journal of Applied Linguistics, 26(3), 291-310. 
$\rightarrow$ Holstein, J. A. and Gubrium, J. F. (1995). The Active Interview, London: Sage Publications.

$\rightarrow$ Jiang, L., Zhang, L. J. and May, S. (2019). Implementing English-medium instruction (EMI) in China: teachers' practices and perceptions, and students' learning motivation and needs, International Journal of Bilingual Education and Bilingualism, 22(2), 107-119.

$\rightarrow$ Klaassen, R. (2008). Preparing lecturers for English-medium instruction. In: R. Wilkinson, V. Zegers (eds.), Realizing Content and Language Integration in Higher Education (pp. 32-42). Maastricht: Maastricht University.

$\rightarrow$ Klaassen, R. G. and Graaff, E. de (2001). Facing innovation: Preparing lecturers for English-medium instruction in a non-native context, European Journal of Engineering Education 26(3), 281-289.

$\rightarrow$ Lasagabaster, D. (2018). Fostering team teaching: Mapping out a research agenda for English-medium instruction at university level, Language Teaching 51(3), 400-416.

$\rightarrow$ Macaro, E., Curle, S., Pun, J., An, J. and Dearden, J. (2018). A systematic review of English medium instruction in higher education, Language Teaching, 51(1), 36-76.

$\rightarrow$ Maiworm, F. and Wächter, B. (2002). English-Language-Taught Degree Programmes in European Higher Education. Bonn: Lemmens.

$\rightarrow$ Napoli, J., Sourisseau, J. (2013). L'EMILE est-il applique dans l'enseignement superieur? Enquetes sur le site toulousain. Recherche et Pratiques Pedagogiques En Langues de Spécialité, Cahiers de l'Apliut, 32(3), 123-143.

$\rightarrow$ Nickerson, R. S. (1998). Confirmation bias: A ubiquitous phenomenon in many guises, Review of General Psychology, 2, 175-220.

$\rightarrow$ Potter, J. and Hepburn, A. (2012). Eight challenges for interview researchers. In: J. F. Gubrium, J. A. Holstein (eds.), Handbook of Interview Research ( $2^{\text {nd }}$ ed.) (pp. 555-570). London: Sage Publications.

$\rightarrow$ Shulman, L. S. (1986). Those who understand: Knowledge growth in teaching, Educational Researcher, 15(2), 4-14.

$\rightarrow$ Siwiński, W. (2017). Foreign students in Poland 2017. Where are we? Education Foundation Perspektywy [Studenci zagraniczni w Polsce 2017 Gdzie jesteśmy? Fundacja Edukacyjna Perspektywy], www.studyinpoland.pl/narada2017/pdf/ Otwarcie-narady-W-Siwinski.pdf

$\rightarrow$ Strauss, A. and Corbin, J. (1998). Basics of Qualitative Research Techniques and Procedures for Developing Grounded Theory. Thousand Oaks: Sage Publications.

$\rightarrow$ Wächter, B. and Maiworm, F. (2008). ETPs in European Higher Education. The Picture in 2007. Bonn: Lemmens. 
$\rightarrow$ Wächter, B. and Maiworm, F. (eds.) (2014). English-Taught Degree Programmes in European Higher Education. The State of Play in 2014. Bonn: Lemmens.

$\rightarrow$ Werther, C., Denver, L., Jensen, C. and Mees, I. M. (2014). Using English as a medium of instruction at university level in Denmark: The lecturer's perspective, Journal of Multilingual and Multicultural Development, 35(5), 443-462.

$\rightarrow$ Wilkinson, R. and Zegers, V. (eds.) (2008). Realizing content and language integration in higher education. Maastricht: Maastricht University. 


\section{World Fducates Us... Naturally?}

DOI: $10.47050 / 66515321.326-345$

Anna Krzyżanowska

The environment that a child/student experiences (including cultural heritage, natural wealth and digital opportunities) is an exceptional space for students and teachers to discover and learn about the world itself. When learning something, especially in the Early Years stage, children need to discover things comprehensively, which requires a need to see and touch, to smell and work with the content. Accordingly, it is essential to let children build and transform new findings through various channels - perception, language, art, movement, self-expression, etc. Keeping a reasonable balance between modern technology, an emphasis on educational factors and the cultural-natural roots of humanity is necessary for two reasons: (1) the importance of the comprehensive development of the child (their current knowledge, skills, competencies, attitude and passions that will evolve in the future); (2) teachers' need for a sense of effectiveness and feelings of professional growth (including the joy of teaching and keeping motivation and dedication through the process).

Reaching the solutions for quality teacher education, we should not forget about the direct impact of teachers' professional attitude on the person of a child and their growth and well-being. Therefore, it is important to raise teachers' awareness and understanding of the $21^{\text {st }}$ century need for building as strong a connection between a child and nature as possible, at least as strong as their bond with technology.

\section{Keywords:}

connections

childhood

development 


\section{Educational perspectives}

I find, in my professional work, a unique opportunity to look at the education of a child from two complementary perspectives - teacher and educator. Observing, analysing and searching for solutions is a constant challenge with regard to both young and adult human beings.

Thinking about a child as the centre of the entire process comes from 17 years of experience as a preschool teacher and a therapist of children with disabilities and various learning difficulties. Every single day in preschool is a surprise when you need to react to children's thoughts and needs, unexpected ideas, and a wide spectrum of behaviour. In a way, children nowadays do not seem to differ a lot from those growing up a decade ago, especially when focusing on their entire needs, inner desires or development requirements. Why, then, in the area of perception and independence do we find them as they were from another planet?

Surprisingly, the same happens to teachers! I allow myself to state that not only because I have observed my kindergarten colleagues' attitudes towards their work but also due to my own self-evaluation - looking back through the years to assess my own commitment, motivation and targets.

Moreover, working as an educator and preschool teacher advisor leaves me with the impression that we all have lost (or at least became disoriented) the direction of the efforts we intensify every day. The political climate, strong economic factors and high expectations from parents put all of us in an academic skills race, making the process of teaching and learning a kind of educational roller-coaster ride. And it is not an overstatement to say so.

While searching for the optimal learning path, the reflective teacher sits on a methodological and philosophical swing. Setting the hierarchy of pedagogical priorities is a tough task when considering the position of knowledge versus students' skills and active attitude towards learning, especially when taking the social expectations of teachers into consideration. The domination of the quantity dimension above quality in education and the pressure on the evaluation of effectiveness are still current and undecided dilemmas (see Krzyżanowska, 2018).

The decisive factor that sets us down the teaching path, despite all our doubts and hesitations, is often a willingness to help children discover the world and to make them sufficiently prepared for what it will bring. That kind of mission is marked by a risk of failure, mainly 
because we understand such "discovering" and "preparation" differently. Moreover, we constantly evaluate our work priorities according to our professional and personal experience. Is it not then high time to ask about the optimal vision of teaching in the $21^{\text {st }}$ century and beyond? It is a question about what we focus on while educating future teachers.

When talking about the future of education, I find it necessary and interesting to first look back to a certain time in the past.

At the turn of the $19^{\text {th }}$ and $20^{\text {th }}$ centuries, Jean-Marc Côté and other French artists published a series of futuristic pictures known as En L'An 2000 (see The Public Domain Review, n.d.). Their work includes a vision of a school in the year 2000. The picture in Figure 1 (titled At School) displays a projection of progress in technology and the novel vision of using it for distributing knowledge in the educational process. A peculiar issue is the direction of transfer, which remains unaltered - from a person or tutor through books (as the educational resource) directly into students' heads, with no space for initiative or dialogue. Some teachers would probably appreciate such concentration and silence in a classroom, but apart from these, pure knowledge gained through memorisation and passivity appear here.

Figure 1. At School, Jean-Marc Côté

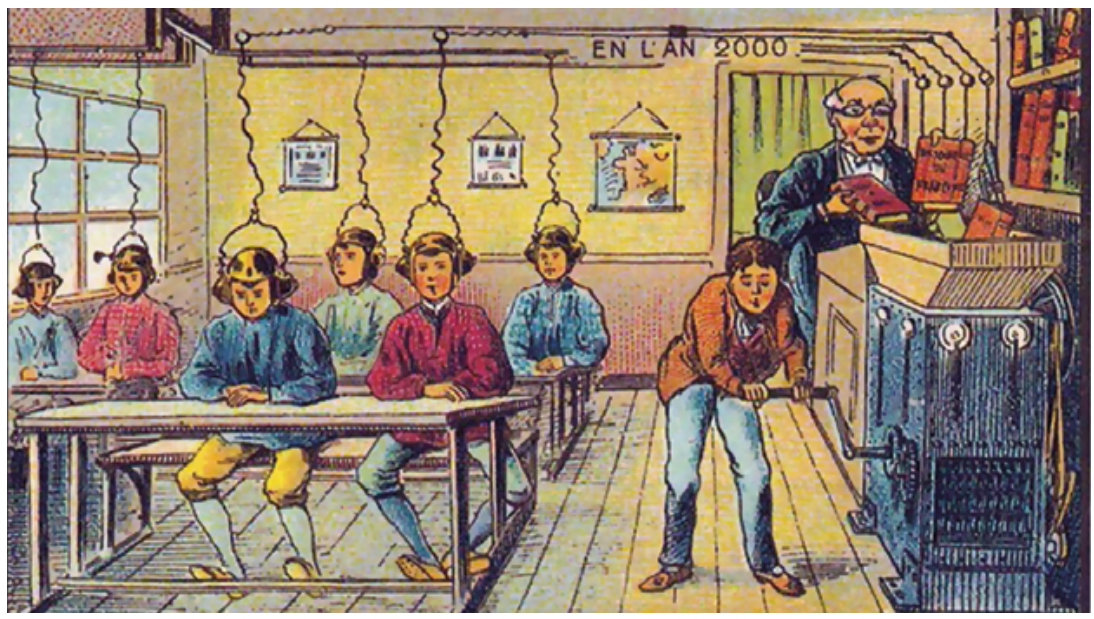

Surprisingly, when turning the clock back another 250 years, we come across Rembrandt's piece of art displaying a contrary vision 
of a lesson - The Anatomy Lesson of Dr. Nicolaes Tulp (1632) (Figure 2). Educational tools seem to be sparse and simple; we can spot a book, notes and an indicator in the hands of a surgeon. Looking at the painting with contemporary teachers' eyes, we could discuss speaker and listener content or the active and passive roles of the learners, but the most precious issue is beyond this. School, according to Rembrandt, calls out to us with just four words: See. Touch. Experience. Discover. Indeed - nothing can relieve the real! Pure learning by doing and problem-solving through multichannel experiences and handling. Is that not content that we are all searching for and find to be developmental necessities nowadays?

Figure 2. The Anatomy Lesson of Dr. Nicolaes Tulp, Rembrandt

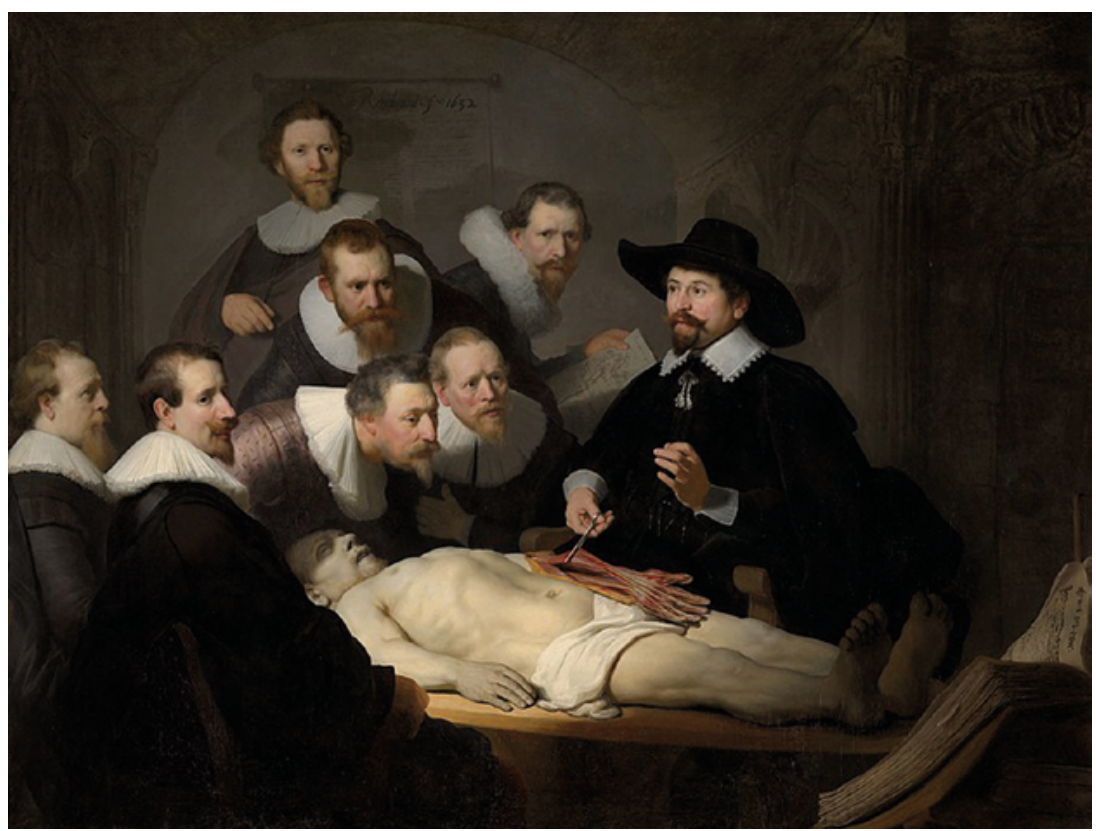

When I was a teenager, I stumbled upon Robert Fulghum's book titled All I really need to know I learned in kindergarten. It would be a slight exaggeration to say that it brought me to the preschool teacher profession, but there is truly magic in his words and simple advice: "clean up your own mess", "do not hit people", "be aware 
of wonder", "everything you need to know is there somewhere", and finally, "when you go out into the world, it is best to hold hands and stick together" (see Fulghum, 1994). I feel that most of Fulghum's tips could be signposts when searching for a path to early childhood education. But there is no denying that there is a truth in Peter Gray's thesis that claims that "most of the important lessons we take in life are not connected with a particular place, such as kindergarten or school, but are lessons given by life itself" (Gray, 2015, p. 11). By saying that "children do not need a school anymore but more freedom and an environment for discovering the world", he provokes educators to become active change-makers. His vision of change rests on perceiving children's competencies and leaving them a space for gaining knowledge and skills with natural methods and instincts. Otherwise, children will not be able to take responsibility for their own paths, being afraid of life's challenges and its dangers (see Gray, 2015, pp. 31-34). So, how can we make them prepared enough?

\section{Learning environment}

That is the way to learn the most, that when you are doing something with such enjoyment that you do not notice that the time passes.

Albert Einstein

Finding an effective educational formula turns out to be a demanding task and is anathema for teachers and policy makers. Even if we follow the world-centred approach in education, we still experience the clashes between methodological praxis, teaching routines, digital challenges and cultural impact. It is in everyone's best interests that there is an interaction between these factors, as well as a reasonable balance enabling students to meet the world and find a personal relation with it in order for them to feel at home.

We already stated that way of cognoscence requires a direct perception of the object. Without real experience and handling, learning is incomplete. Here, I would like to share a meaningful example of raising cognoscence at the preschool level, proof that it is not a one-shot action for success but a long-lasting multidimensional process that starts in early childhood. 
Figure 3. Multisensory learning with nature
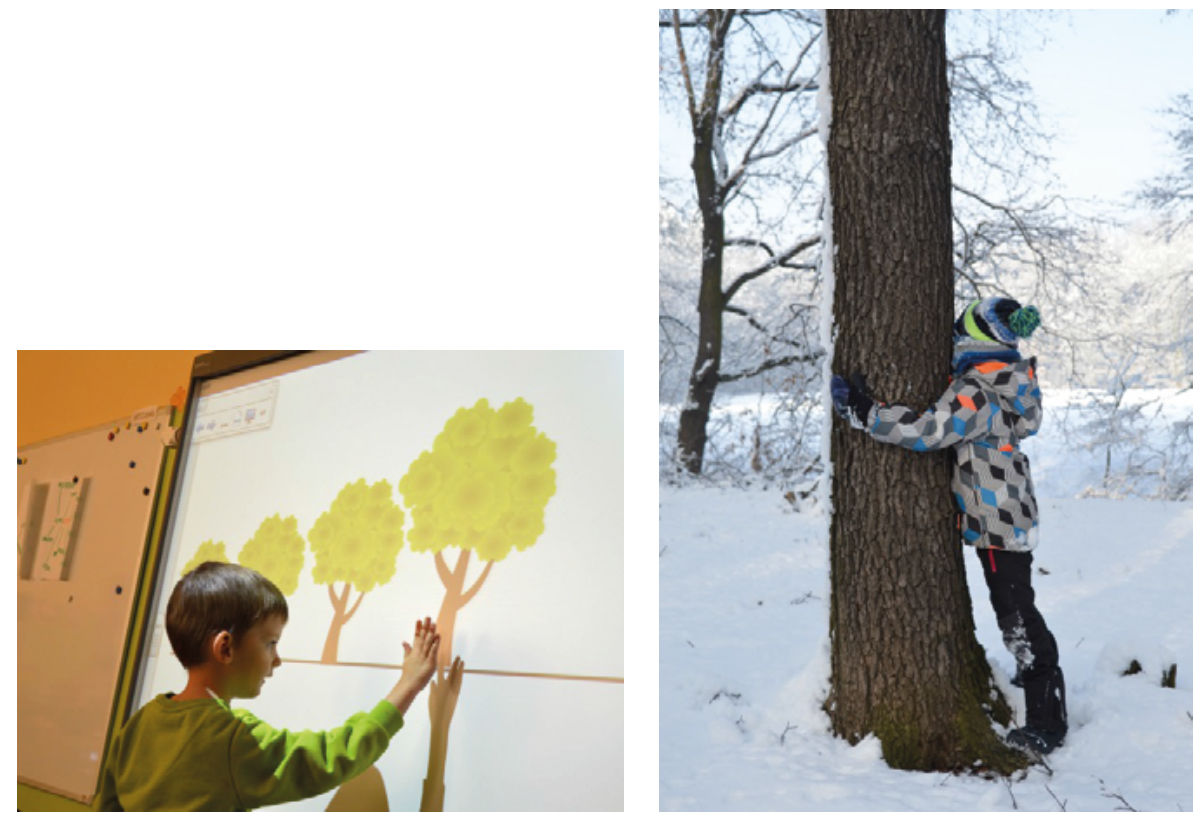

These two photographs, which I found complemented each other, were taken while working in my preschool with my last group of "Bees". In the left picture, there is a boy facing a task that combines mathematical perception with the topic of trees. The boy successfully managed the measurement activity of putting tree icons in order from the smallest to the tallest, capably manipulating them on an interactive whiteboard. Including other activities in the lesson, e.g. introducing knowledge about various tree species, such as the different appearances of their leaves and fruit, still does not bring the full concept of the tree into children's minds. That is why, especially at a young age, a child needs an opportunity to observe the real object and discover it in a multisensory way - to see, touch, smell, eat and play with it (if possible) in order to know it. Sometimes it is possible to start a relationship with it - to hug it, like it, or love it. That is what you can see in the right photograph, can't you?

Scott Sampson, in his work How to Raise a Wild Child: The Art and Science of Falling in Love with Nature, acquaints his readers with 
three key factors working for empiric cognoscence, connecting them with the need for a profound relationship with the natural world. He distinguishes the issues of experience, learning and understanding in the spiral set of events that a child is faced with during the process of entering into a relationship with the world.

Sampson highlights that "the best place for finding a love of nature in ourselves is the place we currently are", so any place could then be treated as the optimal learning space if only it is grasped with a wider perspective and creativity. He agrees that the basis to achieve the empiric features in education is a direct multisensory experience supported by nature and the emotions it carries to children's minds. In Sampson's opinion, learning becomes most effective when a child is engaged in exploration, concentrating on his play instead of "processing information" received from the teacher-mentor, who is to be more a listener and observer, a live stimulation for a student, rather than a book of answers. Finally, understanding comes, but it requires a wider perspective of awareness and intellectual ability in order to make connections between phenomena (see Sampson, 2016, pp. 79-81).

Educational deliberations lead nowhere if they omit the role of a modern-quality teacher and a modern-quality school. The specific picture of a teacher and the learning space he/she creates is a direct answer to the humanistic view of a child. I strongly agree with Ewa Kaliszuk, who writes that a teacher "cannot be a monopolist in knowledge distribution anymore, but has to become a guide and facilitator in the process of discovering leading to learning" (Kaliszuk, 2019 , p. 23). After all, a child is not an empty box, a tabula rasa of mankind, when entering a preschool and a school system.

It is not rare to see a child demonstrate quite well-developed personal competencies, such as perceptiveness, mindfulness, patience and enthusiasm in experimenting, zest and involvement in doing that teachers can extend and develop in the process of discovering. Such a learning path, filled with a variety of emotions (like happiness and enthusiasm taken from experimentation but also anger and sadness caused by failure), supports a child's growth in mental resilience. A readiness for inconvenience and an optimistic attitude towards meeting challenges are connected with far-reaching results, such as gaining independence in decision-making and having 
courage for one's actions, which are essential to one's preparation for being and living in a changeable and unforeseeable world (see Kaliszuk, 2019).

The modern vision of the developmental process to be carried out at school requires both world-centred and action-centred attitudes for learning.

Christopher Clouder's deliberations over knowledge and learning by doing perfectly tunes the discussion. In his opinion, "knowledge is not enough and [...] the future will be built by those who can collaborate and apply insight and sound judgement to different and unexpected challenges", understood as "the moments of learning that come unexpectedly and unplanned" (Clouder, 2014, p. 78). Clouder finds such an opportunity in children's unstructured play, when they are so absorbed in a task that it challenges them to do the best they can, achieving the "flow" effect - so welcomed in the learning by doing concept. He strongly asserts the meaning of enthusiasm within children and youth actions, which are more relevant than curricula targets or expectations of future exam results.

This surprisingly corresponds with the matter of space and time for boredom in a child's life. The pace of life that we all suffer from and separation from natural environs have a lot in common. Aldo Leopold, a $20^{\text {th }}$ century naturalist, explains this as follows: "Your truly modern Man is separated from Earth due to numerous go-betweens and material inventions. He has no genuine bonds [...]. Leave him for one day somewhere on a piece of land and, if it is not a golf course or a scenic park, he will get bored to death" (Leopold, cited in: Haskell, 2017, p. 322).

What is more, Clouder points out parents' feelings of guilt or wishes for their children's achievement, which results in them filling their free time with an abundance of activities or technologies. Whereas, as he writes, "in a hyperactive and driven world we can forget that children too have the right to stillness", and later states that "boredom is not comfortable but out of this empty space much creativity can be born" (Clouder, 2014, p. 79).

This directly matches my professional experience within the unstructured play that children embrace during their time outdoors in a park or some woods, and, more generally, the understanding of teaching resources. Leaving aside an individual teacher's vision 
on using the natural environment as an educational aid (suitable for mathematics and literacy skills, scientific knowledge and other areas of the curriculum), it is extremely worthwhile to set a time and space aside for children to freely observe, play and wonder at the world.

After the first moments of "I-have-nothing-to-do" and "I-am-bored", creativity arrives together with the readiness to "do things" together with others. Following the simple ideas inspired by nature itself, children manipulate accessible items and truly create, in collaboration with others or individually, bringing their own concepts into life. Besides, a world-book for academic skills is within their hands, as they can search for the shapes of letters among the shapes of sticks, make comparisons with the items around them, and count up to high numbers using stones. For me, as a teacher, these are the most valuable moments in which they learn about and in the world. It is accessible from the very beginning, even with 3-year-olds, so there is no need to wait until they get older! That would simply be a waste of precious time!

And I am totally sure that, after a few years spent in preschool, they will forget all of their book activities, most of the interactive whiteboard tasks, and even my exceptional teacher talks about everything and nothing. But they will not forget the time they were running around the playground barefoot to enjoy the morning dew, playing with those sticks and stones, building forest food containers with snow and filling them with carrots and apples, or just hugging or sitting under the trees with their eyes closed.

The basic question is whether teacher educators sufficiently value such a learning path", building the strong belief in future teachers that the environment is a kind of a textbook they need to use in the learning process. Are they able to grasp a variety of competencies to evolve within not only academic ones but also soft skills, so important to children's daily lives? Wollman-Mazurkiewicz makes this plain by saying that "there came the end of developing single lessons which became an absurdly chock-full pot and an empty one, all at once" (Wollman-Mazurkiewicz, 2000, p. 65).

Therefore, the main question is not even "How can I set up a good lesson?" but "Where is the classroom in which our students learn the most?" and "How can I support their life progress?" 
According to Kaliszuk, a fundamental aspect in searching for the point in a child's development is grasping two equal sides of the issue: the subject and the object.

Obviously, the subject is a child and his/her regular development. The key task for us, as adults, is to lay on the appropriate environment for this vital process. The environment Kaliszuk talks about includes family, siblings, friends, but also nature, without which we simply do not exist. And nature itself is an object in the process of development where important resources are found, essential for our well-being. Subject and object can coexist in a unique relationship. Building and then nursing that relation "seems to be the crucial task of our lives" (Kaliszuk, 2019, p. 37). And again, as Kaliszuk highlights, it is adults' responsibility to create an opportunity and a space for establishing the conscious bond between a child and nature.

\section{On the natural path}

The more high-tech we become, the more nature we need.

Richard Louv

When talking about teachers' mission in the students' path towards nature, we could paraphrase Conor O'Gorman, who stated that "the best step that parents can make is the first step through the doors. It is not children who need an inducement to manage this, but parents" (cited in: Komorowska, 2019, p. 8). By replacing parents with teachers in his statement, we can discover that such a step should be made towards the classroom doors too. Are teachers encouraged enough to do so? To focus our teaching on such a direction and put our efforts into learning through nature, we need to be convinced why it is important and get an idea of how to manage it, including through our own personal contribution. 
Figure 4. On the natural path

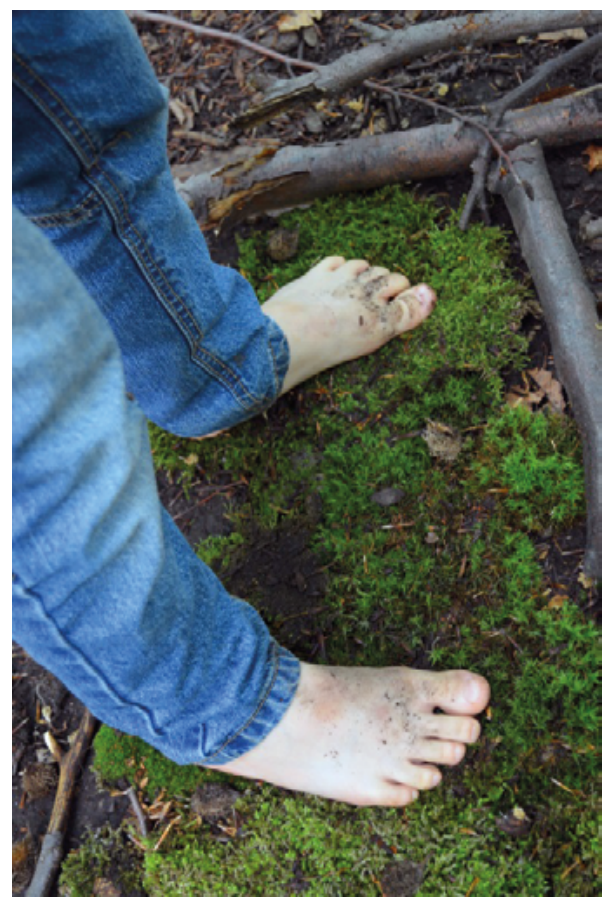

There is quite a lot of qualitative research that has established educational, physical and mental advantages from the direct contact of a man (and so of a child) with nature. Discussions, empirical studies and evidence-based medicine support this connection, which takes effect in such initiatives as shinrin-yoku (Japanese in origin, nowadays a worldwide practice of forest bathing for multisensory stimulation and relaxation) or treating nature as a kind of dietary supplement (prescribed seriously by Scottish doctors for medical reasons).

We can find interesting observations and comments on the situation of the modern child in the case studies of Richard Louv (in his works Last Child in the Woods: Saving our Children from Nature-deficit Disorder and Vitamin N: The Essential Guide to a Nature-Rich Life), Florence Williams (in The Nature Fix: Why Nature Makes Us Happier, Healthier, and More Creative) and in Tim Gill's report called Sowing the Seeds: Reconnecting London's Children with Nature. These are three "Gospels" for parents and "must-reads" for educators, especially 
those searching for solutions to the development difficulties children commonly suffer from nowadays that are connected with Louv's term "nature-deficit disorder".

As the child's relationship with nature is frequently and diversely estimated against the role and impact of technologies on new generations and its after-effects on education, the topic requires increased attention and a personal stance.

It is essential not just because our lives have generally shifted indoors, separating us from the outdoor environment. A more serious disturbance has been observed and described by Louv as the "physical limitation of childhood in the urban world, where experiencing nature is just one of the victims" (Louv, 2016a, p. 54). The walls of the house are the apparent boundaries, but there are other serious limitations of space that have a negative impact on children's development and health. Playpens, high chairs, and car seats are among them, but also baby carriers used by parents when walking or running outdoors. Children are also faced with other restrictions put on them by adults, mainly due to safety reasons or overwhelming fears, which appear in "be careful" and "it's dangerous" sentences and go together with "don't run", "don't jump", "don't climb" and of course "don't make yourself dirty!" Jane Clark uses the term "containerized kids" to explain their horrendous state (see Louv, 2016a, pp. 53-54) and calls for freedom to be restored to childhood. Of course, following this concept requires breaking quite a lot of personal and institutional barriers, including educational trends, structural directions, curriculum time pressures and fears for children's safety. A dozen recommendations for parents, educators and other decision makers were delivered by Gill (2014, pp. 154-157) as a starting point for such a change. 
Figure 5. Getting children in touch with nature

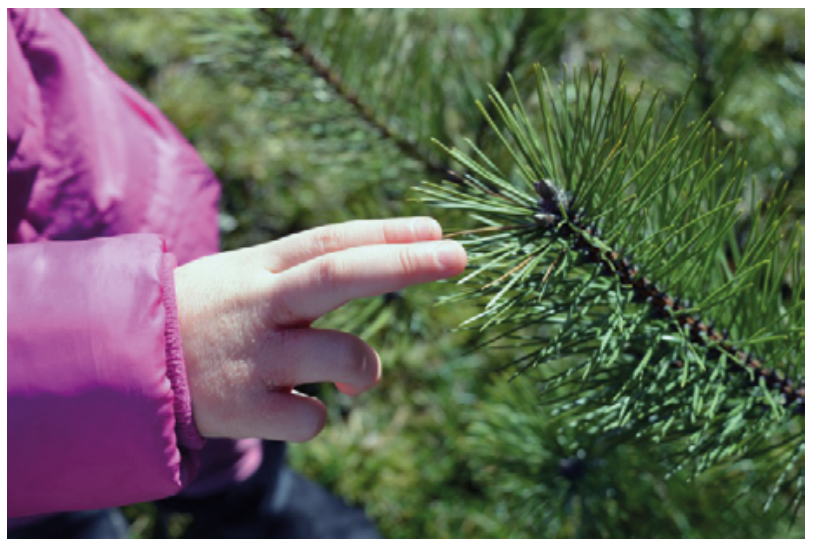

As Richard Louv states, the situation of childhood nowadays demands sustained actions, and this change should be made urgently. Obviously it will not come about by itself - waiting idly will not work, so it is both parents' and teachers' task to bring the change to children. Rachel Carson (cited in: Louv, 2016a, p. 201) calls adults' attention to the simple fact that "while introducing nature to a child, we need to feel it first, and then to know". His appeal corresponds with Lidia Wollman-Mazurkiewicz, who states that "it is not possible to focus children's attention on natural phenomena when we are not absorbed in nature ourselves. Only our own delight and feelings showed freely are catching and shaping. It is then most important just to Be with children" (2000: 215). For me, Magdalena Lisak has the final word here when she says that "we are a part of nature even though we retreat from it. We search for comfort and quick solutions, but hide behind the lack of time, and increasingly we look at greenery only through our windows. Our only hope is to find an inner child in ourselves, the one who desires to spend all their free time outdoors" (Lisak, 2019, p. 9).

This all means that it is only with our own positive personal attitude towards the environment and time being given to such a mission that achievements in this matter will be possible. What is more, it has been recognised that engaging children with nature becomes much harder when they grow up, and therefore such human activity is necessary from the very beginning of childhood, including during preschool 
education, and it should be continued in primary schools. If only we, as teachers, can let our inner child speak...

I strongly agree that (as the word "preschool" indicates) this time of childhood is also devoted to appropriate preparation for school, which includes the acquisition of a set of skills and competencies. But then, do children learn anything or do they just play and absorb vitamin D while they are outdoors? A meaningful answer to this is given by Lidia Wollman-Mazurkiewicz, who furthers the scheme formed by Kirsti Vindal Halvorsen on the topic of education through environmental factors.

Halvorsen presents three circles of cognoscence, bringing different structures into the process. These are: to be (understood as experience, developing social contact and an attitude towards nature), to learn (read as discovery leading to knowledge) and to dare (which brings action, and then persistence and creativity) (Wollman-Mazurkiewicz, 2000, pp. 213-215).

Indeed, learning is an imperative factor of the educational process, comprising a set of facts and abilities gained within intentional activities in literacy, mathematics, science and art for the development of intellectual and emotional functions. However, the learning environment can be successfully set outdoors, both in natural surroundings (gardens, parks, forests, or even a little green space between blocks of flats) and in urban settings (industrial landscapes, cultural places and human-made constructions), if the closest vicinity is understood as a teaching resource.

Dahlgren and Szczepanski state clearly that "the natural environment offers a wide range of visual impressions, scents, movements, sounds and shapes, appealing to all of the child's senses in a way which no other environment is capable [of]" $(2005$, p. 24). They emphasise that multisensory stimulation is essential in the world-centred process because "when we meet the world around us, we learn how it works, how it tastes, smells and feels. We get to know the world in parts and wholes, at the same time as we create roles towards our environment" (ibidem). 
Figure 6. Education in the natural environment

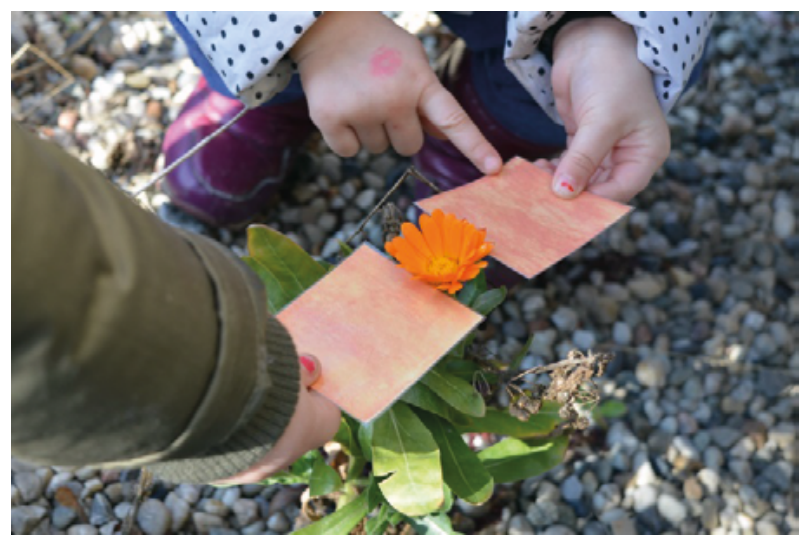

Both authors see the red light in the matter of understanding the natural world as an educational aid, writing that "in today's school, there is a sharp contrast between life in the classroom and life in a schoolyard. In the learning environment of the classroom, there are pedagogic tools that the teacher is actively using. The pedagogic tools of the outdoor environment, however, are invisible for most teachers" (Dahlgren \& Szczepanski, 2005, p. 35).

Nonetheless, as they claim, "outdoor education in practice becomes an important methodological tool that can make the intentions of curricula come alive" (ibidem, p. 23). They highlight a multitude of hands-on methods thanks to which a student gets trained to interpret and analyse processes observed in an outdoor environment, providing qualities that cannot be created in a classroom or any indoor space. Thanks to time and actions taking place outdoors, children usually have many opportunities to collaborate together, which affects their socialisation processes. Meaningful learning situations engage both children's minds and bodies, as they certainly encourage creativity and are more profoundly secured in memory by confronting children with sensory perceptions and bringing positive impressions.

Rycielski and Rycielska refer to Liz O'Brien's research on the evaluation of Forest School's effectiveness, showing empirical merits from contact with the natural environment and the setting up of a learning space in a spirit of freedom and time for exploring (2019, pp. 24-26). 
Significant beneficial effects are seen in:

$\rightarrow$ the increase of self-confidence and self-control;

$\rightarrow$ growth in social competences;

$\rightarrow$ relevant/vital improvements in communication with a group;

$\rightarrow$ the awareness of consequences from their actions towards others - both humans and nature itself;

$\rightarrow$ the acceleration of language development;

$\rightarrow$ the evolution of motivation and attention management;

$\rightarrow$ the increase of gross and fine motor skills and strength;

$\rightarrow$ a better acquirement of knowledge and understanding of educational content;

$\rightarrow$ mental support through the increase of good moods, subjective levels of energy, and a decrease in affective disorder risks (including depression).

The three circles of cognoscence of Halvorsen complement the "learning by doing" concepts in education of Dahlgren and Szczepanski, which link knowledge, non-academic competencies and the role of the tutor in the process. First of all, they remark that "knowledge does not exist in a part of Man, but Man as a part of activity". Then, they add that "training and learning by doing and noticing are anchored in a dialogue-based structure between the student and a tutor in direct contact and dialogue with each other" (Dahlgren \& Szczepanski, 2005, p. 32).

Molander's theory of knowledge and learning in action is of interest here, as he believes that action and thinking are not separate, and thus "mind and body live in a community of action". What is more, Molander described seeing, doing and being as "the silent forms of knowledge", finding in them the essential factors of observation and action, and seeing knowledge "in the form of attention to people's activities and practice, where we can see the whole" (cited in: ibidem, p. 31). Going further, Dahlgren highlights Molander's concept of reflection in action in the statement that "the learner must pause in his activity in order to reflect for the activity to be internalised and become knowledge" (ibidem, p. 33).

From the teachers' side, it is therefore important to constantly think about what we are doing, analysing if there is a compromise between active and passive ways of learning, and how we care 
for the internalisation of children's experiences to lead them into knowledge. What resources do we find inspiring in this process? Is there a balance between indoor and outdoor time, visible in our general focus on books, technology and (hopefully) nature? And finally, do teachers set their hearts on students' well-being, in a way caring for their own well-being too?

The Council of Europe gave great importance to Learning for Well-being, describing well-being as a universal human right both now and in the future, taking its individual, societal and global meanings into account. Key components in the learning for well-being framework include a concern for everyone's unique potential (including mental, physical, emotional and spiritual factors), respect for the diversity of each individual, the meaning of communication, relationships, real participation and the engagement of children and youth.

It should not be surprising that in the "Well-being for All" vision, such a strong focus is put on nature and the quality of relationships established in various environments. As people learn primarily through their relationships with others, this includes learning through their relationships with non-human creatures and the natural environment, according to the framework, highlighting the primary importance of a positive relationship with the self, from which self-esteem, self-confidence and self-expression derive (Kickbush, 2012, pp. 28-31).

\section{Nature as a tutor}

In Dymara's opinion, the foundation and a starting point for world-schooling is the relation between man and nature that can be described with three verbs: to get to know, to get to love, and to protect. Working for these abilities can be the most valuable gift we can prepare for our children and students, as nature can become an important part of their lives, an aim of cognoscence, an object of interest, not just a meaningless background or a source of oxygen (Dymara, 2000, pp. 15-16, 21). 


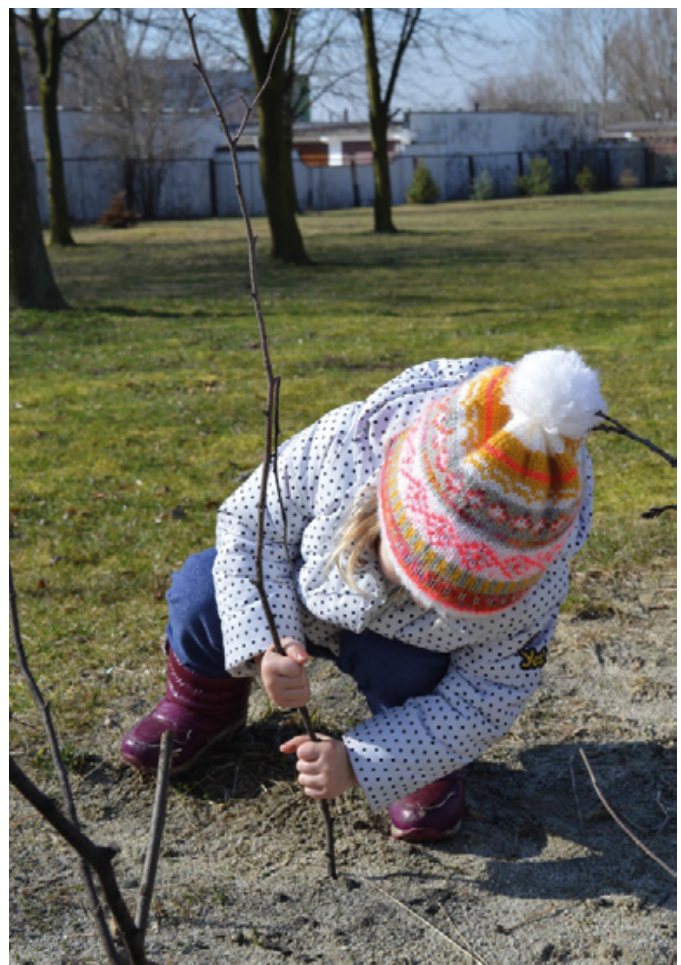

It is therefore also teachers' task to ensure it, which is achievable by bringing nature to children, or rather, bringing it back. Wendell Berry said that "when going back makes sense, you are going ahead" (cited in: Louv, 2016a, p. 313), which, for me, means that by giving children direct contact with nature - which, for "homo urbaniensis", is "so close but so far", as Richard Louv says (ibidem, p. 41) - and by bringing them back to their roots, we are taking an important step for their better future. And surprisingly, for the better future of nature too, according to McGurk's self-explanatory affirmation, which says that if we help children to fall in love in nature, they will care for it, because everyone cares for what they love. I find Gary Snyder's thought even more meaningful when he says that "[n]ature is not a place to be visited. It is home" (cited in: Louv, 2016b, p. 99). Yes, it is. And it is high time to discover that again. 
Therefore, what can we, as educators, teachers and parents, do to prepare children to live in the $21^{\text {st }}$ century with fullness of well-being and world-changing creativity?

First of all, nobody is asking us to go back to the teacher-dominating learning strategies of the $19^{\text {th }}$ century. But maybe there is no other way than to let children discover their natural roots, to keep the bond with the world they "inherit" from us. Secondly, people on all sides of the process are desperate for freedom and trust. That means giving back some freedom to children to leave them a space for growth, as they have a great natural potential to manage that. The same applies to teachers. They also need to be trusted more and need more freedom, opening a space for them to become creative curriculum makers. They have the potential to make education not only high quality, but a masterpiece!

And finally, there is something else that we educators can do to give serious relief to teachers. Let them accept that they do not need to be educational superheroes in preschools and schools. By taking that burden of responsibility and obligation off their backs, we can allow them to fly and shine. Prof. Pavel Zgaga, during the TEPE 2019 conference in Krakow, frankly admitted that what teachers actually need is to be treated as normal human beings, with all the concomitant merits and disadvantages. Then they will be able to take care of students as best they can. In my opinion, they have strong support to use on their path to discovery, which is the path of nature. It becomes an unforgettable pleasure for teachers to teach and for students to learn when we let nature become a tutor for both.

\section{References}

$\rightarrow$ Clouder, C. (2014). Education for the unexpected. In: M. Matthes, L. Pulkkinen, L. M. Pinto, C. Clouder (eds.), Improving the quality of childhood in Europe (Vol. 5, pp. 150-158). Brussels: Alliance for Childhood European Network Foundation.

$\rightarrow$ Dahlgren, L. O. and Szczepanski, A. (2005). Outdoor education. Literary education and sensory experience. An attempt at defining the identity of outdoor education. Linköping: Kinda Educational Centre-Linköping University.

$\rightarrow$ Fulghum, R. (1994). All I really need to know I learned in kindergarten. London: Harper Collins. 
$\rightarrow$ Gill, T. (2014). Children and their connection with nature: Why is it important and how can it be stimulated?. In: M. Matthes, L. Pulkkinen, L. M. Pinto, C. Clouder (eds.), Improving the quality of childhood in Europe (Vol. 5, pp. 150158). Brussels: Alliance for Childhood European Network Foundation.

$\rightarrow$ Gray, P. (2015). Wolne dzieci. Podkowa Leśna: Wydawnictwo MiND.

$\rightarrow$ Haskell, D. (2017). Ukryte życie lasu. Rok podglqqdania natury. Łódź: Wydawnictwo Feeria.

$\rightarrow$ Kaliszuk, E. (2019). Mam marzenie, Kreda. Magazyn Kreatywnej Edukacji. Leśna Edukacja, 5(8), 36-38.

$\rightarrow$ Kickbusch, I. (2012). Learning for Well-being. A Policy Priority for Children and Youth in Europe. A process for change. Kerala: Universal Education Foundation.

$\rightarrow$ Komorowska, A. (2019). Spragnieni natury, Kreda. Magazyn Kreatywnej Edukacji. Leśna Edukacja, 5(8), 5-8.

$\rightarrow$ Krzyżanowska, A. (2018). Efektywna edukacja. W poszukiwaniu balansu między technologią, kulturą i naturą. In: S.M. Kwiatkowski, Kompetencje przyszłości (pp. 206-226). Warszawa: Fundacja Rozwoju Systemu Edukacji.

$\rightarrow$ Lisak, M. (2019). Ogród, w którym zabawom nie ma końca, Kreda. Magazyn Kreatywnej Edukacji. Leśna Edukacja, 5(8), 9-19.

$\rightarrow$ Louv, R. (2016a). Ostatnie dziecko lasu. Warszawa: Mamania, Grupa Wydawnicza Relacja.

$\rightarrow$ Louv, R. (2016b). Witamina N. Warszawa: Mamania-Grupa Wydawnicza Relacja.

$\rightarrow$ McGurk, L. Å. (2018). Nie ma złej pogody na spacer. Tajemnica szwedzkiego wychowywania dzieci. Kraków: Wydawnictwa Literackie.

$\rightarrow$ Rycielski, P. and Rycielska, L. (2019). Na dwór! Rozwój dziecka w kontakcie z naturą, Kreda. Magazyn Kreatywnej Edukacji. Leśna Edukacja, 5(8), 24-26.

$\rightarrow$ Sampson, S. D. (2016). Kalosze pełne kijanek. Białystok: Wydawnictwo Vivante.

$\rightarrow$ The Public Domain Review (n.d.). A $19^{\text {th }}$-century Vision of the Year 2000, https:// publicdomainreview.org/collection/a-19th-century-vision-of-the-year-2000

$\rightarrow$ Williams, F. (2018). Natura leczy, czyli co sprawia, że jesteśmy szczęśliwsi, zdrowsi i bardziej kreatywni. Kraków: Wydawnictwo Uniwersytetu Jagiellońskiego.

$\rightarrow$ Wollman-Mazurkiewicz, L.(2000).Przyrodaiedukacja.In:B.Dymara, S.Michałowski, L. Wollman-Mazurkiewicz (eds.), Dziecko w świecie przyrody (pp. 189-234). Kraków: Impuls. 


\section{Authors}

Marine H. Arakelyan

Sultan Qaboos University

ORCID iD: 0000-0002-1752-8819

\section{Nataliya Avshenyuk}

Ivan Ziaziun Institute of Pedagogical and Adult Education of the NAES

of Ukraine

ORCID iD: 0000-0003-1012-005X

\section{Stefania Bakirtzi}

International Organization

of Migration (IOM)

ORCIDid: 0000-0007-7773-309

\section{Louise Campbell}

University of Dundee

ORCID iD: 0000-0002-2924-5154

Jenny Johana Izquierdo Casadiego

Immanuel Kant Baltic Federal University

ORCID iD: 0000-0003-1276-7076

\section{Wanda Dróżka}

Jan Kochanowski University in Kielce

ORCID iD: 0000-0002-0628-1179

\section{Melanie Ellis}

Silesian University of Technology ORCID iD: 0000-0002-7274-0564

\section{Meretguly Gurbanov}

Turkmen National Institute of World Languages named after D. Azady

"Diller Dunyasi" Language Institute ORCID iD: 0000-0002-9719-0714

\section{Maria Antonietta Impedovo}

Aix-Marseille University

ORCID iD: 0000-0003-2172-7105

\section{Magdalena Jelonek}

Cracow University of Economics

ORCID iD: 0000-0003-0321-0209

\section{Irene Katsama}

Democritus University of Thrace

ORCID iD:0000-0002-4679-557

\section{Suzanne O'Keeffe}

Maynooth University

ORCID iD: 0000-0002-4344-2488 


\section{Marcin Kocór}

Jagiellonian University in Kraków

ORCID iD: 0000-0002-5280-7258

\section{Anna Krzyżanowska}

$48^{\text {th }}$ Kindergarten with Special and Integration Units in Zabrze

ORCID iD: 0000-0002-5511-3497

Joanna Madalińska-Michalak

University of Warsaw

ORCID iD: 0000-0001-9980-6597

Svitlana Shchudlo

Ukrainian Educational

Research Association

Drohobych Ivan Franko State

Pedagogical University

ORCID iD: 0000-0002-4901-1053

\section{Nataliya Seminikhyna}

Taras ShevchenkoNational University

of Kyiv

ORCID iD: 0000-0001-6246-4132

\section{Martina Šipošová}

Comenius University in Bratislava

ORCID iD: 0000-0002-0329-1363

\section{Dimitrios Stamovlasis}

Aristotle University of Thessaloniki

ORCID iD: 0000-0003-0808-9065

\section{Eugenia Tsiouplis}

Aristotle University of Thessaloniki ORCID iD: 0000-0001-7482-1379

\section{Olesya Parakhina}

Immanuel Kant Baltic Federal University

ORCID iD: 0000-0001-6574-4594

\section{Barbara Worek}

Jagiellonian University in Kraków

ORCID iD: 0000-0001-5384-0773

\section{Oksana Zabolotna}

Ukrainian Educational

Research Association

Pavlo Tychyna Uman State

Pedagogical University

ORCID iD: 0000-0003-4901-1053 
So far, the Key Concepts Series has included:

Vol. 1: Teacher Education Policy and Practice. International Perspectives and Inspiration

Vol. 2: $\quad$ Teacher Leaderschip (Przywództwo nauczycieli)

Vol. 3: Kompetencje przyszłości

Vol. 4: Przestrzenie i miejsca edukacji dorosłych w Polsce

Vol. 5: Kształtowanie kompetencji przedsiębiorczych

Vol. 6: Education-Relationships-Play. Multifaceted Aspects of the Internet and Child and Youth Online Safety (Edukacja-Relacja-Zabawa. Wieloaspektowość internetu w wymiarze bezpieczeństwa dzieci i młodzieży)

Vol. 7: $\quad$ Edukacja włączajq̨ca w przedszkolu i szkole

Vol. 8: Kreatywność w systemie edukacji

Vol. 9: Wykształcenie zawodowe. Perspektywa systemu edukacji i rynku pracy

Vol. 10: Studies on Quality Teachers and Quality Initial Teacher Education

FRSE publications are available on:

www.czytelnia.frse.org.pl

fD| FRSE

Sê Publications
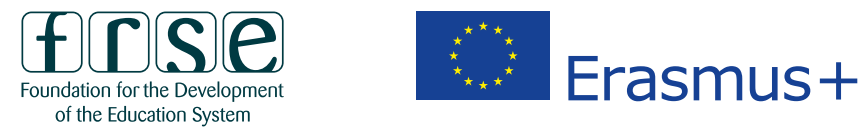
The Teacher Education Policy in Europe (TEPE) Scientific Network is an academic network that builds on the work and community from the previous European collaborative projects in the field of teacher education policy, including TNTEE and EUDORA. TEPE Network central goals relate to advancing research in and on Teacher Education, increasing mobility and extending the European Dimension in Teacher Education, enhancing quality through the renewal of evaluation cultures in Teacher Education.

The motivation for the theme of this book, Studies on Quality Teachers and Quality In-service Teacher Education, has been to examine different aspects of teaching and teacher education as well as responses to the challenges posed by the current conditions to teacher education and the teaching profession. Therefore this publication provides a significant contribution to the wider body of scholarly literature on teacher education policy, research and practice in different countries through the lenses of quality teachers and quality teacher education.

Foundation for the Development of the Education System (FRSE) operates as the Polish National Agency of the Erasmus+ Programme implemented in the years 2014-2020 and as the Polish National Agency of the European Solidarity Corps. FRSE is also responsible for other European educational and information initiatives in Poland, such as eTwinning, Eurodesk, Eurydice, Europass, ECVET and EPALE. The Foundation also supports cooperation with countries in the East via the Polish-Lithuanian Youth Exchange Fund, the Polish-Ukrainian Council of Youth Exchange, SALTO-EECA Eastern Europe and Caucasus Resource Centre. Since 2014, FRSE has been involved in the implementation of the Operational Programme Knowledge Education Development. The Foundation organizes many educational events including competitions promoting projects' results. It coordinates the European Youth Week and coorganizes events in the framework of the European Day of Languages. It also conducts research. FRSE Publishing House issues, among others, such quarterly periodicals as Języki Obce w Szkole (Foreign Languages at School) and Europa dla Aktywnych (Europe for the Active). 